\title{
Residual Capacity of Blast-Damaged Reinforced Concrete Columns
}

\author{
by \\ Isaac Kwaffo
}

A thesis submitted to the Faculty of Graduate and Postdoctoral Affairs in partial fulfillment of the requirements for the degree of

\author{
Master of Applied Science \\ in
}

Civil Engineering

Carleton University

Ottawa, Ontario

(C) 2017, Isaac Kwaffo 


\begin{abstract}
The use of suitcase bombs has severe consequences on infrastructures as they can be placed close to or in contact with key structural elements. The detonation of such an explosive charge may cause severe structural damage to key load-bearing members leading to their failure and initiation of progressive (disproportionate) collapse of the structure due to the localized failure of the load-bearing member. One of the most useful information when assessing the post-event capacity of a structure and the possibility of progressive collapse of a damaged structure is the residual axial capacity of its loadbearing members such as columns.
\end{abstract}

This research project forms part of a larger program designed to assess the blast resistance and residual capacity of reinforced concrete columns. Earlier phases of the program included the testing of reinforced concrete column under live explosion loading and numerical modelling of the columns. The primary objective of this current phase of the project reported in this thesis is the investigation of the residual capacity of the blastdamaged reinforced concrete columns. Twenty (20) reinforced concrete columns with different transverse reinforcement detailing were exposed to various blast threat scenarios in the near-field range (scaled distance $(\mathrm{z})<1.0 \mathrm{~m} / \mathrm{kg}^{1 / 3}$ ) and their responses measured in a previous study by Siba (2014).

Thirteen (13) of the columns were tested in this residual capacity test program. Four (4) were undamaged control samples while the remaining nine (9) survived the field tests carried out by Siba (2014). The residual capacity tests were carried out by the applying axial force in a load control mode then lateral force in a displacement control mode.

The columns were instrumented with three (3) string potentiometers (string-pots) to record the displacement of the test column along its height. Strain gauges were attached to the longitudinal reinforcement of the test columns before the blast testing and were used to record the reinforcement strains during the residual capacity testing. 
In general, reinforced concrete columns that were tested at a smaller scaled distance had lower residual capacities. The damage they sustained in the field test, visible or not, affected their performance in the residual capacity test. The results showed that reinforced concrete columns designed following seismic detailing guidelines have an inherent resistance against blast load. Again, columns tested at a greater scaled distance, exhibited higher residual capacity, with columns having a scaled distance of $0.86 \mathrm{~m} / \mathrm{kg}^{1 / 3}$ showing residual capacities close to the control column capacity. 


\section{Acknowledgements}

Nothing worth pursuing comes easy. I am first grateful to God for the blessings and help throughout this academic pursuit. A special appreciation to my supervisor, Dr. Abass Braimah, for guiding and directing me in this research work and in my goal of attaining a Master of Applied Science at Carleton University in furtherance of my career. In addition, to my family who supported me from many miles away in Ghana, I am forever grateful for your support. I am also grateful to the Carleton University; Civil structures lab staff headed by Stanley Conley for their help and expertise input in my work. 


\section{Table of Contents}

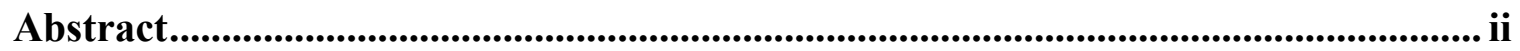

Acknowledgements ........................................................................................................................ iv

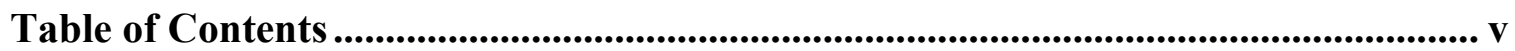

List of Tables ............................................................................................................................... ix

List of figures................................................................................................................................... $\mathrm{x}$

List of symbols and abbreviations ....................................................................................... xvi

1 Chapter: Introduction .......................................................................................................... 1

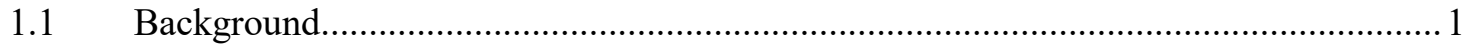

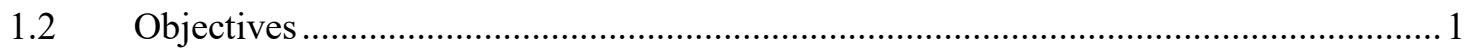

$1.3 \quad$ Thesis Outline

2 Chapter: Literature Review...................................................................................... 4

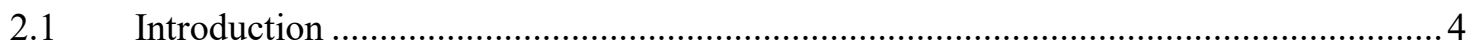

2.2 Accidental and premeditated explosions …………………………………….....

2.2.1 Tianjin port explosion -2015 ........................................................................

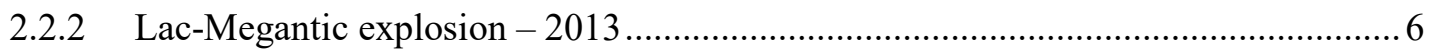

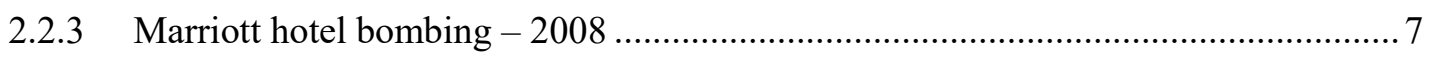

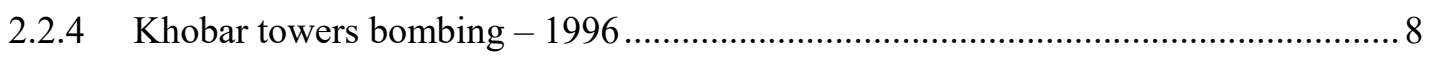

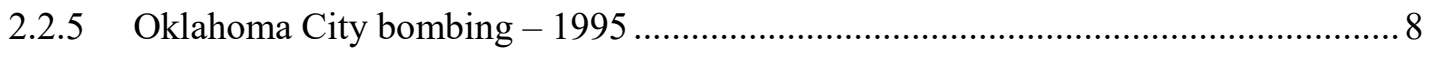

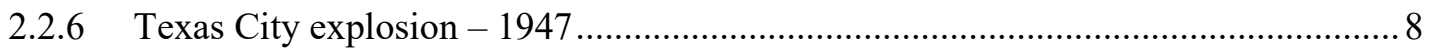

2.3 Previous research on the effects of blast loads on RC columns .................................. 9

2.3.1 Astarlioglu et al. (2013) ....................................................................................

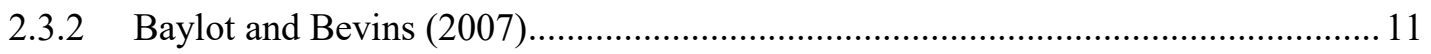




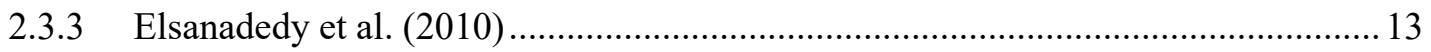

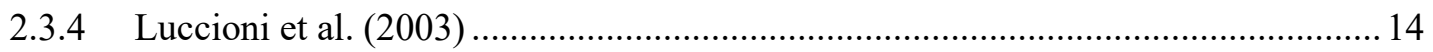

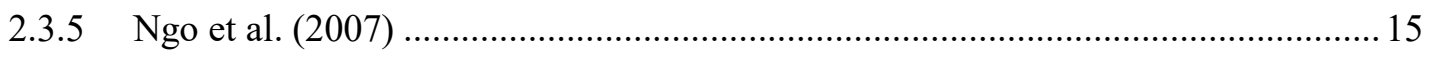

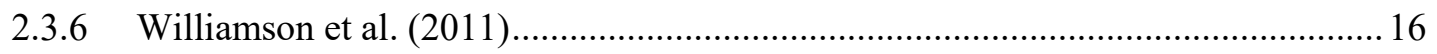

$2.4 \quad$ Review of previous work on residual capacity of damaged RC columns ....................20

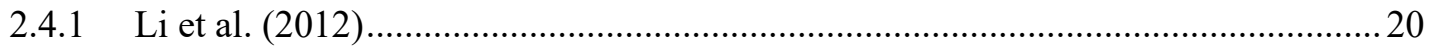

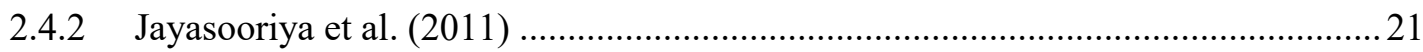

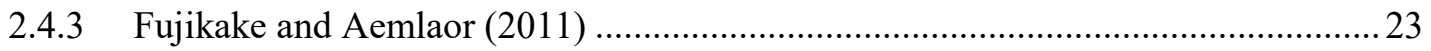

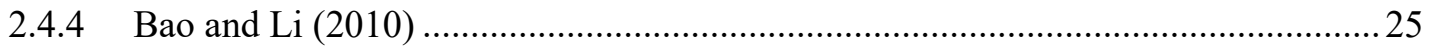

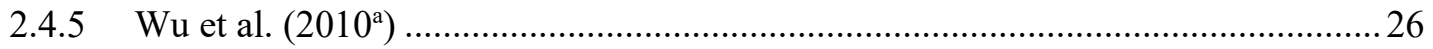

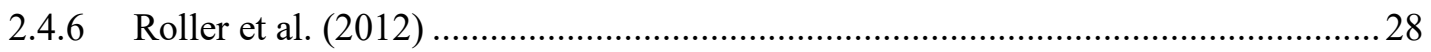

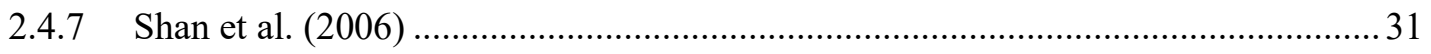

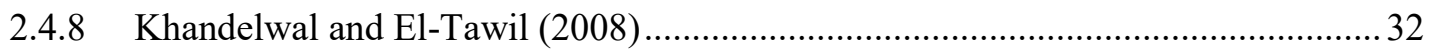

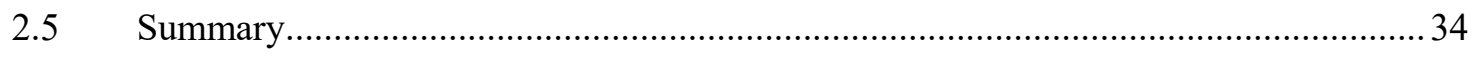

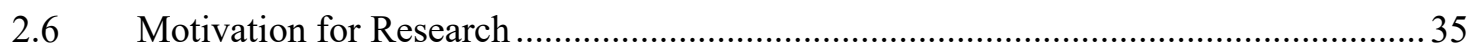

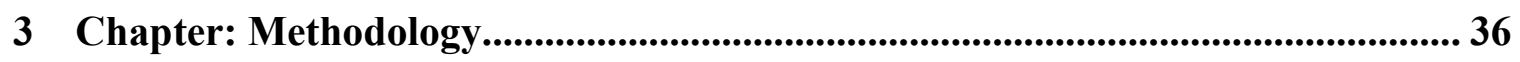

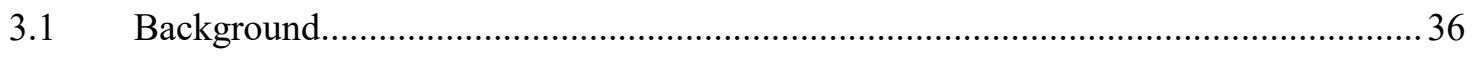

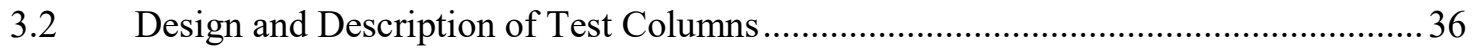

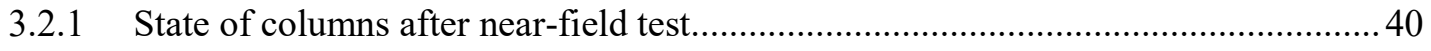

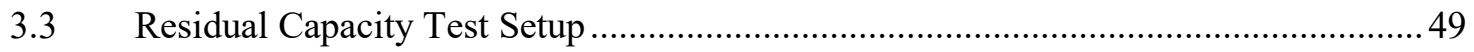

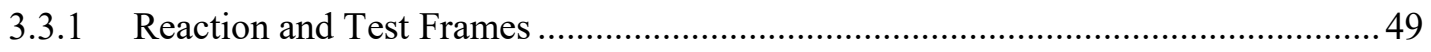

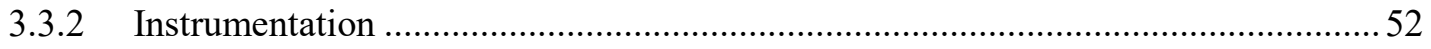

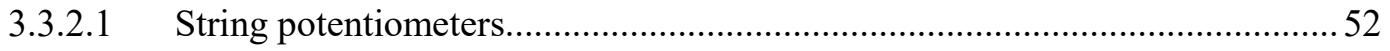

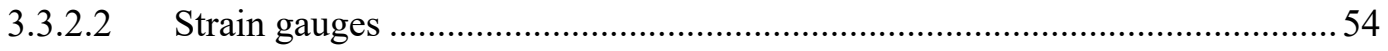

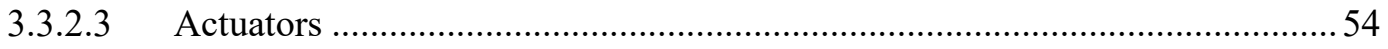




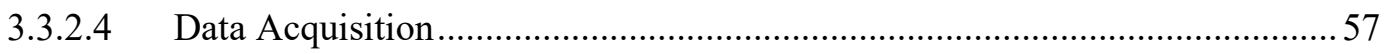

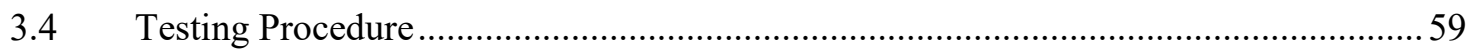

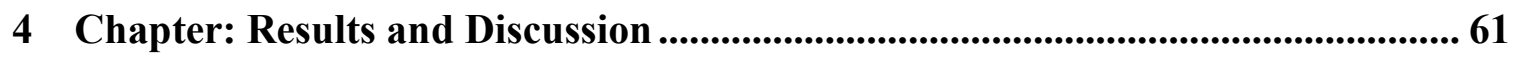

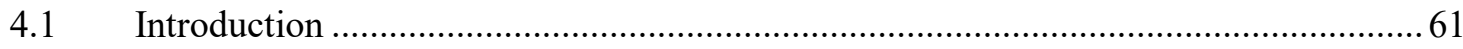

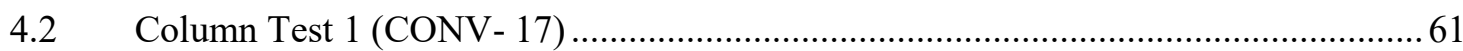

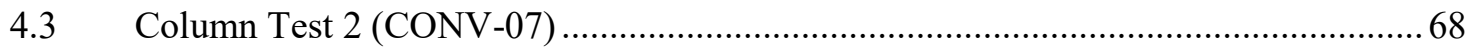

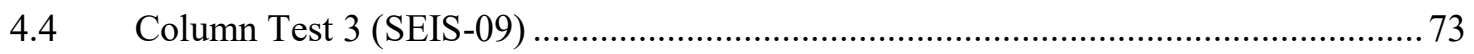

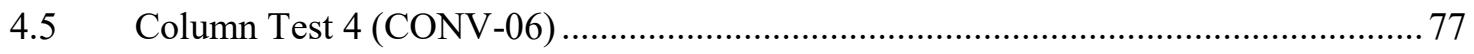

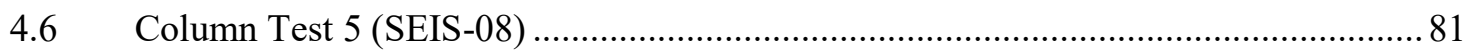

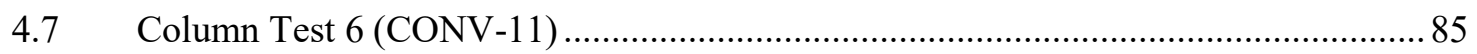

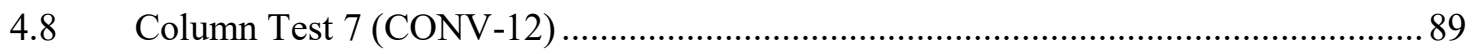

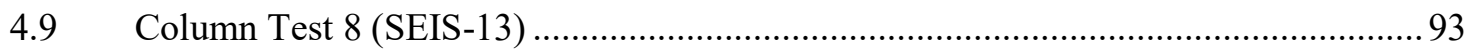

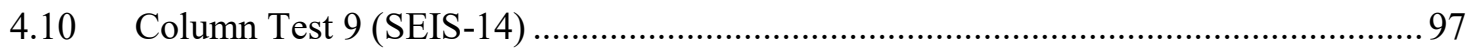

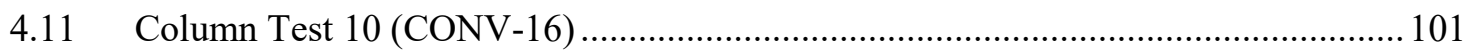

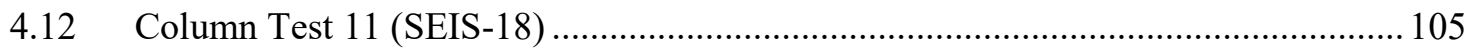

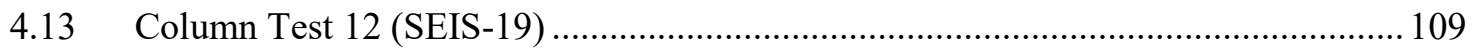

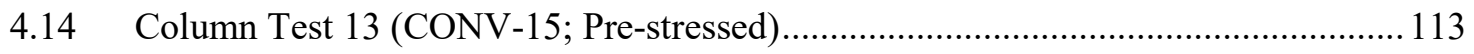

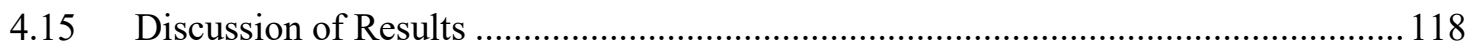

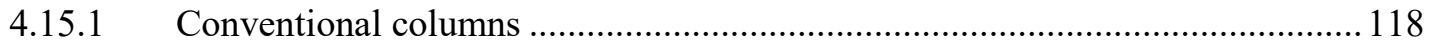

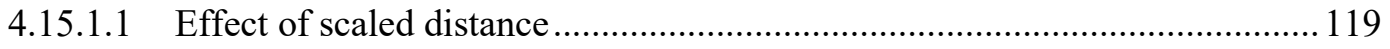

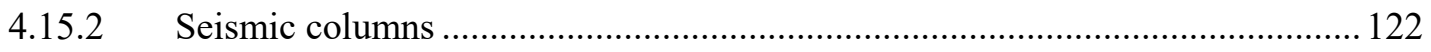

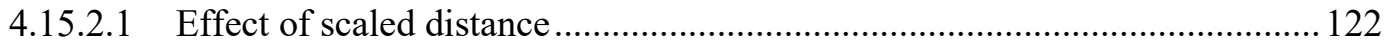

4.15.3 Effect of transverse reinforcement detailing ................................................ 125

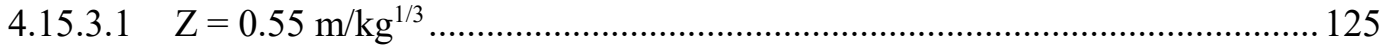

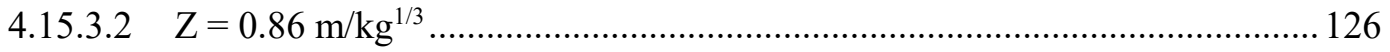


4.15.3.3 Undamaged columns $(\mathrm{z}=$ infinity)

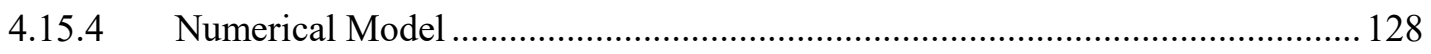

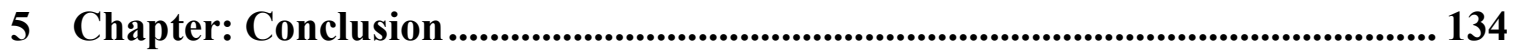

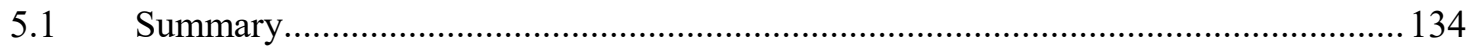

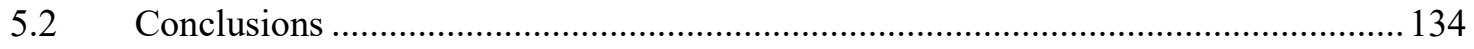

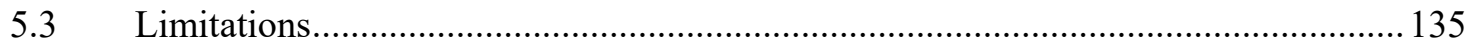

References ....................................................................................................................................... 136

Appendix: Summary of Results ..................................................................................... 140 


\section{List of Tables}

Table 2-1: Table of column details tested in experimental program by Williamson et al

Table 2-2: Summary of close-in blast test carried out by Williamson et al (2011) - first

half 18

Table 2-3: Summary of close-in blast test carried out by Williamson et al (2011) - second half. 19

Table 3-1 Column nomenclature, tie spacing, scaled distance and axial load ratio details

Table 3-2 Strain gauge locations as installed on columns by Siba (Siba (2014))..... 54

Table 4-1: Summary of test results for conventional columns (loads and displacements).

Table 4-2: Summary of test results for seismic columns (loads and displacements).... 124

Table 5-1: Summary of column strains under axial load only. 147

Table 5-2: Summary of strains under lateral load. 148 


\section{List of figures}

Figure 2-1: Ariel view of Lac-Megantic explosion (taken on a police helicopter on same day) 7

Figure 2-2: RC column in a tensile membrane action post-blast threat. (Crawford et. al 2001)

Figure 2-3: Damaged columns after contact detonation, with cross-sections made of (a) RC, (b) SIFCON, (c) DUCON, and (d) UHPC (Roller et al. (2012)) 30

Figure 2-4: Comparison of the residual capacities of test specimen (Roller et al. (2012))

Figure 2-5: Elevation of 10-storey steel frame ……………......................................... 33

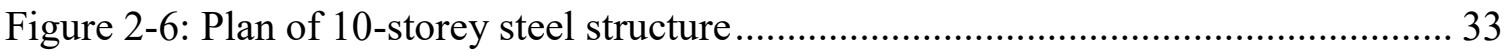

Figure 3-1: (a) Conventional column detailing (b) Seismic column detailing (Siba (2014))

Figure 3-2: Post-field test photograph of CONV-07: (a) front face, (b) right side (c) back face (d) left side (Siba (2014)). 41

Figure 3-3: Post-field test photograph of SEIS-08: (a) \& (b) front face, (c) back face, (b) $\&$ (d) side faces (Siba (2014))......

Figure 3-4: Post-field test photograph of SEIS-09: (a) front face, (b) right face (c) back face (d) left face (Farouk 2014) 43 Figure 3-5: Post-field test photograph of CONV-06: (a) front face, (b) right face, (c) back face and (d) left face (Farouk 2014) 44 Figure 3-6: Post-field test photograph of SEIS-13: (a) front face, (b) right face, (c) back face and (d) left face (Siba (2014)) 45 
Figure 3-7: Post-field test photograph of SEIS-14 (a) front face, (b) right face, (c) back face and (d) left face (Siba (2014)) 46

Figure 3-8: Post-field test photograph of CONV-11 (a) front face, (b) right face, (c) back face and (d) left face (Siba (2014)) 47

Figure 3-9: Post-field test photograph of CONV-12: (a) front face, (b) right face, (c) back face and (d) left face (Siba (2014)) 48

Figure 3-10: Post-field test photograph of CONV-15: (a) front face, (b) right face, (c)

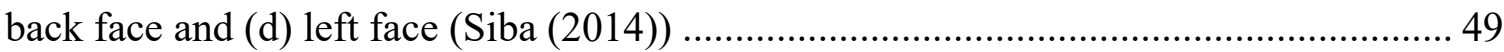

Figure 3-11: Reaction structure at the civil structures lab of Carleton University. .......... 50

Figure 3-12: (a) Experimental setup of the residual capacity test (b) Pin reaction at top (c) Fixed reaction system 52

Figure 3-13: String potentiometer attached to supporting steel column and connected to

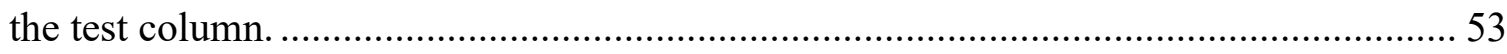

Figure 3-14: Steel frame supporting axial $(1045-\mathrm{kN})$ actuator.................................... 55

Figure 3-15: Axial load-moment interaction for a typical test column. ........................ 56

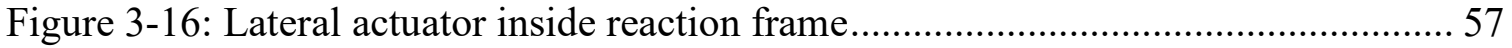

Figure 3-17: Photograph of NI cDAQ-9178 data acquisition system............................ 58

Figure 3-18: Two MTS 458.10 Micro Consoles used for the two hydraulic actuators. ... 58

Figure 4-1: Strains in longitudinal reinforcement during the first stage of testing.......... 62

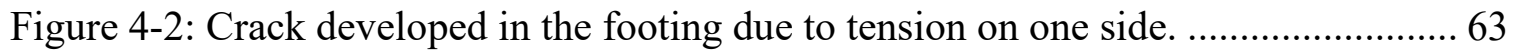

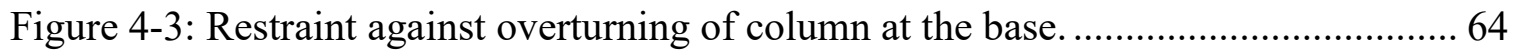

Figure 4-4: Lateral load-displacement graphs showing all three string pots. .................. 65

Figure 4-5: Strain gauge readings during the application of the lateral load................... 66 
Figure 4-6: Photograph of CONV-17 (a) Front face with compression spall (b) Several

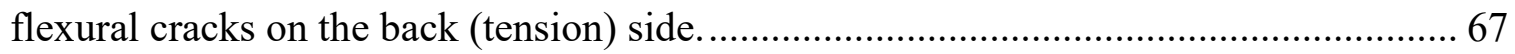

Figure 4-7: Compression strains during first stage of loading column CONV-07......... 69

Figure 4-8: Lateral load against displacements for CONV-07................................. 70

Figure 4-9: Strains in the longitudinal reinforcement during entire testing of CONV-07.71 Figure 4-10: (a) Shear cracks developed near the base of column CONV-07 (b) Flexural

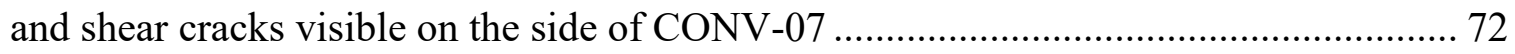

Figure 4-11: Concrete spall around mid-height of column CONV-07......................... 72

Figure 4-12: Recorded strains after axial service load was applied to SEIS-09............. 74

Figure 4-13: Lateral load against displacement for SEIS-9, showing constant service load. 75

Figure 4-14: Strains recorded during entire testing of SEIS-9. ............................... 76

Figure 4-15: Photographs of SEIS-09 showing (a) A chunk of concrete spall on the compression (front) side of SEIS-09 post-test (b) Tension (back) side of SEIS-09 showing the spall before testing and light cracks after test. 77

Figure 4-16: Shear crack existing in CONV-6 prior to residual capacity test. 78

Figure 4-17: Strains in longitudinal reinforcement during axial load application stage in CONV-06. 79

Figure 4-18: Lateral load versus displacement for CONV-6.................................... 80

Figure 4-19: Post-test photograph of CONV-6 showing shear failure. ......................... 81

Figure 4-20: Strains recorded as column SEIS-08 was loaded axially......................... 82

Figure 4-21: Lateral load versus displacement for SEIS-08, showing constant service load. 83 
Figure 4-22: Strains during the second stage of loading SEIS-08. 84

Figure 4-23: Post-test photograph of SEIS-08 showing (a) Flexural failure at the fixed support location post-test (b) Minor flexural cracks on the back side. 85

Figure 4-24: Compressive strains recorded during the first stage of loading CONV-11. 86 Figure 4-25: Lateral load versus displacement for CONV-11 .................................. 87

Figure 4-26: Strain recording in the lateral loading stage of CONV-11 ...................... 88 Figure 4-27: Shear failure exposing deformed longitudinal and transverse reinforcement

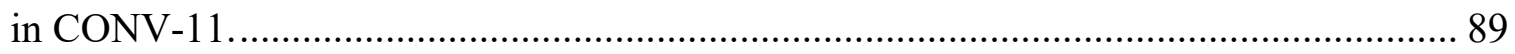

Figure 4-28: Strains indicating compressive stress in first stage of loading column

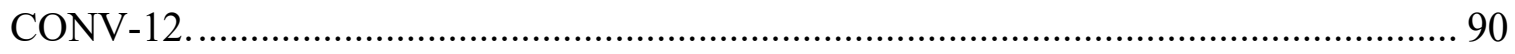

Figure 4-29: Graph of lateral load against displacements for columnsCONV-12.......... 91

Figure 4-30: Graph of strains in the longitudinal reinforcement for CONV-12 ............ 92

Figure 4-31: Shear cracks on the both sides of CONV-12 post-test............................. 93

Figure 4-32: Strains in the longitudinal reinforcement indicating compression stress in

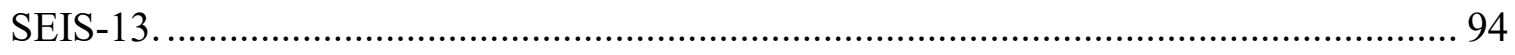

Figure 4-33: Lateral load versus displacement for column SEIS-13 ........................... 95

Figure 4-34: Strain gauge recording during second stage of testing SEIS-13 ............... 96

Figure 4-35: Photograph of concrete spall exposing reinforcement: (a) front view (b) Side

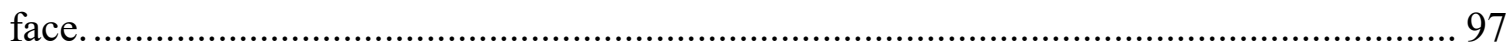

Figure 4-36: Strains in column SEIS-14 during the first stage of loading..................... 98

Figure 4-37: Load-displacement graph of column SEIS-14 ..................................... 99

Figure 4-38: Strains recorded during the second stage of loading for SEIS-14. ........... 100 
Figure 4-39: Post-test photograph of SEIS-14 showing: (a) Shear cracks near bottom of column SEIS-14 (b) Concrete spall on the mid-front face indicative of flexural stress. 101 Figure 4-40: Strains at various locations on the longitudinal reinforcement (CONV-16).

Figure 4-41: Lateral load against displacements for CONV-16. 103

Figure 4-42: Strain at various locations on the longitudinal reinforcement (CONV-16).

Figure 4-43: Severe shear failure with bent longitudinal reinforcement after the test

(CONV-16). 105

Figure 4-44: Strains in the axially loaded SEIS-18 column......................................... 106

Figure 4-45: Load-displacement curves for column SEIS-18 ...................................... 107

Figure 4-46: Longitudinal reinforcement strains during lateral loading of SEIS-18.... 108

Figure 4-47: (a) Flexural cracks propagating from tension face onto sides along with shear cracks (b) Flexural cracks propagating from tension face onto sides along with shear cracks. 109

Figure 4-48: Strain reading with increasing axial load during the first stage of the test (SEIS-19)

Figure 4-49: Load-displacement curve for column SEIS-19.

Figure 4-50: Strains in the top and middle locations on SEIS-19 during lateral load application.

Figure 4-51: (a) Concrete spalled off on the compression side (front) at the upper load contact point (b) Tension cracks due to flexure in SEIS-19. 113 
Figure 4-52: CONV-15 put on an assembly of steel washers to accommodate the posttensioning cap.

Figure 4-53: Lateral load versus displacement for CONV-15 (post-tensioned). 115

Figure 4-54: Strain recording in CONV-15 during the application of the lateral load... 116 Figure 4-55: (a) Shear cracks beginning to develop. (b) Fully formed shear failure in CONV-15. 117

Figure 4-56: Comparison of capacity of conventionally designed RC columns. 120

Figure 4-57: Comparison of seismically detailed columns. 123

Figure 4-58: Comparison of column tested at a scaled distance of about $0.55 \mathrm{~m} / \mathrm{kg} 1 / 3.126$

Figure 4-59: Constant scaled distance $(\mathrm{z}=0.86 \mathrm{~m} / \mathrm{kg} 1 / 3)$. 127

Figure 4-60: Comparison of the performance of undamaged control columns. 128

Figure 4-61: Unconfined concrete model by Hognestad (Wu et al 2006) 129

Figure 4-62: Concrete model developed by Chang and Mandar 1994. 131

Figure 4-63: OpeenSees model compared to experimental results 133 


\section{List of symbols and abbreviations}

$\begin{array}{ll}\mathrm{A}_{\mathrm{g}} & \text { Gross sectional area } \\ \mathrm{A}_{\mathrm{s}} & \text { Area of steel reinforcement } \\ \text { ALR } & \text { Axial load ratio } \\ \text { ANFO } & \text { Ammonium nitrate fuel oil } \\ \text { CONV } & \text { Conventional reinforced concrete column } \\ \mathrm{d}_{\mathrm{b}} & \text { diameter of reinforcement bar } \\ \mathrm{E}_{\mathrm{c}} & \text { Modulus of elasticity for concrete } \\ \mathrm{f}_{\mathrm{c}}{ }^{\prime} & \text { characteristic strength of concrete cylinder } \\ \mathrm{f}_{\mathrm{y}} & \text { Yield strength of steel reinforcement } \\ \mathrm{matTag}_{\mathrm{L}} & \text { Material tag } \\ \mathrm{P}_{\mathrm{L}} & \text { Axial load/capacity } \\ \mathrm{P}_{\mathrm{rmax}} & \text { Maximum axial load capacity }\end{array}$




$\begin{array}{ll}\text { R } & \text { Range (distance of target from centre of explosion) } \\ \text { RFRS } & \text { Reinforced Concrete } \\ \text { S } & \text { Seismic force resisting system } \\ \text { SEIS } & \text { Spacing of transverse hoops } \\ v & \text { residual capacity index } \\ \text { W } & \text { Charge mass in kg } \\ \mathrm{z} & \text { Scaled distance } \\ \rho & \text { reinforcement ratio } \\ \varepsilon & \text { Strain in material } \\ \Phi_{c} & \text { Concrete material resistance factor } \\ \Phi_{s} & \text { Steel material resistance factor }\end{array}$




\section{Chapter: Introduction}

\subsection{Background}

Evidence from recent blast events around the world has shown that explosions at standoff distances of more than $20 \mathrm{~m}$ generally cause damage to the façade elements of buildings with minimal damage to their load-bearing members such as columns (Jayasooriya et al. 2011). However when the blast threat is closer to the building as in the case of near-field explosions, load-bearing elements could suffer significant damage, possibly leading to structural progressive collapse of a large portion of the structure, if not complete structural collapse.

Iconic and public buildings can be protected from severe blast threats by façade hardening or provision of physical security measures that make it difficult for large amounts of explosives to be detonated close enough for maximum damage. Smaller amounts of explosives such in suitcase bombs are difficult to restrict to the secure perimeter and their explosion can have severe consequences on infrastructures as they can be placed close to key structural elements. When an explosive device is detonated close to a building whose load-bearing members (such as columns) do not collapse, the need arises to evaluate the building to determine if it is safe for immediate occupancy or must be shut down until remedial measures are taken to make it safe. In cases such as these, engineers must be able to assess the residual capacity of the blast-damaged columns to determine the safety of the building for immediate occupancy. Residual capacity of a column is also key to assessing the progressive collapse potential of a structure, post blast event.

\subsection{Objectives}

The main objective of this experimental research program is to investigate the residual capacity of blast-damaged reinforced concrete (RC) columns. Siba (2014) built the columns in the 
structures laboratory at Carleton University. The RC columns were designed with different transverse reinforcement detailing with three columns post-tensioned to achieve an axial load ratio of about 0.32 . The columns were exposed to various blast threat scenarios through live explosive testing, in the near-field, at the Canadian Forces Base (CFB) Petawawa, Ontario. The primary objective of this phase of the overall experimental program is to investigate the residual capacity and resilience of the blast-damaged columns. This will throw more light on the performance of typical ground floor columns that have been subjected to high blast loads. At the end of this program, contribution will be made to existing guidelines for assessing the residual capacity of columns post-blast event.

The main objectives of the research presented in this thesis are:

- To study the capability of blast-damaged columns to resist the service level design loads

- To study the effect of scaled distance on the residual capacity of blast-damaged RC columns

- To study the effects of transverse reinforcement detailing on the residual capacity of blast-damaged RC columns

\subsection{Thesis Outline}

This thesis is organized into the following chapters;

Chapter 1 briefly introduces the subject matter of blast loads and residual capacity of columns. It also presents the objectives and motivation for the research. The chapter then ends with a thesis outline that summarizes the individual chapters making up the thesis.

Previous work on RC column resistance under blast loading and residual capacity of RC columns are reviewed in Chapter 2. Accidental explosions and terrorist attacks on buildings as well as 
previous research work on the effects of blast loads on the behavior of columns, in general, are also reviewed. Chapter 3 presents a description of the test columns and the level of damaged sustained during the live explosion testing. Cracking and permanent deformations, if any, are noted. Additionally, the residual static test procedure, instrumentation, and data acquisition system used in the residual capacity testing are described.

Chapter 4 presents the results of the experimental testing and discussion of the test results while chapter 5 highlights relevant conclusions and recommendations drawn from the experimental results presented in this thesis. 


\section{Chapter: Literature Review}

\subsection{Introduction}

Progressive collapse is defined as the disproportionate collapse of a structure caused by localized damage to a primary structural element. The failure of a primary structural member often times overburdens adjoining elements and this may trigger a more global failure of the structure. When the key structural members in a building do not collapse in a blast-event, there is the need to assess their capacities and to identify those that have adequate capacity to resist their design load. If a RC column's capacity is insufficient to resist its design loads, it can be retrofitted to increase its capacity otherwise the building could be demolished. It is thus important that engineers have the tools to assess the residual strength of a structure, post-disaster, to identify those that require retrofit, replacement or to demolition the entire building.

This chapter presents a literature review on previous research work on the effects of blast loads on columns in general with a special emphasis on the residual capacity of blast-damaged reinforced concrete columns. Recent accidental explosions and terrorist attacks around the world are also presented to highlight the effects of explosions on infrastructure systems.

In their 2014 report, the US Department of State reported a 43\% increase in global terrorism in 2013 over previous year. A total of 9,707 terrorists' attacks, with over 17,800 deaths and more than 32,500 injuries were reported in 2013 (U.S. Department of State, 2014). About 57\% of the reported terrorist's attacks involved the use of explosives and many with the capacity to damage infrastructure. The effects of explosion attacks on infrastructure can be minimized through security protocols and blast hardening of structures to protect human life and property. 
Security protocols are generally designed to detect, delay, deter and defeat terrorists' attacks against critical infrastructure and systems. They are also supposed to keep the explosive away from the infrastructure in order to reduce the blast loads on structural elements. When the security protocols fail, however, the blast-hardened structure is expected to resist the abnormally high loads and to protect the building occupants while limiting structural damage to an acceptable level.

It has become a concern to most building owners and governments to reduce the vulnerability of infrastructures against explosion effects thus increasing the survivability of occupants and sensitive and critical equipment. Buildings such as embassies, courthouses, and other important public institutions are prime candidates for protection against terrorists' attacks and explosion effects. As a result, researchers and structural engineers seek to understand the characteristics of blast loads and the response of structural components as well as entire structures to blast loading. They also seek to develop new techniques and guidelines for the design of new and retrofit or existing buildings to withstand blast loading.

\subsection{Accidental and premeditated explosions}

Many human lives and property have been lost because of accidental and premeditated (terrorist) explosions. Unfortunately, industrial accidents, leading to explosions within inhabited areas accounts for a large number of lost human lives and property damage. This section highlights some of the notable premeditated (terrorists) and accidental explosions that have occurred in different parts of the world and their effect on the built environment and the population. 


\subsubsection{Tianjin port explosion $\mathbf{- 2 0 1 5}$}

A warehouse containing flammable and hazardous chemicals including calcium carbide, sodium cyanide, potassium nitrate, ammonium nitrate and sodium nitrate, exploded in two (2) massive successive explosions, killing more than 100 people and injuring hundreds more on August 17, 2015 in the port of Tianjin, China. The China Earthquake Centre estimated the first explosion to be the equivalent of a 3-ton TNT explosion while the second explosion was a 21-ton TNT equivalent. The blast-affected area was in a radius of $5 \mathrm{~km}$ form the centre of explosion. Outside the blast-affected areas, components of buildings close to ground-zero, including doors and window glasses, were damaged due to the blast wave and explosion-induced ground shocks. (Zhao B (2016)).

\subsubsection{Lac-Megantic explosion - 2013}

On July 6, 2013, a 72-car train carrying large quantities of crude oil ran off its tracks and exploded in Lac-Megantic, Quebec, Canada (Jébrak, 2014). The explosion killed about 50 people and destroyed more than 30 buildings including the municipal library, the town's archives, heritage buildings, businesses and residences (E Network, 2013). Reports indicated the blast caused damage to infrastructure within a 1-km distance from train explosion. Figure 2-1 presents an aerial view of the Lac-Megantic explosion and shows many building and structures set ablaze from the explosion effects. 


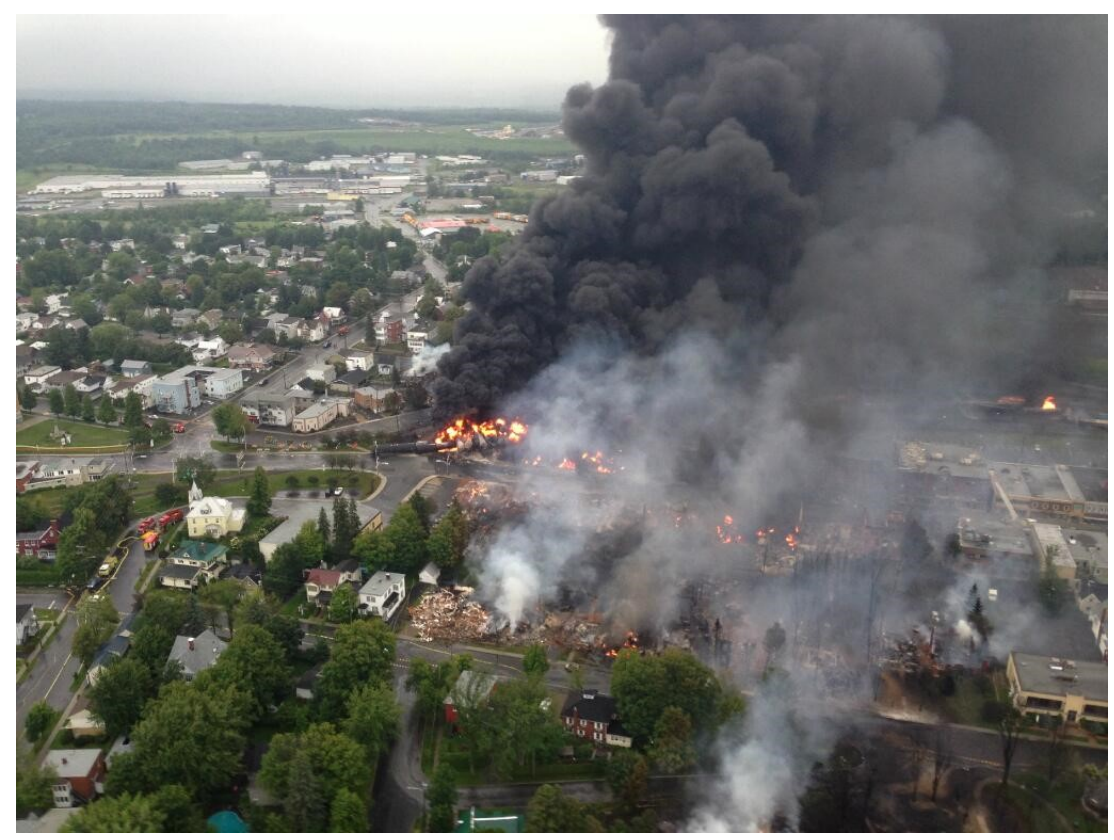

Figure 2-1: Ariel view of Lac-Megantic explosion (taken on a police helicopter on same day) (The Canadian Press (2013))

\subsubsection{Marriott hotel bombing - 2008}

On September 20, 2008, the Marriott hotel in Islamabad, Pakistan was attack by terrorists. A dump truck filled with explosives (approximately $600 \mathrm{~kg}$ of RDX mixed with TNT) was detonated at the side of the building close to the security gates. The Marriott hotel is one of the most prestigious hotels in the Pakistani capital (Gunaratna, 2008), its location near government buildings, diplomatic missions and embassies, and its patronage by foreign nationals and diplomats made it an attractive target. The attack killed about 54 people and injured 266 others. The explosion left a 20-m wide and 6-m deep crater outside the hotel (Wernick and Von Glinow (2012)) whereas the blast wave caused severe damage to the five-story reinforced concrete building, especially the glazing on the front façade. A natural gas leak accompanying the explosion set ablaze the hotel building. 


\subsubsection{Khobar towers bombing - 1996}

On June 25,1996 , a truck loaded with about $2200 \mathrm{~kg}$ of explosives was detonated a few meters from the eight-story reinforced concrete Khobar towers in Dhahran, Saudi Arabia. The Khobar Towers housed US Army personnel stationed in Saudi Arabia. The blast caused severe damage to the front façade and many floor slabs of the Khobar towers (Thompson et al., 2004; Ruby, 2002). Twenty people were killed and as many as 372 others were injured.

\subsubsection{Oklahoma City bombing -1995}

On April 19, 1995, a truck loaded with approximately $2200 \mathrm{~kg}$ ANFO was detonated at $4.75 \mathrm{~m}$ from a peripheral column of the Alfred P. Murrah Federal Building in Oklahoma City, USA. This terrorist attack killed 168 people, injured more than 680 others, and damaged as many as 324 buildings within the neighborhood of the Alfred P. Murrah Building. Four main columns of the nine-story reinforced concrete Alfred P. Murrah Building failed leading to progressive collapse of part of the building (Corley at al., 1998; Mlakar et al., 1998). The Oklahoma City bombing is one of the most devastating acts of domestic terrorism in US history (Piotrowski and Vodanovich, 2007).

\subsubsection{Texas City explosion -1947}

The Texas City explosion was an industrial accident that occurred on April 16, 1947 in Texas City, USA. The explosion was because of a fire outbreak aboard a French merchant marine vessel - Grandcamp, which was carrying approximately 2300 tons of ammonium nitrate fertilizer. The fire ignited the ammonium nitrate fertilizer resulting in a tremendous explosion; killing 581 people and injuring more than 5000 people. The explosion also destroyed over 500 homes and rendered over 2000 people homeless. Vibrations from the explosion were felt more 
than $100 \mathrm{~km}$ away (Blocker and Blocker Jr., 1949; Strehlow and Baker, 1976; Stephens, 1997). This accident is considered the worst industrial explosion in US history (Meyers and Shanley, 1990) and though devastating, led to the discovery of a cheap explosive - Ammonium nitrate fuel oil (ANFO), which could be made from ammonium nitrate.

The foregoing has presented both accidental and premeditated explosions in history and their effect on buildings, human casualties, and society. The failure of building components such as load-bearing members can have a devastating impact, as in the Oklahoma City Bombing, because the direct impact of the blast is reinforced with the fatalities and injuries resulting from the accompanying progressive collapse. Thus there is an increasing need to understand the response of building components to blast loading and to develop blast-resistant design strategies to protect buildings and the population at large. A number of targeted research works have been carried out for this purpose. The following section presents a summary of this research.

\subsection{Previous research on the effects of blast loads on $\mathrm{RC}$ columns}

\subsubsection{Astarlioglu et al. (2013)}

Astarlioglu et al. (2013) carried out numerical studies on the response of RC columns using a single-degree-of-freedom (SDOF) model as well as ABAQUS. $406 \times 406 \times 3660 \mathrm{~mm}$ reinforced concrete columns with fixed end supports were used in this study. The columns were loaded axially to $2224 \mathrm{kN}, 3559 \mathrm{kN}$ and $6672 \mathrm{kN}$ before the lateral blast loads were applied. The axial loads correspond to axial load ratios of $0.3,0.5$ and 1.0 respectively. The axial loads were applied by means of support displacement. The blast loads ranged from 5.1 MPa to $36.3 \mathrm{MPa}$ in peak pressure with associated impulse ranging from 3.6 MPa-millisecond to $25.9 \mathrm{MPa}-$ millisecond. The axial load was present throughout the blast loading stage. It was revealed that 
the level of axial compressive stress on the column influences its response to lateral blastinduced loads. A tensile membrane response was observed in RC beams when there is a high deflection. For there to be a tensile membrane action in a column, the longitudinal reinforcement must be continuous through its length and anchored in the supports. In addition, the compression in the columns is considered lost due to failure. The Dynamic Structural Analysis Suite (DSAS), capable of performing time-history analysis was used to carry out numerical analysis of RC columns under blast loads. DSAS was developed by the Centre for Infrastructure Protection and Physical Security (CIPPS) at University of Florida, Gainesville. It uses the equivalent SDOF analysis approach. Most columns analysed failed in flexural behavior. In cases of high axial stress, this led to tensile membrane action. Direct shear failure was also observed in columns under high impulsive blast loads. It was observed that in most of the loading scenarios the columns failed in tension membrane. Under moderate or low axial loads, columns failure was either by flexure or direct shear depending on whether the blast loads were low to moderate or high, respectively. In addition, when the longitudinal reinforcement ratio was higher in a column, more blast load was resisted. Tensile membrane action tends to make columns resist more blast loads but they also lose their axial capacity. Thus if surrounding columns do not have excess capacity to take redistributed load, a progressive collapse may be initiated. Figure $2-2$ shows a reinforced concrete column in tension membrane action. Secondary effects due to the large displacement will render such a column incapable of carrying its designed load. 


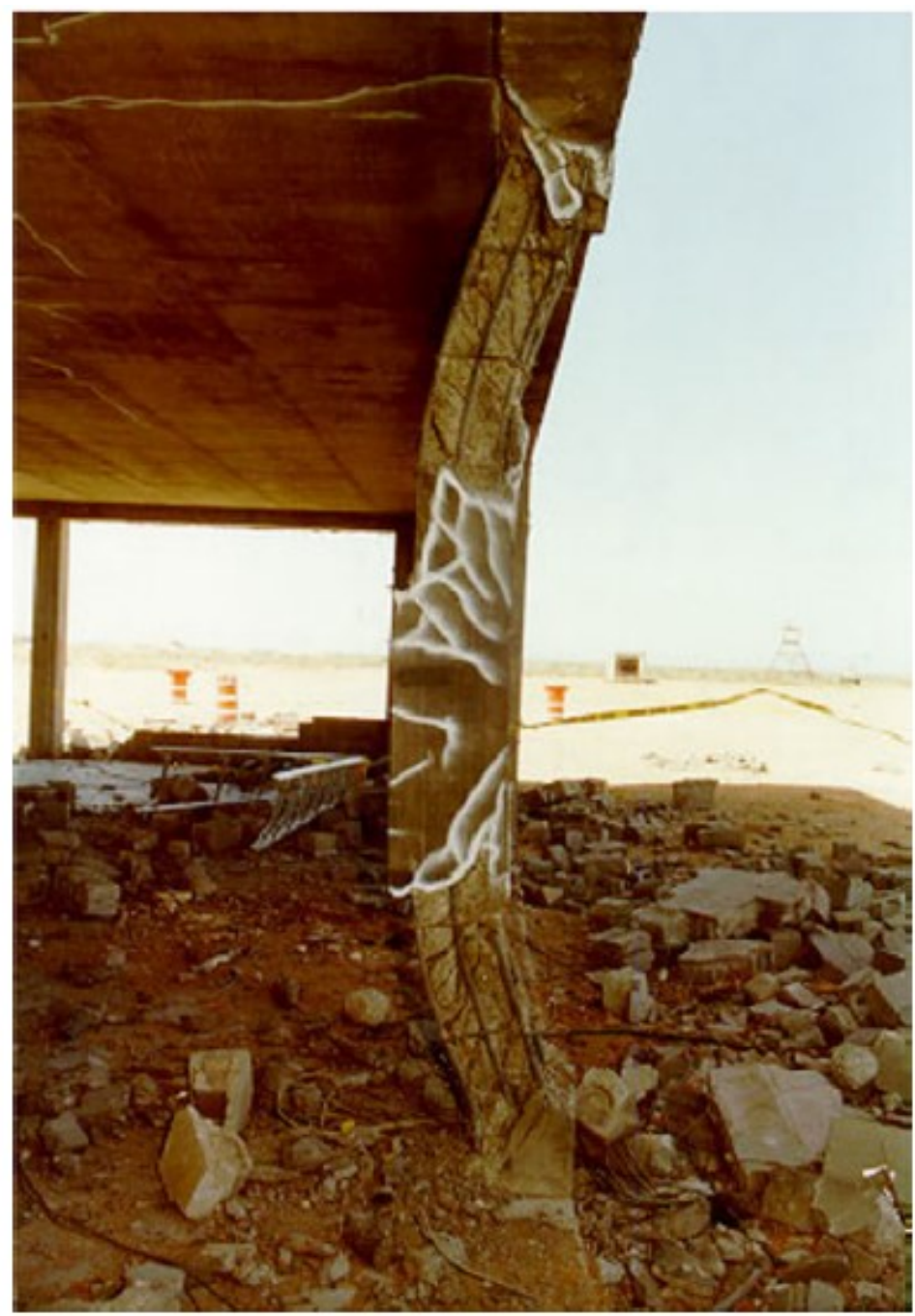

Figure 2-2: RC column in a tensile membrane action post-blast threat. (Crawford et. al 2001)

\subsubsection{Baylot and Bevins (2007)}

Baylot and Bevins (2007) carried out close-range experimental and numerical research to investigate the effect of non-structural exterior walls on the response of reinforced concrete columns subjected to air-blast loading. Exterior infill walls in concrete frame structure are nonload bearing, i.e. they do not contribute to supporting the gravity loads of a structure. Although these walls are non-structural, they can affect the loads applied to exterior columns and thus the response of the structure as a whole. To understand the effects of non-structural walls on 
columns subjected to blast loading, the researchers carried out numerical simulations and experimental investigations for a two-story reinforced concrete structure with and without exterior infill concrete masonry unit (CMU) walls. The experimental phase of the research was divided into two stages to investigate a full-scale and a quarter-scale models. A charge mass of $454 \mathrm{~kg}$ of $\mathrm{C} 4$ at a standoff distance of $6.1 \mathrm{~m}$ was pre-selected for the full-scale experimental test. Baylot and Bevins (2007) explained that the pre-selection of the $454 \mathrm{~kg}$ of C4 at a standoff distance of $6.1 \mathrm{~m}$ was purposely to cause failure of an exterior column so that the potential for progressive collapse of the building could be evaluated. Based on the charge mass of $454 \mathrm{~kg} \mathrm{C} 4$ and standoff of $6.1 \mathrm{~m}$ for the full scale experiment, the charge mass and standoff for the quarterscale experiment was calculated using the Hopkinson scaling law to be $7.1 \mathrm{~kg}$ of $\mathrm{C} 4$ charge at a standoff distance of $1.52 \mathrm{~m}$. The objective of the first quarter-scale experiment was to reproduce response the full-scale experiment. After the first quarter-scale experiment however, Baylot and Bevins (2007) observed minimal damage to the reinforced concrete column in comparison to the full-scale test. In order to determine the requisite standoff distance for the $7.1 \mathrm{~kg} \mathrm{C} 4$ charge to cause a significant damage to the column in the absence of CMU walls, a numerical simulation technique was employed and a standoff distance of $1.07 \mathrm{~m}$ was established.

Baylot and Bevins (2007) concluded that, the interaction of blast load with failing exterior CMU wall has a significant effect on the response of the column. Impulse was slightly higher for columns with CMU walls compared to those without CMU walls. They concluded that, the duration of the blast was longer due to the presence of CMU walls. 


\subsubsection{Elsanadedy et al. (2010)}

Elsanadedy et al. (2010) undertook a numerical study of retrofitted concrete columns subjected to blast loading from both far-field and close-in explosions. The study was aimed at investigating the effects of blast loading on Carbon Fibre Reinforced Polymer (CFRP)-retrofitted columns. The researchers used the parameters of an existing reinforced concrete column for their simulation. An RC column of circular cross-section, with a diameter of $600 \mathrm{~mm}$ and a height of 4 m was selected for the study. The column was reinforced longitudinally with sixteen (16) 16-mm diameter reinforcing bars and 10-mm diameter transverse bars spaced at $200 \mathrm{~mm}$. The concrete had a compressive strength of $30 \mathrm{MPa}$.

To understand the effects of the CFRP-retrofit, the researchers considered two sets of columns: CFRP-retrofitted columns and un-retrofitted columns. The CFRP-retrofitted columns were wrapped with 1-mm thick CFRP sheets to increase concrete confinement and enhance shear and flexural capacity of the columns. Different TNT equivalent charge masses of $100 \mathrm{~kg}, 200 \mathrm{~kg}, 500$ $\mathrm{kg}$ and $1000 \mathrm{~kg}$ at standoff distances of $1 \mathrm{~m}, 4 \mathrm{~m}$ and $15 \mathrm{~m}$ were used for the numerical simulations. Elsanadedy et al. (2010) observed that $500 \mathrm{~kg}$ and $1000 \mathrm{~kg}$ charge masses at a standoff distance of $1 \mathrm{~m}$, destroyed both the retrofitted and un-retrofitted columns. For a blast load from $100 \mathrm{~kg}$ charge mass at $15 \mathrm{~m}$ standoff distance, the researchers detected that both sets of columns did not show any damage, however, the maximum displacement for the un-retrofitted column was higher, compared to the retrofitted column as expected. Similarly, the maximum and permanent displacements observed for different combinations of the charge masses and standoff distances showed that retrofitting of the column reduced the maximum and permanent lateral displacements, considerably. The reduction of lateral displacement varied from $8 \%$ for a charge mass of $100 \mathrm{~kg}$ at a standoff of $4 \mathrm{~m}$ to $79 \%$ for a charge mass of $500 \mathrm{~kg}$ at a standoff of $4 \mathrm{~m}$ 
(Elsanadedy et al., 2010). The concrete was crushed over the bottom one-third of the unretrofitted column subjected to a blast load from $100 \mathrm{~kg}$ TNT at a standoff of $1 \mathrm{~m}$, while the retrofitted column showed no appreciable damage as the FRP retrofit provided good confinement to the concrete. In addition, for a blast load from $200 \mathrm{~kg}$ TNT charge at a standoff of $1 \mathrm{~m}$, the researchers observed that concrete in the bottom half of the un-retrofitted column was completely blown out, with longitudinal bars severely bent out of shape and tie bars made ineffective. The retrofitted column however, showed minimal damaged to concrete as the CFRP wraps confined the concrete. Longitudinal bars bent out of shape at the blast height with a few ties fractured at the bottom $1 \mathrm{~m}$ height of the retrofitted column. The CFRP wrap was ruptured at the bottom one-third for this particular simulation.

Elsanadedy et al. (2010) concluded that retrofitting of RC columns reduces the peak lateral displacement considerably as well as damage to concrete and rebars, thereby providing considerable resistance to blast loads and generally most other loads as well.

\subsubsection{Luccioni et al. (2003)}

Luccioni et al. (2003) carried out a close-in numerical investigation to analyze the behaviour of a reinforced concrete building subjected to blast loading. Luccioni et al. (2003) modeled a reinforced concrete building following the structural and architectural plans of the AMIA (Israel's mutual society of Argentina) Building. The four-story AMIA Building was subjected to a full-scale blast test by the Defense Threat Reduction Agency (DTRA) as part of a research and development program to investigate measures to retrofit US embassies and other critical structures worldwide (Luccioni et al., (2003)). The full-scale model of the building was composed of a reinforced concrete frame (columns, beams and slabs) with masonry infill walls. 
The columns were square in cross-section with $300 \times 300 \mathrm{~mm}$ and a height of $5 \mathrm{~m}$. The columns were reinforced with a longitudinal reinforcement ratio of 0.04 . A 400-kg TNT charge at a standoff distance of $2.5 \mathrm{~m}$ was chosen in order to reproduce the same level of damage as in the terrorist attack on the AMIA Building.

Luccioni et al. (2003) observed that columns closer to the centre of the explosion failed by the direct effect of reflected blast pressure. Columns on the farther end of the building lost connection with the upper and lower beams. This could have been because of the tension effect imparted by the upward push on the first floor slab in that region. Indeed, Luccioni et al. (2003) stated that the first three lines of ground floor columns and the first two floor levels were completely destroyed, thereby resulting in the collapse of the upper floors. Based on their numerical investigation, it was concluded that the structural collapse of the reinforced concrete building was due to a gravitational mechanism originated by the destruction of the lower columns.

\subsubsection{Ngo et al. (2007)}

Ngo et al. (2007) carried out a close range numerical study to investigate the effects of blast loading on reinforced concrete columns with different transverse reinforcement detailing and concrete strengths. A 6.4-m high ground floor column of a typical story building in Australia was used for their study. Normal strength concrete (NSC) with compressive strength of $40 \mathrm{MPa}$ and high strength concrete (HSC) of compressive strength $80 \mathrm{MPa}$ were modelled. A column size of $500 \times 900 \mathrm{~mm}$ was used for the NSC columns, while a $350 \times 750-\mathrm{mm}$ size was used for the HSC columns. Both sets of columns were detailed as conventional and seismic columns. The tie spacing used for the conventional columns was $400 \mathrm{~mm}$ while that used for the seismic column 
was $100 \mathrm{~mm}$. Ngo et al. (2007) observed that HSC columns had better energy absorption capacity in comparison with the NSC columns. The researchers also observed a significant effect of the shear reinforcement. At failure, the ultimate lateral displacement for HSC column with 400-mm tie spacing was $45 \mathrm{~mm}$ and that for HSC column with 100-mm tie spacing HSC was 63 $\mathrm{mm}$. Similarly, the ultimate peak displacements were $20 \mathrm{~mm}$ and $30 \mathrm{~mm}$ for NSC columns with 400-mm tie spacing and 100-mm tie spacing respectively. Ngo et al. (2007) concluded that ductile reinforcement and strength of concrete significantly improve the performance of structures under severe load conditions.

\subsubsection{Williamson et al. (2011)}

Williamson et al. carried out a half-scale close-in blast test on bridge columns. The most important parameters investigated were cross-sectional shape, length-to-depth ratio, volumetric transverse reinforcement ratio, type of transverse reinforcement and splice location. Concrete with compressive strength of $28 \mathrm{MPa}$ and steel with yield strength of $420 \mathrm{MPa}$ were used in their experimental test program. Ten (10) RC columns were tested. Eight out of the 10 were distinct with 2 of them being duplicates. Three major column types were designed. The first type was a 457-mm (18-in) diameter circular column reinforced longitudinally with 6-\#6 (19.1-mm diameter) bars and \#4 (12.7-mm diameter) bars used as transverse hoops, ties or spirals. The second column type was a 762-mm (30-in) diameter circular column. This column was reinforced with 18-\#6 longitudinal bars and \#4 bars were used for transverse detailing. The last type of column was a square column of side $762 \mathrm{~mm}$ (30 inches). 24-\#6 bars provided longitudinal reinforcement while \#4 bars were used as transverse ties. Because of testing in the field, a robust reaction structure was built on-site to take several rounds of testing loads without 
severe damage. Due to security reasons, the charge masses and standoff distances used for the testing were not disclosed. Two parameters $\mathrm{w}$ and $\mathrm{x}$ were used to represent charge mass and standoff distance respectively. Columns were not loaded axially partly because bridge columns tend to have lower service loads to capacity ratios compared to other axial load carrying elements. The details of the test columns are shown in Table 2-1 below for ease of description.

Table 2-1: Table of column details tested in experimental program by Williamson et al (2011).

\begin{tabular}{|c|c|c|c|c|c|c|c|}
\hline \multirow{2}{*}{$\begin{array}{l}\text { Small standoff } \\
\text { test number }\end{array}$} & \multirow{2}{*}{$\begin{array}{c}\text { Column } \\
\text { designation }\end{array}$} & \multicolumn{2}{|c|}{ Column geometry } & \multirow{2}{*}{$\begin{array}{c}\text { Longitudinal reinforcement } \\
\text { Splice location }^{\mathrm{a}} \\
\end{array}$} & \multicolumn{3}{|c|}{ Transverse reinforcement } \\
\hline & & Shape & Size (in.) & & Pitch/spacing (in.) & Type & Volume ratio $\rho_{s} \%$ \\
\hline 1 & $1 \mathrm{~A} 1$ & Round & 18 & $0.25 \mathrm{~L}$ & 6.0 & Hoops & 0.82 \\
\hline 2 & $1 \mathrm{~A} 2$ & Round & 18 & $0.25 \mathrm{~L}$ & 6.0 & Hoops & 0.82 \\
\hline 3 & 1B & Round & 18 & $0.25 \mathrm{~L}$ & 6.0 & Spiral & 0.82 \\
\hline 4 & $2 \mathrm{Al}$ & Round & 30 & $0.25 \mathrm{~L}$ & 6.0 & Hoops & 0.47 \\
\hline 5 & $2 \mathrm{~A} 2$ & Round & 30 & $0.25 \mathrm{~L}$ & 6.0 & Hoops & 0.47 \\
\hline 6 & $2 \mathrm{~B}$ & Round & 30 & None & 6.0 & Spiral & 0.47 \\
\hline 7 & 2-Seismic & Round & 30 & None & 3.5 & Spiral & 0.80 \\
\hline 8 & 2-Blast & Round & 30 & $0.25 \mathrm{~L}$ & 2.0 & Spiral & 1.40 \\
\hline 9 & $3 \mathrm{~A}$ & Square & 30 & $0.25 \mathrm{~L}$ & 6.0 & Ties & 0.47 \\
\hline 10 & 3-Blast & Square & 30 & $0.25 \mathrm{~L}$ & 2.0 & Ties & 1.40 \\
\hline
\end{tabular}

Note: $1 \mathrm{in} .=25.4 \mathrm{~mm}$.

${ }^{\text {a }}$ Splice location of $0.25 \mathrm{~L}$ indicates the center of the splice is located $25 \%$ of the span length above the footing.

An important note was the use of volumetric transverse reinforcement ratio in 2-Blast and 3Blast that is $50 \%$ more than what was used in 2-Seismic column. This increased ratio resulted in better column response. Another parameter investigated was tie anchorage. Based on results obtained, the researchers recommended a 135-degree hook with embedded hook length of $20 \mathrm{~d}_{\mathrm{b}}$ as opposed to the existing standard of 90-degree hook with hook length of $6 \mathrm{~d}_{\mathrm{b}}$ (Williamson et al (2011)). 
Table 2-2: Summary of close-in blast test carried out by Williamson et al (2011) - first half

\begin{tabular}{|c|c|c|c|c|c|}
\hline Column & Design & Charge Size & Standoff & Column & st-Blast \\
\hline & & & & damage & picture \\
\hline $1 \mathrm{~A} 1$ & Gravity & $2.8 w$ & $5.8 x$ & Superficial & \\
\hline $1 \mathrm{~A} 2$ & Gravity & $2.9 w$ & $3.2 x$ & Failure & \\
\hline 1B & $\begin{array}{l}\text { Gravity } \\
\text { w/ spiral }\end{array}$ & $3.4 w$ & $2.6 x$ & Minor & \\
\hline $2 \mathrm{~A} 1$ & Gravity & $2.8 w$ & $3.9 x$ & Superficial & \\
\hline $2 \mathrm{~A} 2$ & Gravity & $3.3 w$ & $2.4 x$ & Minor & \\
\hline
\end{tabular}


Table 2-3: Summary of close-in blast test carried out by Williamson et al (2011) - second half

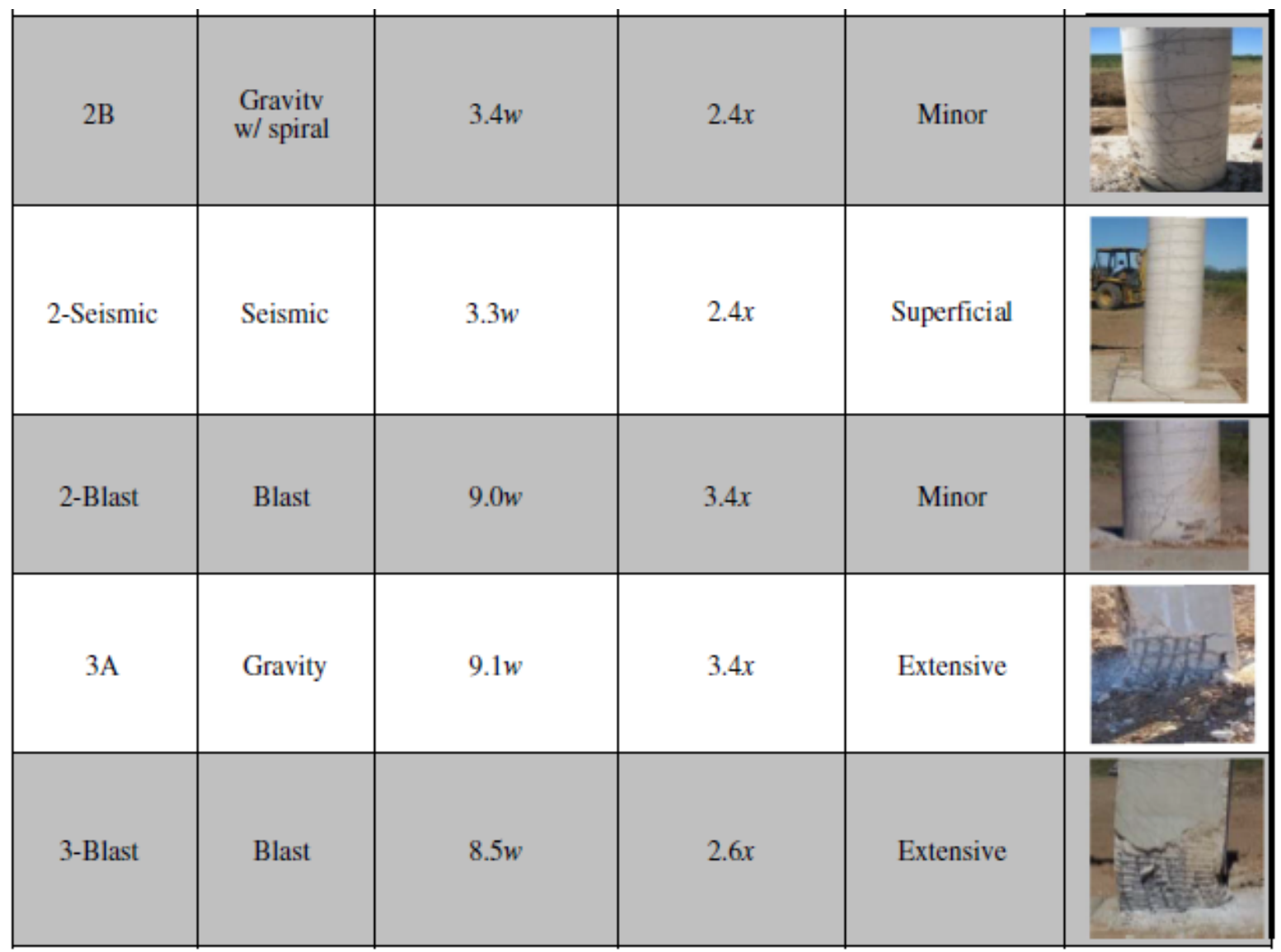

Notes: $w=$ charge weight parameter; $x=$ standoff parameter

Williamson et al recommended continuous spiral reinforcement for columns designed for blast.

This can be seen in the post-test photographs of column $1 \mathrm{~A} 2$ and $1 \mathrm{~B}$ in Table 2-2. The columns were exposed to similar blast threats. Column 1A2 suffered severe shear damage while column 1B showed minor surface cracks as the spiral reinforcement protected the concrete core. In summary, seven of the 10 columns tested in this close-in experimental program experienced a combination of shear and flexural cracking, while three columns sustained severe shear damage. Again column 3A with tie spacing of $150 \mathrm{~mm}$ suffered a more severe shear and spall damage compared to column 3-Blast which had a tie spacing of $51 \mathrm{~mm}$. The ties in the latter held the concrete core intact and tie hooks remained in concrete core after the test. 


\subsection{Review of previous work on residual capacity of damaged RC columns}

\subsubsection{Li et al. (2012)}

$\mathrm{Li}$ et al. conducted research work on the residual axial capacity of blast-damaged RC columns. The experimental program consisted of two series of columns. The first was designated limited seismic (LS) and the other non-seismic (NS). All column types were $260 \times 260 \times 2400 \mathrm{~mm}$. Both series consisted of two RC columns. The two LS columns were designated S1 and S3 while the NS columns were S2 and S4. LS columns had $135^{\circ}$ transverse hooks with a transverse reinforcement ratio of $0.58 \%$. The transverse ties in NS column were bent at $90^{\circ}$ and had a ratio of $0.19 \%$. All four columns were loaded axially to a pre-determined axial load level in a displacement-control mode. The columns had a longitudinal reinforcement ratio of $2.3 \%$. The concrete had a compressive strength of $32 \mathrm{MPa}$. Longitudinal reinforcement was 16-mm diameter bars with yield strength of $460 \mathrm{MPa}$ while 6-mm diameter bar with yield strength of $250 \mathrm{MPa}$ was used as transverse reinforcement. Three horizontal actuators then loaded them laterally. This, according to the authors was done to obtain similar blast-damage levels as predicted by a validated numerical model. These mid-height displacements were $28.3 \mathrm{~mm}, 41.2$ $\mathrm{mm}, 52.8 \mathrm{~mm}$ and $64.8 \mathrm{~mm}$ for S1, S2, S3 and S4 respectively. Columns S1 and S2 were loaded to a higher axial load level of $0.4 f_{c}^{\prime} A_{g}(810 \mathrm{kN})$ while S3 and S4 were loaded to $0.2 f_{c}^{\prime} A_{g}$ (406 $\mathrm{kN}$ ). Column S1 was loaded with an axial load of $810 \mathrm{kN}$ before the simulated blast damage using mid-height displacement criterion was applied with the axial load kept constant. After it was able to sustain both loads, the axial load was increased to measure its residual capacity. A maximum load of $982 \mathrm{kN}$ was reached. The same initial axial load of $810 \mathrm{kN}$ was applied to column S2. Lateral loads from the three horizontal actuators causing a mid-height displacement of $41.2 \mathrm{~mm}$ was applied. Approaching the target lateral displacement, column S2 dropped the 
axial load to a sustained value of $771 \mathrm{kN}$. Column S3 was pre-loaded axially to a load of $406 \mathrm{kN}$ before a target mid-height displacement of $52.8 \mathrm{~mm}$ was applied laterally to it. After this, it was able to sustain an axial load of $535 \mathrm{kN}$. Lastly column S4 was also loaded to a load level of 406 $\mathrm{kN}$, was laterally loaded to a mid-height displacement of $64.8 \mathrm{~mm}$. S4 was able to carry a maximum axial load of $526 \mathrm{kN}$. The results obtained from this experimental program supports the conclusion that the presence of the axial load during the lateral loading reduces the lateral displacements. This is ideal for lower axial loads as the converse is true beyond a certain axial load level. This improved the residual capacity of the columns; S1 and S2 had higher residual capacities compared to S3 and S4. Another observation was the effect of closer transverse bar spacing or higher transverse reinforcement ratio. The LS series (S1 and S3) had smaller lateral displacements compared to the NS series (S2 and S4) of same axial load levels. This is due to the confinement provided for longitudinal bars and concrete core. Columns S1 and S3 also performed better in shear. The less severe damage level also contributed to a higher residual capacity in them.

\subsubsection{Jayasooriya et al. (2011)}

Jayasooriya et al. (2011) carried out a two-part numerical study on the global stability of a 10storey RC frame building. SAP2000 was used to first observe the global response of the structure to gravity, wind and blast loads in the linear elastic and pseudo elasto-plastic response regimes. Detailed analysis was then performed using LS DYNA code to investigate the non-linear response of the most vulnerable RC elements identified in the first stage. All columns were $1000 \times 1000 \mathrm{~mm}$ in cross-section and a height of $4.7 \mathrm{~m}$ on the ground floor and $4 \mathrm{~m}$ for the upper stories. The columns were reinforced with longitudinal reinforcing bars corresponding to a 
reinforcement ratio of 0.02 . The reinforced concrete beams were $600 \times 600 \mathrm{~mm}$ in the direction parallel to the direction of the blast load and $600 \times 800 \mathrm{~mm}$ perpendicular to the direction of blast wave propagation. Both beam types had a longitudinal reinforcement ratio of 0.01 . The bay lengths were $7 \mathrm{~m}$ in the direction parallel to blast wave propagation and $8 \mathrm{~m}$ in the perpendicular direction. A slab thickness of $200 \mathrm{~mm}$ and shear wall thickness of $250 \mathrm{~mm}$ were used. The walls and cladding were assumed to be frangible; hence, no loads were transferred from them to structural members. The blast threat was from $500 \mathrm{~kg}$ of TNT at a standoff distance of $5 \mathrm{~m}$ from the building. The explosive was placed at a height-of-burst of $1 \mathrm{~m}$ above ground. Based on the initial SAP2000 analysis, about six columns closest to the centre of detonation on the first and second floors along with elements, which frame into them were selected for the more rigorous non-linear FEM analysis in LS-DYNA. Design forces and moments were obtained from the linear analysis while the capacities were evaluated with the interaction diagrams developed from the columns' cross-section. Analyses using dynamic increase factors (DIF) of 1.5 and 2.0 for both concrete and steel were also carried out. These values are rather high but were used solely for studying the effect of dynamic increase factors. From the SAP 2000 analysis, the demandcapacity ratios for the columns nearest to the centre of explosion exceeded 2.0 in both flexure and shear. The gravity load was applied in 150 milliseconds and the blast load followed for the next 100 milliseconds. Two ground columns were selected for damage evaluation as the damage levels were different (total and partial damage). The most affected ground floor column failed, 50 milliseconds into the blast-loading phase and this initiated progressive collapse. Section analysis of partly damaged columns, at a greater distance from the centre of explosion was carried out. It showed portions of the cross section to have failed in tension. The extent of 
damage and residual load carrying capacity of the columns were determined using the minimum and maximum principal stress plots extracted for selected elements at critical locations.

Jayasooriya et al. (2011) concluded that the residual capacity depends on the undamaged part of the $\mathrm{RC}$ columns at the critical section and is evaluated by assuming that the undamaged concrete is in the unconfined state due to loss of confinement following the concrete disintegration. The residual capacity of the column directly behind the front column was found to be $39 \%$ of the service load (Jayasooriya et al. 2011). Results obtained also showed that the use of DIF's increased the load carrying capacity and hence indirectly also affects the post-test gravity load carrying capacity after the blast.

\subsubsection{Fujikake and Aemlaor (2011)}

This study was carried out to investigate the level of damage RC columns suffer under blast load to help quantify and qualitatively assess how much explosive is needed in demolition works of highly ductile columns designed to resist seismic loads. The compressive and flexural residual capacities of the columns were also studied using scaled specimen $(180 \times 180 \times 1200 \mathrm{~mm} \mathrm{RC}$ columns) in experimental blast testing. The longitudinal bars were 10-mm diameter deformed bars while the shear reinforcement was 3-mm diameter bar. The compressive strength of the concrete used was $51.6 \mathrm{MPa}$ while the yield strength of reinforcing steel was $345 \mathrm{MPa}$. Composition 4 (C4) explosive was used in the experimental testing. Masses of $\mathrm{C} 4$ of $5 \mathrm{~kg}, 13 \mathrm{~kg}$ and $19.5 \mathrm{~kg}$ were used in the tests. Longitudinal reinforcement ratios investigated were $0.9 \%$ and $2.5 \%$ while shear reinforcement ratios were $0 \%, 0.1 \%$ and $0.26 \%$. Compression and flexural load tests were conducted on both the undamaged and blast-damaged columns to investigate the residual capacities. 
Although the length of exposed reinforcement after the blast test was found to be smaller for columns with a greater amount of shear and longitudinal reinforcement, the shear reinforcement ratio significantly affected the residual capacity of the columns. The effect of compressive concrete strength was more evident when the shear reinforcement ratio was $0.26 \%$ while at $0 \%$ no effect of compressive strength was observed. This is because the concrete core is more effectively confined when the stirrups are more closely spaced. Analytical studies were also carried out before and after the blast test by section analysis. While both concrete and steel contribute to axial and moment resistance in the pre-blast analysis, only the steel reinforcement is considered in the post- blast analysis. Fujikake and Aemlaor (2011) adopted an elastic perfectly plastic material model for steel reinforcement in their work. The compressive buckling strength after the blast was computed based on the length of the exposed longitudinal reinforcement in equation (2-1).

$$
f_{c r}=\frac{\pi^{2} E_{S} \varnothing_{L}^{2}}{4 L_{\text {exp }}^{2}} \leq f_{s y}
$$

Where $f_{c r}$ is the compressive buckling strength (MPa), $\emptyset_{L}$ is the longitudinal bar diameter $(\mathrm{mm})$, $L_{\text {exp }}$ is the exposed length of the bar $(\mathrm{mm})$ and $f_{s y}$ is the yield strength of the bar (MPa).

The test results were close to the calculated interaction curves for both the undamaged and blastdamaged columns. Since the aim of their work was to reduce the residual capacity as much as possible for the demolition works, Fujikake and Aemlaor (2011) established the ideal explosive factor as $0.4-0.6 \mathrm{~kg} / \mathrm{m}^{2}$. Also, the lower the explosive factor, the higher the residual capacity ratio (ratio of post-blast strength to the original capacity). Overall, the residual compressive capacity ratio of the test specimen varied from $1.0 \%$ to $17.6 \%$ while the residual flexural capacity ratio varied from $4.8 \%$ to $67.9 \%$. 


\subsubsection{Bao and Li (2010)}

High-fidelity physics-based computer program, LS-DYNA was used in this numerical parametric study to investigate the dynamic response and residual axial capacity of twelve (12) reinforced concrete columns subjected to close-range blast loading. The effects of axial loads, transverse bar spacing and longitudinal reinforcement ratio were investigated. The gravity axial load was applied prior to blast loading. The axial load was then sustained during and after the blast loading. Bao and Li (2010) limited their research to close-in explosions and used a standoff distance of $5 \mathrm{~m}$ for their simulation, stating that recent terrorist attacks on public structures involved explosions at a short standoff distance (less than $10 \mathrm{~m}$ ). Due to restrictions on the weight of explosives that can be obtained at the particular location, a maximum TNT equivalent charge mass of $907 \mathrm{~kg}$ ( 1 ton) was selected in this work. The authors then varied the explosive charge mass between 0 and $907 \mathrm{~kg}$ ( 0 and 1 ton) to obtain different levels of damage to the columns.

The columns investigated had a cross-section $355 \times 355 \mathrm{~mm}$ and heights ranging from $2130 \mathrm{~mm}$ to $3480 \mathrm{~mm}$. Six (6) of these columns were reinforced with 20-mm diameter longitudinal reinforcement bars while the other six (6) were reinforced with 25-mm diameter longitudinal reinforcement bars. All twelve columns had 10-mm diameter ties. The axial load applied on the columns resulted in reduced lateral displacements. Increasing the amount of transverse reinforcement increased the shear capacity, ensuring columns attained flexural failure rather than shear failure while also preventing buckling of longitudinal bars.

Bao and $\mathrm{Li}$ (2010) also observed that increasing transverse reinforcement ratio required commensurately higher failure loads. Higher longitudinal reinforcement ratios increased the moment and axial load capacity of the columns. Based on their numerical study, Bao and Li 
concluded that seismic detailing significantly reduced the degree of blast induced damage and subsequent collapse of RC columns. Bao and Li (2010) recommended further experimental investigation of residual axial strength of blast damaged reinforced concrete columns to supplement the limited data set used to develop their proposed equation (Equation 2-2) for estimating the residual axial capacity ratio of reinforced concrete columns based on mid height displacement to height ratios.

$$
\begin{aligned}
& v=\left[76.65 \rho_{v}+8.465 \rho_{g}-0.020879(L / b)+\right. \\
& 0.104] e^{\left[89284.22 \rho_{v}-1308.64 \rho_{g}-9.68(L / b)-382.12\right]\left(y_{r} / L\right)\left(P_{L} / f_{c} A_{g}\right)}
\end{aligned}
$$

The above equation requires transverse reinforcement ratio $\left(\rho_{v}\right)$, longitudinal reinforcement ratio $\left(\rho_{g}\right)$, column aspect ratio $(\mathrm{L} / \mathrm{b})$, axial load ratio $\left(P_{L} / f_{c} A_{g}\right)$ and permanent mid-height displacement to column height ratio $\left(y_{r} / L\right)$. The calculated value $v$, represents the residual axial capacity based on damage level (permanent mid-height displacement) and axial load. The proposed equation compared very well with numerical results.

\subsubsection{Wu et al. $\left(2010^{a}\right)$}

In this research, two RC column specimens were subjected to blast loading from a near-field explosion. High-fidelity physics based computer program, LS-DYNA was used to provide numerical simulations of the dynamic response of the RC columns under blast loading. After the blast-damage, residual axial capacity of columns was also investigated. The test results of the two RC columns were used to validate the accuracy of the numerical model. The numerical modelling was accomplished in three stages. In the initial stage, a linearly increasing axial load up to the service axial load $\left(\mathrm{P}_{\mathrm{L}}\right)$ was applied to the column prior to the blast loading to simulate the gravity load effects present in the column. The axial load was gradually applied in an explicit 
dynamic analysis. The initial axial load applied to the column was dependent on the axial load ratio (ALR), expressed in Equation 2-3.

$$
A L R=\frac{P_{L}}{f_{c}{ }^{\prime} A_{g}}
$$

Where $f_{c}{ }^{\prime}$ is the compressive strength of the concrete and $A_{g}$ is the gross cross-sectional area of the column. ALR used in this study was between 0.2 and 0.4 , representing the typical loads in ground floor columns in medium-rise buildings. In the second stage, blast loading was applied to the front face of the columns. The simulation was ran until the velocities at the nodes approached $0.1 \mathrm{~m} / \mathrm{s}$ since it takes a long time for it to come to a complete halt. In the post-blast stage, the axial load was gradually increased and the residual capacity index (RCI) as well as the softening portion of the loading curve were captured using the displacement history. In assessing the vulnerability of a column, the ALR must be less than the RCI which is defined by Equation 2-4.

$R C I=\frac{P_{r}}{f_{c}{ }^{\prime} A_{g}}$

$P_{r}$ is the residual axial capacity of the column. In the experimental study, the two RC columns were subjected to an explosive charge, equivalent to $25 \mathrm{~kg}$ of TNT, which was placed at two different standoff distances: 200 and $500 \mathrm{~mm}$. The columns were built to two-third scale of the column size of a twenty story building in Singapore. The columns had a cross-section of $400 \times 400 \mathrm{~mm}$ and a height of $2.4 \mathrm{~m}$. Eight (8) $20-\mathrm{mm}$ diameter, high tensile strength bars with a yield strength of $420 \mathrm{MPa}$, were used as longitudinal reinforcement while 6-mm diameter mild steel bars spaced at $125 \mathrm{~mm}$ was used as transverse reinforcement. The reinforcement scheme resulted in a longitudinal reinforcement ratio of $1.57 \%$ and transverse volumetric ratio of $0.21 \%$. The specimen were tested in a horizontal position with the $25 \mathrm{~kg}$ test charge placed $900 \mathrm{~mm}$ from the top of the foundation. 
An increase in the transverse reinforcement ratio increased the shear and moment capacity of the $\mathrm{RC}$ column. This is due to the confinement it provided to the concrete core and lateral restraint against buckling of the longitudinal reinforcement. The numerical simulations showed that the residual capacity index $(\mathrm{RCI})$ of blast damaged $\mathrm{RC}$ column with low transverse reinforcement ratio was significantly less than that of the blast-damaged RC column with high transverse reinforcement ratio. Wu et al. (2010a) generated two empirical equations using the numerical results to predict RCI based on a non-dimensional column dimension parameter. Comparison of the numerical results with values from the empirical formulae showed close correlation. Residual axial capacity of the columns can be further studied by varying parameters such as material strength, column details and blast scaled distance.

\subsubsection{Roller et al. (2012)}

Roller et al. (2012) studied the enhancement of residual load carrying capacity by comparing conventional columns to retrofitted columns made with advanced composite materials. The columns were built to a scale of one-third nominal size. The scaled columns were subjected to contact and close-range PETN explosion testing. The columns were circular with a diameter of $150 \mathrm{~mm}$ and reinforced with eight (8) $7.5-\mathrm{mm}$ diameter longitudinal reinforcement (reinforcement ratio of 2.2\%). The columns were also reinforced with $2.5-\mathrm{mm}$ diameter spiral reinforcement. Blast threat varied from a few hundred grams at a standoff of $200 \mathrm{~mm}$ to tens of kilograms at $667 \mathrm{~mm}$. Four (4) material modification types were considered in this study. The first was polymer concrete, which according to Roller et al. (2012) was designed to absorb energy from strong shock waves. It had good porosity that was achieved by the addition of waste products from corncobs and resin and flax fibres. The Slurry Infiltrated Fiber Concrete 
(SIFCON) is concrete with short steel fibers added to the mix. According to this study, it reaches roughly three times the compressive strength of normal weight concrete.

The third material is Ductile Concrete (DUCON) embedded with micro reinforcement. The effect is the combined action of an optimized concrete and a mesh mat with variable mesh size. The last material investigated was Ultra-High Performance Concrete (UHPC) made from high strength cement and has good crack bridging ability. The conventionally reinforced column had a residual capacity of $5 \%$ after being tested with contact blast. When it was tested in close range, the residual capacity increased to $16 \%$ of its original capacity. Another conventional column with longitudinal reinforcement ratio of $8 \%$ was also tested under contact detonation. It had a $35 \%$ residual capacity compared to the undamaged conventional control column. The modified samples were also testing against same blast threat scenarios and their residual capacities measured. Photographs of the post-test columns are shown in Figure 2-3 while Figure 2-4 shows an improved performance of the modified specimen compared to the conventional column. The residual capacities of the columns with modifications of polymer, SIFCON and DUCON (fine aggregate) were over $65 \%$. This is higher than the $5.5 \%$ residual capacity achieved for the conventional column. DUCON with coarse aggregates showed a lower residual capacity value than that made with fine aggregates. 


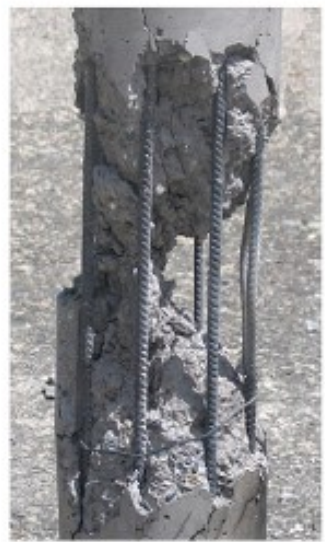

(a)

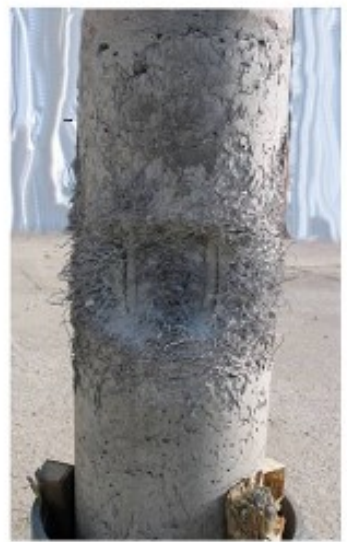

(b)

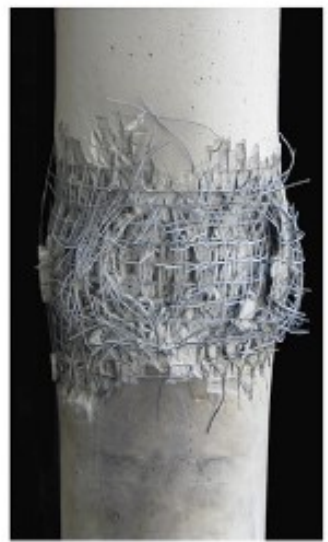

(c)

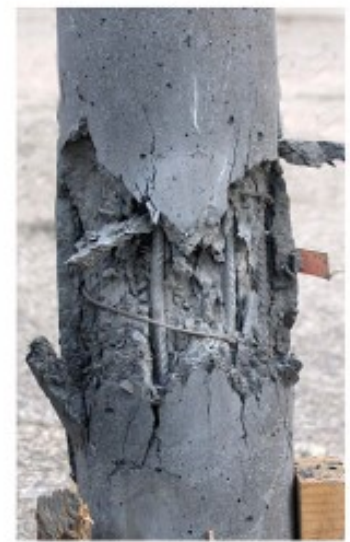

(d)

Figure 2-3: Damaged columns after contact detonation, with cross-sections made of (a) RC, (b) SIFCON, (c) DUCON, and (d) UHPC (Roller et al. (2012))

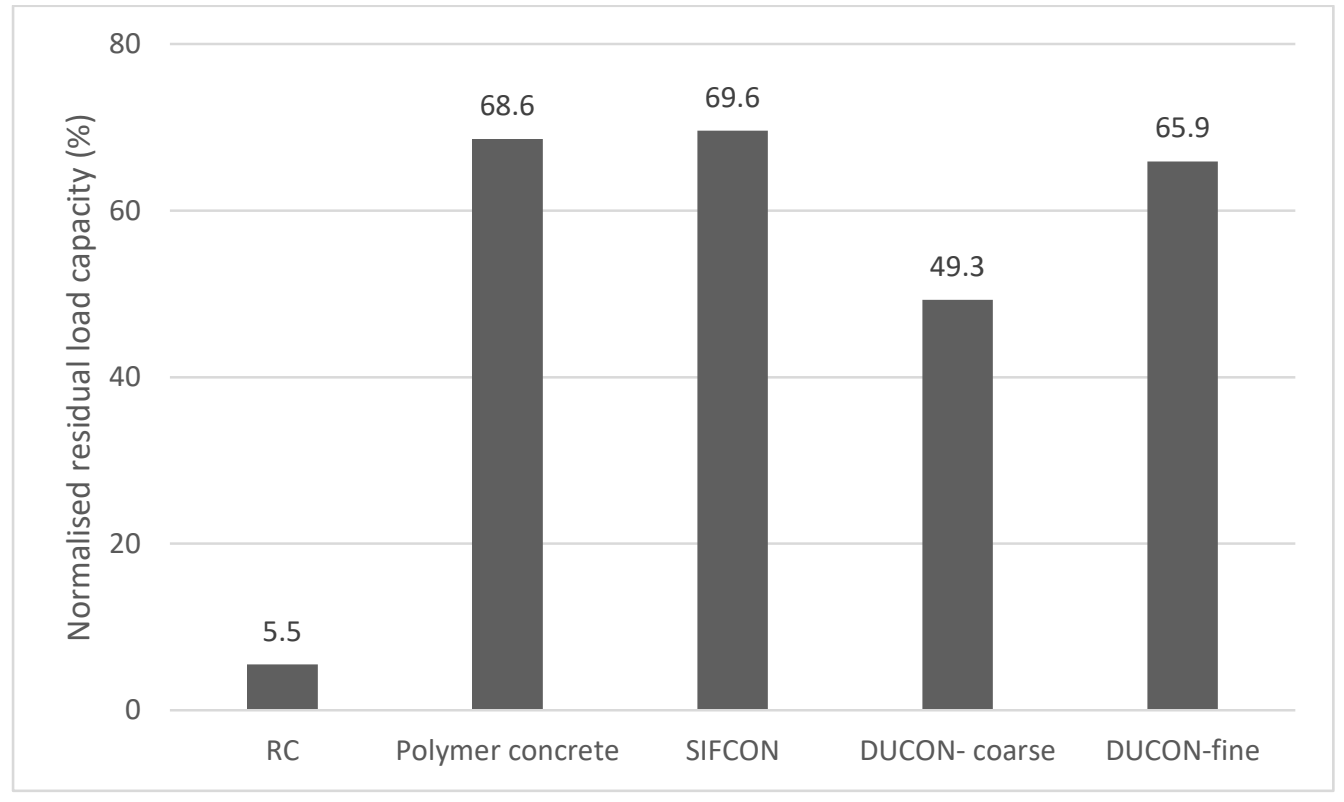

Figure 2-4: Comparison of the residual capacities of test specimen (Roller et al. (2012)) 


\subsubsection{Shan et al. (2006)}

Eight (8) reinforced concrete columns were built to carry out a study on axial residual capacity of retrofitted columns. Three main types of columns were investigated; conventional gravity load designed columns, columns with Glass fibre reinforced plastic (GFRP) and Carbon fibre reinforced plastic (CFRP). All columns were circular with a diameter of $375 \mathrm{~mm}$, reinforced longitudinally with twelve $12-\mathrm{mm}$ diameter bars resulting in a reinforcement ratio of $1.2 \%$. Transverse spiral reinforcement consisted of 6-mm diameter bars spaced at $60 \mathrm{~mm}$. The transverse reinforcement provided was $44 \%$ of the seismic design requirement as per the ACI 318 code (Shan et al. (2006)). Concrete strength for different variations of test specimen ranged from $34 \mathrm{MPa}$ to $41.4 \mathrm{MPa}$. The yield strength of longitudinal steel and transverse hoops were $372 \mathrm{MPa}$ and $332 \mathrm{MPa}$, respectively. Four layers of CFRP and five layers of GFRP were wrapped for a 400-mm section near the bottom end of the column, above the footing. An additional wrapping of two layers in each case, was provided above the lower 400-mm. According to Shan et al., the FRP retrofit together with the existing transverse reinforcement provided the columns with a comparable seismic resistance, which slightly exceeded the current ACI 318 code requirement. In general, two tests were conducted: a cyclic lateral load application test and a long-term axial load test. During the lateral load application test, $20 \%$ of the axial load capacity $\left(\mathrm{A}_{\mathrm{g}} \mathrm{f}_{\mathrm{c}}{ }^{\prime}\right)$ was applied on the column throughout the test. The conventional control column, CFRP-retrofitted, and GFRP-retrofitted columns, failed at drift ratios of $6 \%, 8 \%$ and $10 \%$ respectively. In the second test, the columns had their residual displacements removed (straightened out) and tested under long-term axial loads. An axial load level of $0.2 \mathrm{Ag}_{\mathrm{c}} \mathrm{f}_{\mathrm{c}}^{\prime}$ was applied for 30 days prior to testing. This had no effect on the columns. The axial load was increased to $0.4 \mathrm{Ag}_{\mathrm{c}} \mathrm{f}^{\prime}$ and left for 60 days. During long-term axial loading test after being 
subjected to some degree of lateral loading damage, the deformation of the FRP-retrofitted columns was lower when compared with the non-retrofitted column subjected to a similar loading condition. It was found however, that within the testing range of the axial load ratios between $0.2 \mathrm{Ag}_{\mathrm{c}} \mathrm{f}^{\prime}$ and $0.4 \mathrm{Ag}_{\mathrm{c}} \mathrm{f}^{\prime}$ the post damage long-term axial loading would not cause any major creep effects to the FRP retrofitted columns.

\subsubsection{Khandelwal and El-Tawil (2008)}

According to Khandelwal and El-Tawil (2008), the Alternate Path Method (APM) only verifies that a building will not go into progressive collapse after it has sustained serious local failure. However, it does not indicate the level of residual capacity of the structure. In their paper, the authors demonstrated by pushdown analyses, residual capacity of steel columns. The concept of this analysis is to increase gravity loads beyond the designed level until failure. Numerical simulation using high-fidelity physics-based computer program, LS-DYNA, was used to study the residual capacity of a 10-story steel intermediate moment resisting frame as defined by the American Society for Civil Engineers (ASCE) seismic provisions, with five bays in each direction. The load level at first failure was denoted the reference load. In the first scenario, after the removal of a ground floor column, the gravity load was uniformly increased for the entire structure. The ratio of the collapse load to the reference load was denoted the overload factor. In the second scenario, only the bay with the removed column was subjected to an increase in gravity load. The last scenario was an incremental dynamic pushdown method where the gravity loads in the damaged bay are increased dynamically. Different ground floor columns on grids C1, D1, E1 and F1 were removed for each method and the overload factors and primary failure mode recorded. 


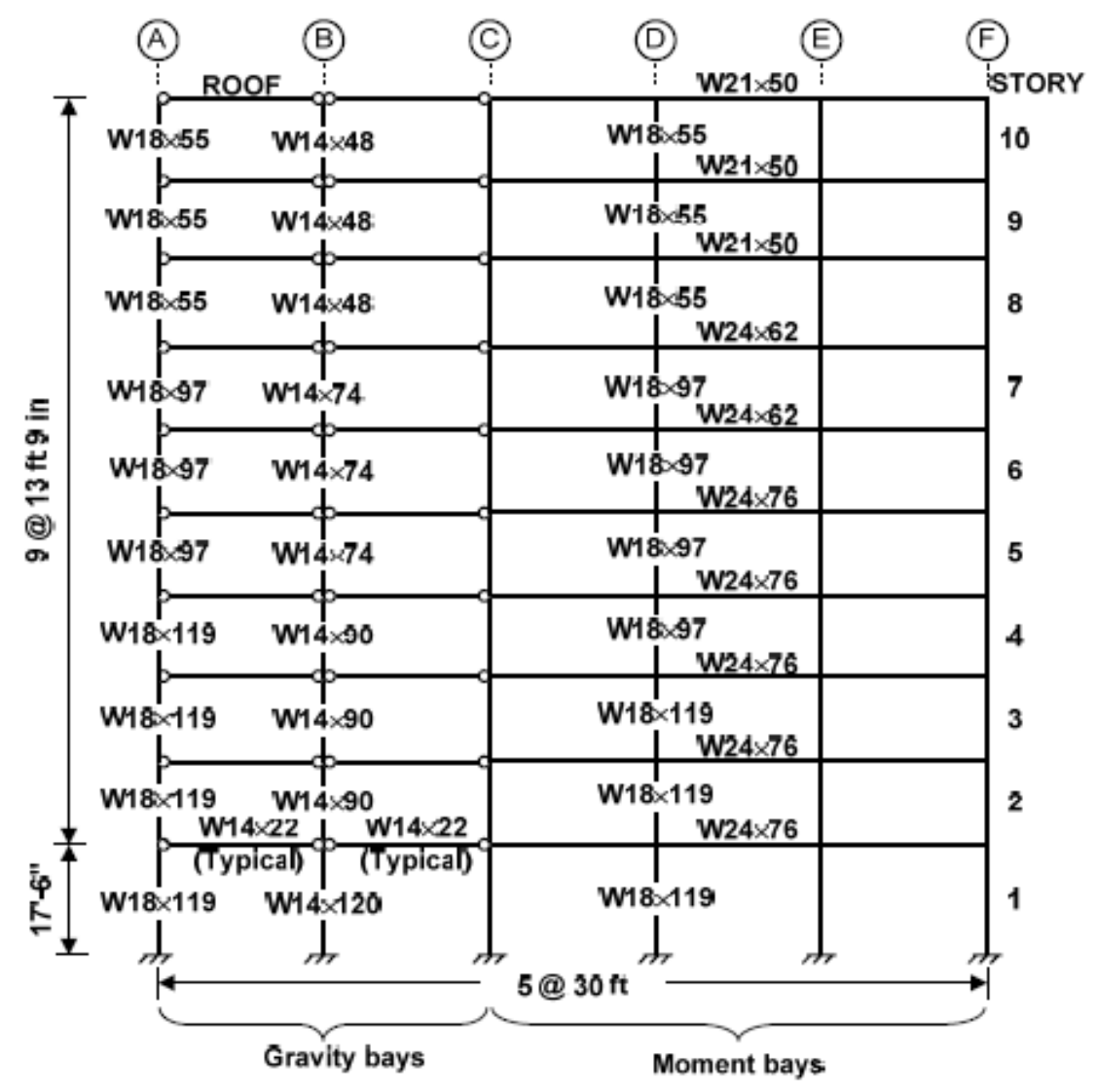

Figure 2-5: Elevation of 10-storey steel frame

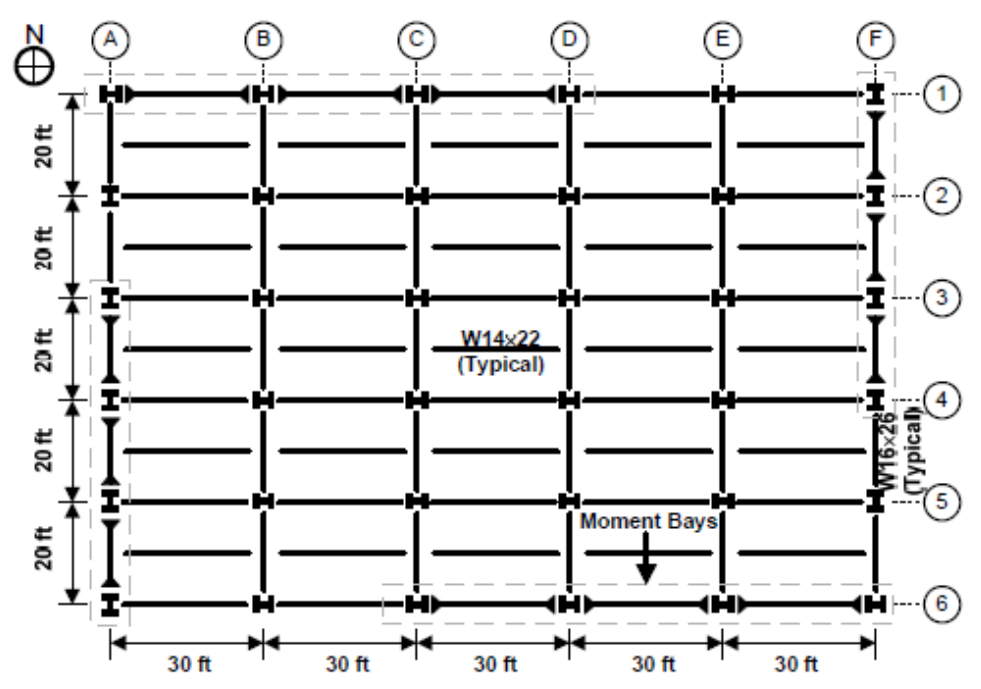

Figure 2-6: Plan of 10-storey steel structure

Figure 2-5 and 2-6 show the elevation and grid plan of the building respectively. The grids on plan were from A to F and 1 to 6 as shown in Figure 2-6. The average overload factors for the 
uniform pushdown was 2.21 while those for bay pushdown and incremental dynamic pushdown were 2.45 and 1.1 respectively. In all three cases, the removal of column $\mathrm{C} 1$ caused a shear failure at the right end of beam C-D while a buckling of adjacent ground floor columns caused the building to fail when D1, E1 or F1 was removed.

\subsection{Summary}

This chapter provided a background of recent terrorist attacks and accidental explosions, which have afflicted major structures and cities. The response of columns and their residual capacity after blast damage were also reviewed. In general, blast research work is gaining much ground and attention. In the review of literature presented in this chapter, $\mathrm{RC}$ columns were identified as essential load carrying members with their collapse in blast loading often leading to catastrophic consequences. From the literature review:

- Some research work focused on retrofitting and hardening measures for RC columns while other research works investigated the effect of column detailing and standoff distances on the response and residual capacity of reinforced concrete columns. However not enough has been done to consider the effect of simultaneously loading the RC columns under both blast loading and compressive axial loading.

- Williamson et al. (2011) tested RC bridge columns at half-scale while Luccioni et al. (2003) tested at full-scale. In this research, the RC columns are tested at full-scale.

- Some researchers carry out axial residual capacity. In this regime, the test columns are loaded axially until failure. This is quite different from the approach adopted in this thesis work. The test columns are loaded axially only to service load level $(1000 \mathrm{kN})$. If failure does not occur, lateral load is then applied in displacement control mode. 


\subsection{Motivation for Research}

The above findings show that a lot of work has been done and still is ongoing on the performance of reinforced concrete columns under blast loading. Moreover, most of the research works reported in the literature are based on numerical simulations using high fidelity physics based programs. As the performance of the columns affects their residual capacity, it is important to establish ways to determine if RC columns, post-blast, will be able to resist the design loads. However not much full-scale experimental testing is available to validate the numerical works available in the literature. This thesis aims to contribute to previous works on the residual strength of RC columns post-blast event by investigating the residual capacity of previously damaged RC columns. 


\section{Chapter: Methodology}

\subsection{Background}

A test program was designed to investigate the response of reinforced concrete columns under close-in blast loading. A set of twenty (20) reinforced concrete columns were built with different reinforcement detailing representative of columns designed for predominantly gravity load resistance and columns designed to undergo deformation as part of primary seismic loadresisting structures (SFRS). These columns do not form part of the lateral load resisting system of a building but are expected to undergo the lateral displacement of the lateral load resisting system. Sixteen (16) of the twenty (20) columns were tested under live explosion loading, while four columns (CONV-16, CONV-17, SEIS 18 and SEIS-19) remained in the structures laboratory of Carleton University for static testing. The four columns designated for static testing and the columns from the explosion testing that did not suffer significant damage are the focus of this study to investigate the residual capacity of blast-damaged columns. The residual capacity testing was carried out in the structures laboratory at Carleton University.

\subsection{Design and Description of Test Columns}

Column designation, tie spacing, column type and axial load ratio of the columns are shown in Table 3-1. The columns were designed and detailed in accordance with CAN/CSA-A23.3-04 (CSA 2004) and had a cross-section of $300 \times 300 \mathrm{~mm}$ and a total height of $3200 \mathrm{~mm}$. The columns were cast together with $700 \times 700 \times 300 \mathrm{~mm}$ deep reinforced concrete footings. The columns were reinforced with $4-25 \mathrm{M}$ longitudinal reinforcement to give a longitudinal reinforcement ratio of 0.02 . Six of the columns that were detailed to undergo lateral displacement (drift) in addition to resisting gravity loads were designated SEIS - \# while the ten columns 
designed to resist predominantly gravity loads only were designated CONV - \#. The \# in the designation of the columns represent the column number in each series (Siba 2014). The columns designated CONV- \# and SEIS- \# were detailed as per Figure 3-1(a) and Figure 3-1(b) respectively. Three of the Conventional columns (CONV-5, CONV-10, and CONV-15) were post-tensioned to induce an axial load ratio (ALR) of 0.32 and this resulted in a compression stress of 11.4 MPa. The pre-compression gives a state of stress simulating columns in the lower stories of multi-story buildings. The ALR is a ratio of the design load of a column to its axial capacity.

The two principal ways that the conventional columns vary from the seismic columns is in their tie spacing and the location of the lap splices of the longitudinal reinforcement. Conventional columns were detailed in accordance with CSA A23.3-04 clause 7.6.5.2 (CSA 2004) for columns predominantly resisting gravity loads. The tie spacing was $300 \mathrm{~mm}$ over their entire length (Figure 3-1a). The longitudinal reinforcement was spliced with kicker bars from the reinforced concrete footing at the base of the columns. These longitudinal reinforcing bars were spliced over a length of $870 \mathrm{~mm}$ within the plastic hinge region of the columns (Figure 3-1a).

The Seismic columns were detailed in accordance with clause 21.7.2.2 (CSA 2004) for columns designed to undergo lateral drifts in addition to gravity loads although they do not form part of the structures' lateral load resisting system. The seismic term used is for designation purpose. The ties were spaced at $75 \mathrm{~mm}$ over plastic hinge length of $450 \mathrm{~mm}$ at each end of the column (Figure 3-1b) in accordance with clause 21.7.2.2.3. The closer spacing of ties over the plastic hinge length ensures that the ends of the columns are properly confined. As the support conditions of the columns approximate fixed end conditions, the spacing within the plastic hinge region also meets clause 21.7.2.2.5. Over the remainder of the column, the ties were spaced at 
$150 \mathrm{~mm}$ (Figure 3-1b) as per clause 21.7.2.1.3. This clause ensures that diagonal flexural crack crosses at least two tie bars. The longitudinal rebar splicing was located at mid span of the column to ensure that the splice is outside of the plastic hinge region of the column (clause 21.4.3.2). The concrete columns had a concrete cover of $40 \mathrm{~mm}$ to the ties.

Table 3-1 Column nomenclature, tie spacing, scaled distance and axial load ratio details

\begin{tabular}{|c|c|c|c|c|c|}
\hline $\begin{array}{c}\text { Column } \\
\text { designation }\end{array}$ & $\begin{array}{c}\text { Tie spacing } \\
(\mathrm{mm})\end{array}$ & $\begin{array}{c}\text { Lap } \\
\text { Splice } \\
(\mathrm{mm})\end{array}$ & ALR & $\begin{array}{c}\text { Scaled } \\
\text { distance } \\
\mathrm{z}\left(\mathrm{m} / \mathrm{kg}^{1 / 3}\right)\end{array}$ & $\begin{array}{c}\text { *Permanent } \\
\text { displacement } \\
(\mathrm{mm})\end{array}$ \\
\hline CONV-06 & 300 & 870 & 0 & 0.53 & $-33 / 16$ \\
\hline CONV-07 & 300 & 870 & 0 & 0.58 & $-64 /-30$ \\
\hline SEIS-08 & 75 & 980 & 0 & 0.58 & $0 / 0$ \\
\hline SEIS-09 & 75 & 980 & 0 & 0.52 & $-25 / 11$ \\
\hline CONV-11 & 300 & 870 & 0 & 0.88 & $-30 /-10$ \\
\hline CONV-12 & 300 & 870 & 0 & 0.82 & $-29 /-11$ \\
\hline SEIS-13 & 75 & 980 & 0 & 0.82 & $-7 / 0$ \\
\hline SEIS-14 & 75 & 980 & 0 & 0.86 & $-16 /-9$ \\
\hline CONV-15 & 300 & 870 & 0.32 & 0.86 & $-14 /-5$ \\
\hline CONV-16 & 300 & 870 & 0 & Not tested & 0 \\
\hline CONV-17 & 300 & 870 & 0 & Not tested & 0 \\
\hline SEIS-18 & 75 & 980 & 0 & Not tested & 0 \\
\hline SEIS-19 & 75 & 980 & 0 & Not tested & 0 \\
\hline
\end{tabular}

* A negative sign indicates a displacement toward the front face (centre of detonation). Again, the first number represents the displacement at the top of the column while the second represents the mid-height displacement. 


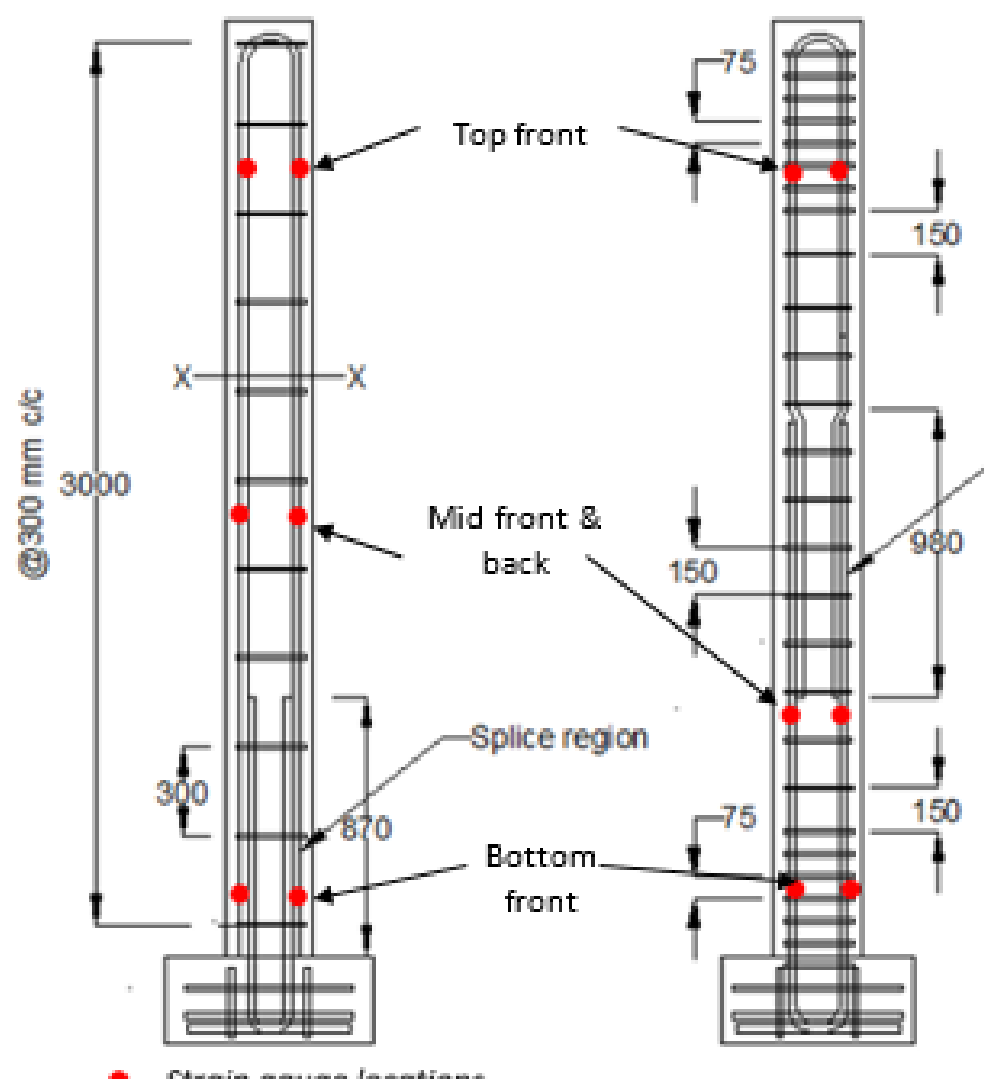

- Strain gauge locations.

।

All dimensions are in $\mathrm{mm}$.

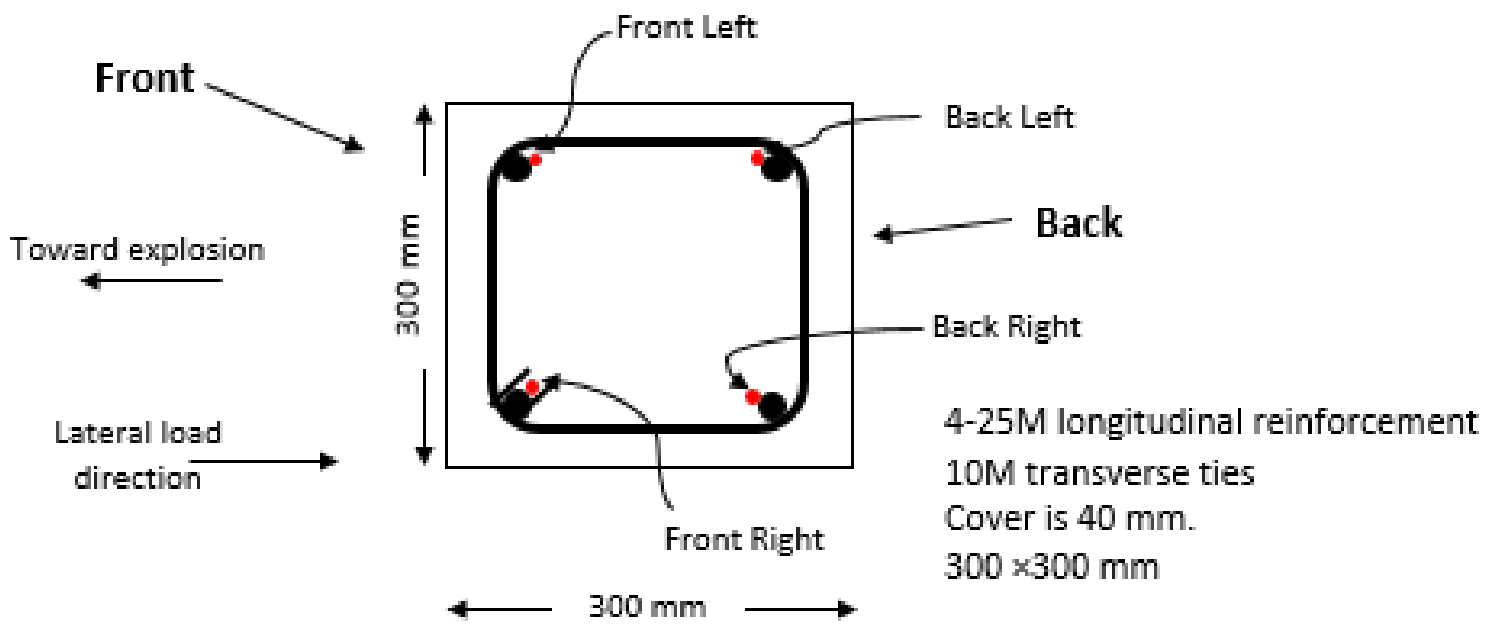

Figure 3-1: (a) Conventional column detailing (b) Seismic column detailing (Siba (2014)). 


\subsubsection{State of columns after near-field test}

Based on the scaled distance and the transverse reinforcement detailing, seven (7) reinforced concrete columns did not survive the near-field explosion testing. A brief description of the postblast condition of the surviving columns is presented.

Columns SEIS-08 and CONV-07 were exposed to blast load from the detonation of 100-kg ANFO at a standoff distance of $2.5 \mathrm{~m}$ from the centre of detonation; resulting in a scaled distance of $0.58 \mathrm{~m} / \mathrm{kg}^{1 / 3}$. In CONV-07, no concrete spall nor visible cracking was observed on the front face of the column. Flexural cracking was however observed on the back face (Figure 3-2 (c)) and sides (Figure 3-2(b) and (d)) of the column. These cracks were mainly in the mid-height region where maximum moment was expected due to the blast loading. However, most likely because of the ineffectiveness of the support restraints out in the field, no cracks were observed on the front face close to the end restraints. Figure 3-2 shows the condition of CONV-07 prior to the residual capacity test (after the field-testing). CONV-07 had a permanent displacement of 64 $\mathrm{mm}$ after the near-field test. 


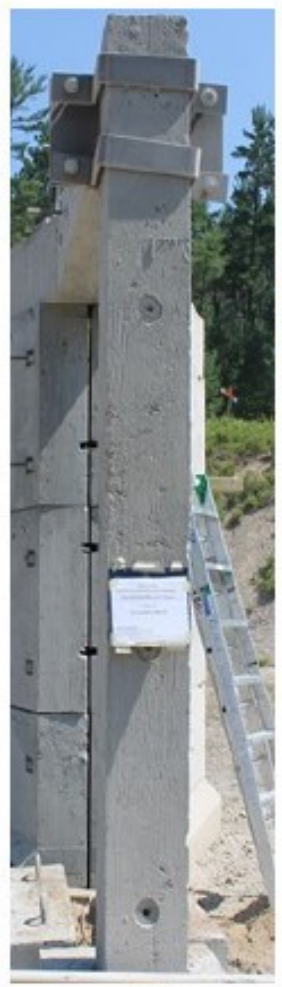

(a)

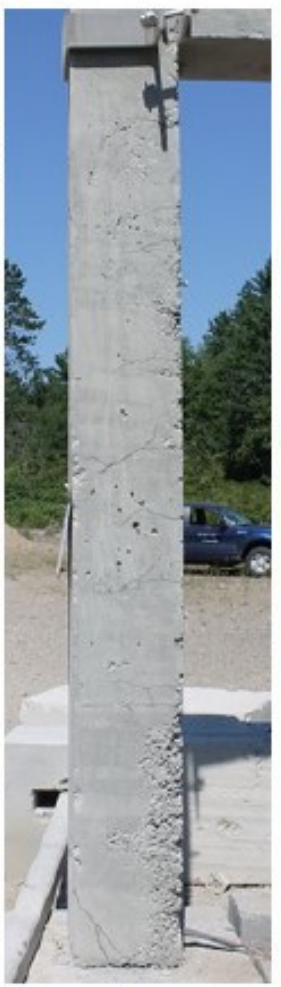

(b)

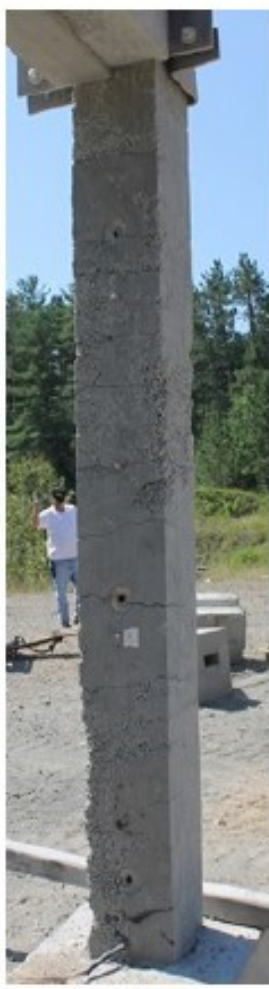

(c)

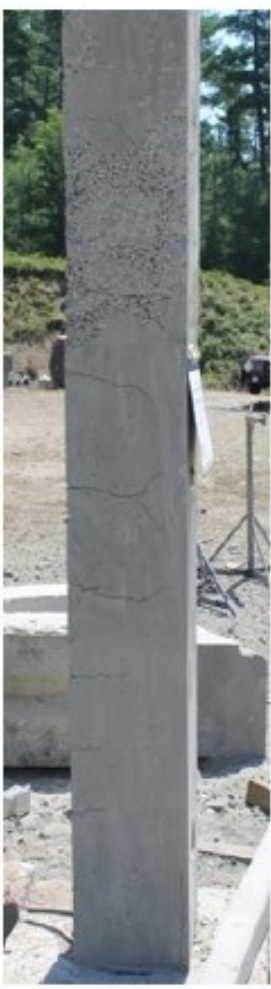

(d)

Figure 3-2: Post-field test photograph of CONV-07: (a) front face, (b) right side (c) back face (d) left side (Siba (2014)).

SEIS-08 showed no obvious spalling of concrete. Minimal cracks occurred on the back and sides of the column. These cracks were relatively smaller than those observed on CONV-07. Figure 33 shows the condition of SEIS-08 after the blast test. The maximum residual (permanent) deflection of the column $5 \mathrm{~mm}$. 


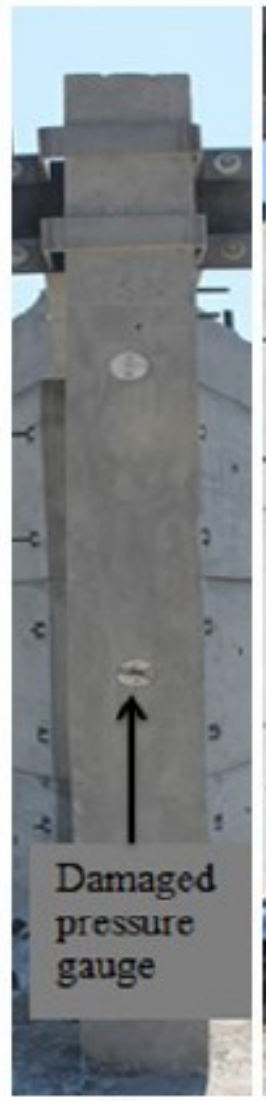

(a)

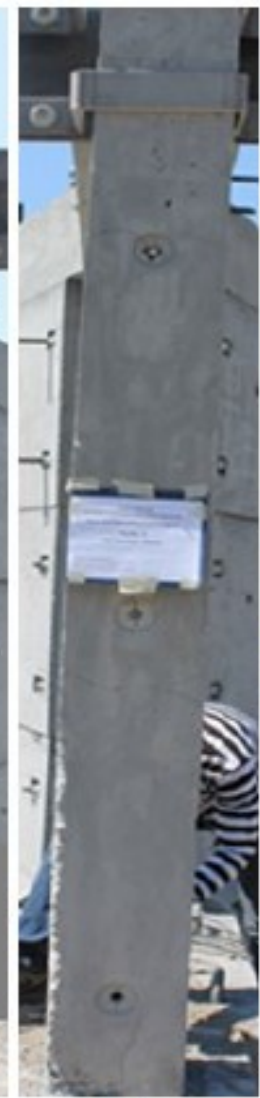

(b)

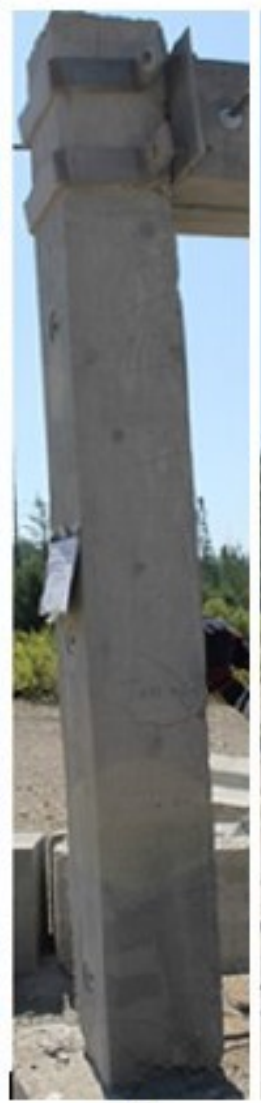

(c)

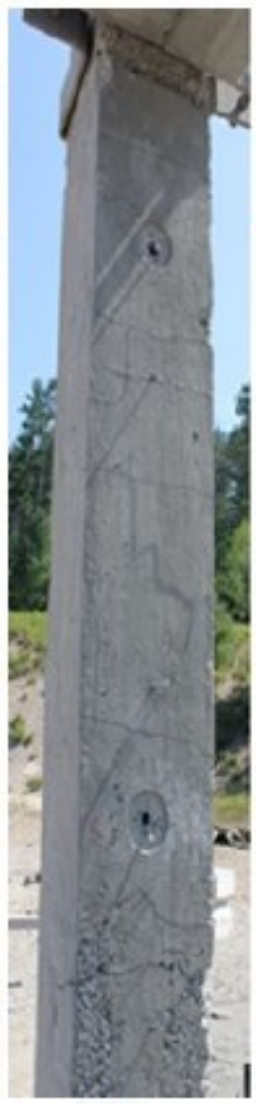

(d)

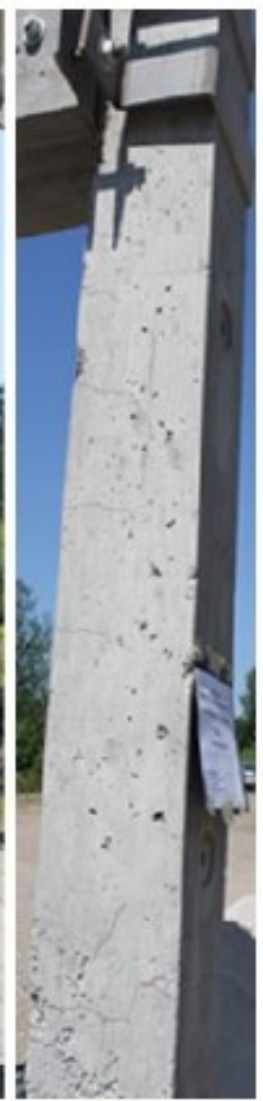

(e)

Figure 3-3: Post-field test photograph of SEIS-08: (a) \& (b) front face, (c) back face, (b) \& (d) side faces (Siba (2014))

SEIS-09 was subjected to blast load from the detonation of 150-kg ANFO placed at a standoff distance of $2.6 \mathrm{~m}$ from the centre of detonation. This resulted in a scaled distance of $0.52 \mathrm{~m} / \mathrm{kg}^{1 / 3}$. The column suffered severe flexural cracking and spalling of concrete at mid-height (Figure 34(c)). Large chunks of concrete, approximately $650 \mathrm{~mm}$ in height, with a depth of $150 \mathrm{~mm}$, spalled from the column due to the explosion. There were also minimal shear cracks in the lower bottom (near the support) of the column. Because of lack of cracking at top support region in comparison to bottom, it appears there was higher fixity at the bottom support. There were also flexural cracks along the entire back and sides of the column. Figure 3-4 shows the blast- 
damaged condition of SEIS-09. A maximum permanent deflection of $25 \mathrm{~mm}$ was measured after the blast testing.

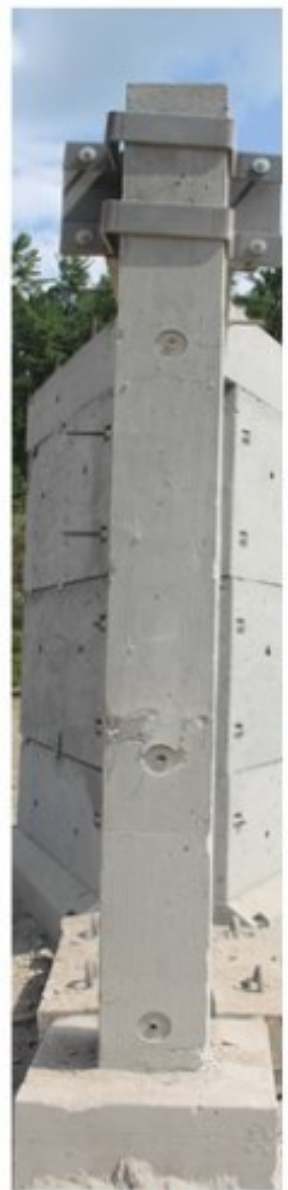

(a)

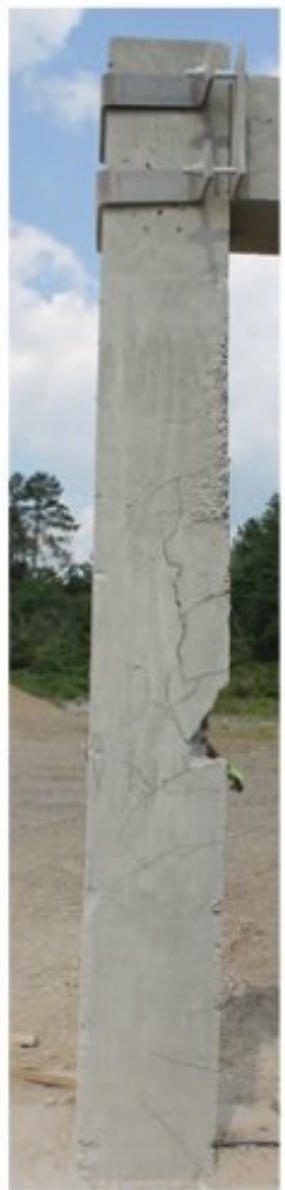

(b)

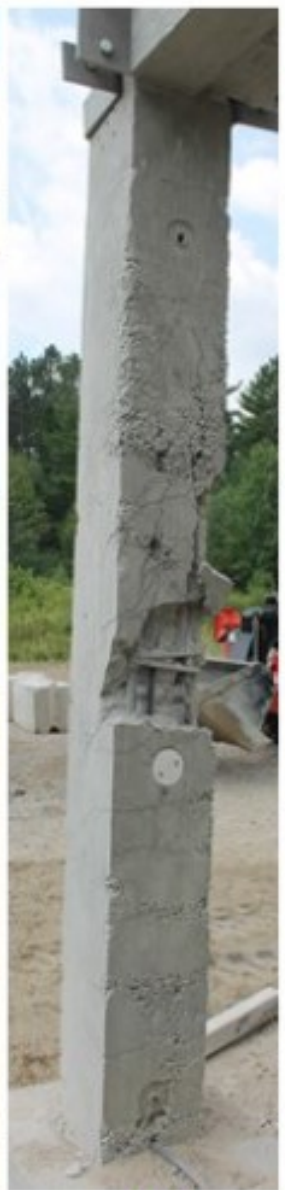

(c)

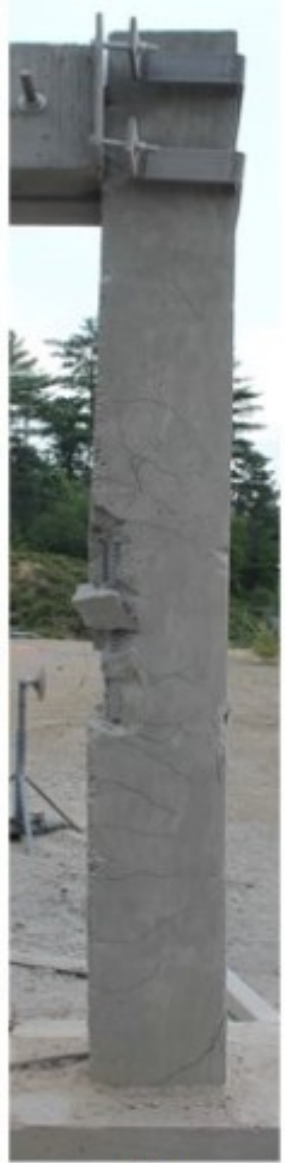

(d)

Figure 3-4: Post-field test photograph of SEIS-09: (a) front face, (b) right face (c) back face (d) left face (Farouk 2014)

CONV-06 column was subjected to blast load from the detonation of 150-kg ANFO placed at a standoff distance of $2.66 \mathrm{~m}$. This is equivalent to a scaled distance of $0.53 \mathrm{~m} / \mathrm{kg}^{1 / 3}$.

Post-test observation of column CONV-06 revealed cracking and spalling of concrete at the lower one-third region of the column (Figure 3-5) while shear cracks were observed near the bottom support of the column. Wide flexural cracks were visible on the back face and sides of 
the column. Figure 3-5 shows CONV-06 after the field test. CONV-06 had a permanent deflection of $33 \mathrm{~mm}$ after the blast test.

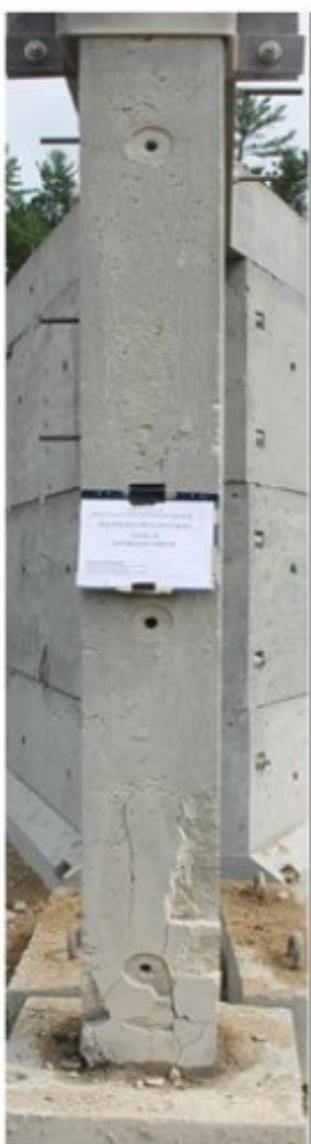

(a)

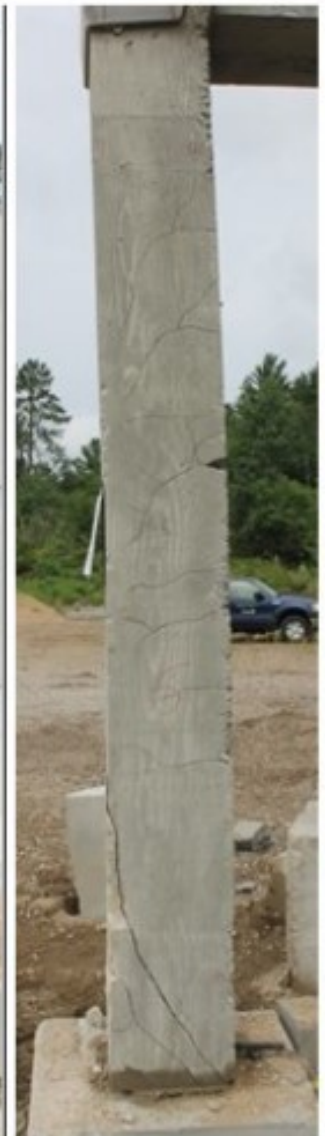

(b)

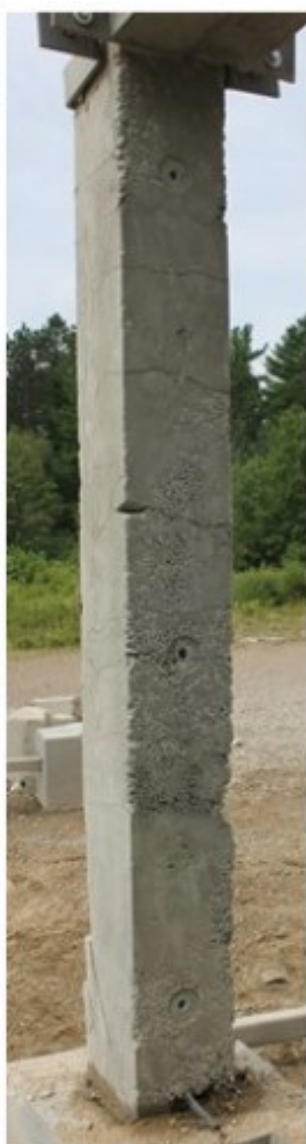

(c)

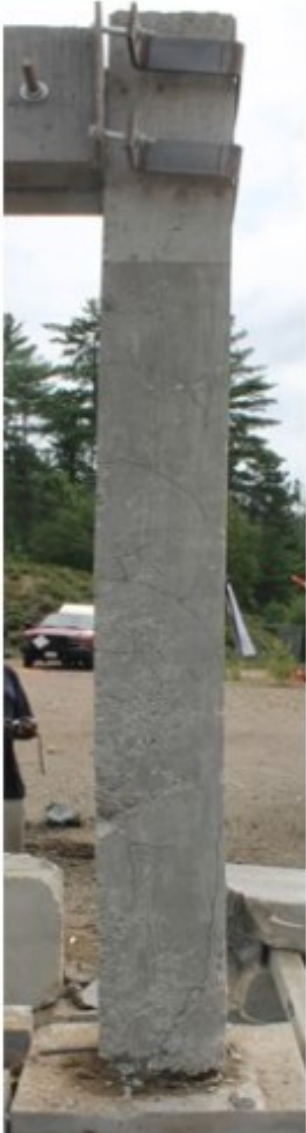

(d)

Figure 3-5: Post-field test photograph of CONV-06: (a) front face, (b) right face, (c) back face and (d) left face

(Farouk 2014)

SEIS-13 was subjected to 150-kg ANFO explosive at a standoff distance of $4.10 \mathrm{~m}$ and showed minimal cracking on the back face of the column. The few cracks on the surface appeared to be flexural. The explosive charge mass and corresponding standoff distances yielded a scaled distance of $0.82 \mathrm{~m} / \mathrm{kg}^{1 / 3}$ for SEIS-13. It had a maximum permanent deflection of $7 \mathrm{~mm}$. Figure 36 shows the post-test condition of column SEIS-13. 


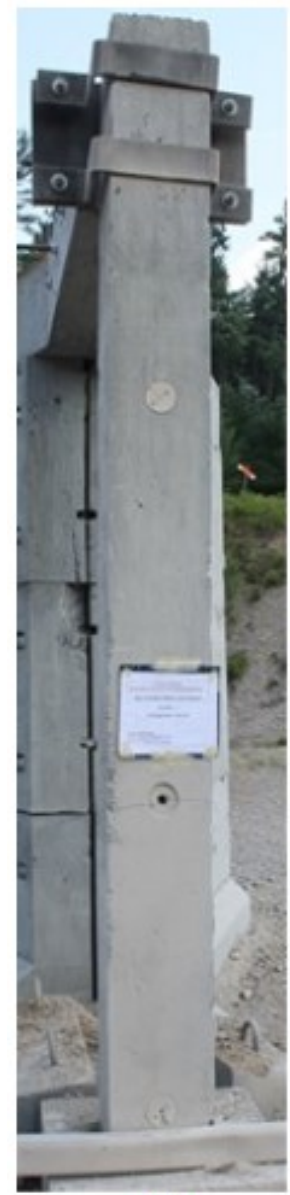

(a)

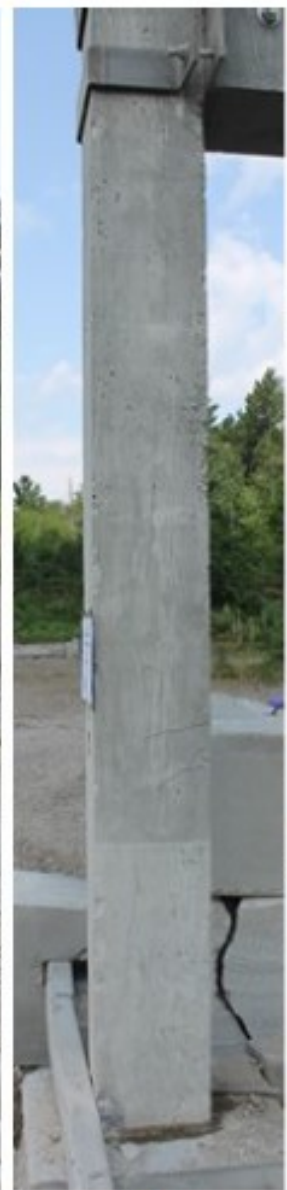

(b)

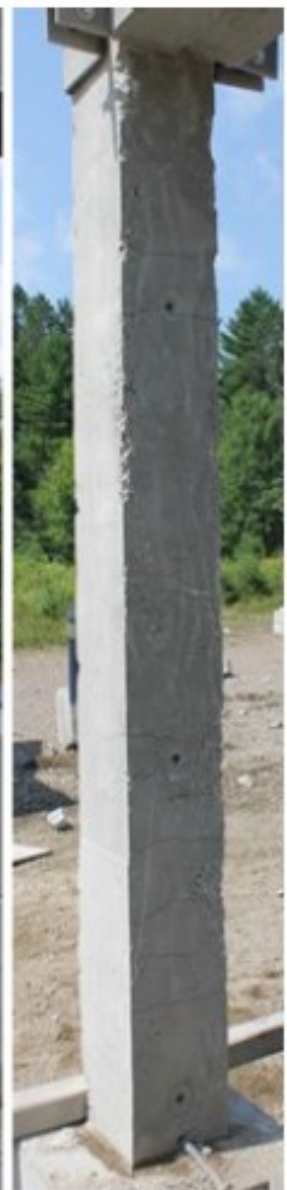

(c)

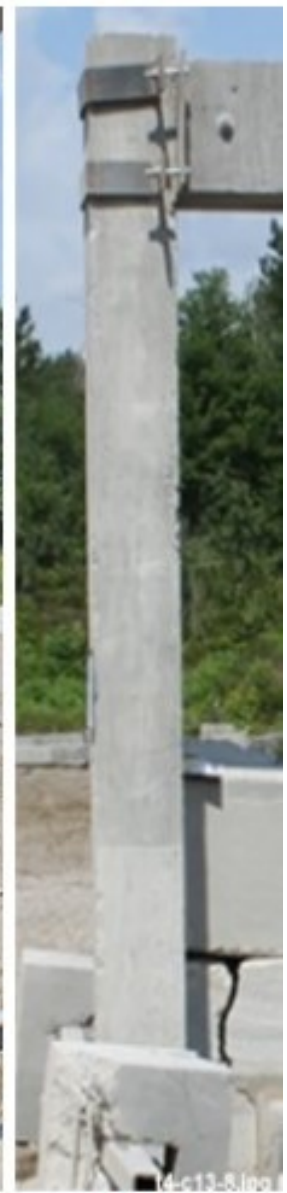

(d)

Figure 3-6: Post-field test photograph of SEIS-13: (a) front face, (b) right face, (c) back face and (d) left face (Siba (2014))

SEIS-14 was subjected to blast loading from $150 \mathrm{~kg}$ ANFO explosion. The distance from the centre of detonation to column SEIS-14 was $4.3 \mathrm{~m}$. The column was not damaged due to the greater scaled distance of $0.86 \mathrm{~m} / \mathrm{kg}^{1 / 3}$. Flexural cracking was observed on the back face and sides of the column. Figure 3-7 shows the post-test photographs of SEIS-14. It had a maximum lateral deflection of $16 \mathrm{~mm}$. 


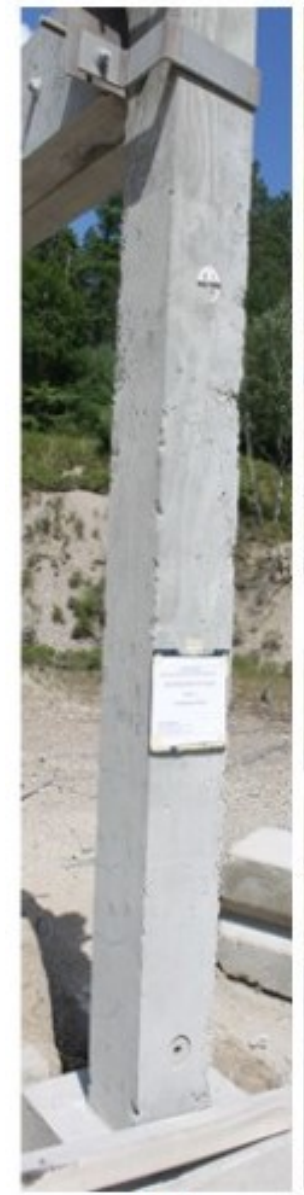

(a)

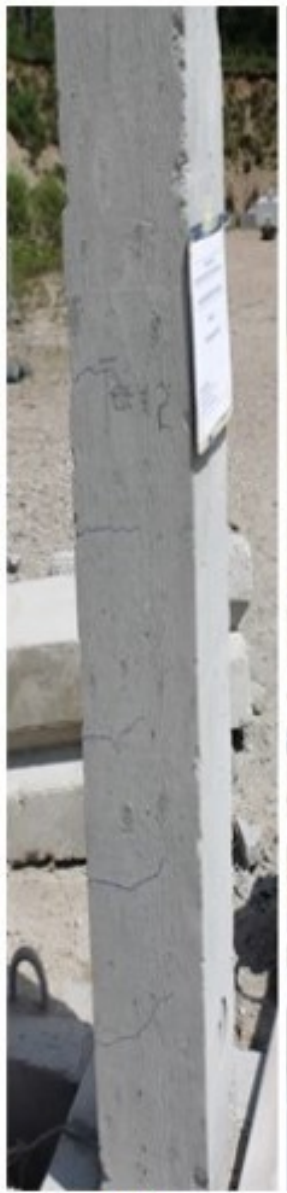

(b)

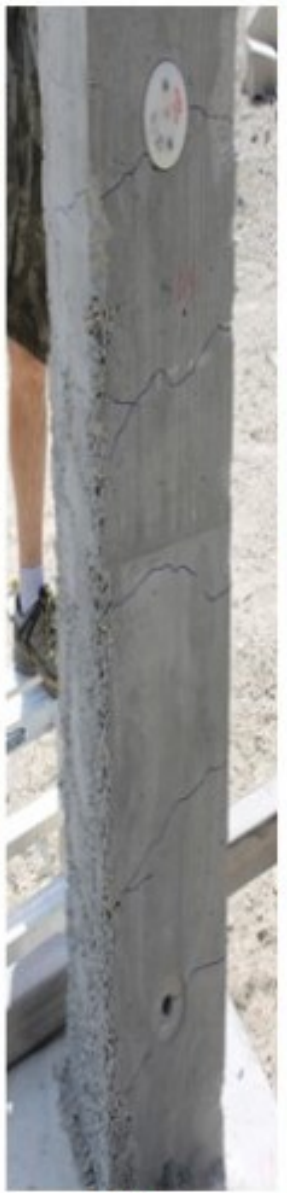

(c)

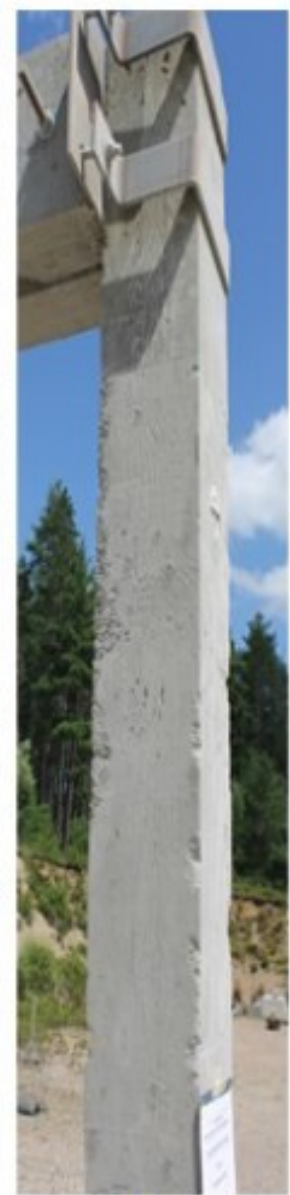

(d)

Figure 3-7: Post-field test photograph of SEIS-14 (a) front face, (b) right face, (c) back face and (d) left face

(Siba (2014))

CONV-11 was subjected to $150 \mathrm{~kg}$ ANFO explosive. The standoff distance of column CONV-11 was $4.4 \mathrm{~m}$ resulting in a scaled distance of $0.88 \mathrm{~m} / \mathrm{kg}^{1 / 3}$. The column suffered minimal cracking after the explosion test. The cracks were predominantly flexural cracks developed on the sides and back of the column. CONV-11 had a permanent deflection of $30 \mathrm{~mm}$ after the explosion testing. Post-field test condition of column CONV-11 is shown in Figure 3-8. 


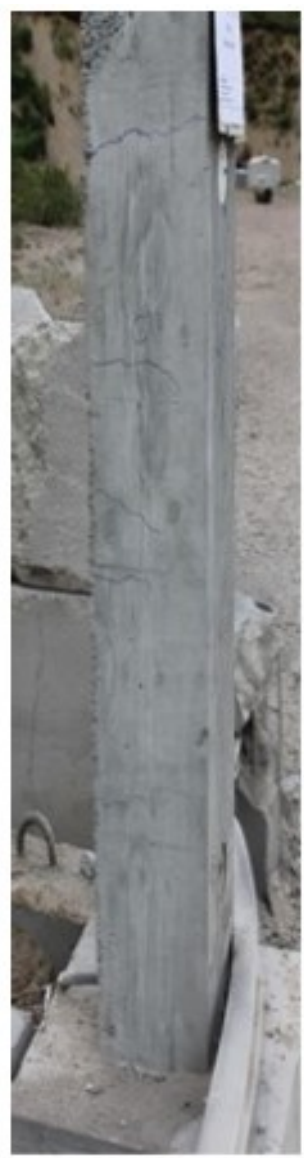

(a)

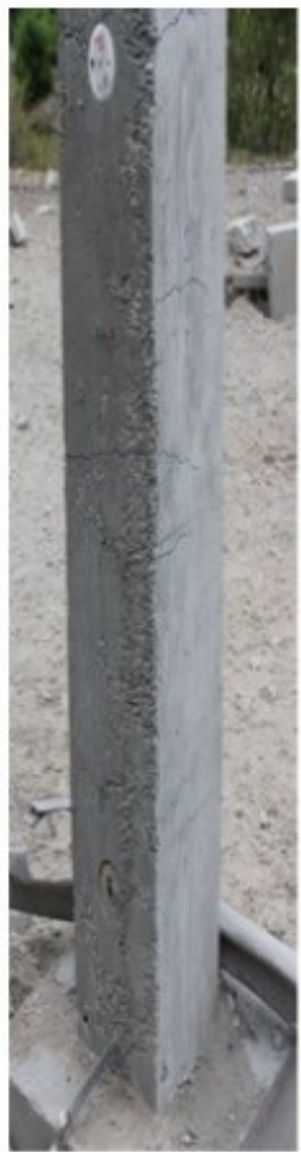

(b)

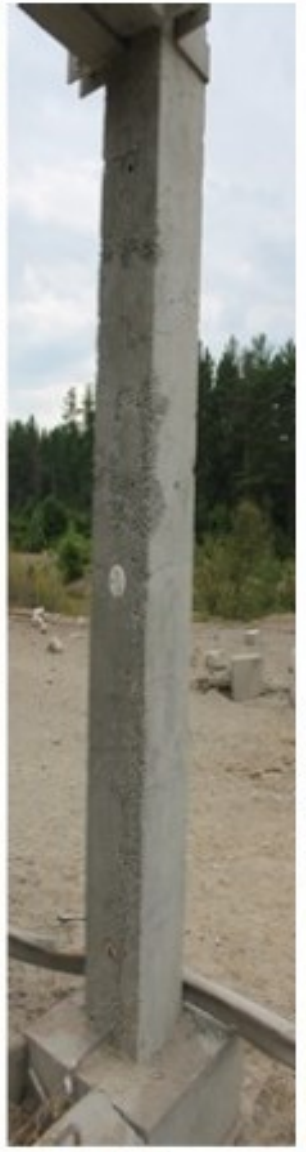

(c)

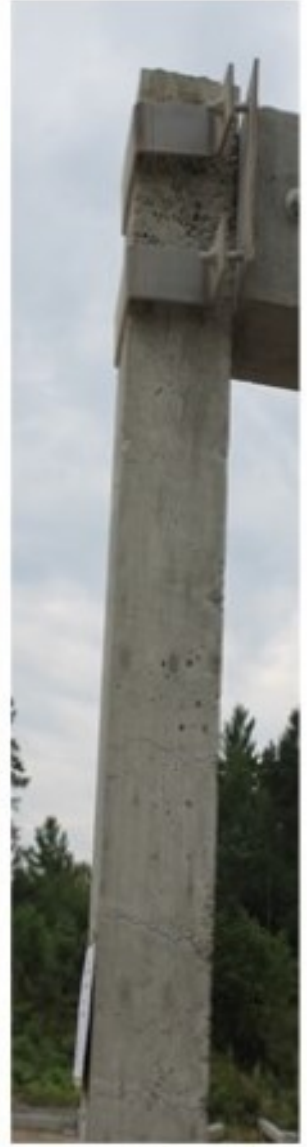

(d)

Figure 3-8: Post-field test photograph of CONV-11 (a) front face, (b) right face, (c) back face and (d) left face (Siba (2014))

CONV-12 was subjected to blast loading from $150 \mathrm{~kg}$ ANFO explosion. The distance from the centre of detonation to column CONV-12 was at $4.1 \mathrm{~m}\left(\mathrm{z}=0.82 \mathrm{~m} / \mathrm{kg}^{1 / 3}\right)$. Minimal flexural cracks developed on column CONV-12. It had a maximum permanent deflection of $29 \mathrm{~mm}$. Figure 3-9 shows the post-test condition of CONV-12. 


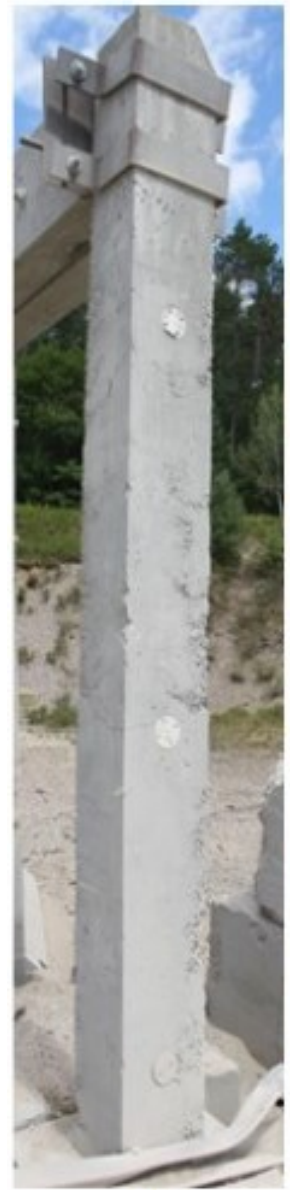

(a)

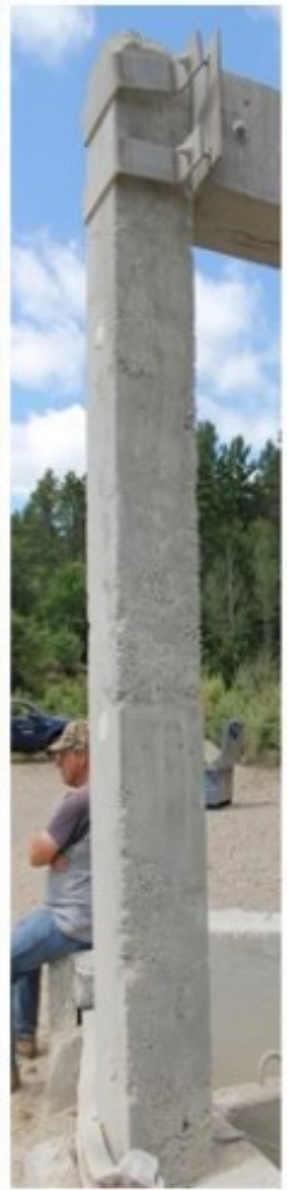

(b)

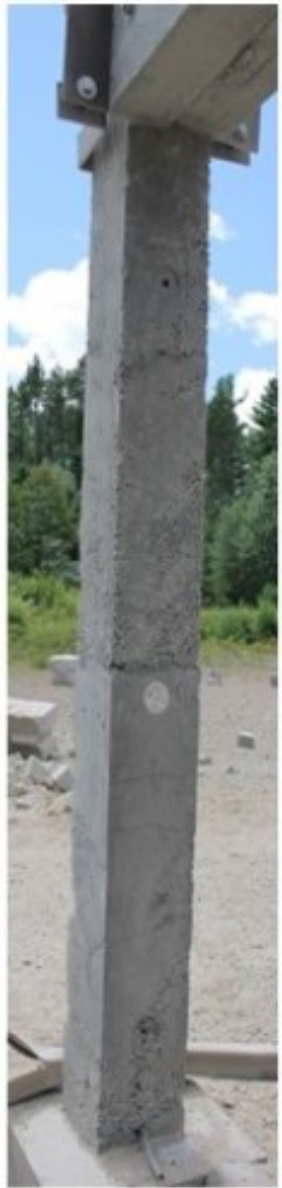

(c)

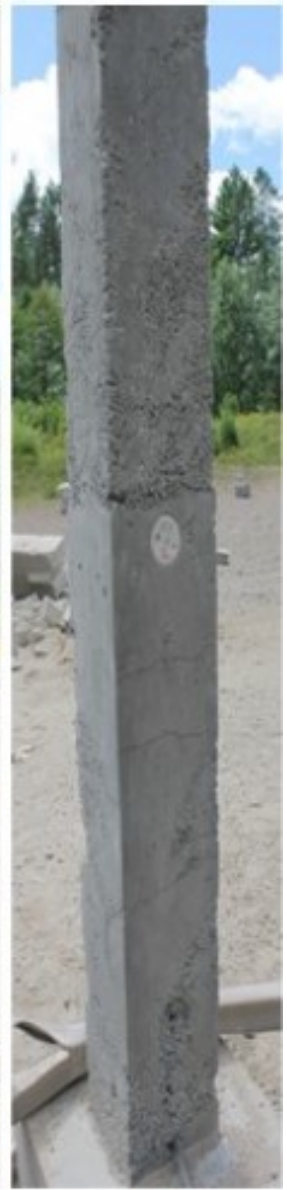

(d)

Figure 3-9: Post-field test photograph of CONV-12: (a) front face, (b) right face, (c) back face and (d) left face (Siba (2014))

Finally, CONV-15 was also subjected to blast loading from $150 \mathrm{~kg}$ ANFO explosion. The distance from the centre of detonation to column CONV-15 was at $4.26 \mathrm{~m}$ from the centre of detonation $\left(\mathrm{z}=0.86 \mathrm{~m} / \mathrm{kg}^{1 / 3}\right)$. CONV15 showed insignificant cracking on the sides and back of the column. This is not easily visible in Figure 3-10. CONV-15 had a permanent deflection of 14 $\mathrm{mm}$ after the field test. 


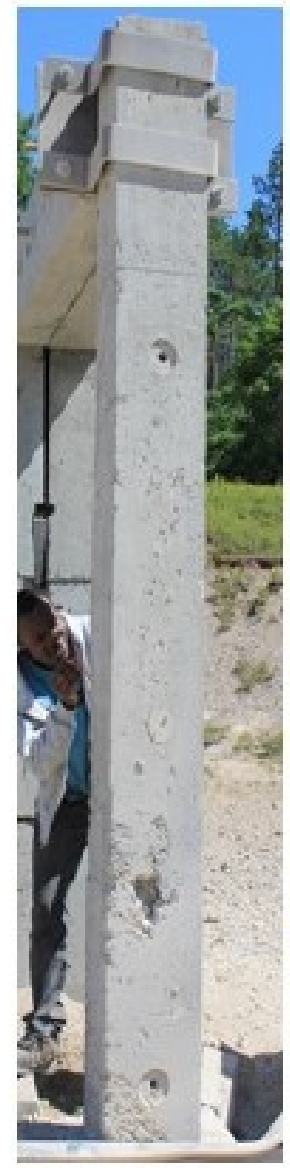

(a)

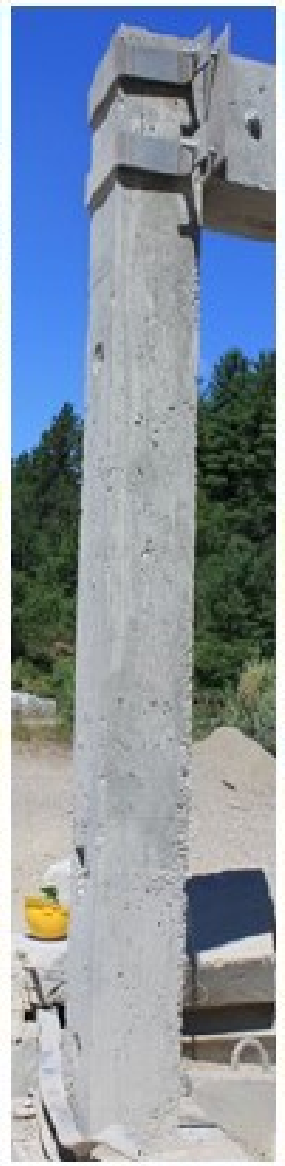

(b)

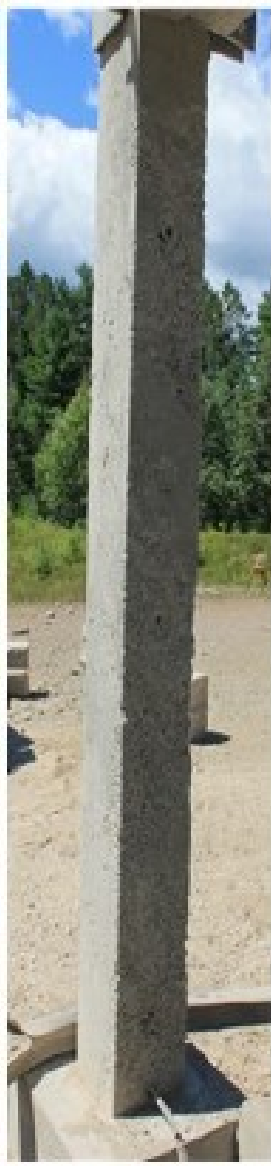

(c)

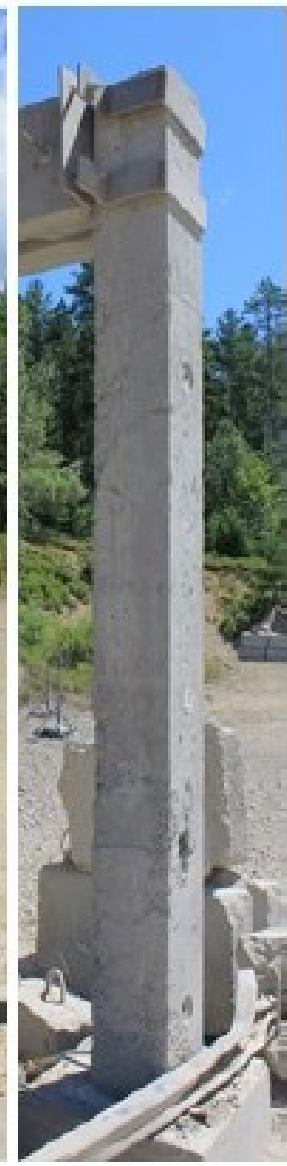

(d)

Figure 3-10: Post-field test photograph of CONV-15: (a) front face, (b) right face, (c) back face and (d) left face (Siba (2014))

CONV-16, CONV-17, SIES-18 and SEIS-19 are control columns, which are used as benchmarks in this test. As such, they were exposed to blast loading prior to the residual capacity testing.

\subsection{Residual Capacity Test Setup}

\subsubsection{Reaction and Test Frames}

A steel reaction wall in the Civil Engineering Structures Laboratory was used as the primary reaction structure. The frame is comprised of four (4) wide welded flange steel columns (WWF500×343) and plate girders welded and bolted together. The reaction structure was bolted 
to the 1-m thick strong floor through base plates of the columns using sixteen (16) $50-\mathrm{mm}$ diameter steel threaded rods with an average length of $2 \mathrm{~m}$. This provides direct support against sliding and rotation of the test columns.

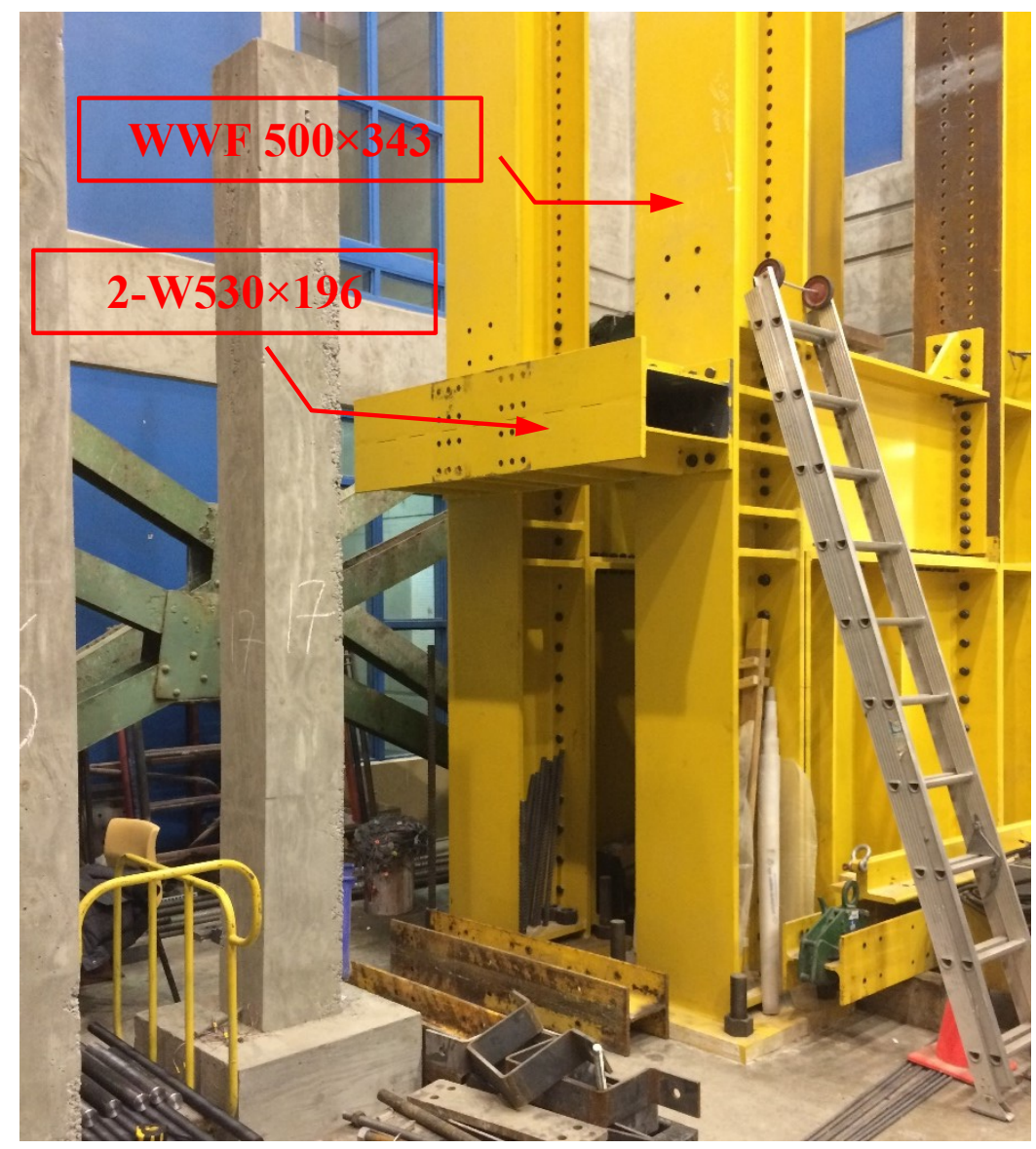

Figure 3-11: Reaction structure at the civil structures lab of Carleton University.

Two W530×196 sections were bolted to the reaction frame across the flanges of two columns (Figure 3-11). A welded assembly of two (2) steel plates and two (2) W150 $\times 30$ sections was then bolted to serve as an outrigger providing top restraint to the test columns. In order to provide a fixed support condition and prevent rotation and sliding of the footing of the columns, the assembly in Figure 3-12c was designed. To prevent sliding of the footing, two W250×89 sections, $1.4 \mathrm{~m}$ in length, were laid along their flange edges with two $\mathrm{W} 150 \times 30$ in axial 
compression put in between them. Two W150×37 sections were placed on top of the footing and held down by back-to-back channel sections $(\mathrm{C} 100 \times 11)$, which was then fastened to the strong floor by high strength threaded steel rods. The axial load actuator was mounted on a portal steel frame in the structures laboratory of the civil engineering department. The frame consists of two steel columns (W610×155), $5.25 \mathrm{~m}$ high with two steel beams $(\mathrm{W} 610 \times 155)$ bolted across the columns on either side as shown in Figure 3-12a. This frame was also fastened to the laboratory's strong floor. Figure 3-12a shows a sketch of the experimental setup. The front face of the column is the face that was directly impacted by the blast loading. In this residual capacity test, the columns were laterally loading in the same direction as the travel of the blast load. 

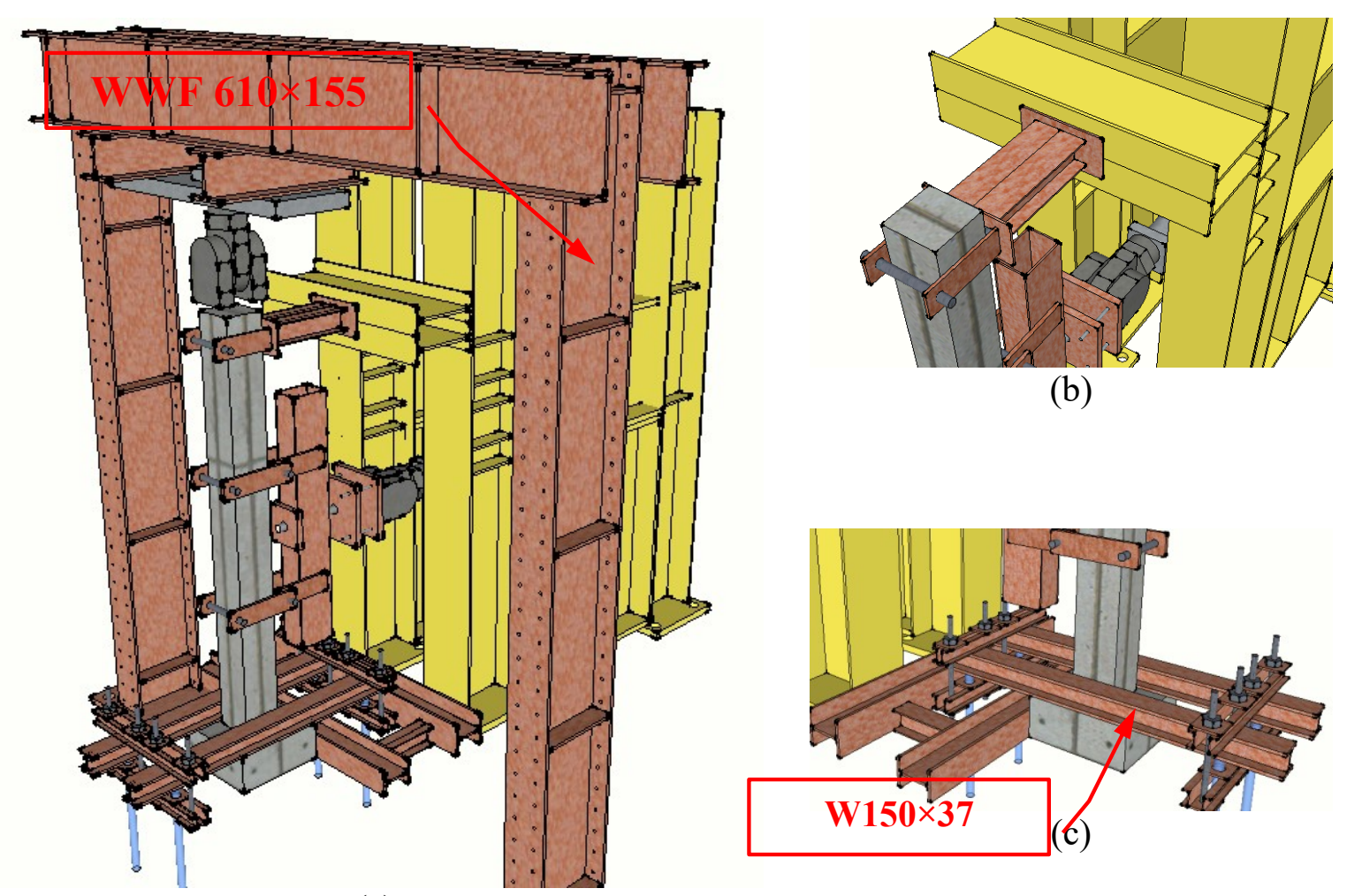

(b)

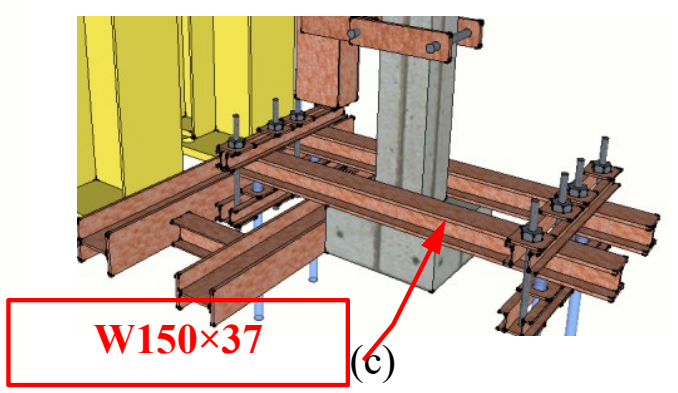

(a)

Figure 3-12: (a) Experimental setup of the residual capacity test (b) Pin reaction at top (c) Fixed reaction system

\subsubsection{Instrumentation}

All the reinforced concrete columns in the residual capacity test program were instrumented with string potentiometers and strain gauges. This section describes the instrumentation as well as the locations of the strain gauges and potentiometers on the columns. Due to high pressures from the near-field tests carried out by Siba (2014), some of the strain gauges were damaged.

\subsubsection{String potentiometers}

Celesco (model SP1shown in Figure 3-13) manufactured the String Potentiometers. The string potentiometers were used to measure column displacements in each test columns at three 
locations. The locations for the string potentiometers were the same for all columns. They were connected directly to the rear face of the column at $1.0 \mathrm{~m}, 1.5 \mathrm{~m}$ from the top of concrete footing and at mid-height. The string potentiometers at the upper third $(2 \mathrm{~m})$ and lower third $(1 \mathrm{~m})$ locations were screwed into the round bars used to apply lateral loads to the columns. String potentiometers are mainly composed of four main parts: retractable cable, spool, spring, and rotational sensor. The casing of the device was mounted onto $2^{\prime \prime} \times 4$ " $(38 \times 89 \mathrm{~mm})$ wood studs attached to a steel column in front of the reinforced concrete column, while the retractable cables were attached to the locations on the front face of the column. Figure 3-13 presents a photograph of the Celesco string potentiometers, with a string length of 25 inches $(600 \mathrm{~mm})$, attached to the reinforced concrete test column.

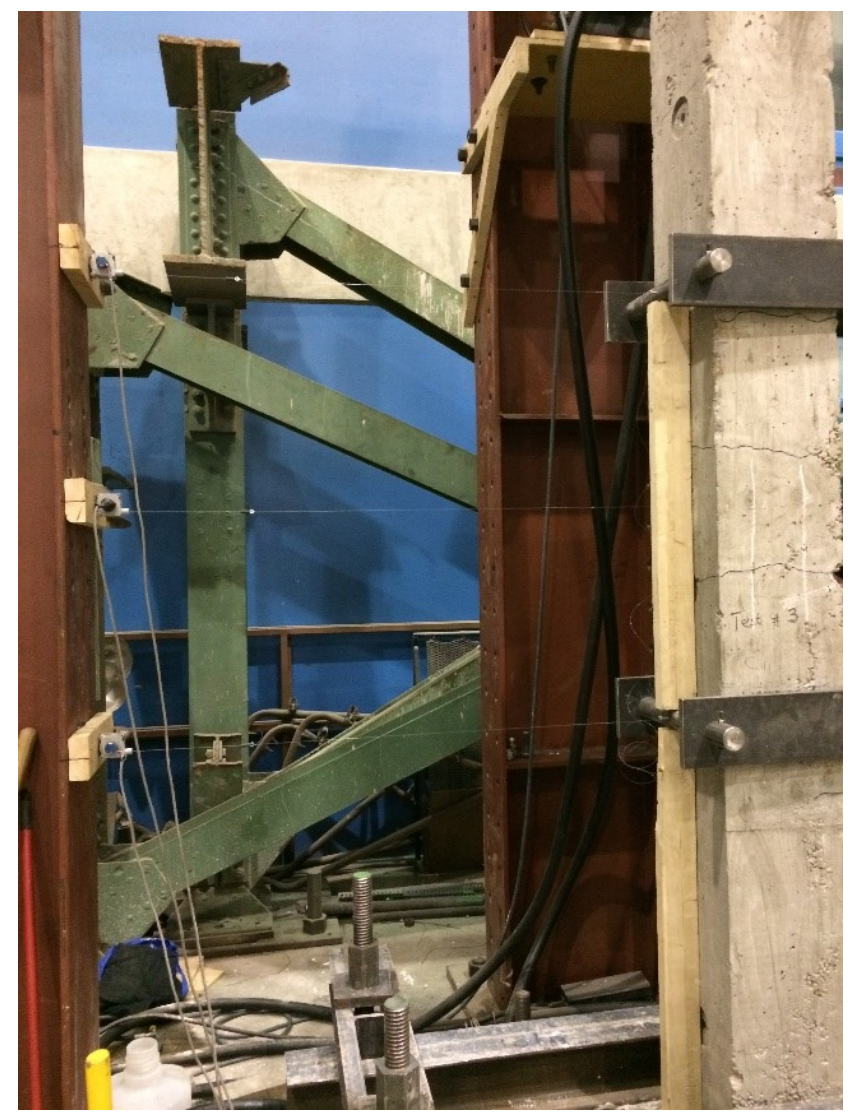

Figure 3-13: String potentiometer attached to supporting steel column and connected to the test column. 


\subsubsection{Strain gauges}

350-ohm resistance strain gauges, FLA-6-350-11, were attached to the longitudinal reinforcing bar of each column (Siba (2014)). The positions of the eight strain gauges on the longitudinal reinforcement in each column are designated: bottom-front-left, bottom-front-right, mid-frontright, mid-front-left, mid-back-left, mid-back-right, top-front-left, and top-front-right. The front face of the column was towards the centre of explosion during the field test while the back was away. Table 3-2 presents the location of the strain gauges on each column as constructed.

Table 3-2 Strain gauge locations as installed on columns by Siba (Siba (2014)).

\begin{tabular}{|l|c|c|c|c|}
\hline \multirow{2}{*}{$\begin{array}{c}\text { Column } \\
\text { designation }\end{array}$} & \multicolumn{4}{|c|}{ Location of strain gauges (mm, measured from top of footing)* } \\
\cline { 2 - 5 } & Bottom-front & Mid-front & Mid-back & Top-front \\
\hline CONV-06 & 250 & 1600 & 1600 & 2400 \\
\hline CONV-07 & 250 & 1600 & 1600 & 2400 \\
\hline SEIS-08 & 250 & 1150 & 1150 & 2350 \\
\hline SEIS-09 & 250 & 1000 & 1200 & 2350 \\
\hline CONV-11 & 250 & 1600 & 1600 & 2400 \\
\hline CONV-12 & 250 & 1600 & 1600 & 2400 \\
\hline SEIS-13 & 200 & 1050 & 1300 & 2350 \\
\hline SEIS-14 & 250 & 1250 & 1100 & 2400 \\
\hline CONV-15 & 250 & 1600 & 1600 & 2400 \\
\hline CONV-16 & 250 & 1600 & 1600 & 2400 \\
\hline CONV-17 & 250 & 1600 & 1600 & 2400 \\
\hline SEIS-18 & 250 & 1050 & 1300 & 2350 \\
\hline SEIS-19 & 250 & 1250 & 1100 & 2400 \\
\hline
\end{tabular}

*- the dimensions shown are same for left and right locations

\subsubsection{Actuators}

The service load (axial load) was applied to the reinforced concrete columns with a $1045-\mathrm{kN}$ capacity MTS 243.60T actuator. The actuator was mounted on a steel frame made up of two (2) 
steel columns (W610×155), $5.25 \mathrm{~m}$ high with two beams (also W610 $\times 155)$ bolted across both columns on either side as shown in Figure 3-14. In order to choose the ideal lateral load actuator, the capacity of an undamaged RC column with the specific material properties and amount of reinforcement was calculated. An axial load and moment interaction curve was generated for the test column. For damage to occur, the applied service load $(1000 \mathrm{kN})$ must combine with a moment of about $180 \mathrm{kNm}$ (Figure 3-15). The load that produces a maximum moment value of $180 \mathrm{kNm}$ was calculated and used in determining the lateral actuator capacity. Another MTS actuator with a capacity of $667 \mathrm{kN}$ (shown in Figure 3-16) was chosen to apply the lateral loads in the residual capacity test program. The actuator has a maximum stroke of $150 \mathrm{~mm}$, which was greater than the expected lateral displacements.

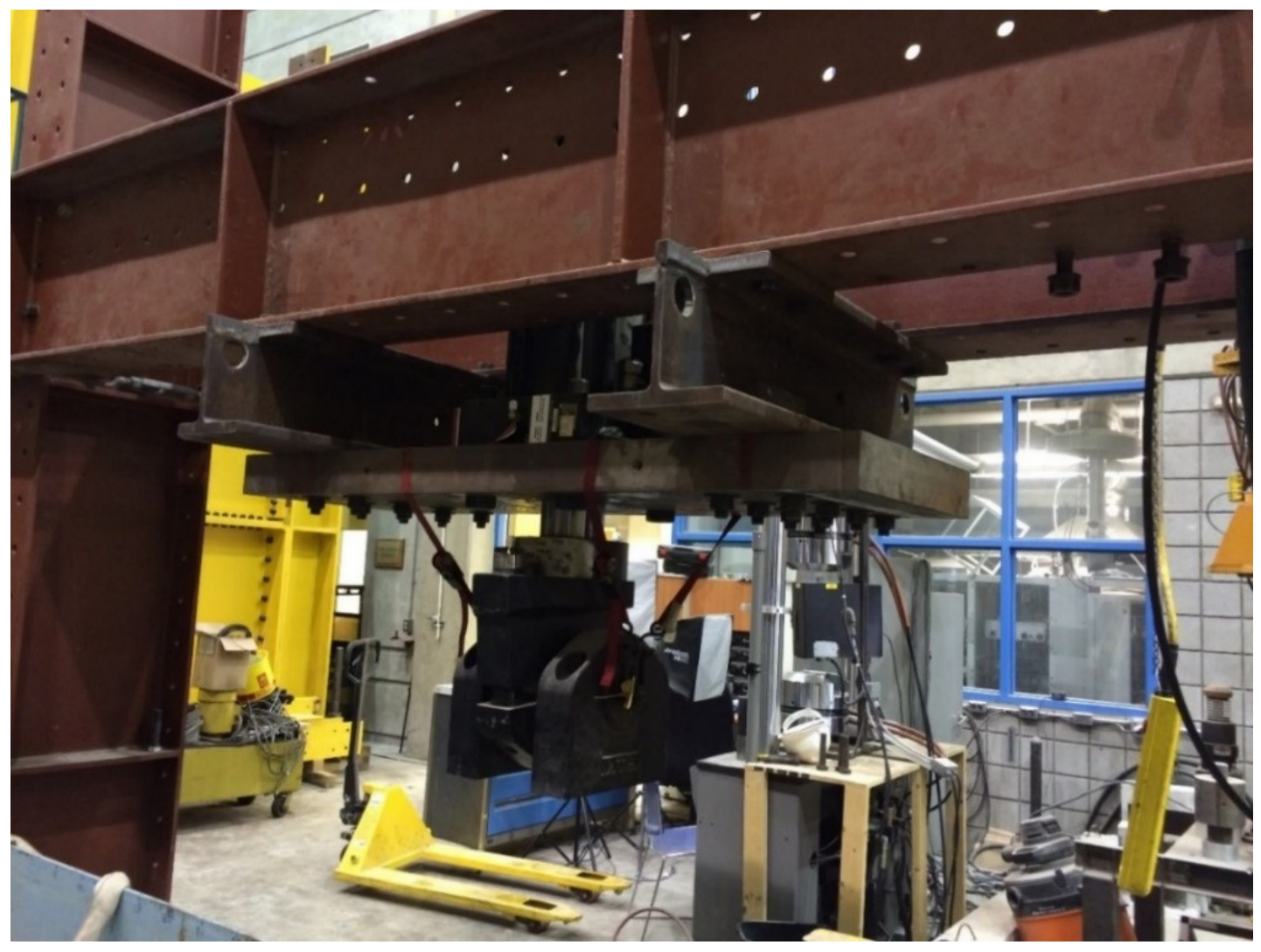

Figure 3-14: Steel frame supporting axial (1045-kN) actuator 


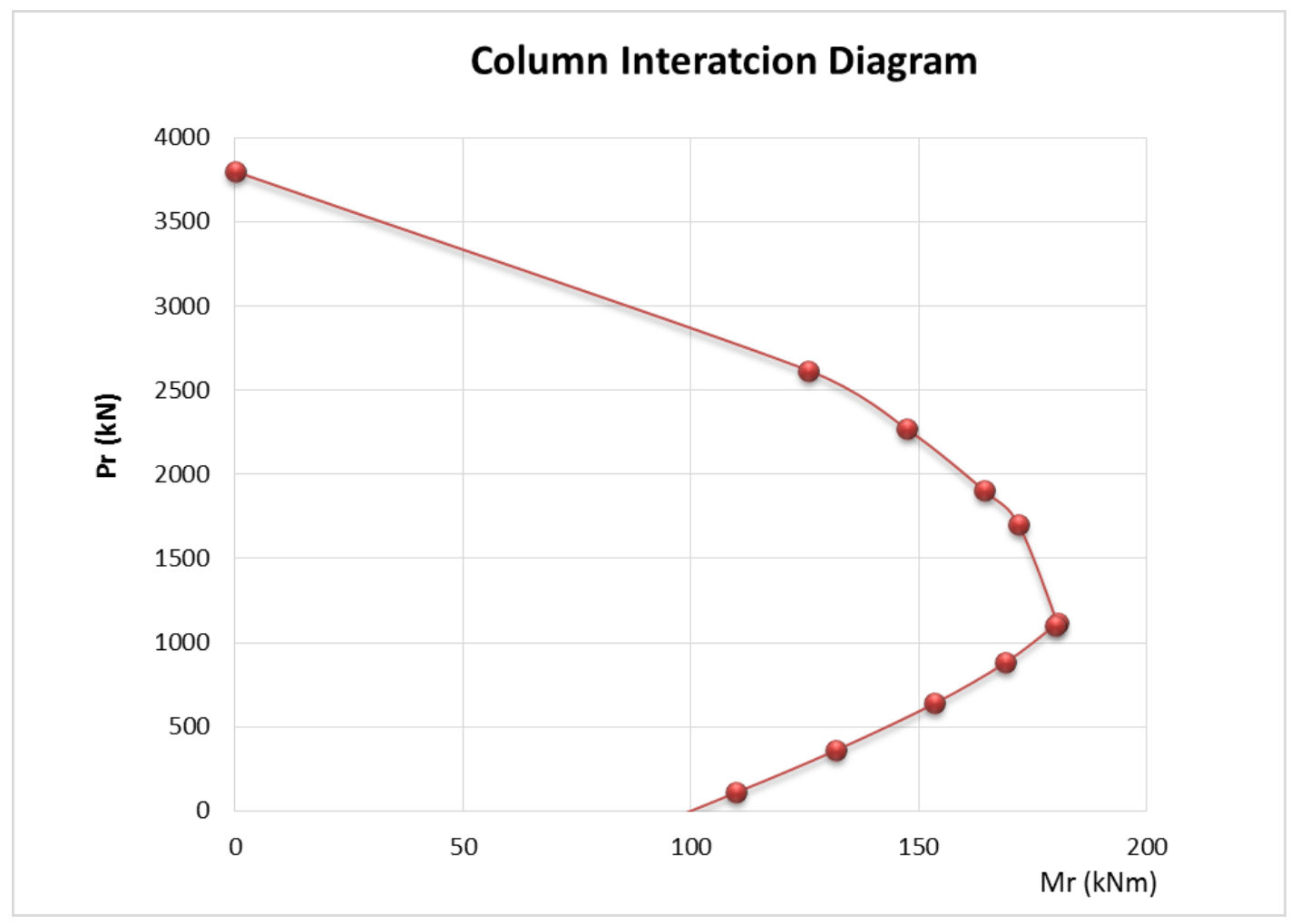

Figure 3-15: Axial load-moment interaction for a typical test column.

The concrete compressive strength used in determining the lateral load actuator capacity was 41.3 MPa determined from concrete cylinder tests by Siba (2014). The column might have achieve more strength since the 28-day cylinder test. The yield strength of the longitudinal steel was $474 \mathrm{MPa}$ and both concrete and steel material resistance factors $\left(\Phi_{c}\right.$ and $\left.\Phi_{s}\right)$ set to 1.0. 


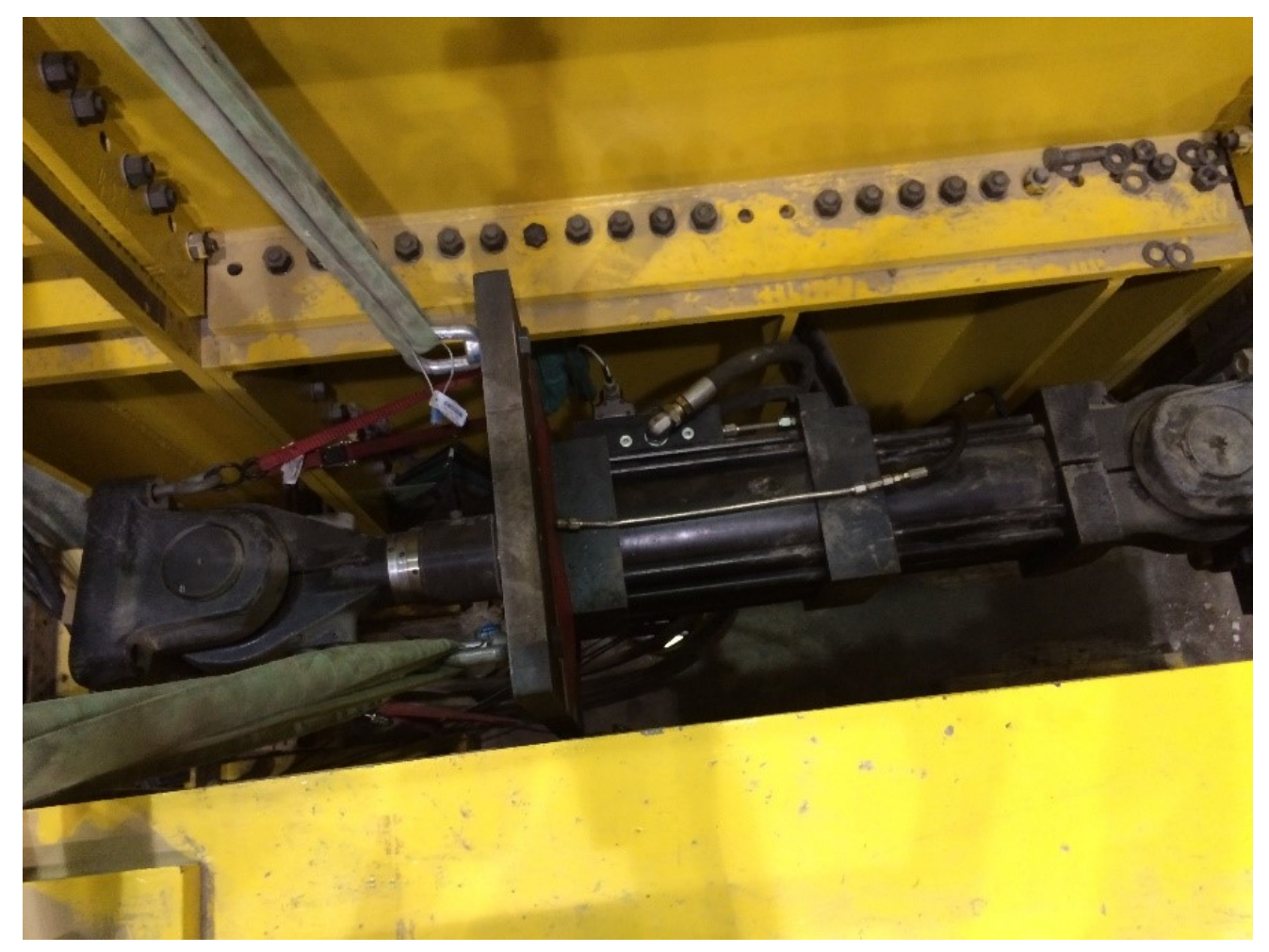

Figure 3-16: Lateral actuator inside reaction frame

\subsubsection{Data Acquisition}

The applied loads from the axial and lateral actuators were measured by built-in load cells of the actuators. The actuator loads and data from the strain gauges and string potentiometers were recorded onto a NI cDAQ-9178 data acquisition system (Figure 3-17). Eight (8) input-channels recorded strain readings and three (3) input-channels recorded displacement readings. The axial and lateral loads and strokes were also recorded. The MTS 458.10 Micro Console system was used for sending loading commands to both hydraulic service manifolds (Figure 3-18) in order to apply test loads. 


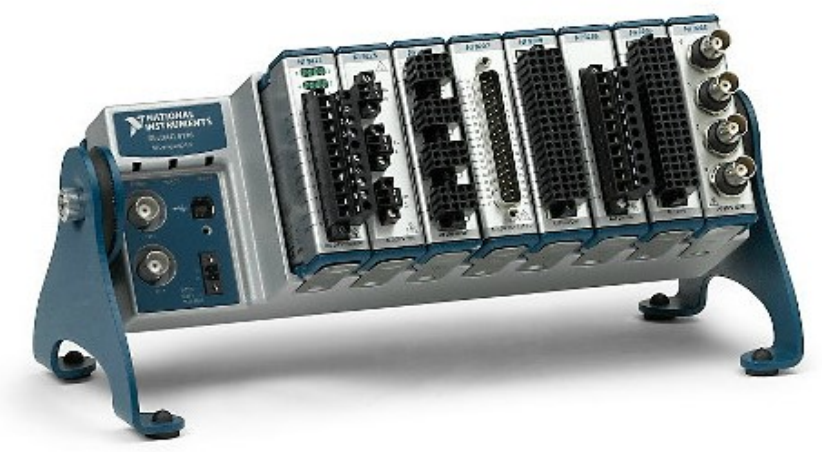

Figure 3-17: Photograph of NI cDAQ-9178 data acquisition system.

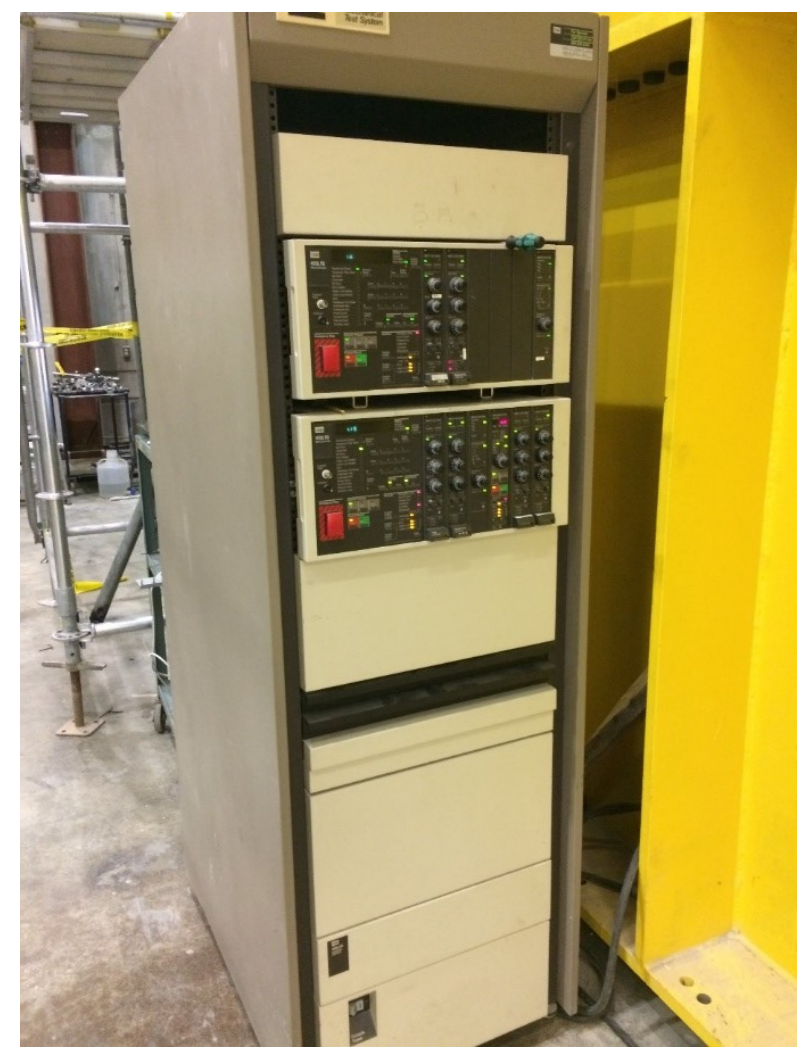

Figure 3-18: Two MTS 458.10 Micro Consoles used for the two hydraulic actuators. 


\subsection{Testing Procedure}

Before each test began, the column was put in place by an overhead crane with a capacity of 10 tons. Previously damaged columns were inspected and the maximum permanent deflections at midpoint and third-points were recorded. The footing was then restrained to prevent sliding and overturning (rotation). The footing of the column was placed on a layer of plaster to ensure uniform load distribution to the floor. A layer of plaster was also placed on top of the column and then the loading platen of the axial load actuator was lowered onto it to ensure uniform contact.

The residual capacity test was carried out in two stages. In the first stage, an axial force of about $1000 \mathrm{kN}$ (service load) was applied. This is a little lower than the design service load level of $1027 \mathrm{kN}$ for an axial load ratio of 0.32 . The axial load was applied in a load-control mode. The load was increased up to $1000 \mathrm{kN}$ and maintained at that load throughout the second stage of testing. This is in keeping with the phenomenon in a structure; service load remain even in the event of a blast or an earthquake. In accordance with ASTM C39, concrete cylinders are tested at a static stress rate of $0.25 \mathrm{MPa} / \mathrm{s}(15 \mathrm{MPa} / \mathrm{min})$ in compression while ASTM C496 specifies a 0.7 $-1.4 \mathrm{MPa} / \mathrm{min}$ in tension. This was to ensure specimen and test frame stability during testing. Reinforced concrete columns experiencing failure before the service load level was applied will be deemed incapable of resisting the service loads post-blast damage. With these as guidelines, a load rate of $100 \mathrm{kN} / \mathrm{min}$ was chosen in applying the axial load in the load-control mode.

Test specimen surviving the first stage of testing were tested in a second stage involving the application of a static lateral force. The lateral loads were applied at third-points using an HSS305 $\times 305 \times 13$ spreader beam (Figure $3-12 a$ ). The lateral force was applied in a displacementcontrol mode. ASTM C78M-15 specifies a load rate corresponding to a tensile stress rate of 0.9 
- $1.2 \mathrm{MPa} / \mathrm{min}$ for modulus of rupture testing. This loading rate was used as a guide in determining the displacement rate of the actuator of $0.8 \mathrm{~mm} / \mathrm{min}$ as per Equation (3-1).

$r=\frac{S b d^{2}}{L}$

where

$\mathrm{r}=$ loading rate, $\mathrm{N} / \mathrm{min}$

$\mathrm{S}=$ rate of increase in maximum stress on the tension face, $\mathrm{MPa} / \mathrm{min}$

$\mathrm{b}=$ average width of the specimen as oriented for testing, $\mathrm{mm}$

$\mathrm{d}=$ average depth of the specimen as oriented for testing, $\mathrm{mm}$

$\mathrm{L}=$ span length, $\mathrm{mm}$

Sheikh and Yeh (1991) tested fifteen $305 \times 305 \times 2740 \mathrm{~mm}$ reinforced concrete columns. In this axial and flexure test, axial loads were increased in steps up to the predetermined load value then kept constant. The lateral actuator was then operated in displacement control at $1.0-1.25$ $\mathrm{mm} / \mathrm{min}$ for the increasing portion of the load - displacement curve. This displacement rate was doubled for ductile columns. In the current residual capacity test program, a displacement rate of loading of $1.5 \mathrm{~mm} / \mathrm{min}$ was adopted for both conventional and seismic designated columns. A major difference in the procedure used in this work is that the columns were not loaded axially to failure as was done by Li et al. (2012), Jayasooriya et al. (2011), Bao and Li (2010). They were loaded to their service load level as is commensurate with columns in buildings. If the column can sustain this load, then they are expected to survive the blast loading. The columns were then loaded laterally to determine their lateral capacity under that service load. This is the distinguishing difference between residual axial capacity and residual lateral capacity. This general procedure was followed for all columns in this test program. 


\section{Chapter: Results and Discussion}

\subsection{Introduction}

The test results and observations during the testing of all thirteen reinforced concrete columns are presented in this chapter. The axial load was applied in increments of about $50 \mathrm{kN}$ until the service load was fully carried by the column. If the column did not fail, the lateral load was then applied in displacement-control at a rate of $1.5 \mathrm{~mm} /$ minute. The presentation of test results is followed by in-depth discussion and comparison of the response of the columns and a study of the effects of various parameters on the residual capacity of the damaged columns. For consistency and ease of discussion, the side that was facing the blast load in the field work carried out by Siba (2014) is referred to as the front face.

\subsection{Column Test $1(\mathrm{CONV}-17)$}

CONV-17 was a virgin conventional column that was not exposed to blast loading. The test began by loading the column axially up to a service load level, $1005 \mathrm{kN}$ and inducing an ALR of 0.32. The axial load rate was very fast due to the hydraulic pump malfunction thus the response of the column was not measured during the axial load regime. Upon full service load, the corresponding stroke to the $1005 \mathrm{kN}$ axial load from the axial actuator was $17.6 \mathrm{~mm}$. Considering the ALR and modulus of elasticity of the concrete, the expected change in height of the column was about $1.24 \mathrm{~mm}$; much less than the stroke recorded. The difference in the recorded stroke and the expected change in height of the column can be attributed to deflection of the steel girders of the portal loading frame used to apply the axial load.

Figure 4-1 presents the longitudinal reinforcement strains versus axial load plot for CONV-17. Strains in the longitudinal reinforcement range from $330 \times 10^{-6}$ to $490 \times 10^{-6} \mathrm{~mm} / \mathrm{mm}$ in 
compression during the first stage of testing. The strain in the column can be calculated from equation 4-1.

$\frac{\Delta}{L}=\frac{P}{E \times A_{t}}$

Where $\Delta$ is the axial shortening, $P$ is the axial load, $E$ is the modulus of elasticity of concrete given as $4500 \sqrt{f_{c}^{\prime}}$, and $A_{t}$ is the transformed cross sectional area of the column. The axial column shortening of $1.23 \mathrm{~mm}$ corresponds to a strain of $386 \times 10^{-6} \mathrm{~mm} / \mathrm{mm}$. This compares well with the strain recorded by the strain gauges on attached to the longitudinal steel reinforcement. The maximum mid-height displacement of the column under the axial load was $0.2 \mathrm{~mm}$, towards the front face of the column.

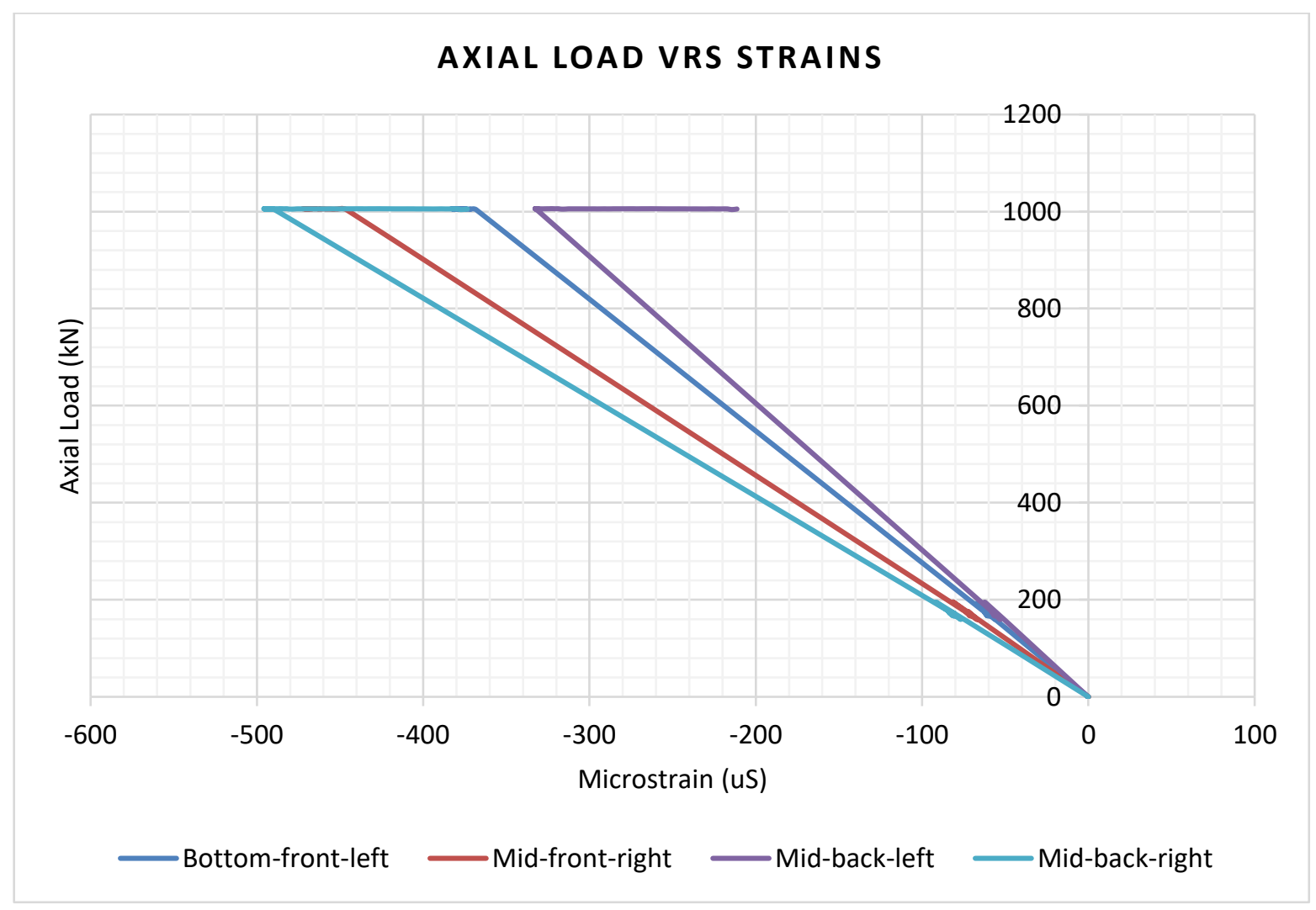

Figure 4-1: Strains in longitudinal reinforcement during the first stage of testing. 
The second stage of the testing commenced after the axial load was applied to the reinforced concrete column. The second stage involved applying lateral loading at a displacement-control rate of $1.5 \mathrm{~mm} / \mathrm{min}$. During lateral loading, a vertical crack developed in the footing and propagated from the bottom towards the top of the footing (Figure 4-2). The crack in the footing is indicative of the lack of full restraint at the bottom of the column. The footing was restrained against overturning by placing two W150×37 steel beams across the top of the footing on either side of the column and anchoring them to the laboratory strong floor with high strength steel threaded rods (Figure 4-3). The nuts of the threaded rods were however, not adequately torqued prior to applying the lateral load in second stage of loading. As a result, the footing rotated and full fixity at the footing base was not achieved (Figure 4-3).

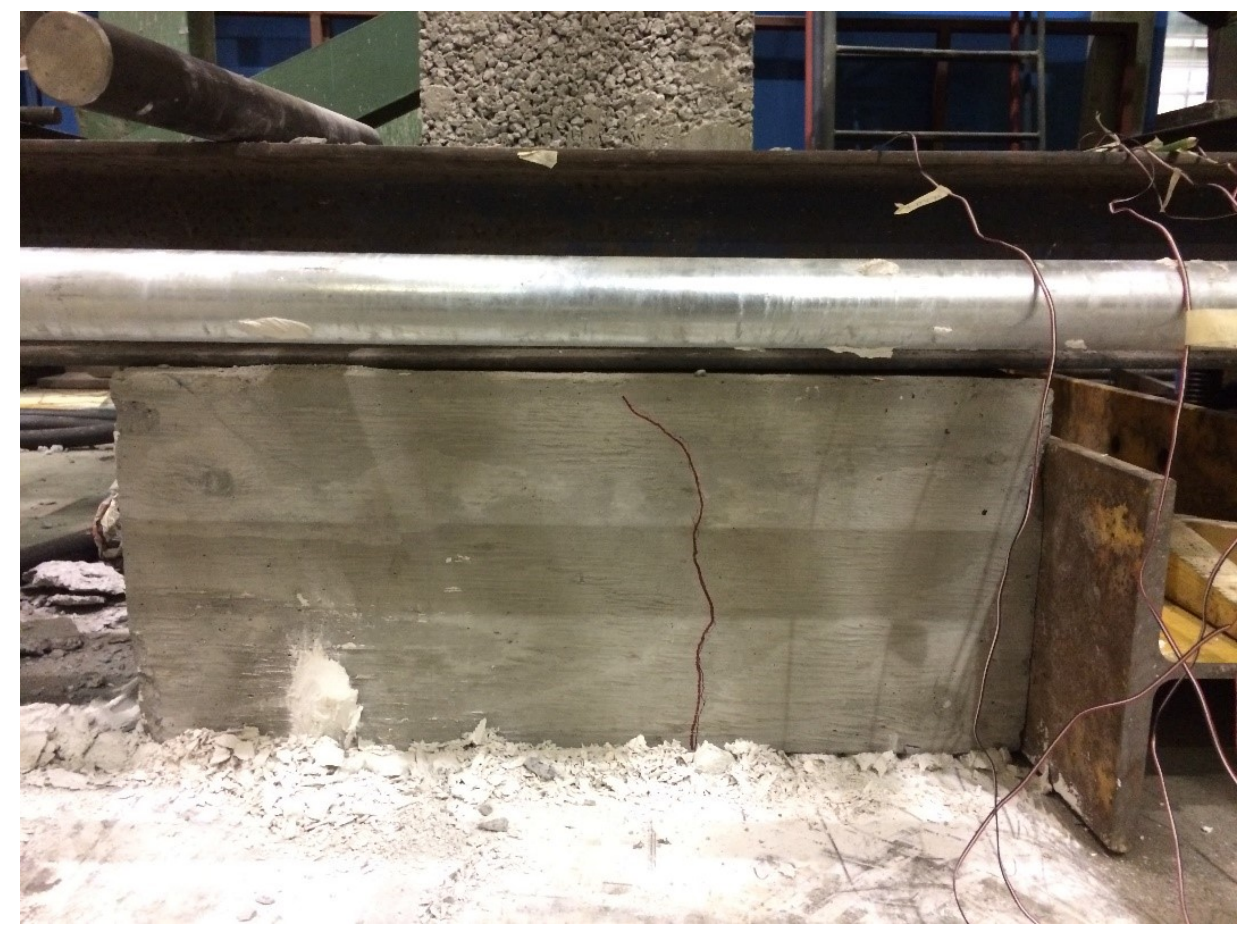

Figure 4-2: Crack developed in the footing due to tension on one side. 


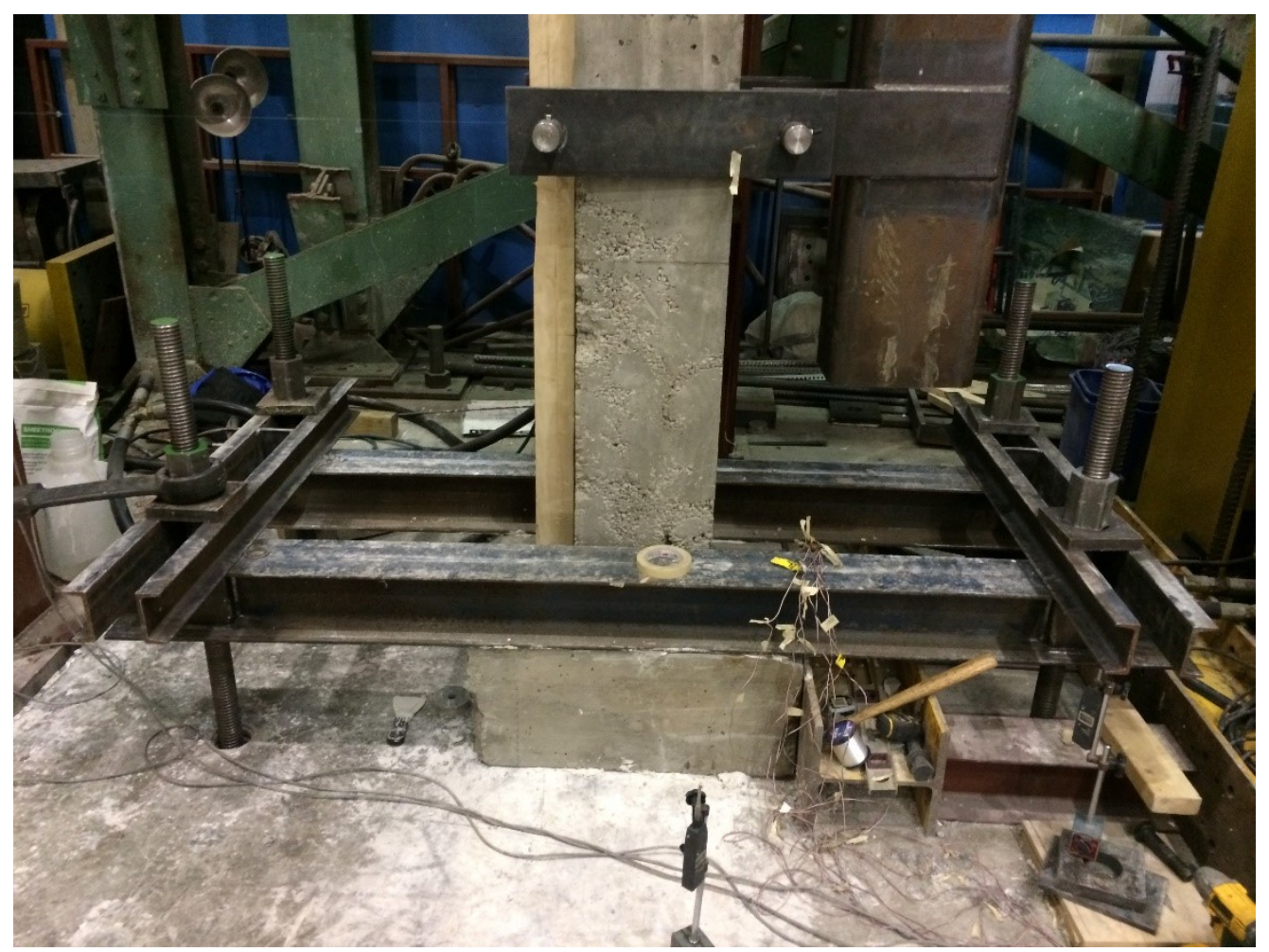

Figure 4-3: Restraint against overturning of column at the base.

The lateral load versus displacement behavior of the column is presented in Figure 4-4, while the lateral load versus reinforcement strain behavior is presented in Figure 4-5. The behavior of the column was linear up to a load of about $140 \mathrm{kN}$ when the first flexural crack appeared, Thereafter the response is nonlinear with a decreasing stiffness until the peak lateral load capacity of the column of $420 \mathrm{kN}$ was reached. The mid-height displacement corresponding to the peak lateral load was $26 \mathrm{~mm}$. At the peak lateral load, the mid-height and upper third point displacements were almost the same and the lower third point displacement was slightly lower. The axial load curve shows that the service load was maintained throughout the second stage of loading. The initial stiffness of the column is about $40 \mathrm{kN} / \mathrm{mm}$. This changed to an average of 12 $\mathrm{kN} / \mathrm{mm}$ at the maximum lateral load. 


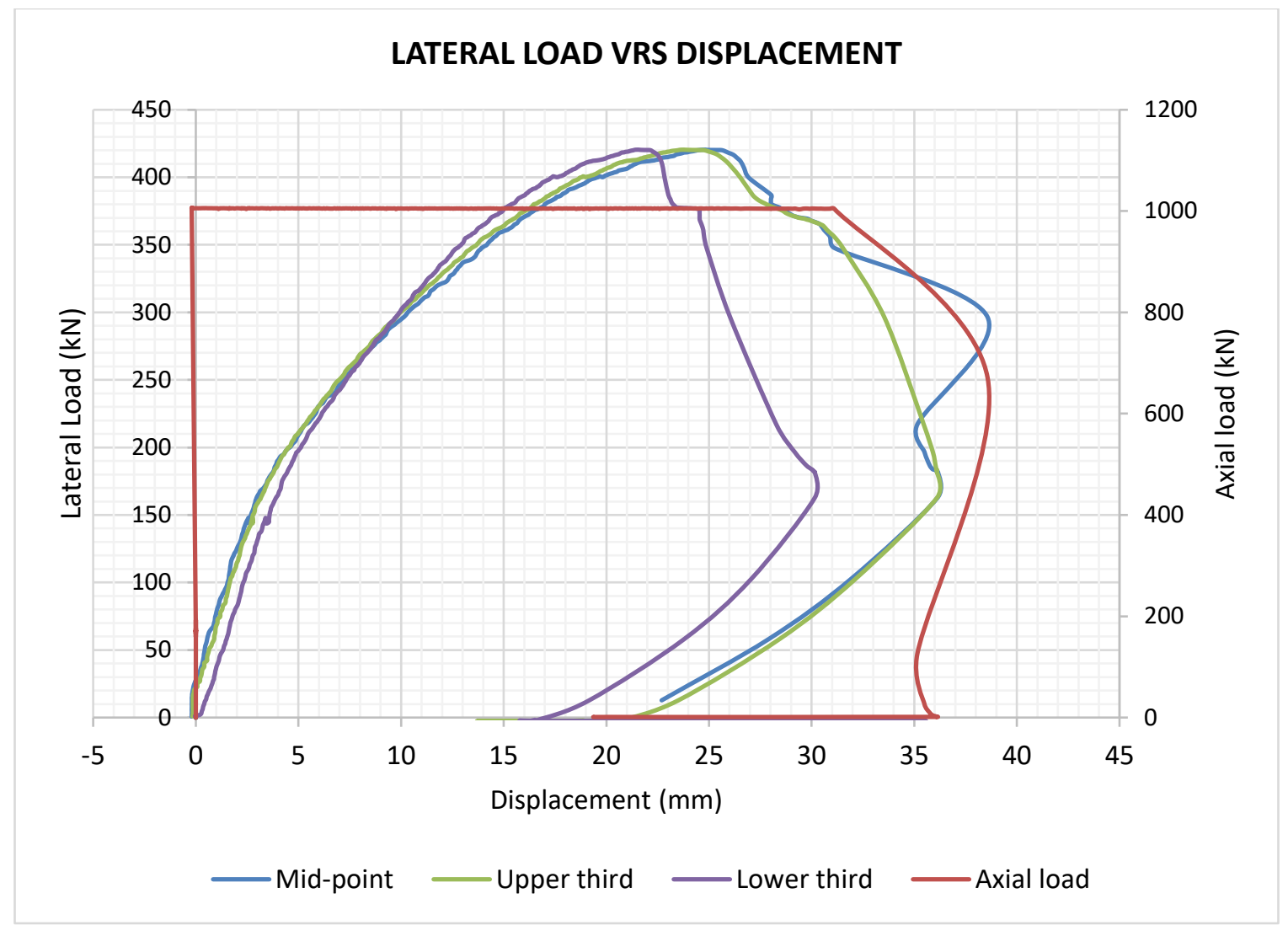

Figure 4-4: Lateral load-displacement graphs showing all three string pots.

Figure 4-5 shows the longitudinal reinforcement strains under the second stage of loading. Under the lateral load, different strain values were recorded at the various strain gauge locations. The highest compressive strain of about $2000 \times 10^{-6} \mathrm{~mm} / \mathrm{mm}$ was recorded at mid-height (Mid-frontright) of the column while the maximum tensile strain of about $3300 \times 10^{-6} \mathrm{~mm} / \mathrm{mm}$ was recorded at Mid-back-left. The strain gauges at the Mid-back-right and Bottom-front-left recorded lower strain values. The compressive strain at the bottom-front of the column confirm the lack of fixity of the bottom of the column into the footing. The rotation of the footing essentially meant the bottom support behaved as a pin support at the column-footing joint, hence the compressive strains in the bottom-front where tensile stresses were expected. 


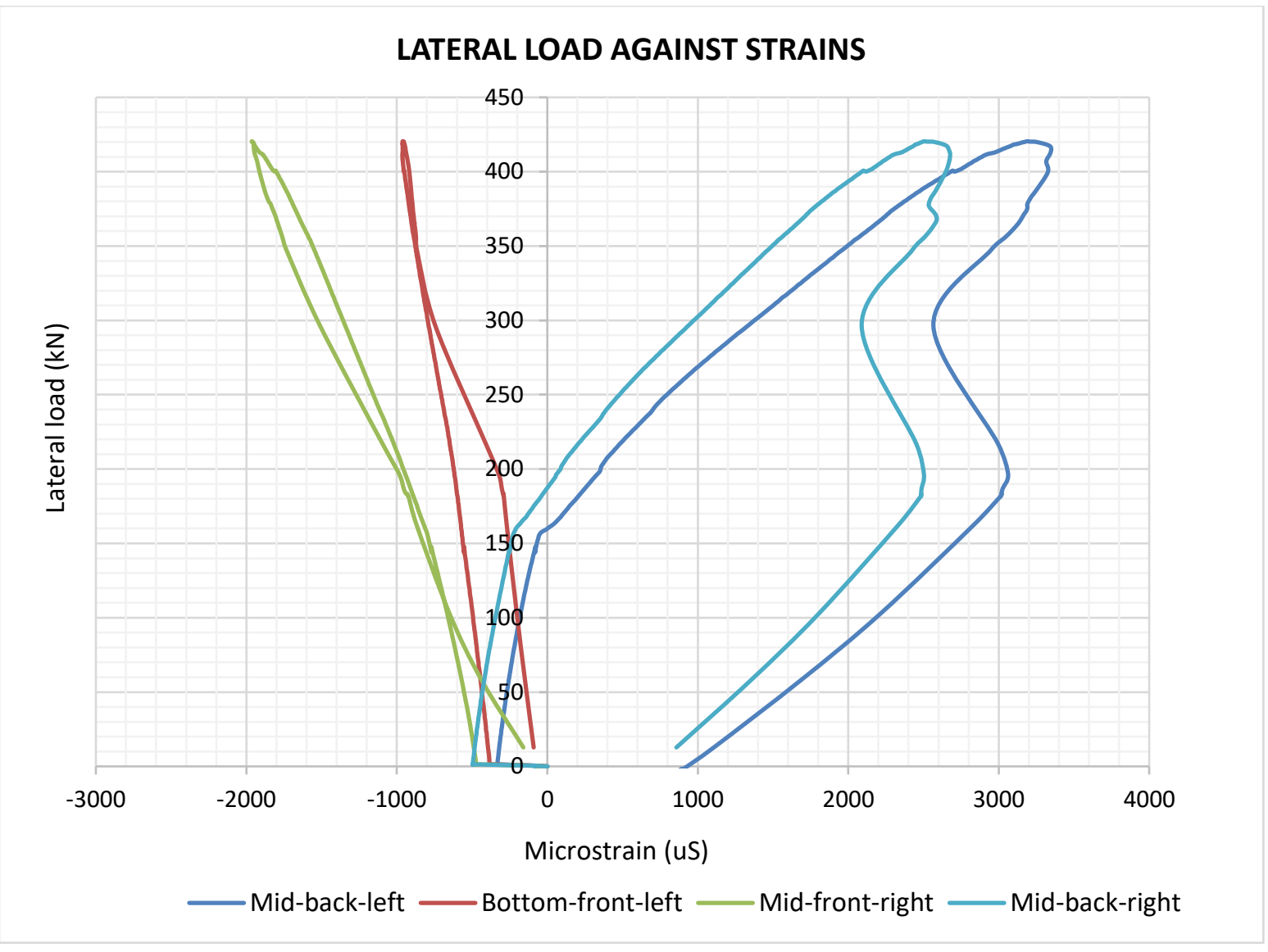

Figure 4-5: Strain gauge readings during the application of the lateral load.

According to Siba (2014), the yield strength of the longitudinal reinforcement was $474.4 \mathrm{MPa}$ and the yield strain was $2400 \times 10^{-6} \mathrm{~mm} / \mathrm{mm}$. From Figure $4-5$, the maximum tensile strains achieved was approximately $3300 \times 10^{-6} \mathrm{~mm} / \mathrm{mm}$. Thus, the mid-back (right and left) strain gauges indicate reinforcement yielding in tension.

The lateral load was applied to the front of the column, which was facing the centre of explosion in the field-testing. The first flexural crack appeared on the back (tensile) side, between the two lateral load points, at a lateral load of about $140 \mathrm{kN}$ and mid-height displacement of $4 \mathrm{~mm}$. As 
the loading increased, more flexural cracks developed on the back face and propagated to the side faces (Figure 4-6b). Shear cracks at about $30^{\circ}$ inclination developed near the upper support. The cracks extended from the compression side and propagated towards the tension side of the column.

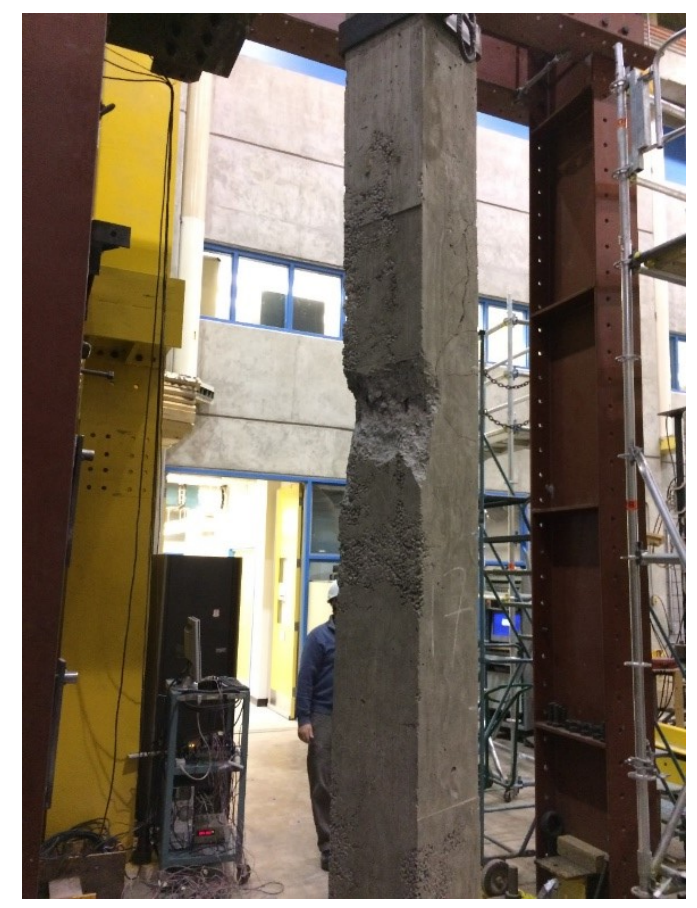

(a)

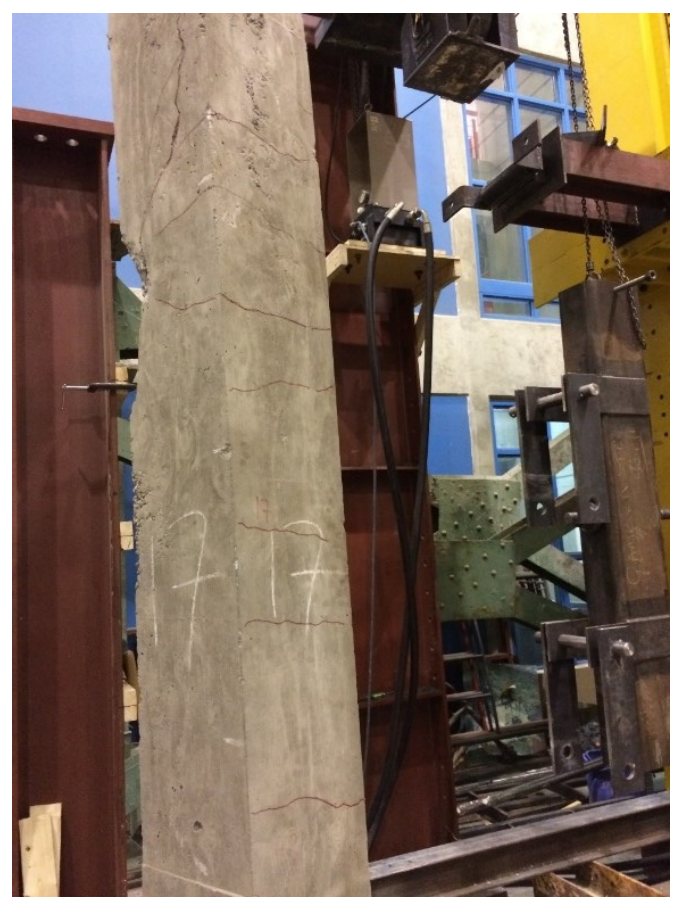

(b)

Figure 4-6: Photograph of CONV-17 (a) Front face with compression spall (b) Several flexural cracks on the back (tension) side.

At a lateral load of $300 \mathrm{kN}$, compression failure of the column occurred at the upper load point and a chunk of concrete spalled off on the compression side of the column. The concrete compression failure occurred after the peak lateral load was reached. The size of the concrete spall was about $400 \mathrm{~mm}$ in height and $50 \mathrm{~mm}$ deep (Figure 4-6a) and exposed the longitudinal reinforcement at that location. 


\subsection{Column Test 2 (CONV-07)}

CONV-07 was previously exposed to blast load at a scaled distance of $0.58 \mathrm{~kg} / \mathrm{m}^{1 / 3}$ in the field testing phase of the overall research program. In the residual capacity test, the bottom fixed restraint was torqued to eliminate the support rotation observed in the testing of CONV-17. Digital dial gauges were installed to monitor any rotation of the $\mathrm{W} 150 \times 39$ beams used to restrain the concrete footing against rotation. The maximum vertical displacement recorded by the dial gauges was less than $0.2 \mathrm{~mm}$ and was thus no rotation of the footing was noticed. There was a maximum permanent displacement of about $64 \mathrm{~mm}$ at the top of the column. Flexural cracks were visible on the back and side faces in the region between the load points. No concrete spalling was observed in the close-in blast test. CONV-07 was loaded in axial compression up to a load of $1000 \mathrm{kN}$ to induce the service level ALR of 0.32 . The columns resisted the imposed loading without distress or failure. Figure 4-7 presents the longitudinal reinforcement strain versus axial load behaviour of the column. The strains are lower at the top of the column. At the mid-height, the maximum strains were about $720 \times 10^{-6} \mathrm{~mm} / \mathrm{mm}$ in the front and $1050 \times 10^{-6}$ $\mathrm{mm} / \mathrm{mm}$ at the back. The difference in the strain indicates column displacement towards the front of the column under axial load of $1000 \mathrm{kN}$. These strains are higher than the calculated strain from Equation 4-1. This could be due to the damage level and orientation of the column. 


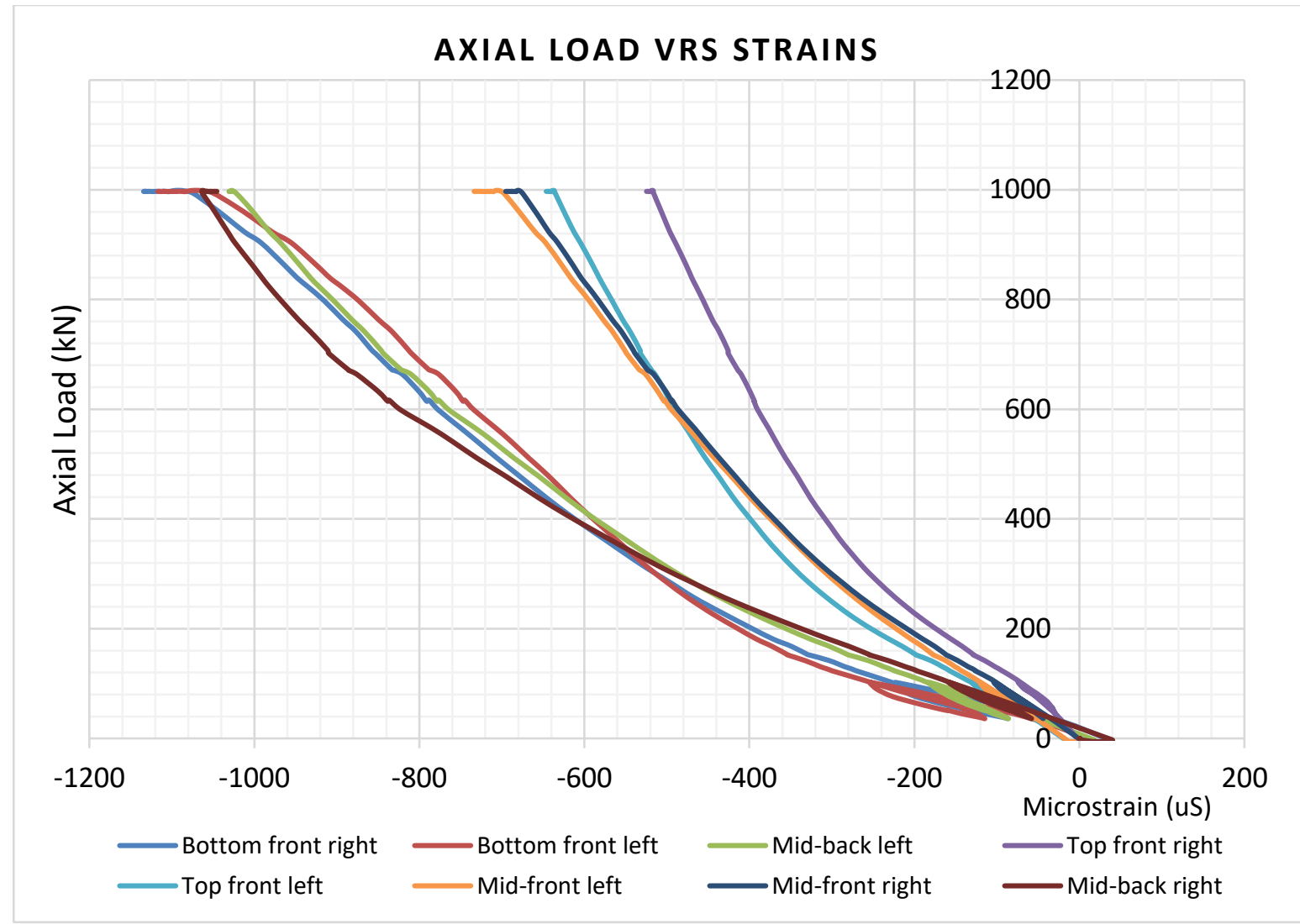

Figure 4-7: Compression strains during first stage of loading column CONV-07.

Figure 4-8 presents the lateral load versus displacement response of the CONV-07 under the second phase loading regime. During the axial load regime, the lateral load actuator was in contact with the column thus as the column was displacing towards the front face of the column, it was restrained by the actuator which recorded a load of about $20 \mathrm{kN}$. After this, the column exhibits a high initial stiffness. The response of the column was generally linear after a lateral load of about $50 \mathrm{kN}$ up to the peak lateral load of about $445 \mathrm{kN}$. The column had an average stiffness of about $15 \mathrm{kN} / \mathrm{mm}$. The corresponding mid-height displacement at the maximum lateral load was about $28.5 \mathrm{~mm}$.

CONV-07 exhibited the highest post blast permanent displacement towards the front face of the column. Thus, under the axial load phase, the lateral load was applied against the bow of the 
column under axial load. The initial column bow was overcome at an axial load level of about 78 $\mathrm{kN}$. This increased the lateral load capacity of the column significantly.

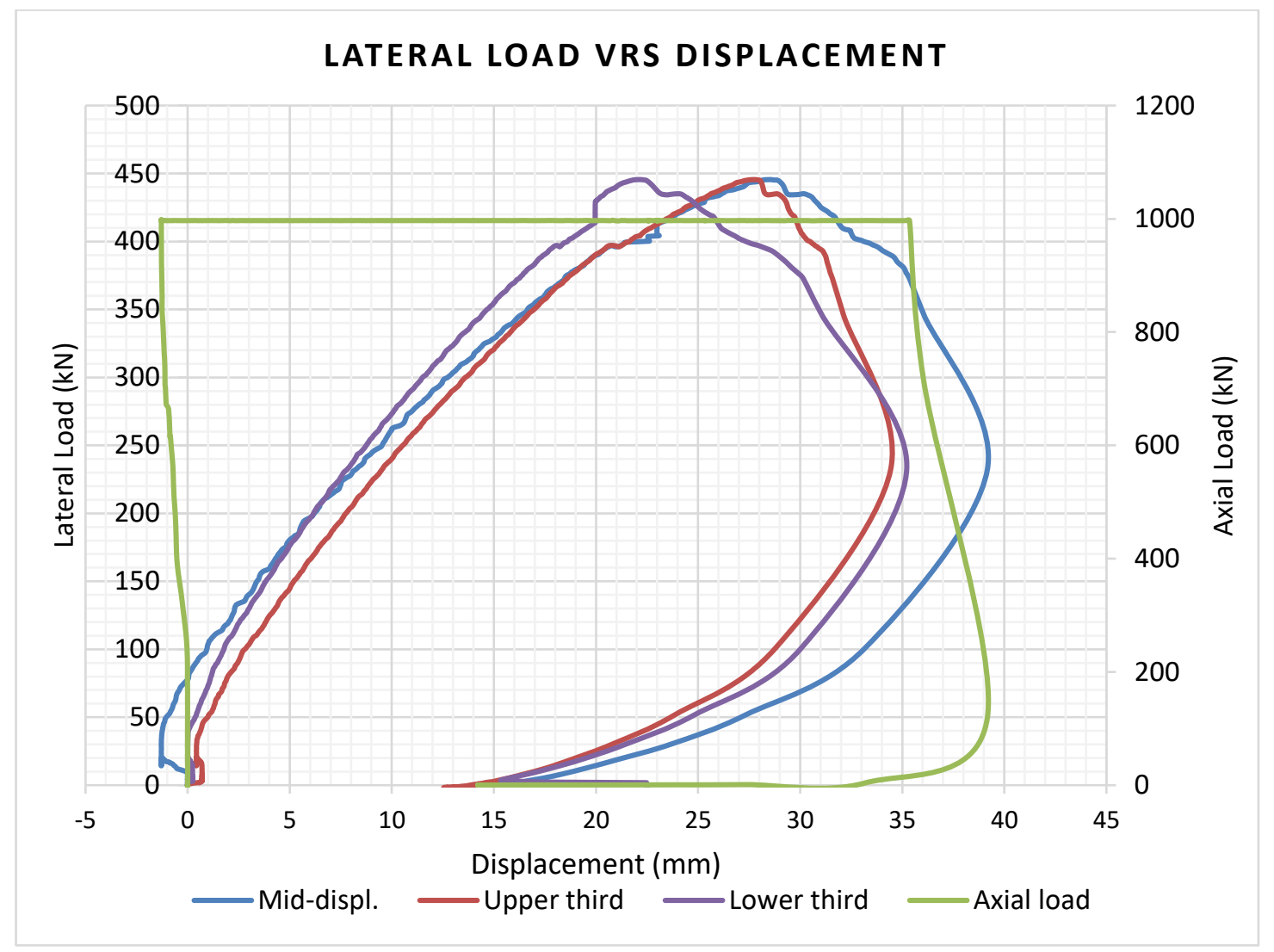

Figure 4-8: Lateral load against displacements for CONV-07.

Figure 4-9 presents the longitudinal reinforcement strain versus lateral load response of the reinforced concrete column. The maximum tensile reinforcement strain was $2100 \times 10^{-6} \mathrm{~mm} / \mathrm{mm}$ recorded in the longitudinal reinforcements close to the back of the column and at mid-height. The corresponding maximum compressive strain of $2800 \times 10^{-6} \mathrm{~mm} / \mathrm{mm}$ was recorded in the longitudinal reinforcements towards the front of the column at mid-height. This high strain confirms the spalling of concrete in the mid-region of the column. 


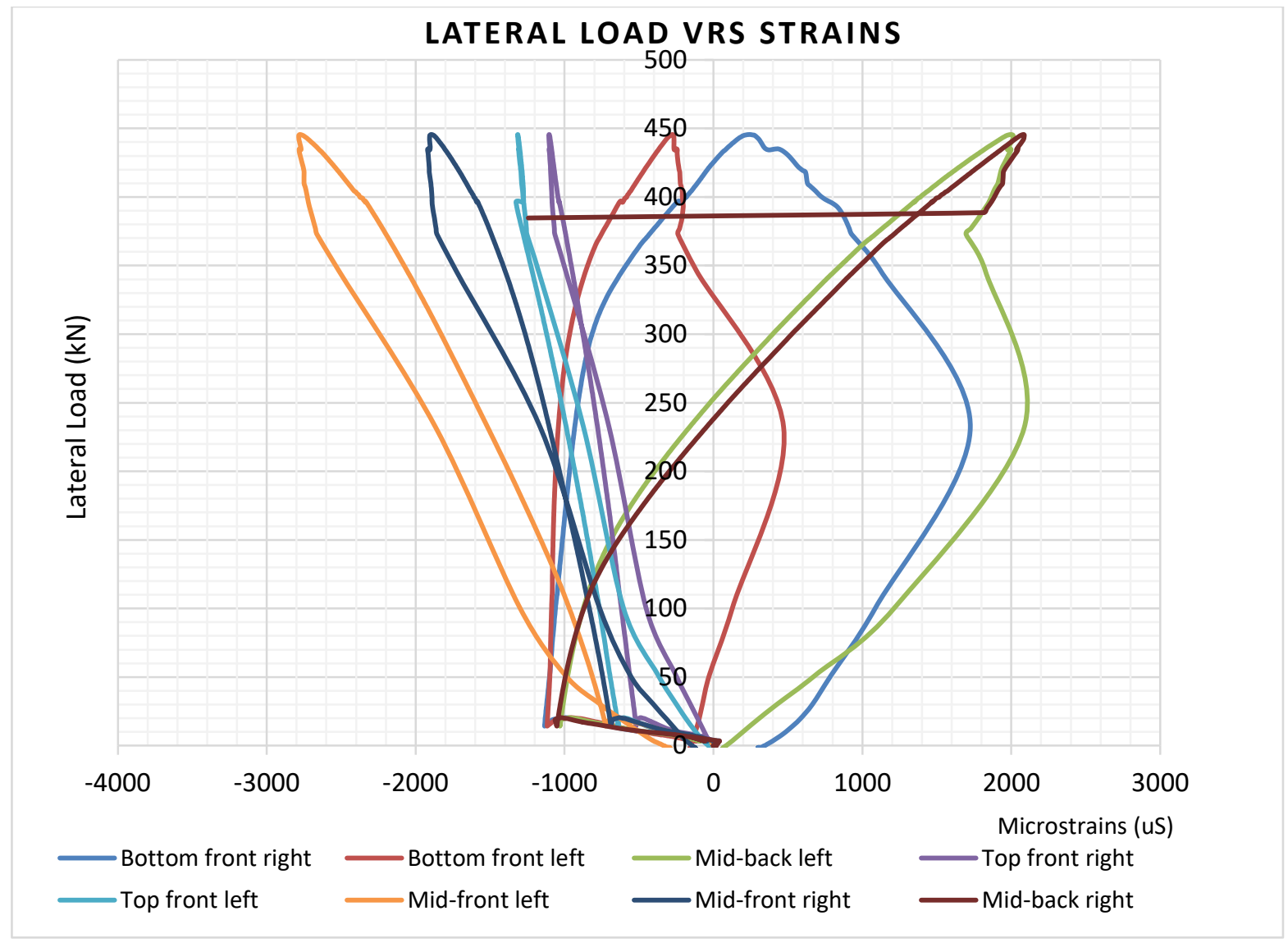

Figure 4-9: Strains in the longitudinal reinforcement during entire testing of CONV-07.

Severe shear cracks with an inclination of about $33^{\circ}$ developed near the bottom fixed support of the column (Figure 4-10). Flexural cracks developed on the tension side of the column in between the load points. As the lateral displacement increased, a piece of concrete spalled off the column in the compression zone on the front side of the column. The piece of concrete spall was $250 \times 30 \mathrm{~mm}$ deep (Figure 4-11) 


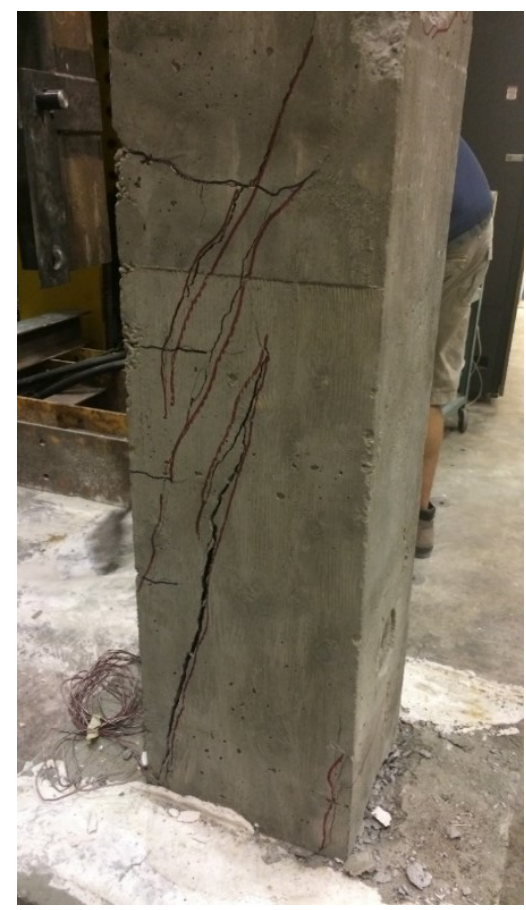

(a)

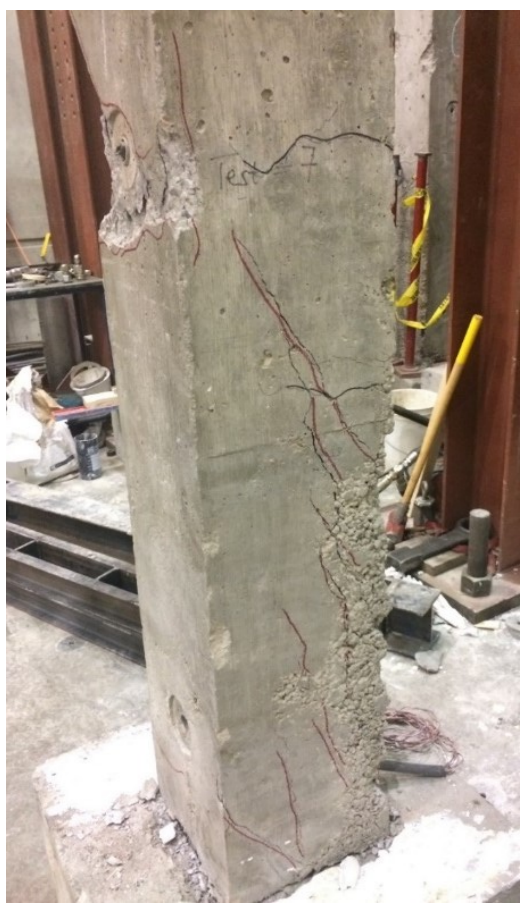

(b)

Figure 4-10: (a) Shear cracks developed near the base of column CONV-07 (b) Flexural and shear cracks visible on the side of $\mathrm{CONV-07}$

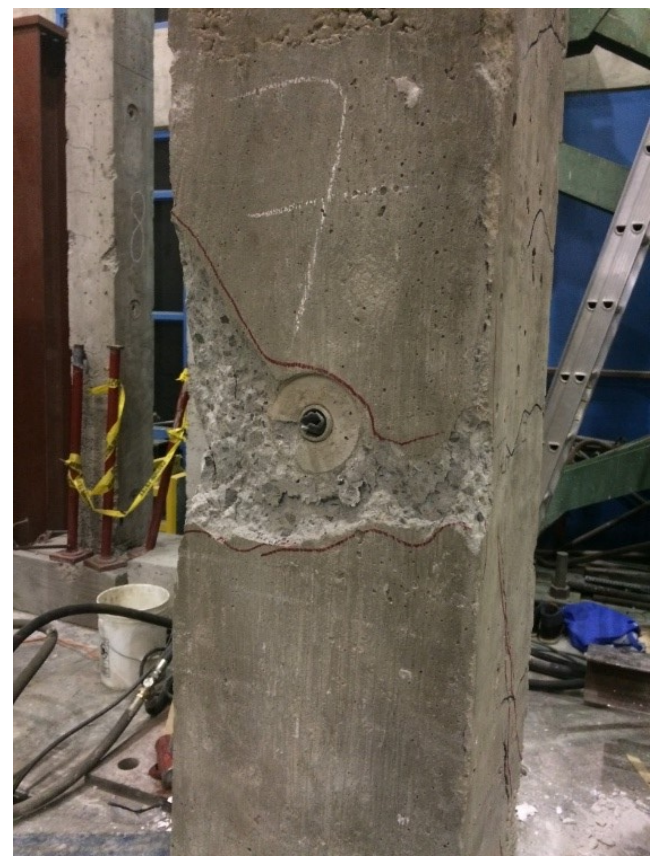

Figure 4-11: Concrete spall around mid-height of column CONV-07. 


\subsection{Column Test 3 (SEIS-09)}

SEIS-09 was exposed to ANFO explosion loading at a scaled distance of $0.52 \mathrm{~m} / \mathrm{kg}^{1 / 3}$. The blast load effect resulted in severe damage on the tension side of the column at mid-height. The concrete cover at the mid-height spalled off, exposing the longitudinal and transverse reinforcement prior to the residual capacity testing (Figure 4-15b). The maximum permanent mid-height displacement prior to residual capacity testing was $25 \mathrm{~mm}$. Consequently, the second order effect induced a moment of $25 \mathrm{kNm}$ in the column under the axial load of $1000 \mathrm{kN}$.

Figure 4-12 presents the longitudinal reinforcement strain versus axial load response of the SEIS-09 column during the axial load regime. All strain gauges recorded compressive strains in the longitudinal reinforcement. The maximum compressive strain was recorded in the mid-front gauges due to the bow in the column prior to testing. Besides the strain in the Mid-front-left being $1500 \times 10^{-6} \mathrm{~mm} / \mathrm{mm}$, the average of the other strains was about $800 \times 10^{-6} \mathrm{~mm} / \mathrm{mm}$. 


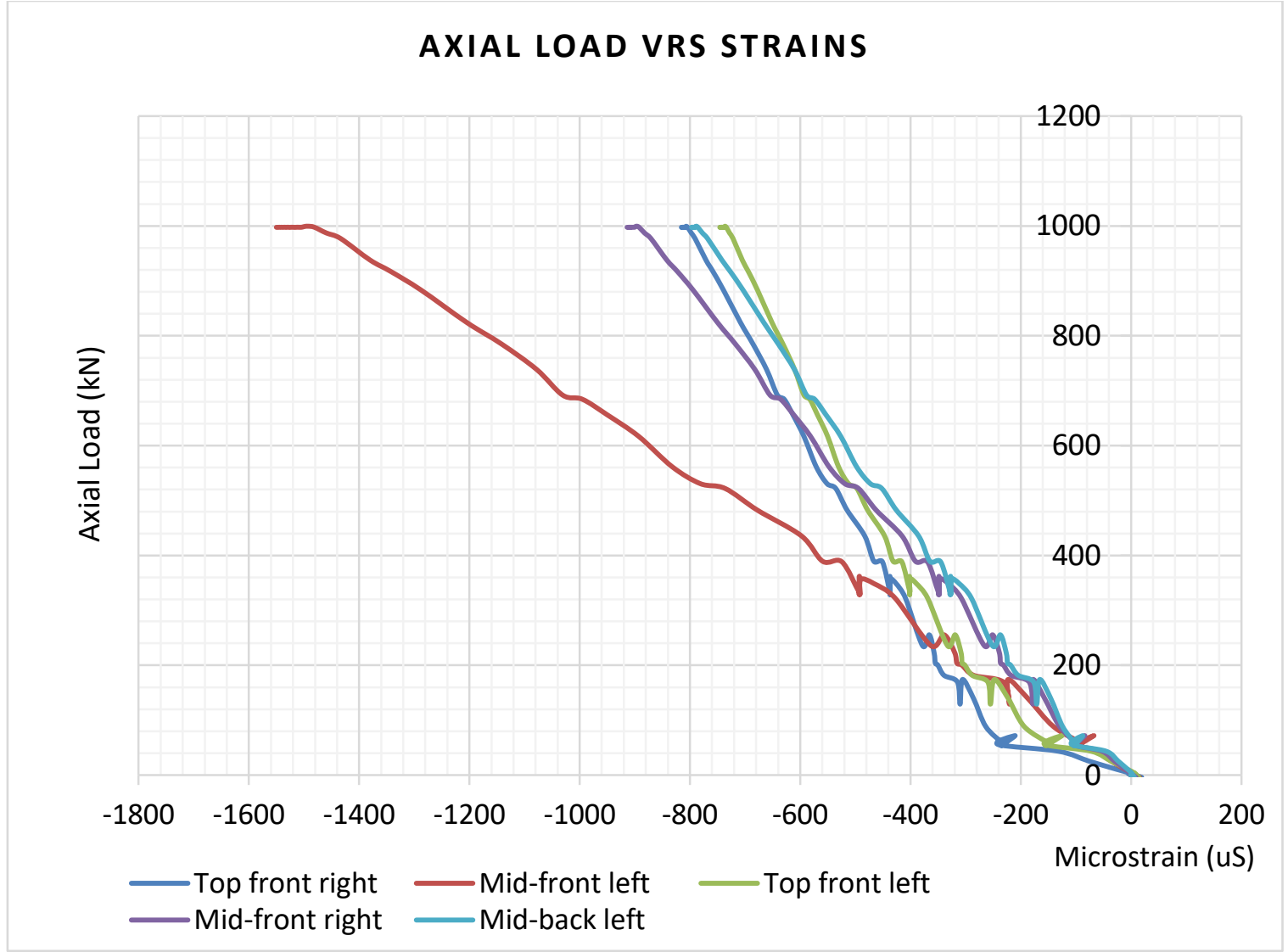

Figure 4-12: Recorded strains after axial service load was applied to SEIS-09.

SEIS-09 was able to sustain the service load, and thus was loaded laterally in a displacement control mode at a rate of $1.5 \mathrm{~mm}$ per minute until failure. In Figure 4-13, SEIS-09 shows a high initial stiffness. This phenomenon is due to the force required to overcome the displacement toward the front face during the first stage of loading. Also, as the lateral actuator was atached to the column under axial loading, it registered a load of about $50 \mathrm{kN}$ restraining the column. After the displacemnt during the axial loading was overcome, the column became less stiff. Overall, SEIS-09 showed a lateral stiffness of about $13.5 \mathrm{kN} / \mathrm{mm}$. SEIS-09 sustained a maximum lateral of $293 \mathrm{kN}$ with a corresponding mid-height displacement of $14.8 \mathrm{~mm}$. 


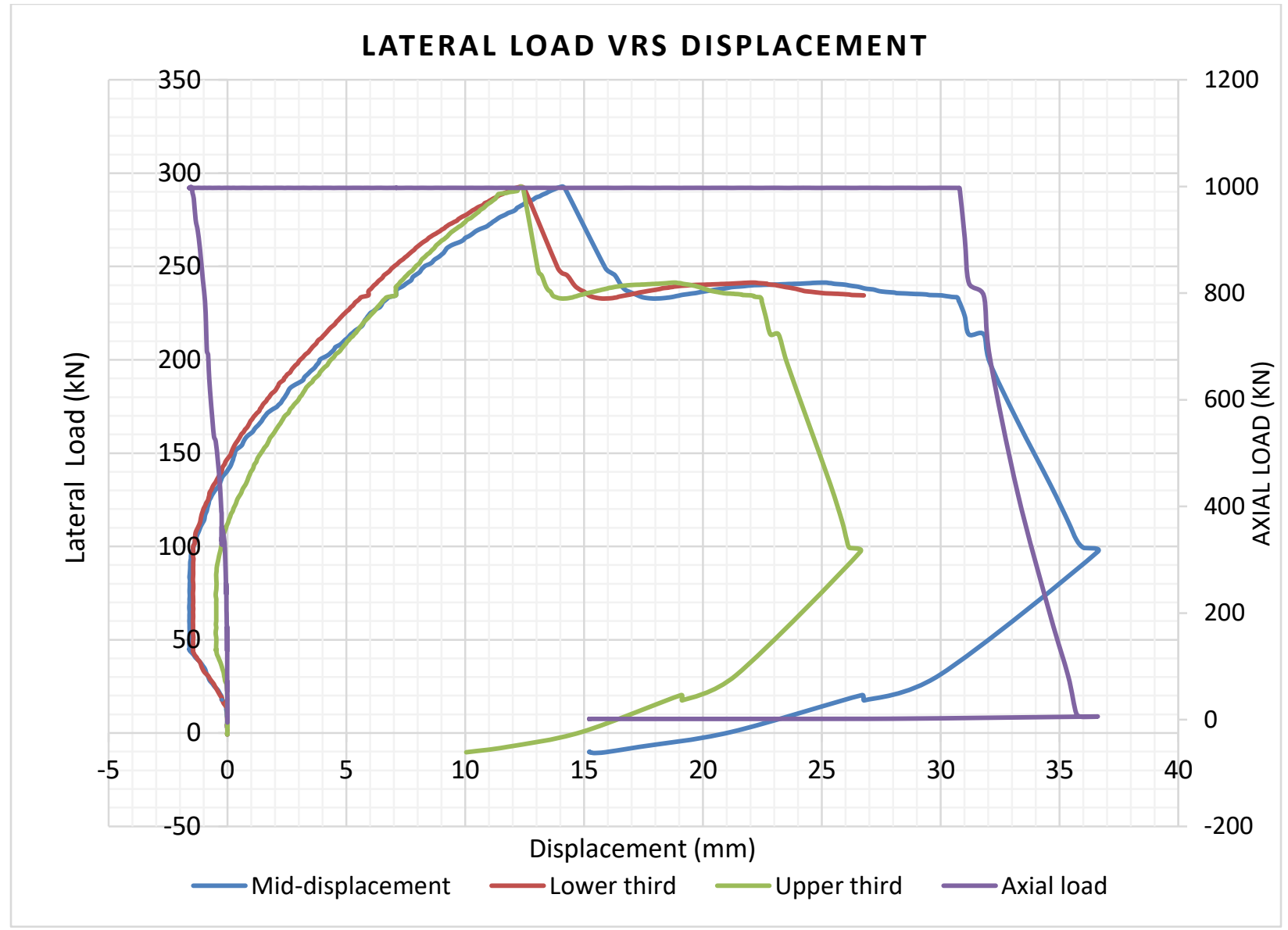

Figure 4-13: Lateral load against displacement for SEIS-9, showing constant service load.

Figure 4-14 presents the lateral load versus longitudinal reinforcement strain for SEIS-09. The compression Mid-front strains reached a maximum of about $2500 \times 10^{-6} \mathrm{~mm} / \mathrm{mm}$ while the tension Mid-back was about $1800 \times 10^{-6} \mathrm{~mm} / \mathrm{mm}$. 


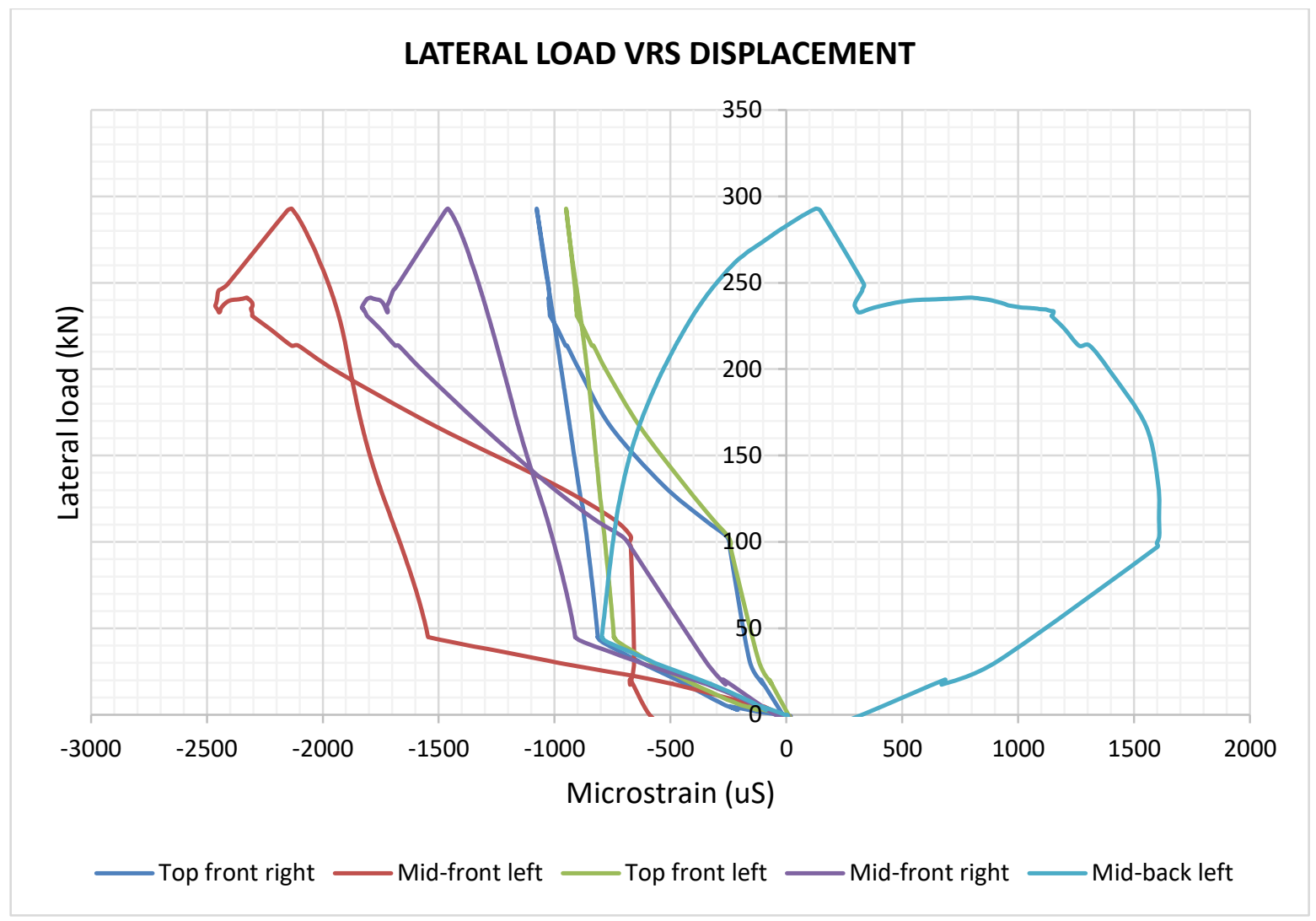

Figure 4-14: Strains recorded during entire testing of SEIS-9.

The was no sign of shear crakcs during the test. Existing flexural cracks opened up; extending from the tension mid-back region to the compression side across the sides. Figure 4-15a shows a $400 \times 40 \mathrm{~mm}$ deep spall on the compression side of the column at the mid-height region. The high strains recorded in the mid-front location is confirmed by the spalling of concrete seen at that location. Effectively, SEIS-09 failed due to compression flexure. 


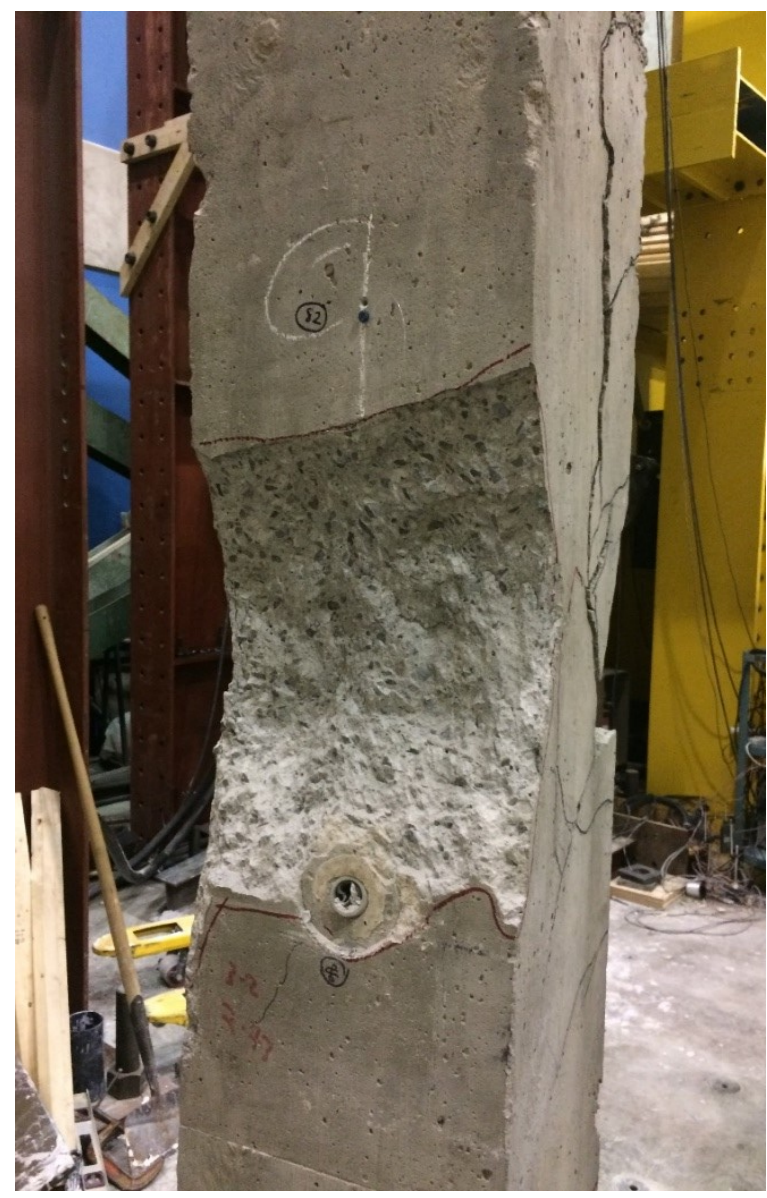

(a)

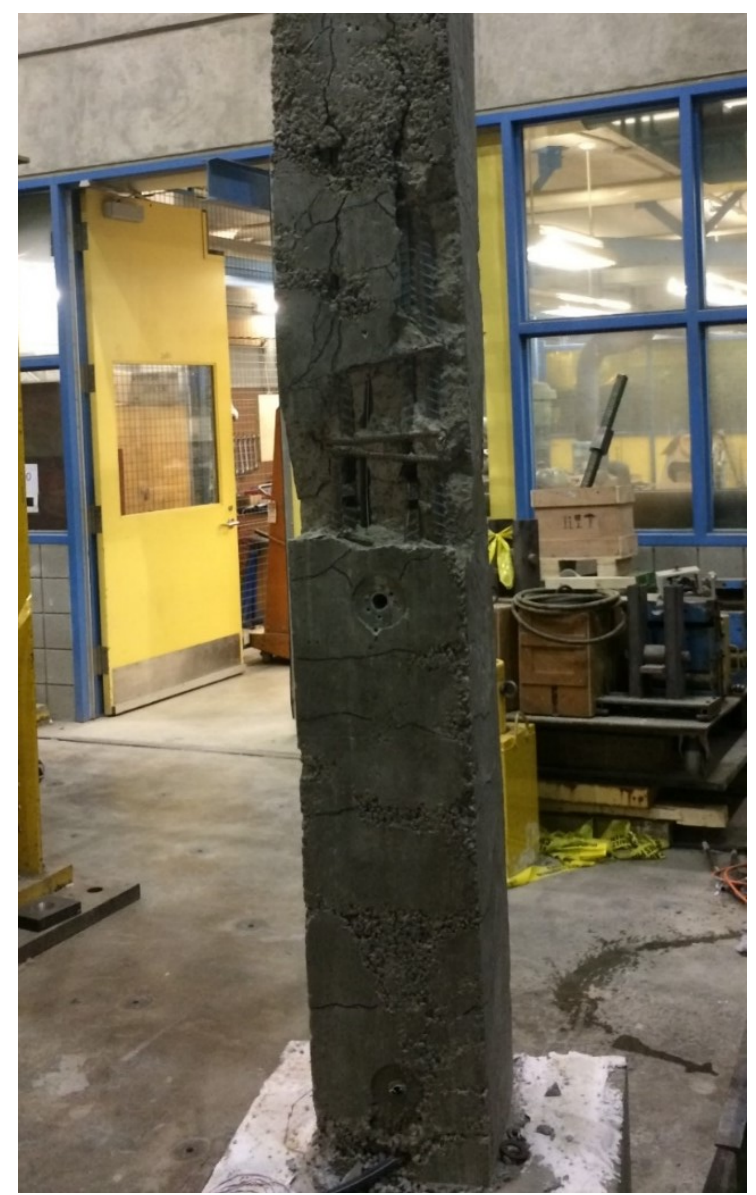

(b)

Figure 4-15: Photographs of SEIS-09 showing (a) A chunk of concrete spall on the compression (front) side of SEIS-09 post-test (b) Tension (back) side of SEIS-09 showing the spall before testing and light cracks after test.

\subsection{Column Test 4 (CONV-06)}

CONV-06 was previously tested in the near-field explosion testing at a scaled distance of 0.53 $\mathrm{m} / \mathrm{kg}^{1 / 3}$. Prior to the residual capacity testing, a significant shear crack was observed over the bottom $800 \mathrm{~mm}$ height as shown in Figure 4-16. A maximum permanent displacement of $33 \mathrm{~mm}$ was recorded on CONV-06 after the close-in blast test. 


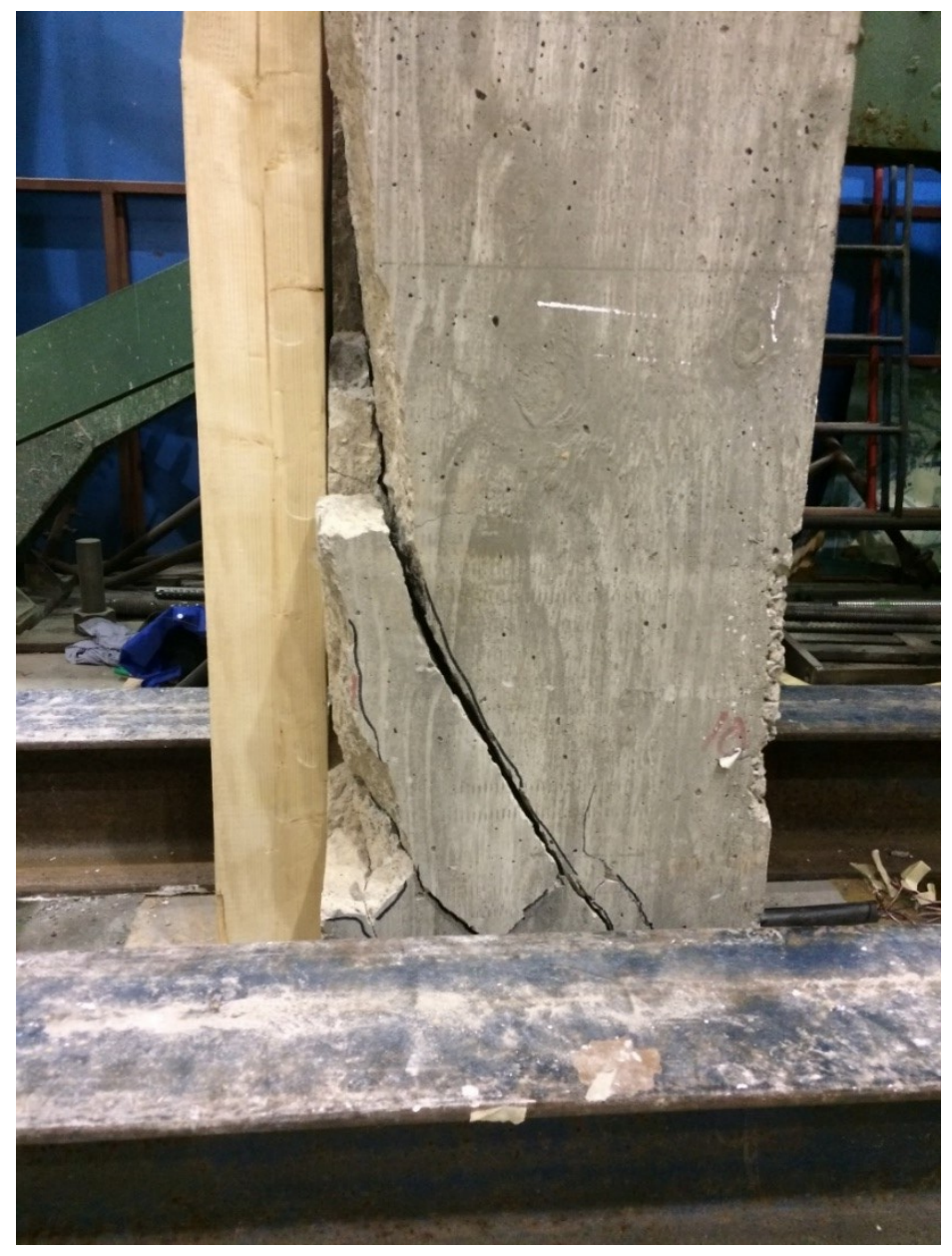

Figure 4-16: Shear crack existing in CONV-6 prior to residual capacity test.

The full service load was applied without failure. Figure 4-17 presents the axial load versus longitudinal reinforcement strain CONV-06 during the axial load regime. Only three strain gauges on the column survived the field explosion testing. The strain gauge at the top recorded a compressive strain of $1000 \times 10^{-6} \mathrm{~mm} / \mathrm{mm}$ under the service load level of $1000 \mathrm{kN}$. Overall, the strain gauges did not record reasonable data and are not discussed for this column. 


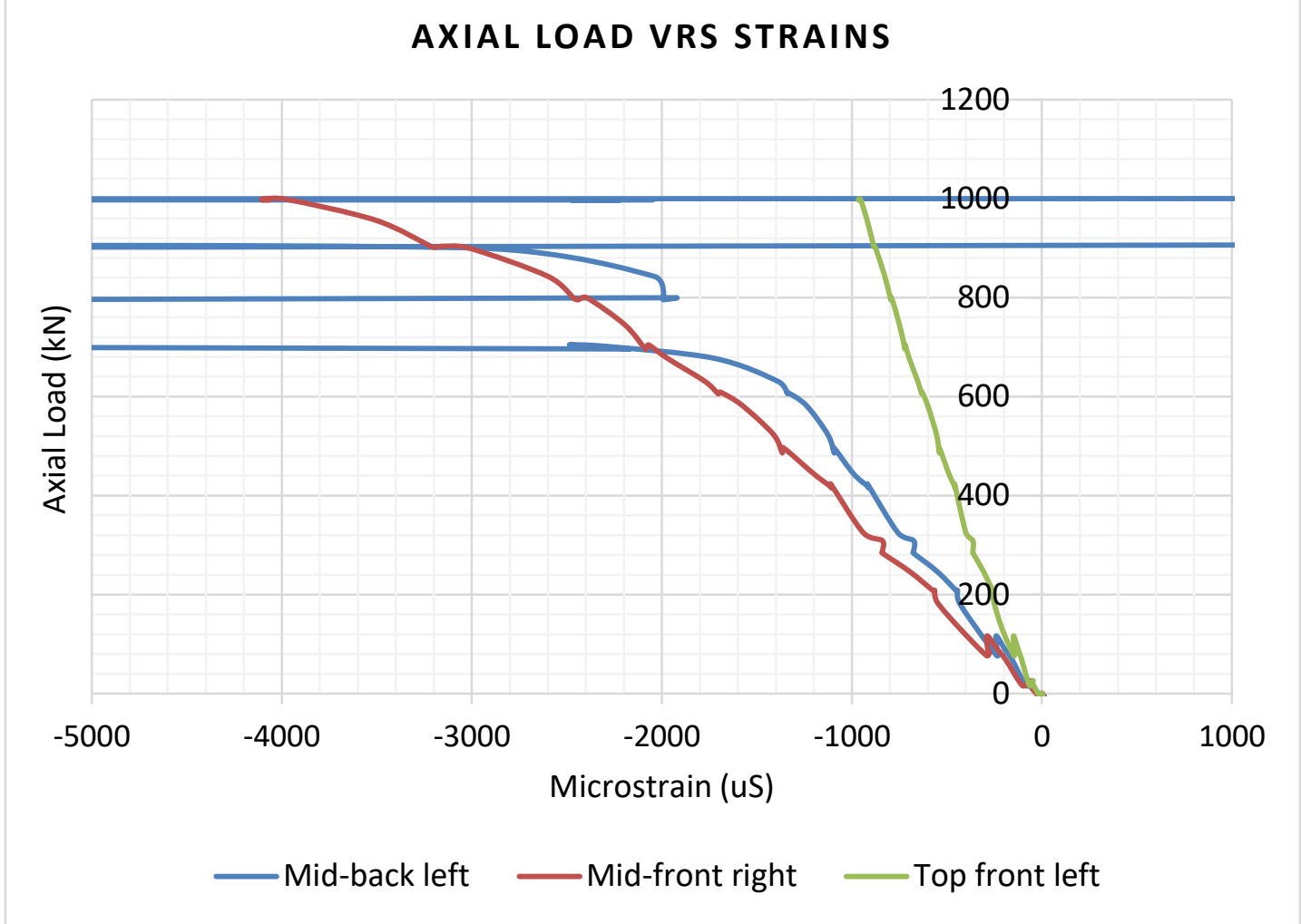

Figure 4-17: Strains in longitudinal reinforcement during axial load application stage in CONV-06.

During the application of the axial load, the column was displaced towards the front face. After the service load was sustained, the lateral load was applied in displacement control. Figure 4-18 presents the lateral load versus displacement response of CONV-06 in the second load regime. During the axial load regime, the lateral actuator restrained the column from free lateral displacement. Thus, the lateral actuator measured the load corresponding to the lateral restraint as $40 \mathrm{kN}$. The column exhibited a high stiffness at the beginning of lateral loading. After a lateral load of about $60 \mathrm{kN}$, the load versus displacement response was linear with an average lateral stiffness of about $10 \mathrm{kN} / \mathrm{mm}$ until failure. The maximum sustained lateral load was $154 \mathrm{kN}$. The corresponding lateral load displacement at failure was $7 \mathrm{~mm}$. The early failure of CONV-06 in 
comparison to other columns was due to the severe shear damage due to the smaller scaled distance at which it was tested in the explosive testing.

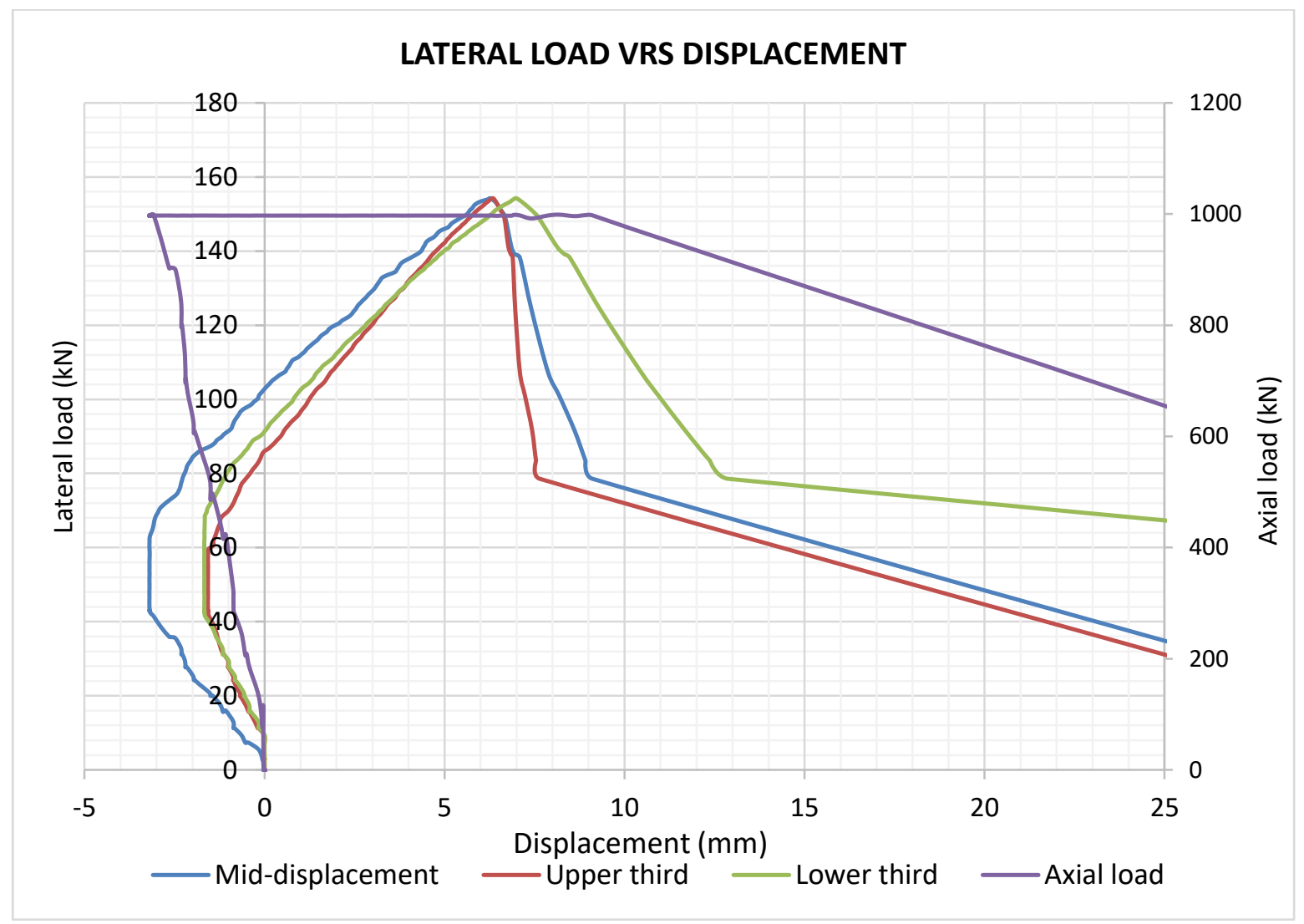

Figure 4-18: Lateral load versus displacement for CONV-6.

Figure 4-19 shows the nature of the failure in CONV-06 after residual capacity testing. Limited flexural cracking with crack widths of about $1 \mathrm{~mm}$ was observed on the tension side (back) of the column. No concrete spalling occurred in the compression zone during this test. The shear stress coupled with flexural tension at the bottom-front location resulted in the catastrophic failure of the column in that region. 


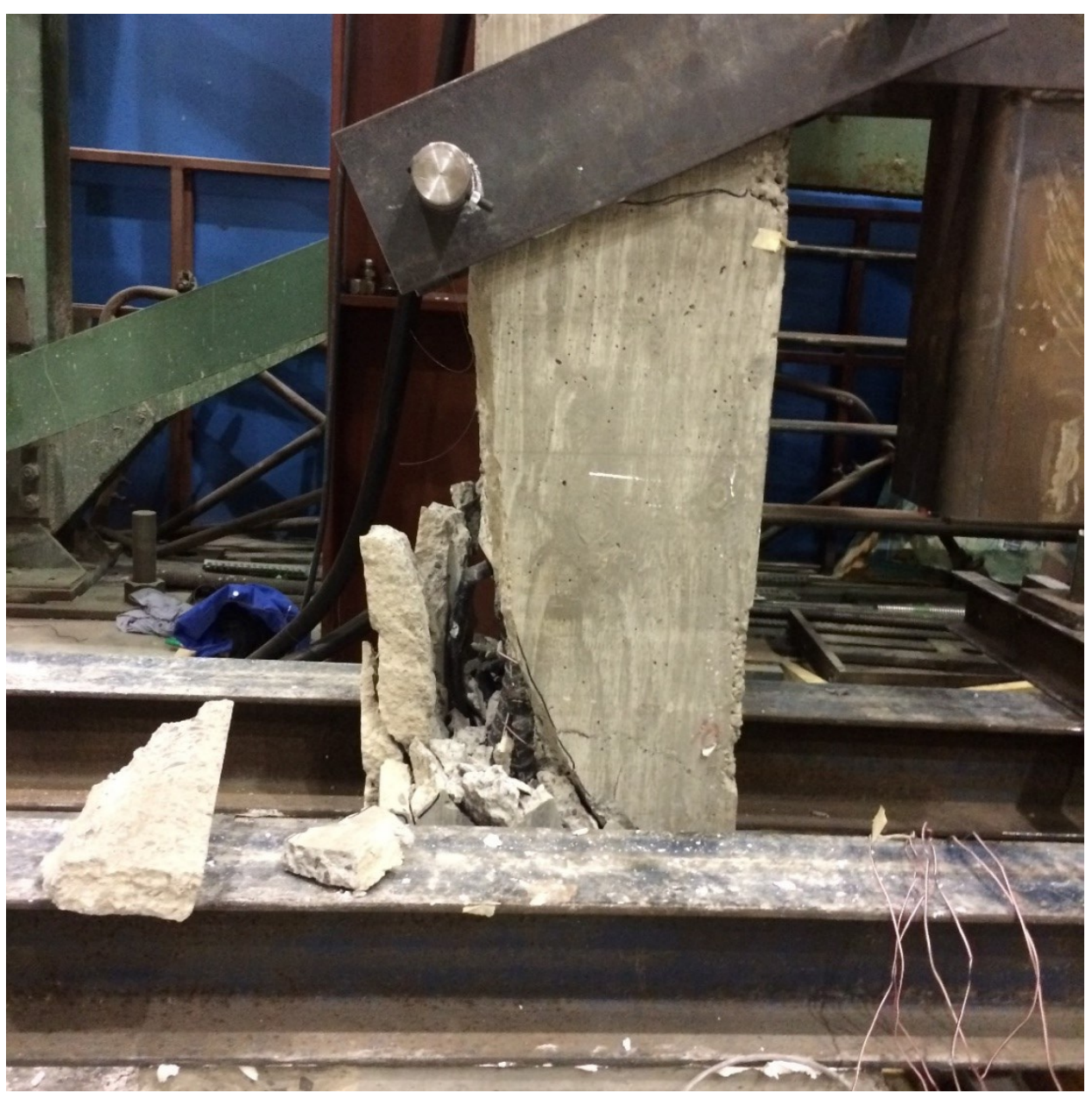

Figure 4-19: Post-test photograph of CONV-6 showing shear failure.

\subsection{Column Test 5 (SEIS-08)}

Although SEIS-08 was exposed to ANFO explosion at a scaled distance of $0.58 \mathrm{~m} / \mathrm{kg}^{1 / 3}$, it was fairly pristine with only a few visible flexural cracks on the back side. Figure 4-20 presents the axial load versus longitudinal reinforcement strain during the first loading regime. The column was capable of resisting the service load level ALR without distress. The strains across the midheight varied from $720 \times 10^{-6} \mathrm{~mm} / \mathrm{mm}$ at the front face to $145 \times 10^{-6} \mathrm{~mm} / \mathrm{mm}$ at the back face of the 
column. The strain distribution is indicative of column displacement towards the back face of the column.

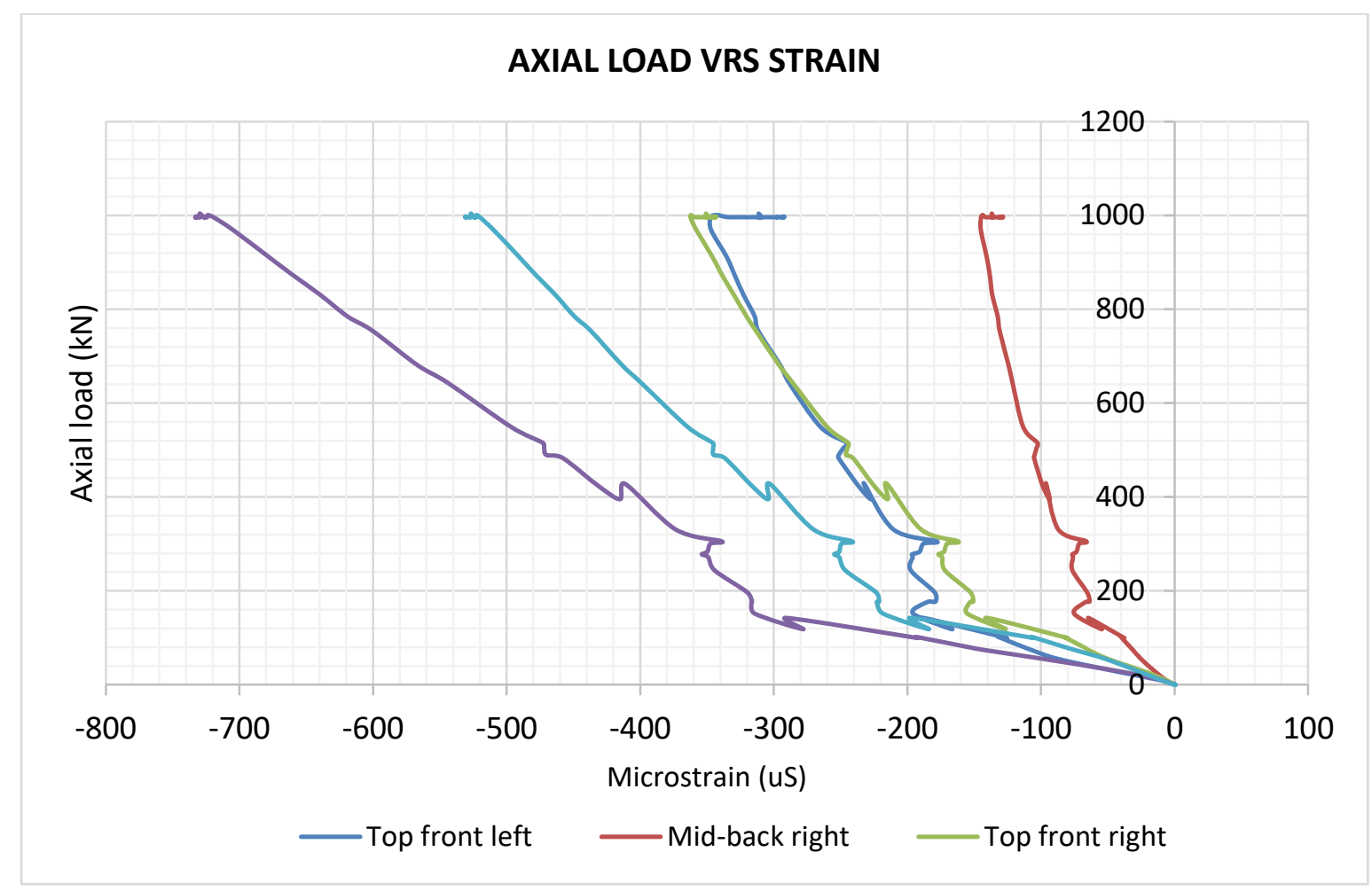

Figure 4-20: Strains recorded as column SEIS-08 was loaded axially.

Figure 4-21 presents the lateral load versus displacement response of SEIS-08 during the second loading regime. The lateral loading began from a displaced position of $-0.65 \mathrm{~mm}$. The loaddisplacement response is essentially linear, after about $50 \mathrm{kN}$. The second stage of loading shows a gradual loss of stiffness close to the peak load. It also indicates a smooth peak, which is characteristic of flexural failures as cracks were restrained by the longitudinal reinforcement. A maximum lateral load of $318.5 \mathrm{kN}$ was attained with a corresponding mid-height displacement of $15.4 \mathrm{~mm}$. 


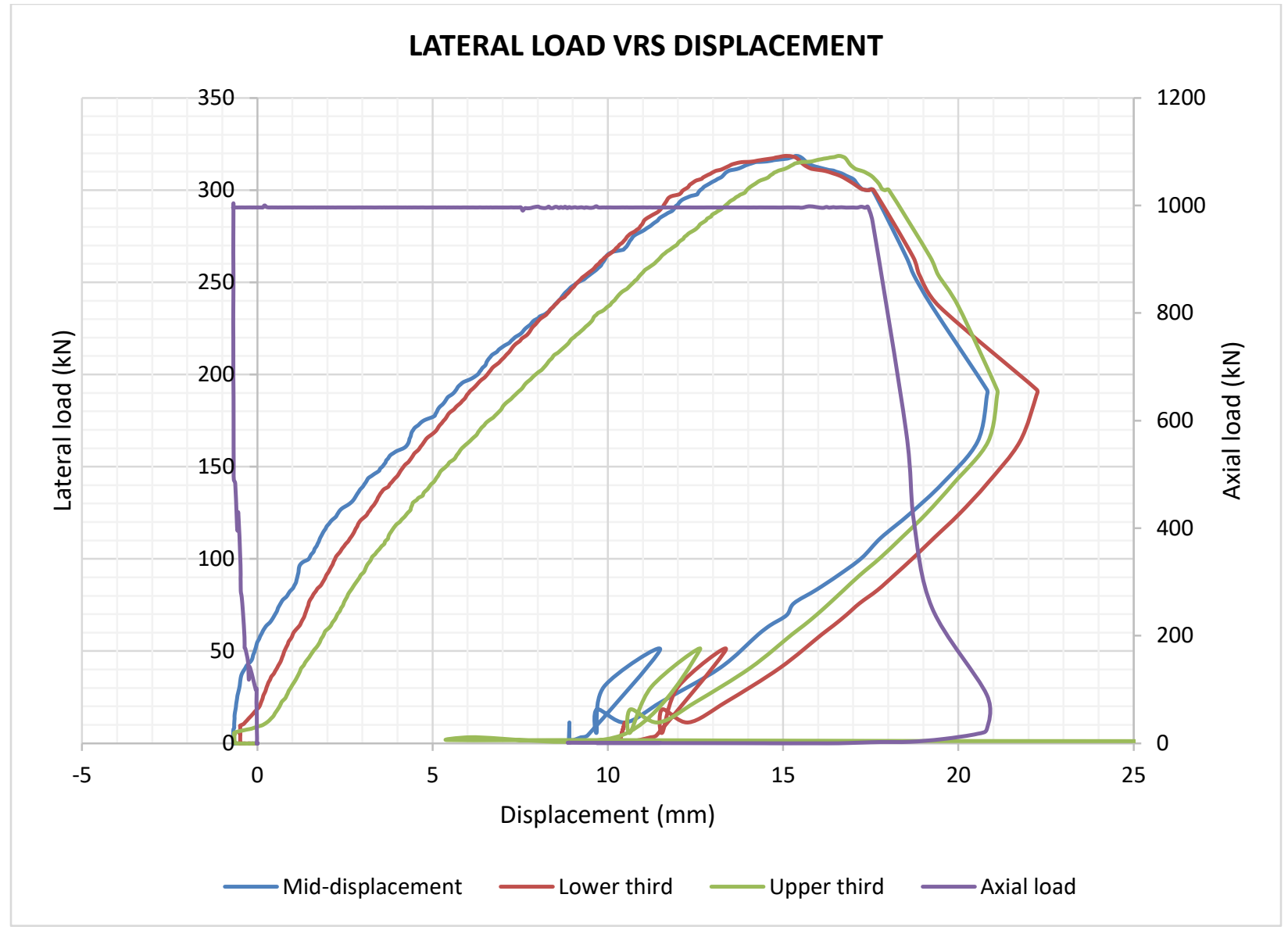

Figure 4-21: Lateral load versus displacement for SEIS-08, showing constant service load.

Figure 4-22 presents the lateral load versus longitudinal reinforcement strain in the second loading regime. The strain gauges in the mid-height section show a linear increase in strain up to failure. The strains in reinforcements towards the front side of the column recorded increased compressive strain while the strain gauge toward the back face of the column show a decrease in compressive strain with a final tensile strain value at the ultimate load. The strain recordings shown in Figure 4-22, indicates a maximum compressive strain of about $1200 \times 10^{-6} \mathrm{~mm} / \mathrm{mm}$. 


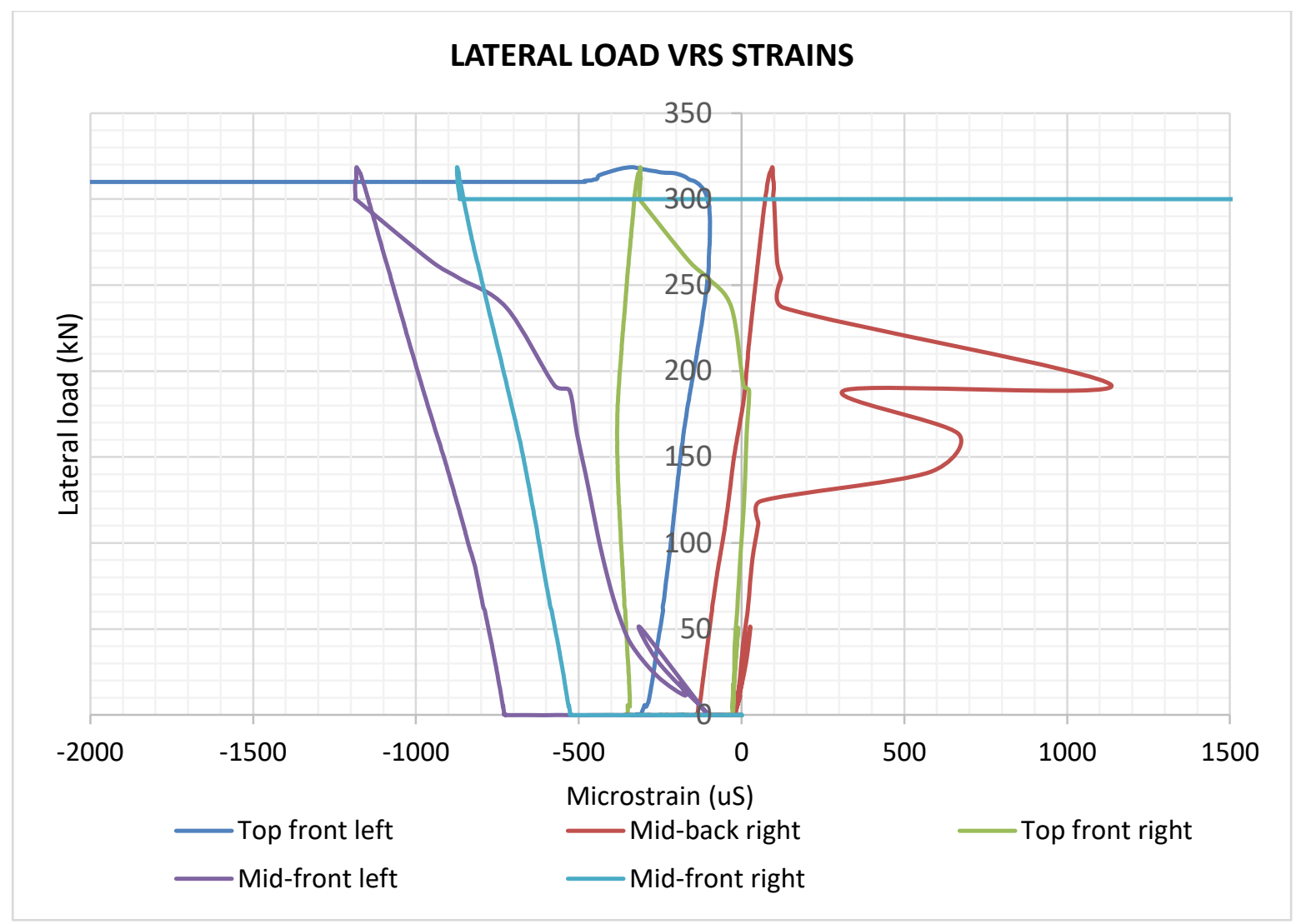

Figure 4-22: Strains during the second stage of loading SEIS-08.

Ultimately SEIS-08 failed by what looked like flexural cracks at the lower front side of the column as shown in Figure 4-23a. There were minor flexural cracks on the mid-back region (Figure 4-23b). 


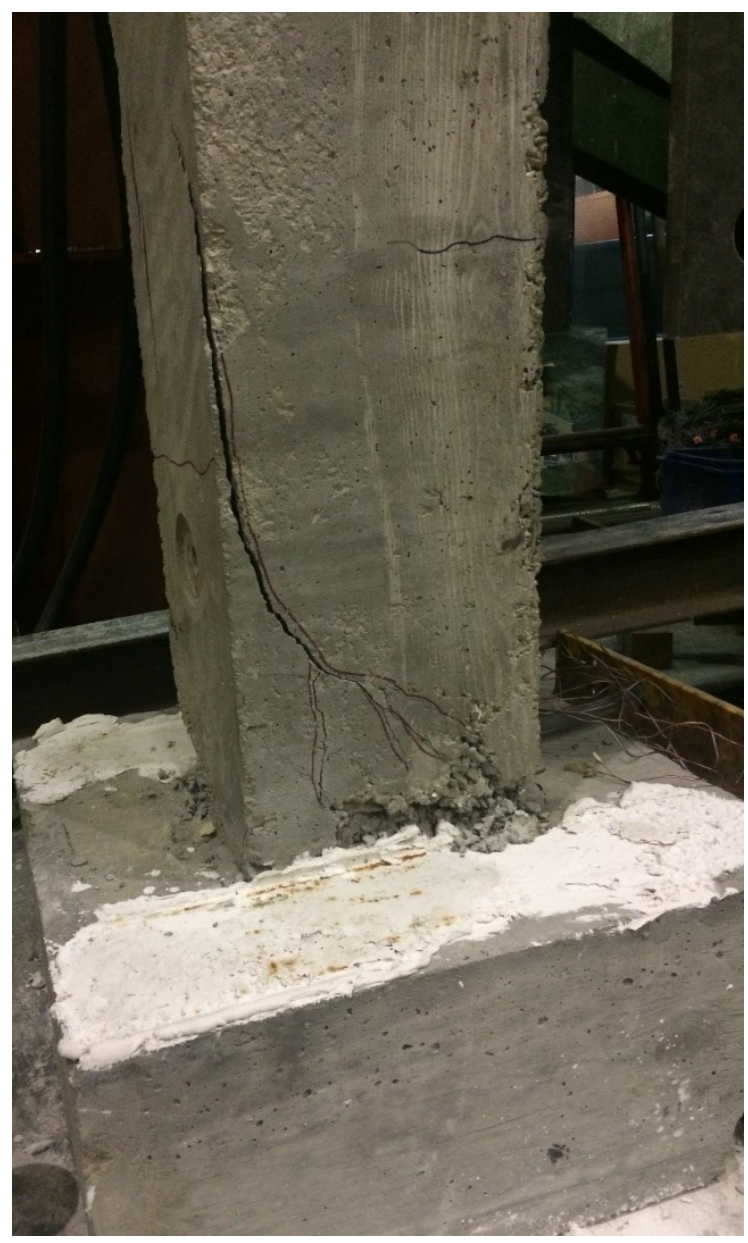

(a)

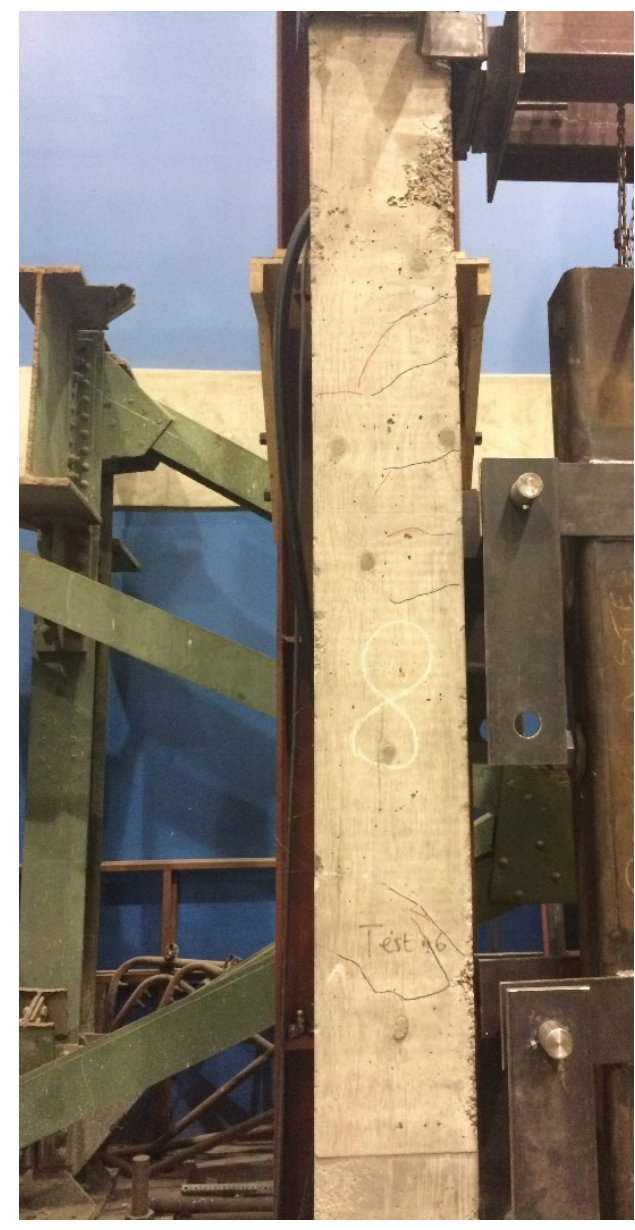

(b)

Figure 4-23: Post-test photograph of SEIS-08 showing (a) Flexural failure at the fixed support location posttest (b) Minor flexural cracks on the back side.

\subsection{Column Test $6(\mathrm{CONV}-11)$}

CONV-11 was exposed to ANFO explosion at a scaled distance of $0.88 \mathrm{~m} / \mathrm{kg}^{1 / 3}$. The column had a maximum permanent lateral displacement of $30 \mathrm{~mm}$ after the explosion field test. There were few flexural cracks on the back and side faces prior to this test. In the first stage of testing, the column was loaded to a service load level of $1000 \mathrm{kN}$ without failure. Figure 4-24 presents the axial load versus longitudinal reinforcement strain response of CONV-11 during the first load 
regime. The maximum-recorded strain was about $850 \times 10^{-6} \mathrm{~mm} / \mathrm{mm}$. After the axial load regime, lateral loading was applied to CONV-11 at a displacement rate of $1.5 \mathrm{~mm} /$ minute. Figure 4-25 presents the lateral load versus displacement response of CONV-11. The lateral loaddisplacement response of the column is almost linear up to the maximum lateral load of 365.6 $\mathrm{kN}$. The corresponding mid-height displacement of the column was $16.2 \mathrm{~mm}$.

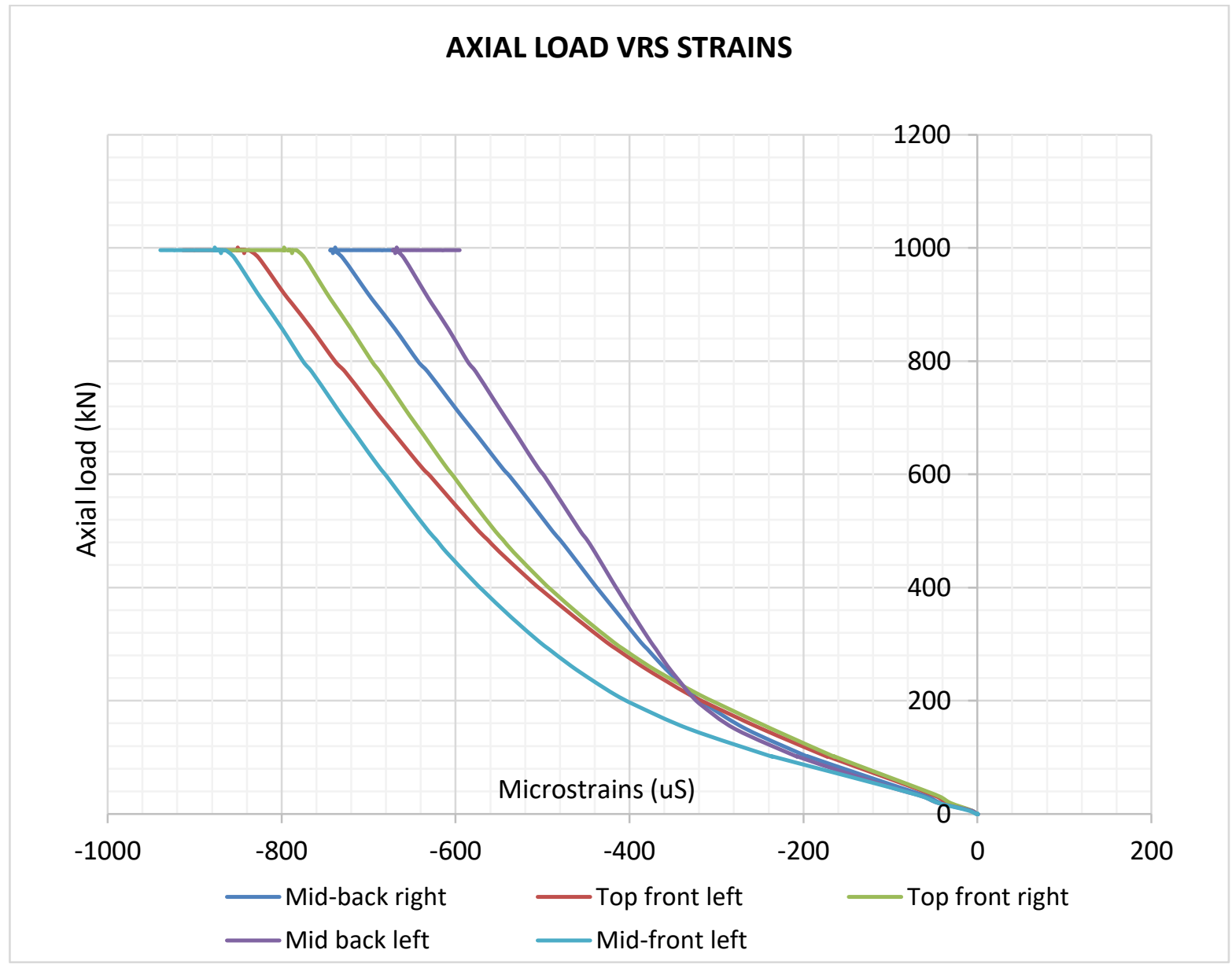

Figure 4-24: Compressive strains recorded during the first stage of loading CONV-11.

In Figure 4-25, column CONV-11 has a linearly response to the lateral load application. It sustains a maximum lateral load of about $365 \mathrm{kN}$. Past the peak point, the column is able to 
sustain some load until it drops to just about $350 \mathrm{kN}$. A combination of shear failure and axial load shortens the column by about $150 \mathrm{~mm}$, bending the longitudinal reinforcement.

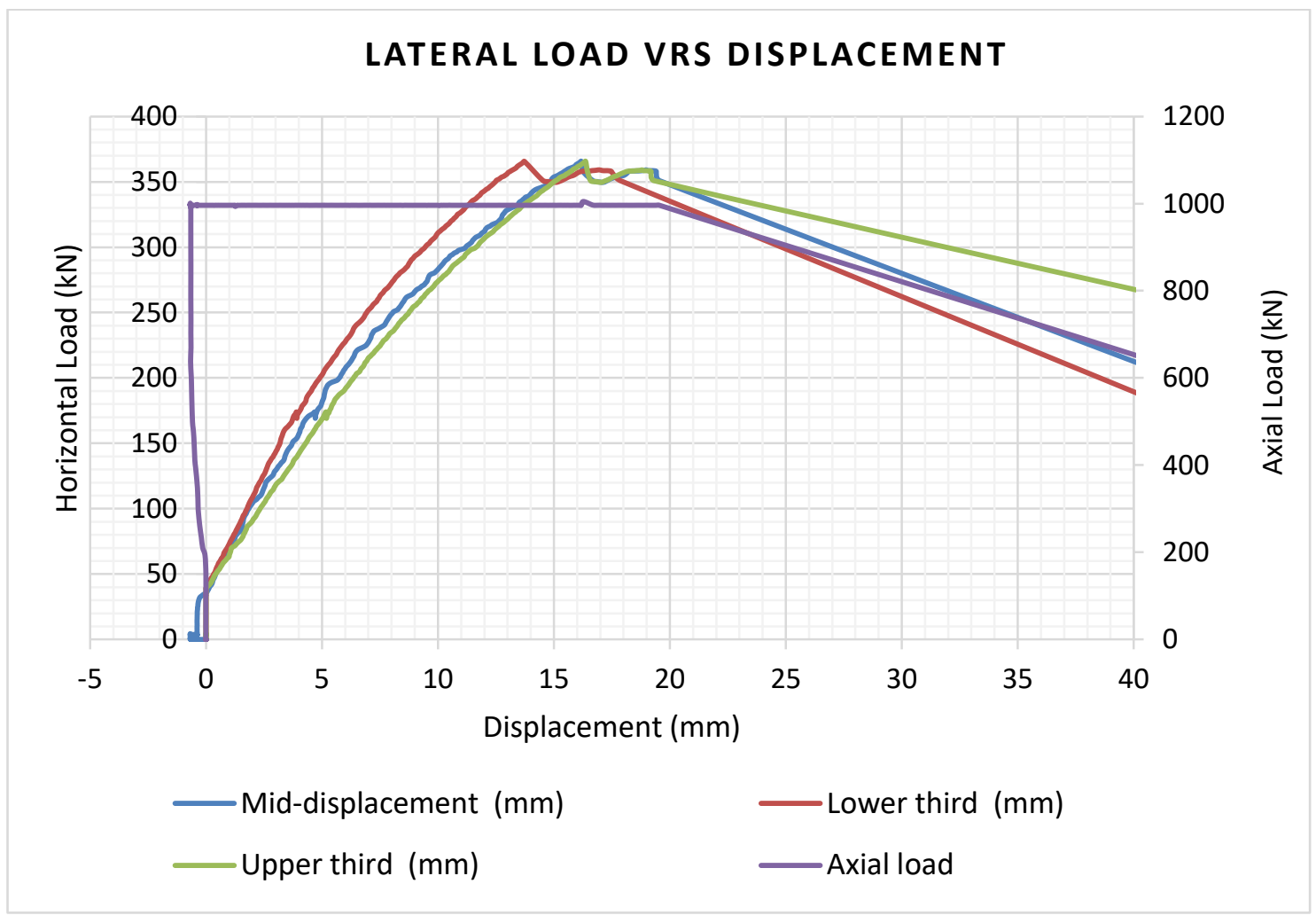

Figure 4-25: Lateral load versus displacement for CONV-11.

Figure 4-26 presents the lateral load versus longitudinal reinforcement strain. The strains in the mid-height section of the column show that the reinforcement close to the front side of the column continued to increase in compression up to a maximum compressive strain of $1670 \times 10^{-6}$ $\mathrm{mm} / \mathrm{mm}$. The strain in the longitudinal reinforcement towards the back of the column at midheight recorded decreasing compressive strain and a final tensile strain of $1240 \times 10^{-6} \mathrm{~mm} / \mathrm{mm}$. Thus, the longitudinal reinforcements in CONV-11 did not reach the yield strain at the failure lateral load. 


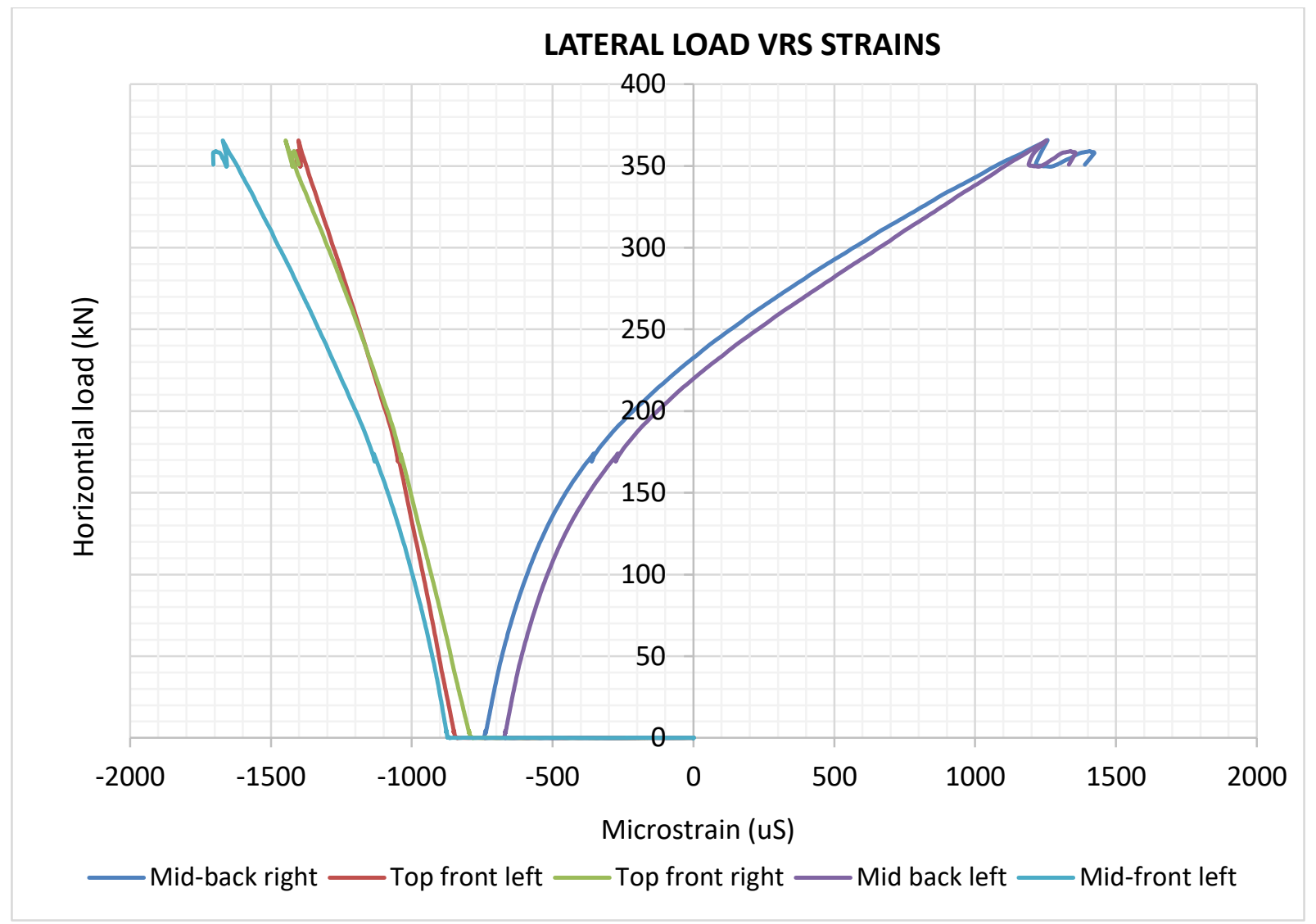

Figure 4-26: Strain recording in the lateral loading stage of CONV-11.

The governing failure mode for CONV-11 was shear. The lower portion of the column failed in shear and was accompanied by buckling of the longitudinal reinforcement due to the presence of the axial service load. Figure 4-27 presents a photograph of the failure of CONV-11. The damage zone was limited to a height of about $400 \mathrm{~mm}$ above the top of the footing. Existing flexural cracks from the field explosion test widened in the mid-back region where the moment was approximately constant. There was no concrete spalling in the mid-front region due to flexural compression. 


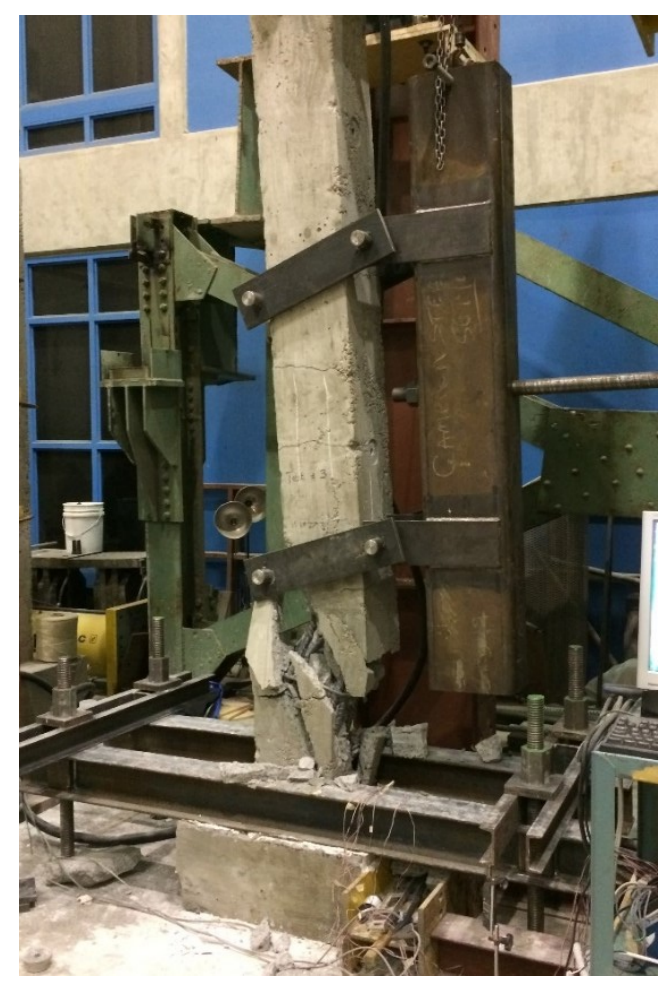

(a)

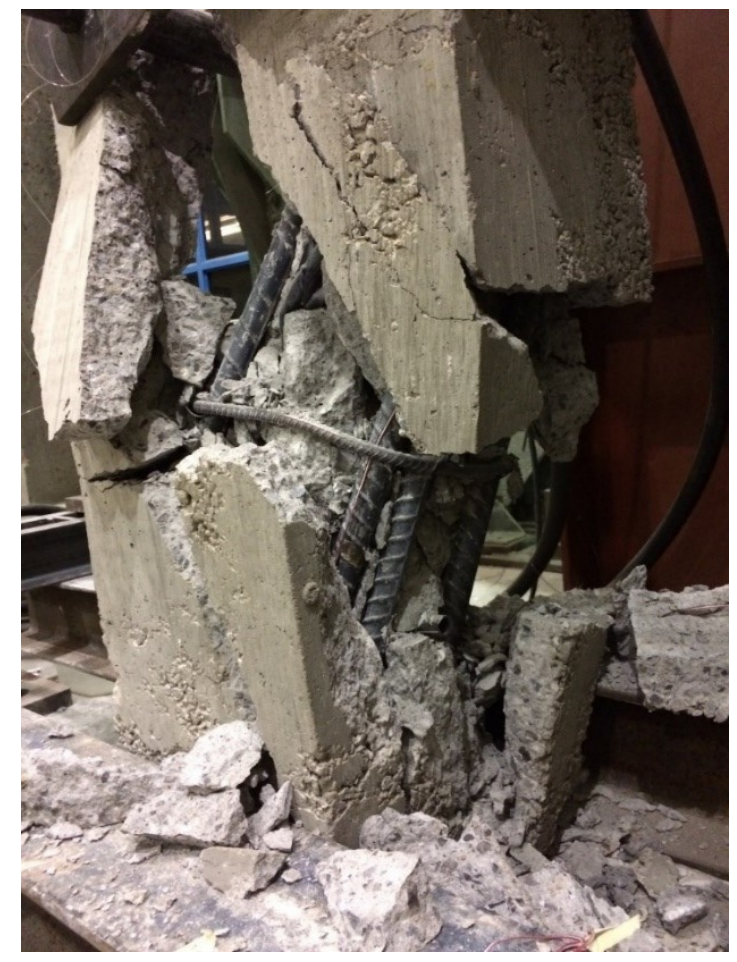

(b)

Figure 4-27: Shear failure exposing deformed longitudinal and transverse reinforcement in CONV-11.

\subsection{Column Test 7 (CONV-12)}

CONV-12 was tested in the near-field explosion test at a scaled distance of $0.82 \mathrm{~m} / \mathrm{kg}^{1 / 3}$. Minimal flexural cracks were developed on the back of the column during the field tests. It also had a maximum permanent displacement of $29 \mathrm{~mm}$ before the residual capacity test program. When the test started, a full service load was applied to CONV-12 without failure. Figure 4-28 presents the axial load versus longitudinal reinforcement strain during the axial load regime. The longitudinal reinforcement strains were all compressive. At the mid-height section, the strain in reinforcements close to the front face of the column were compressive with a maximum value of $950 \times 10^{-6} \mathrm{~mm} / \mathrm{mm}$ while the strain in the longitudinal reinforcement toward the back face of the 
column were lower at $750 \times 10^{-6} \mathrm{~mm} / \mathrm{mm}$ at the maximum axial load of about $1000 \mathrm{kN}$. These are higher than that of a perfect pristine column with a calculated strain of about $400 \times 10^{-6} \mathrm{~mm} / \mathrm{mm}$. The distribution of the strains across the mid-height section is indicative of mid-height displacement towards the back of the column.

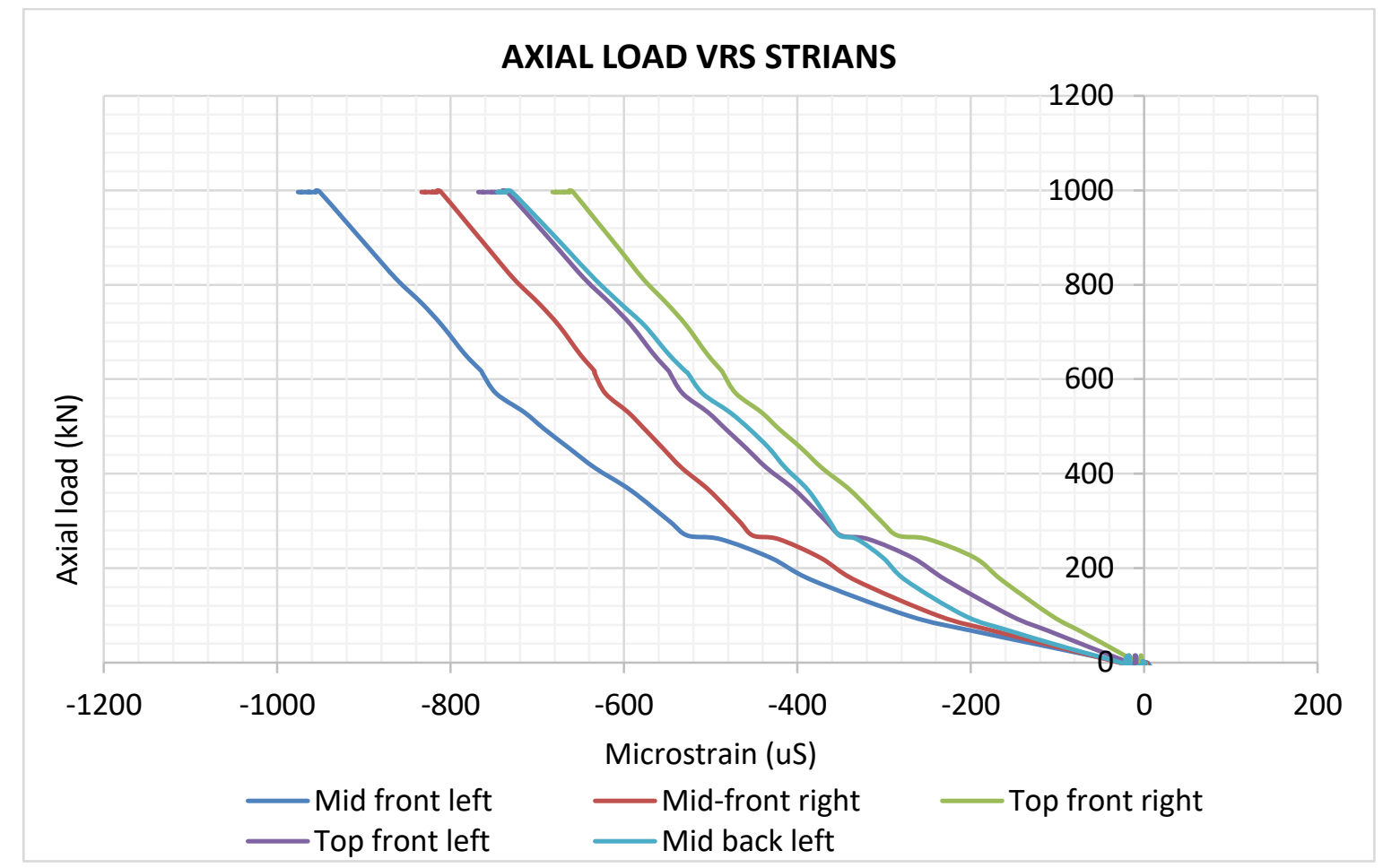

Figure 4-28: Strains indicating compressive stress in first stage of loading column CONV-12.

Lateral loading followed the axial load regime. Figure 4-29 presents the lateral load versus displacement response of CONV-12. For the most part the load-displacement response is linear in the early stages of the loading followed by a nonlinear response up to the failure load of 298.9 $\mathrm{kN}$. The corresponding mid-height displacement is about $15.9 \mathrm{~mm}$. 


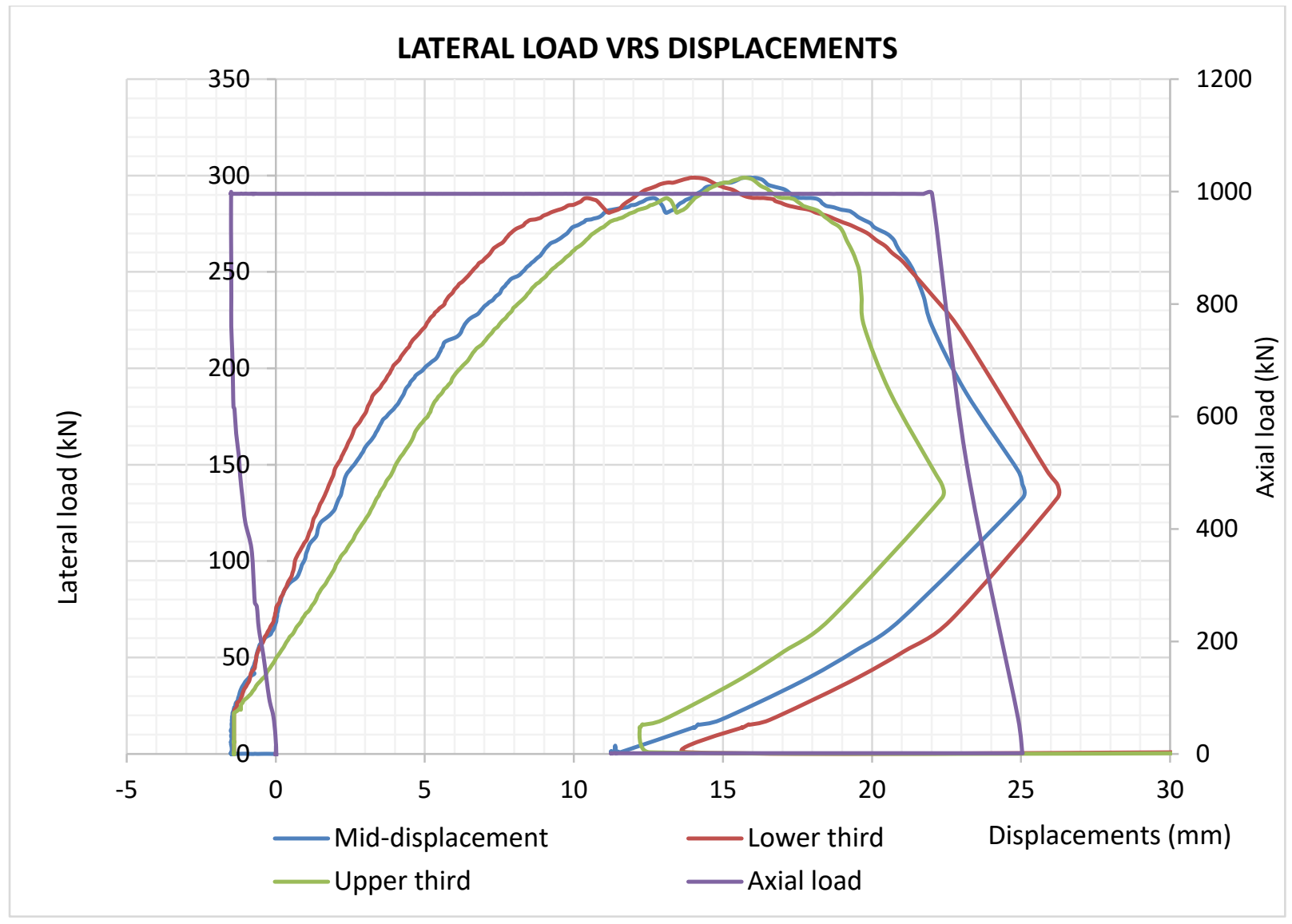

Figure 4-29: Graph of lateral load against displacements for columnsCONV-12.

Figure 4-30 presents the lateral load versus longitudinal reinforcement strain. The strain gauge in the mid-back left recorded data until a lateral load of about $250 \mathrm{kN}$, then it malfunctioned. The strain gauges in the compression zone in the mid-front region recorded a maximum strain of $1800 \times 10^{-6} \mathrm{~mm} / \mathrm{mm}$. 


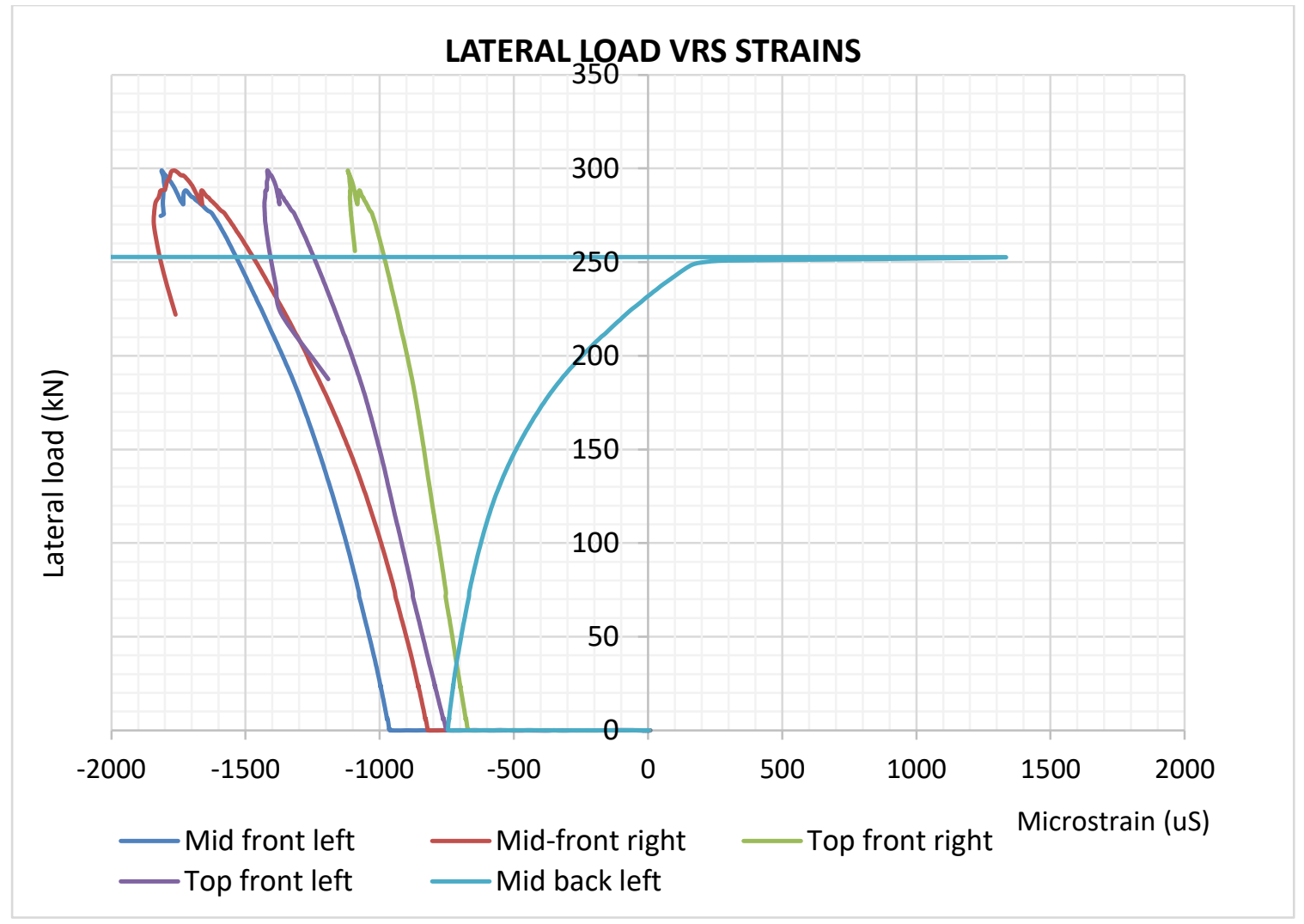

Figure 4-30: Graph of strains in the longitudinal reinforcement for CONV-12.

Figure 4-31 shows the cracking in the reinforced concrete column. Shear cracks developed in the lower $350 \mathrm{~mm}$ above the top of the footing, which caused the column to fail. Minor flexural cracks were also visible. There was no spalling of concrete. As pointed out in earlier test columns, this test ensured the lateral load was kept at zero load during the first stage of axial load application. This is seen in how the curve for mid-displacement begins to rise from zero load ( 0 $\mathrm{kN})$. 

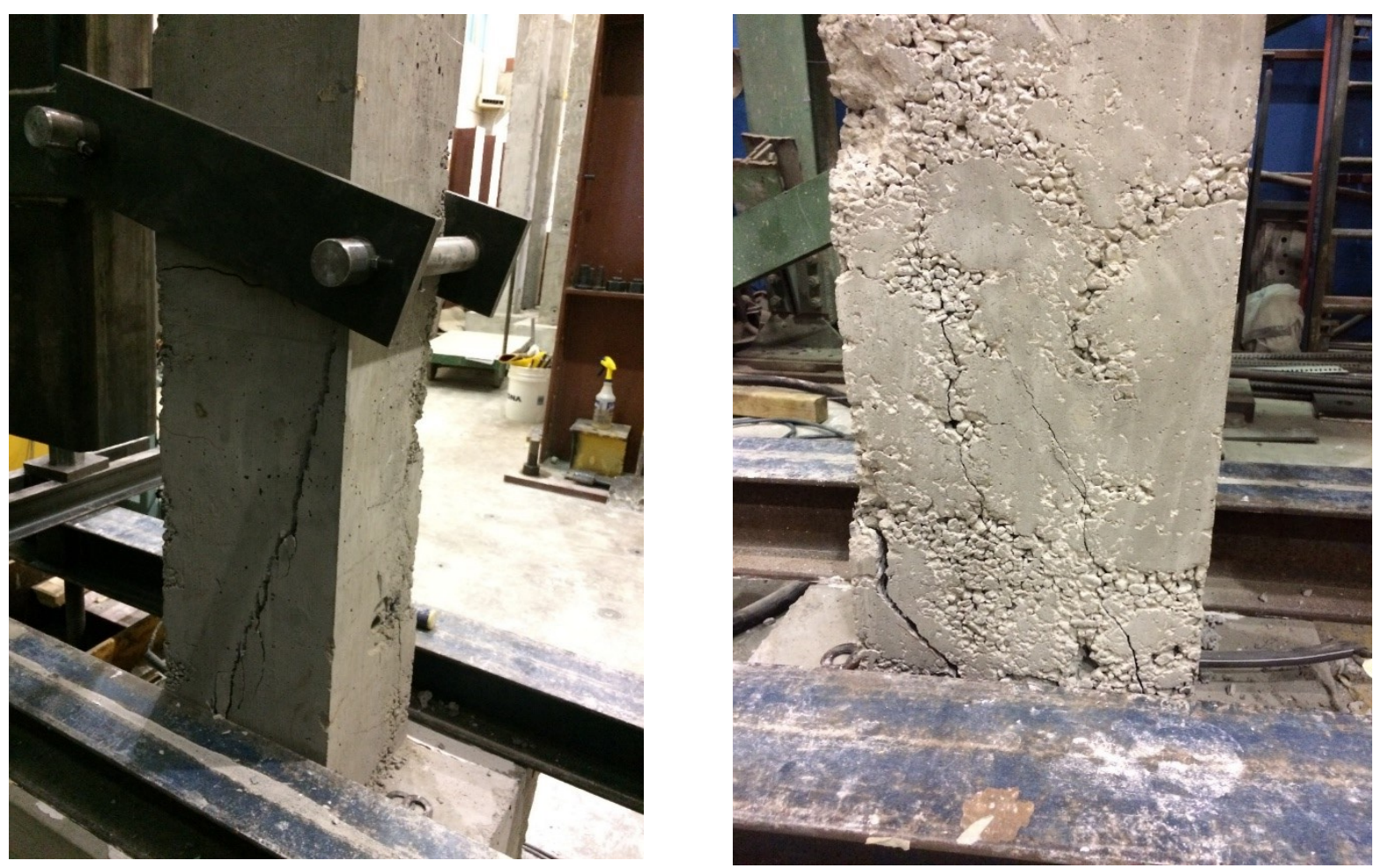

Figure 4-31: Shear cracks on the both sides of CONV-12 post-test.

\subsection{Column Test 8 (SEIS-13)}

SEIS-13 was previously exposed to loading from ANFO explosion at a scaled distance of 0.82 $\mathrm{m} / \mathrm{kg}^{1 / 3}$. The column had a maximum permanent lateral displacement of $7 \mathrm{~mm}$ with minimal flexural cracks on the back and side faces post live explosion testing. The residual capacity test began with the application of the axial load; to the full service load of $1000 \mathrm{kN}$ without failure. Figure 4-32 shows the strains in the longitudinal reinforcement as the axial service load was being applied. Only two strain gauges were functional on SEIS-13. The maximum strain was recorded in the top-front location $\left(680 \times 10^{-6} \mathrm{~mm} / \mathrm{mm}\right)$. The Mid-back-right strain gauge recorded lower strains. 


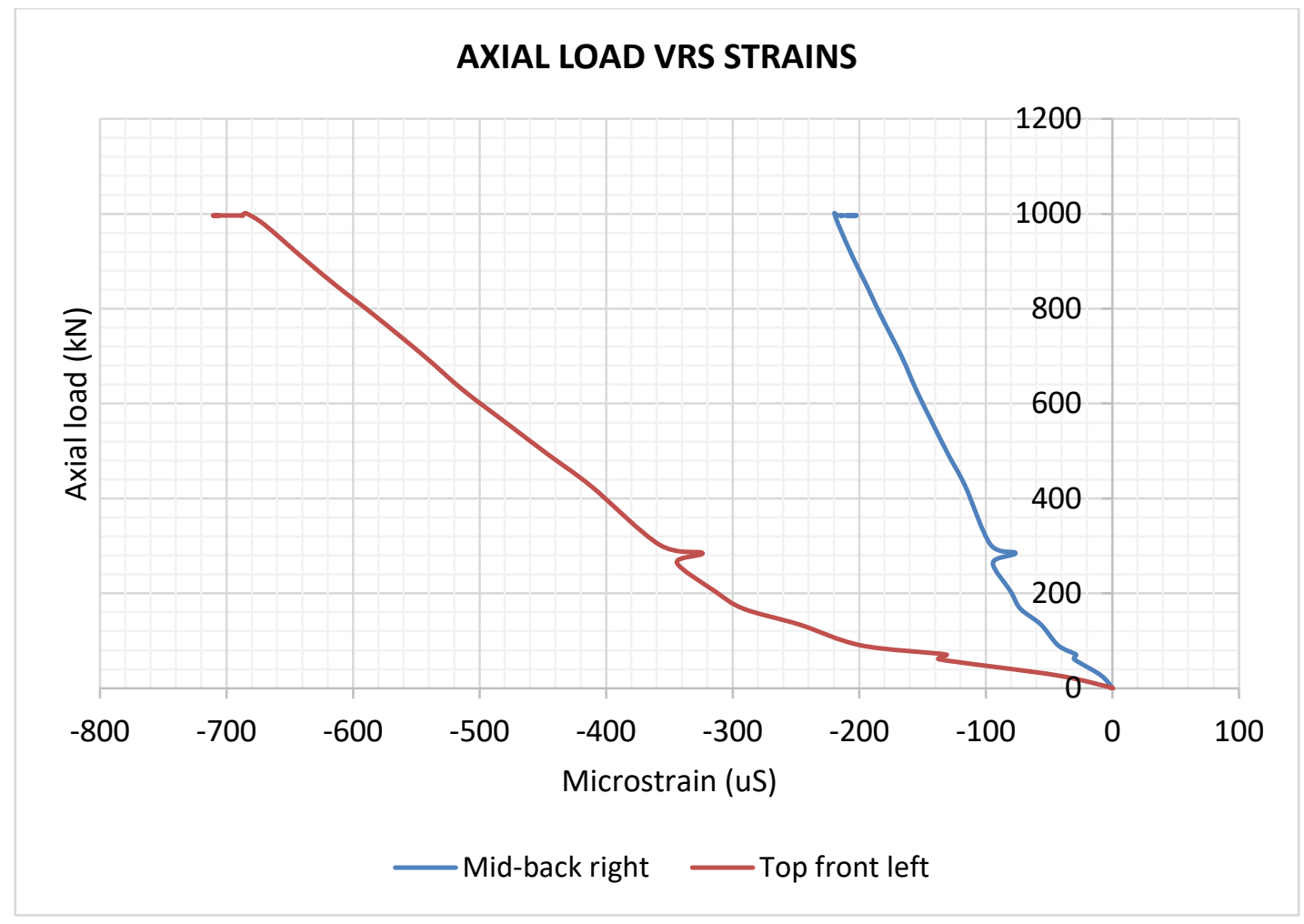

Figure 4-32: Strains in the longitudinal reinforcement indicating compression stress in SEIS-13.

Figure 4-33 presents the lateral load versus displacement response of SEIS-13. The loaddisplacement behaviour was essentially nonlinear until the ultimate load of $461.2 \mathrm{kN}$. The nature of the curves is indicative of the confinement provided by the closer transverse reinforcement. The lateral displacement corresponding to the ultimate load was $22.8 \mathrm{~mm}$. In the top 1-m region of the column, there was severe concrete spalling that exposed buckled longitudinal reinforcement. The nature of the buckle was indicative of the action of the service load. 


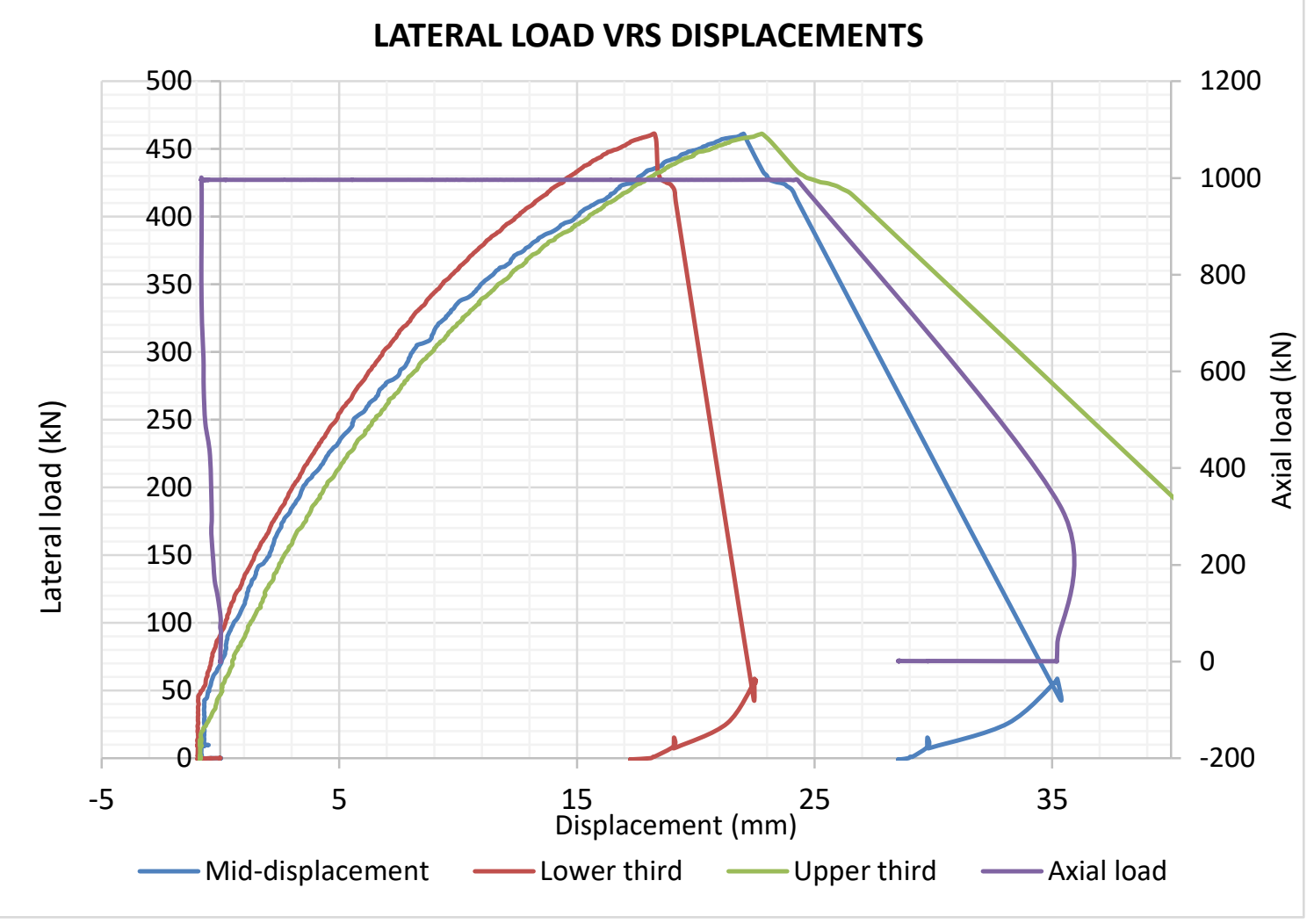

Figure 4-33: Lateral load versus displacement for column SEIS-13.

The top front strain gauge was located $2350 \mathrm{~mm}$ above the top of the footing (Siba (2014)). This is approximate the point just above the upper contact point where the deflection and failure was greatest. The maximum compression strain recorded in the top front left location was $1500 \times 10^{-6}$ $\mathrm{mm} / \mathrm{mm}$ (Figure 4-34). Likewise, the mid-front and mid-back gauges were installed at about $1200 \mathrm{~mm}$ above the footing, thus the lower tensile strain. This is not the case in CONV-\# columns where the mid-height strain gauges were installed at $1600 \mathrm{~mm}$ above the top of footing. 


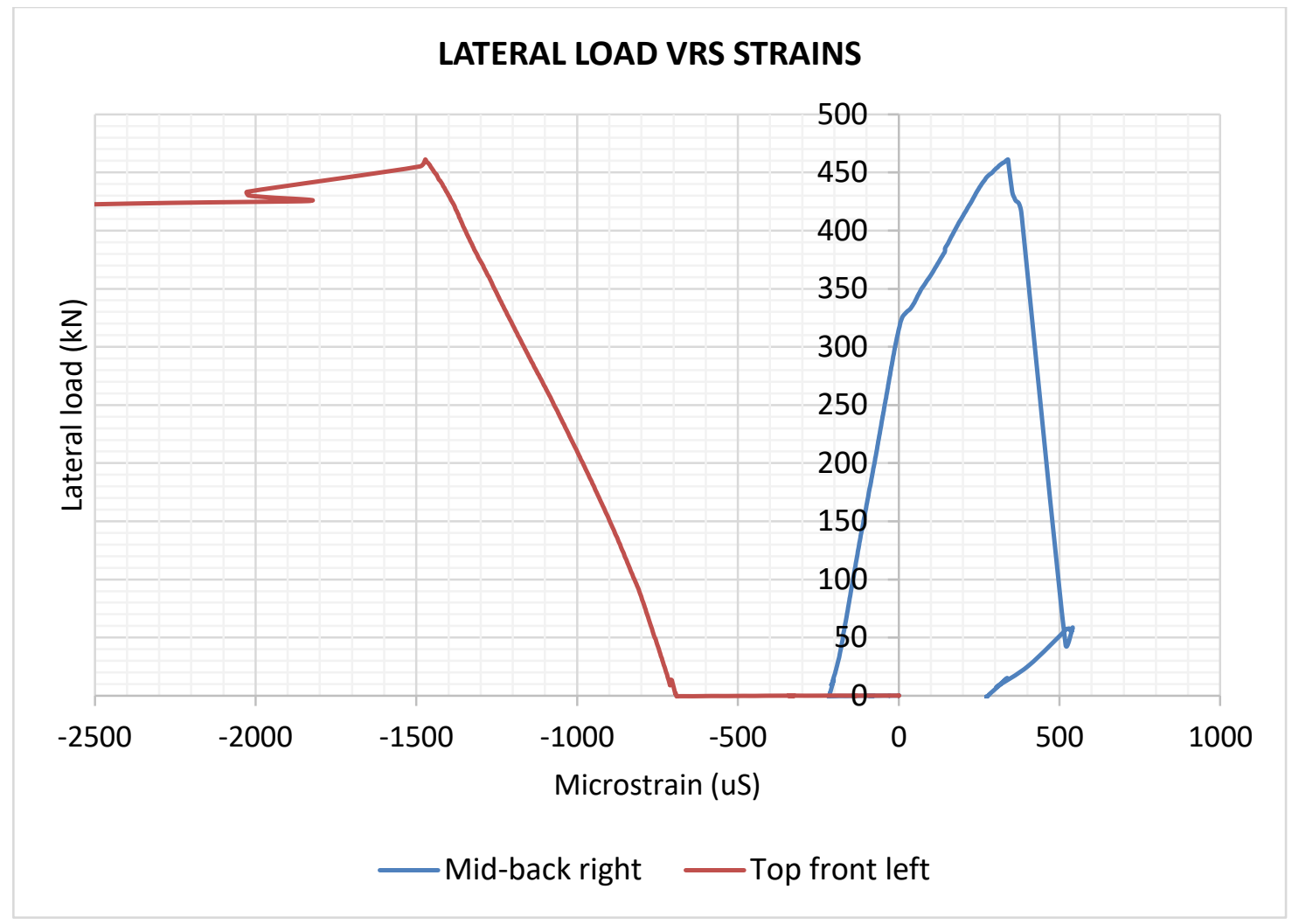

Figure 4-34: Strain gauge recording during second stage of testing SEIS-13.

There were many flexural cracks on the back (tensile) side of the column in the region between the two load contact points. The nature of the failure, as shown in Figure 4-35, is most likely to be due to flexural stress. Concrete in the compression zone just above the upper load contact point was spalled. The reinforcement at this location buckled due to the action of the service load. 


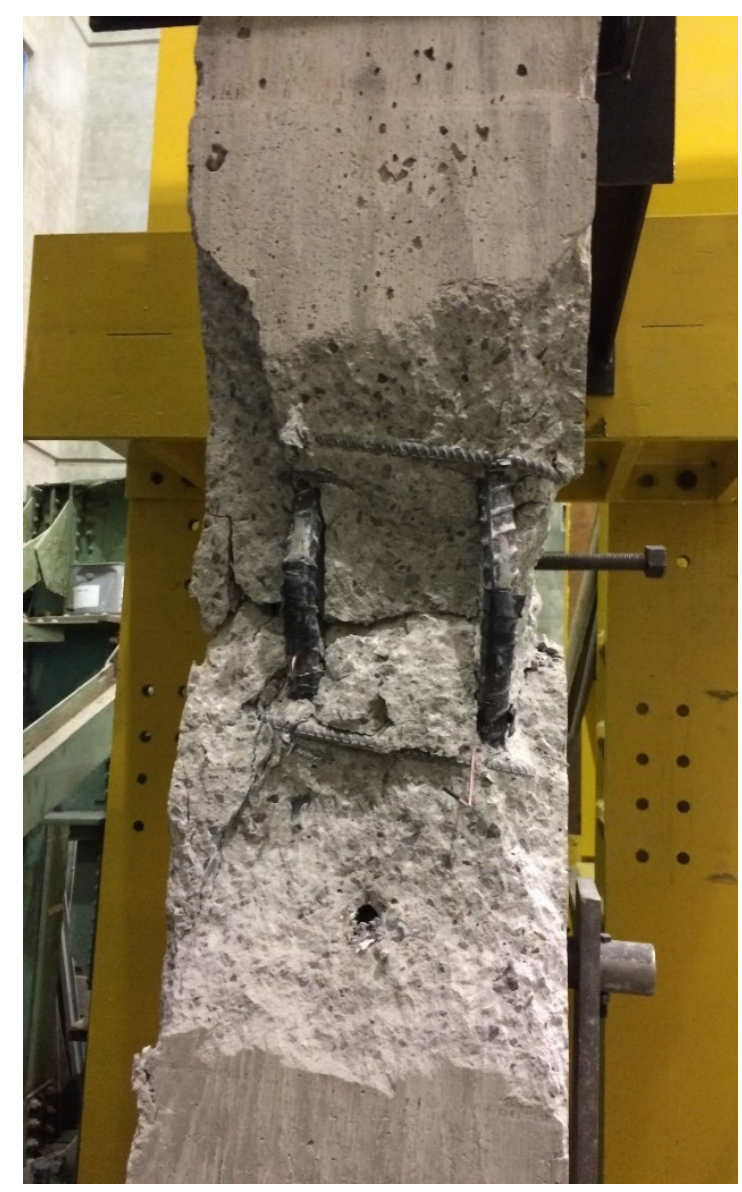

(a)

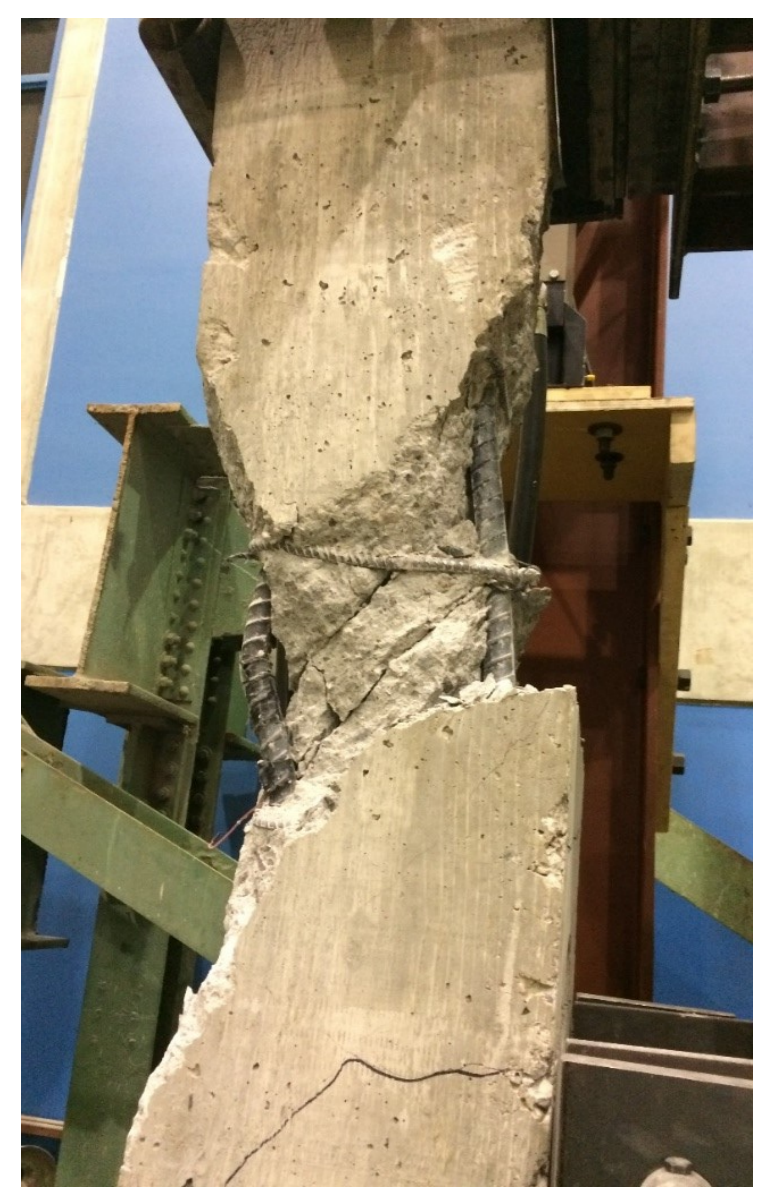

(b)

Figure 4-35: Photograph of concrete spall exposing reinforcement: (a) front view (b) Side face.

\subsection{Column Test 9 (SEIS-14)}

Test 9 was carried out on column SEIS-14 that was blast-damaged by exposure to ANFO explosion at a scaled distance of $0.86 \mathrm{~m} / \mathrm{kg}^{1 / 3}$. A maximum permanent displacement of about 16 $\mathrm{mm}$ was on the column before the residual capacity testing began. After the close-in blast load test, SEIS-14 had minor flexural cracks on the back face. Residual capacity testing began with the application of the axial service load of $1000 \mathrm{kN}$. The axial load was applied in increments of about $50 \mathrm{kN}$ until the entire service load was fully applied to the column. SEIS-14 suffered no 
distress under the axial load. Figure 4-36 shows the axial load versus longitudinal reinforcement strains during axial load application to the service load level and ALR of 0.32 . The strain at the top front location (2400 $\mathrm{mm}$ above footing) was about $800 \times 10^{-6} \mathrm{~mm} / \mathrm{mm}$, while the mid-front right $(1100 \mathrm{~mm})$ recorded a strain of $570 \times 10^{-6} \mathrm{~mm} / \mathrm{mm}$. The gauge in the bottom-front location recorded a rather high strain value $\left(1440 \times 10^{-6} \mathrm{~mm} / \mathrm{mm}\right)$.

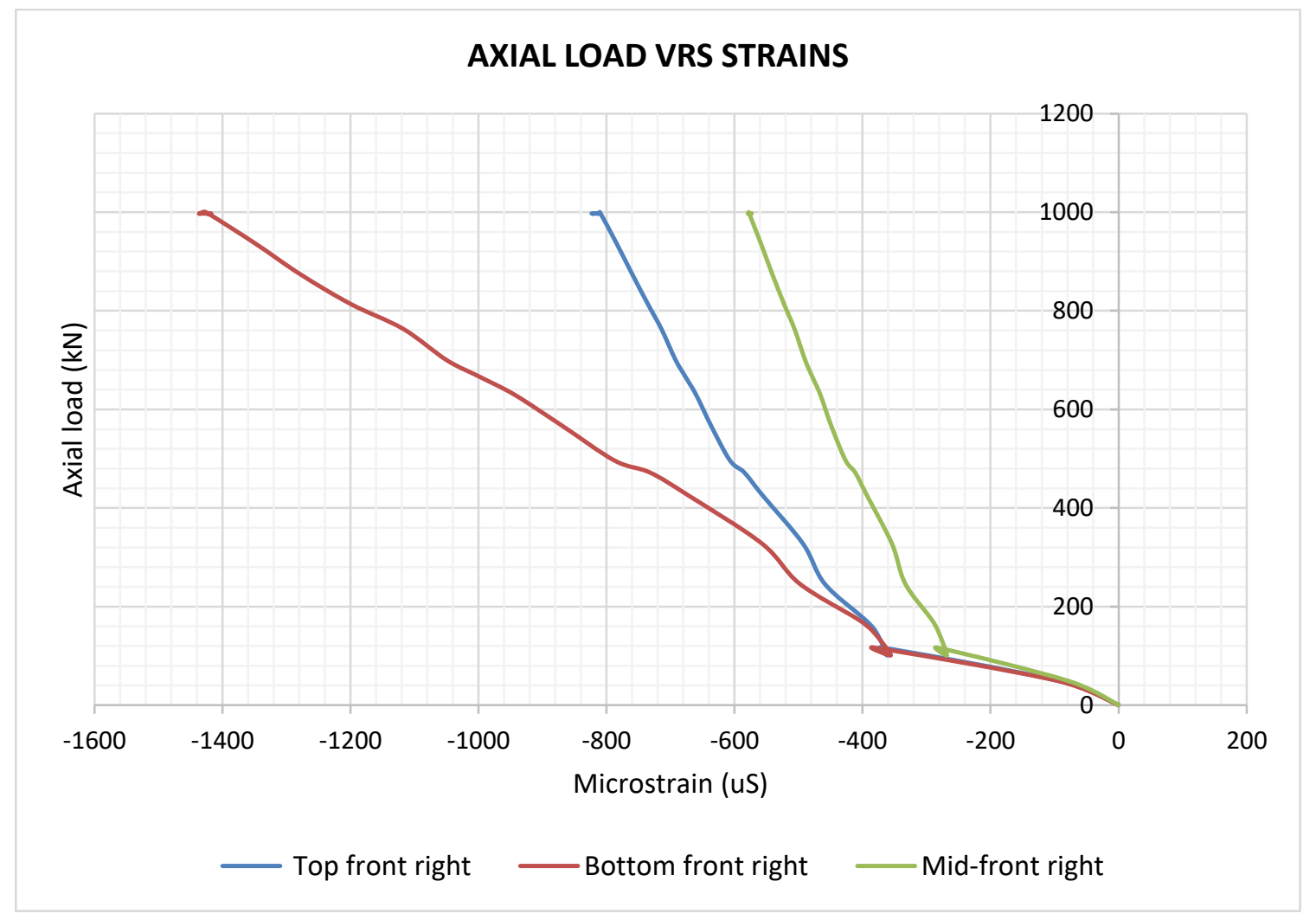

Figure 4-36: Strains in column SEIS-14 during the first stage of loading.

Figure 4-37 presents the lateral load versus displacement response of SEIS-14. It can be seen in Figure 4-37 that during the first stage of loading, the column was displaced towards the front face of the column. This however was unrestrained and hence the lateral actuator recorded no load. The stiffness of the column gently decreased until the maximum load of $416.4 \mathrm{kN}$ was 
reached. The mid-height displacement corresponding to the ultimate load was $23.2 \mathrm{~mm}$. In the second stage of loading, the strain gauge reading in the mid-front recorded a maximum value of about $1500 \times 10^{-6} \mathrm{~mm} / \mathrm{mm}$. (Figure 4-38).

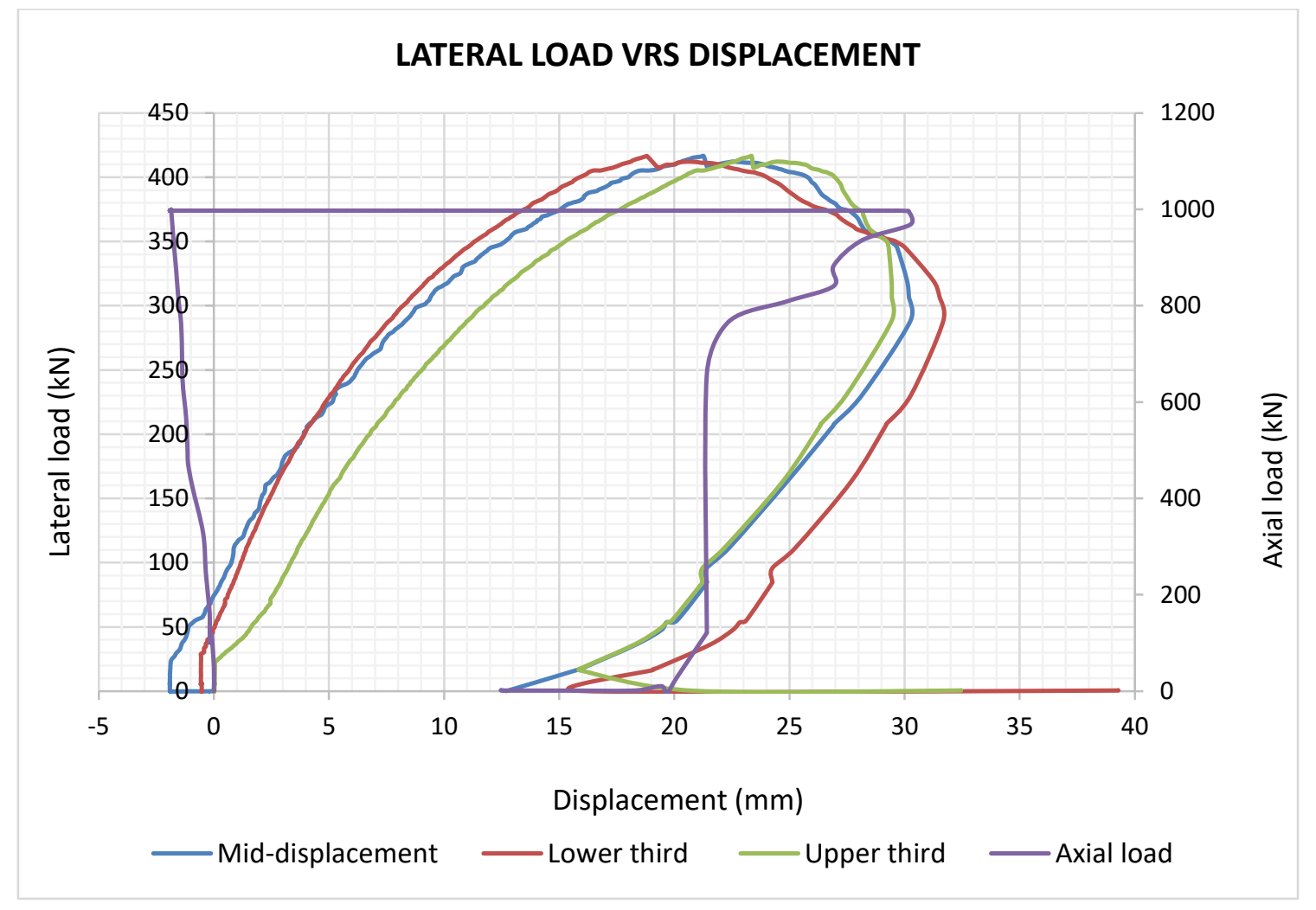

Figure 4-37: Load-displacement graph of column SEIS-14. 


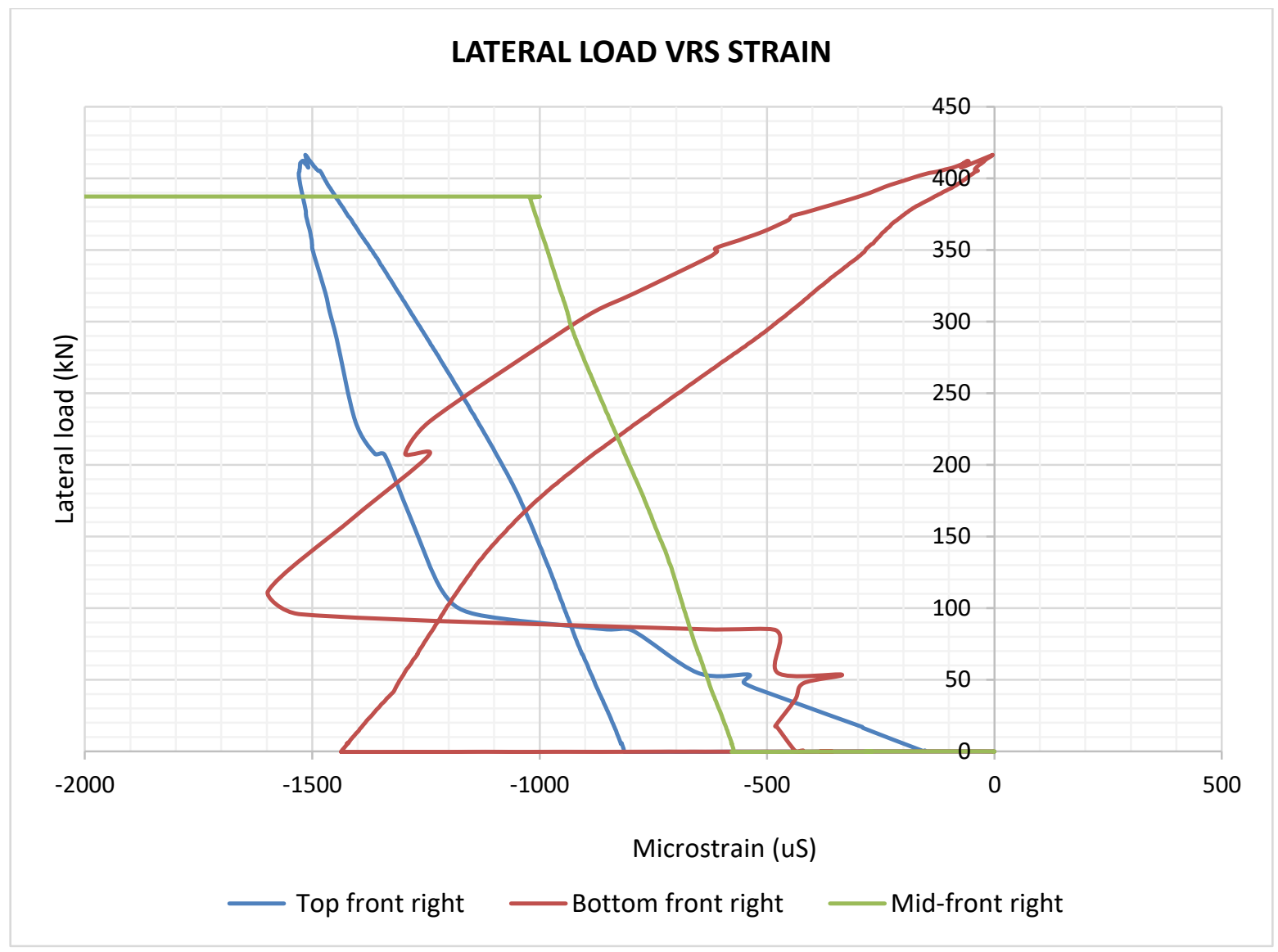

Figure 4-38: Strains recorded during the second stage of loading for SEIS-14.

Visible shear cracks developed in the lower 1-m range of the column (Figure 4-39a). These cracks crossed some flexural cracks that were present prior to the residual capacity testing (indicated by black marking). Minimal flexural cracks were formed in the upper one-third region of the column during the axial loading regime. A small piece of concrete, $300 \mathrm{~mm} \times 200 \mathrm{~mm}$ having a depth of $15 \mathrm{~mm}$ spalled at the lower load contact point. This could either be flexural or simply a bearing failure (Figure 4-39b). 


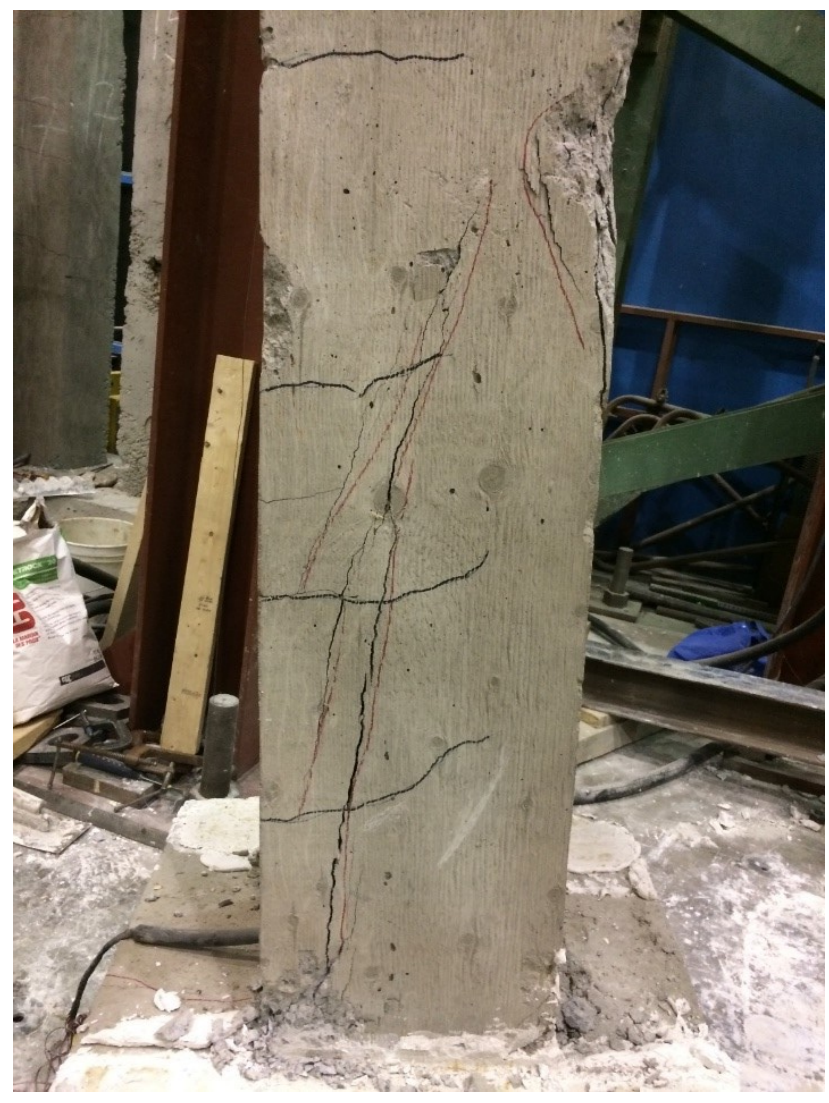

(a)

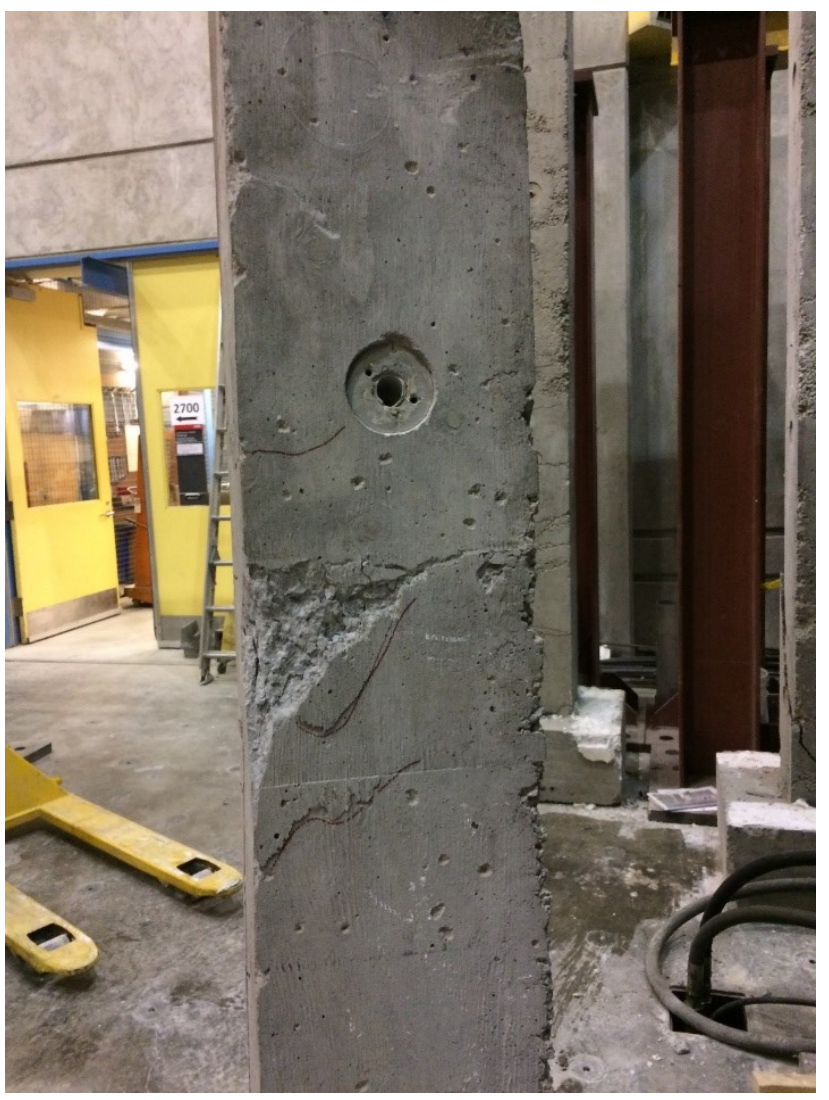

(b)

Figure 4-39: Post-test photograph of SEIS-14 showing: (a) Shear cracks near bottom of column SEIS-14 (b) Concrete spall on the mid-front face indicative of flexural stress.

\subsection{Column Test $10(\mathrm{CONV}-16)$}

CONV-16 was a control column; it was not tested in the near-field explosion test program. As expected, the full service load of $1000 \mathrm{kN}$ was resisted in the first stage of loading without failure. Figure 4-40 presents the axial load versus longitudinal reinforcement strain response of the column under the first phase loading regime. The strains ranged from $300 \times 10^{-6} \mathrm{~mm} / \mathrm{mm}$ in the Bottom-front-left to $550 \times 10^{-6} \mathrm{~mm} / \mathrm{mm}$ in the Top-front-left. This range of strain agrees fairly well with the calculated value of about $400 \times 10^{-6} \mathrm{~mm} / \mathrm{mm}$. 


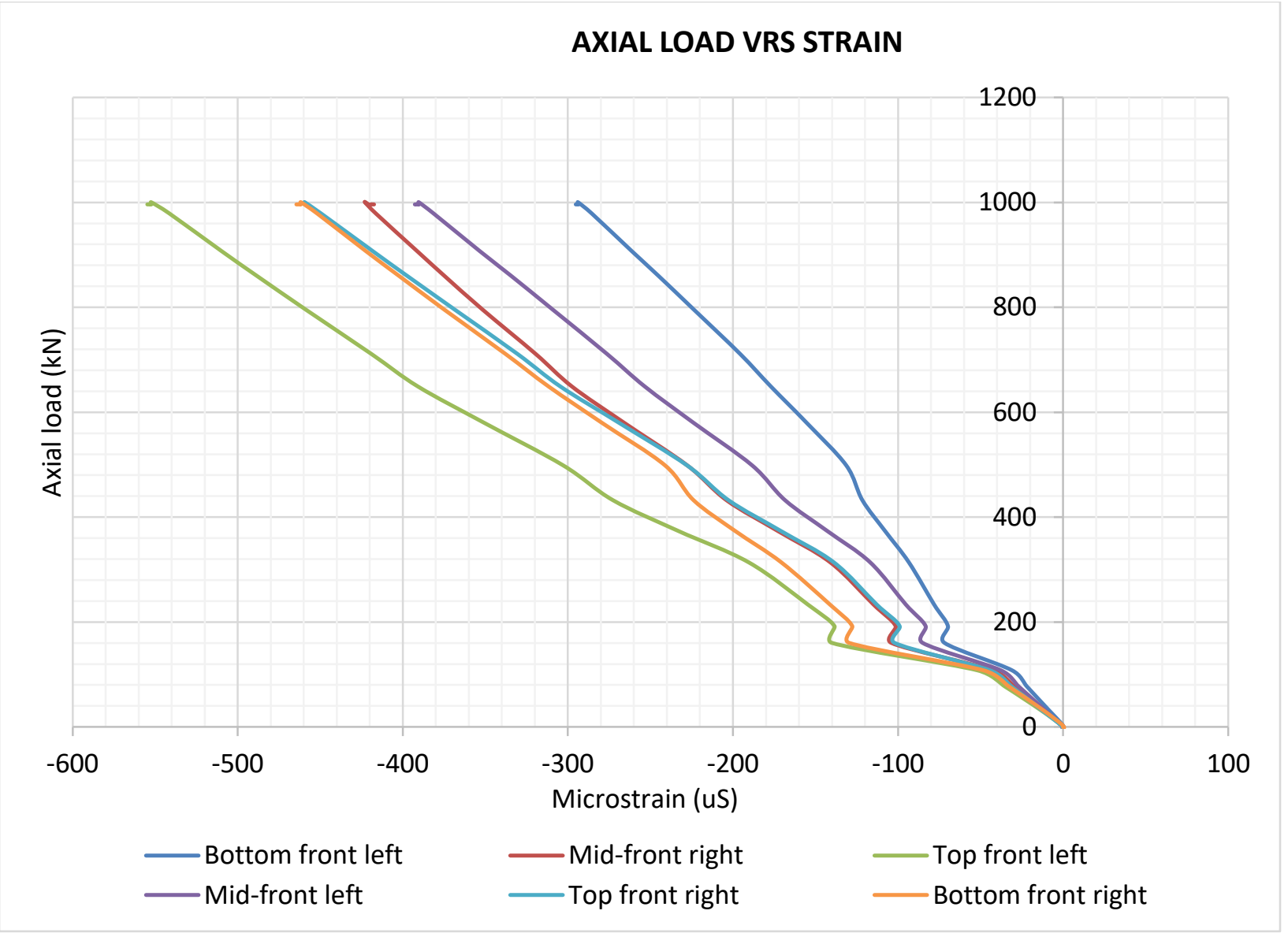

Figure 4-40: Strains at various locations on the longitudinal reinforcement (CONV-16).

The test was continued with the application of the lateral load at the set displacement-control rate of $1.5 \mathrm{~mm} /$ minute. Figure $4-41$ presents the lateral load versus displacment response of CONV16. During the first 5 seconds, the curves show a linear response; up to a load of about $150 \mathrm{kN}$. As the lateral load increased, the column response became non-linear till a peak load of $404.6 \mathrm{kN}$ was reached. The displacement at the ultimate load level was $20.3 \mathrm{~mm}$. The sudden drop in the lateral load is indicative of sudden shear failure of the column. The hydraulics was shut off after this point (indicated by the straight line declinination). 


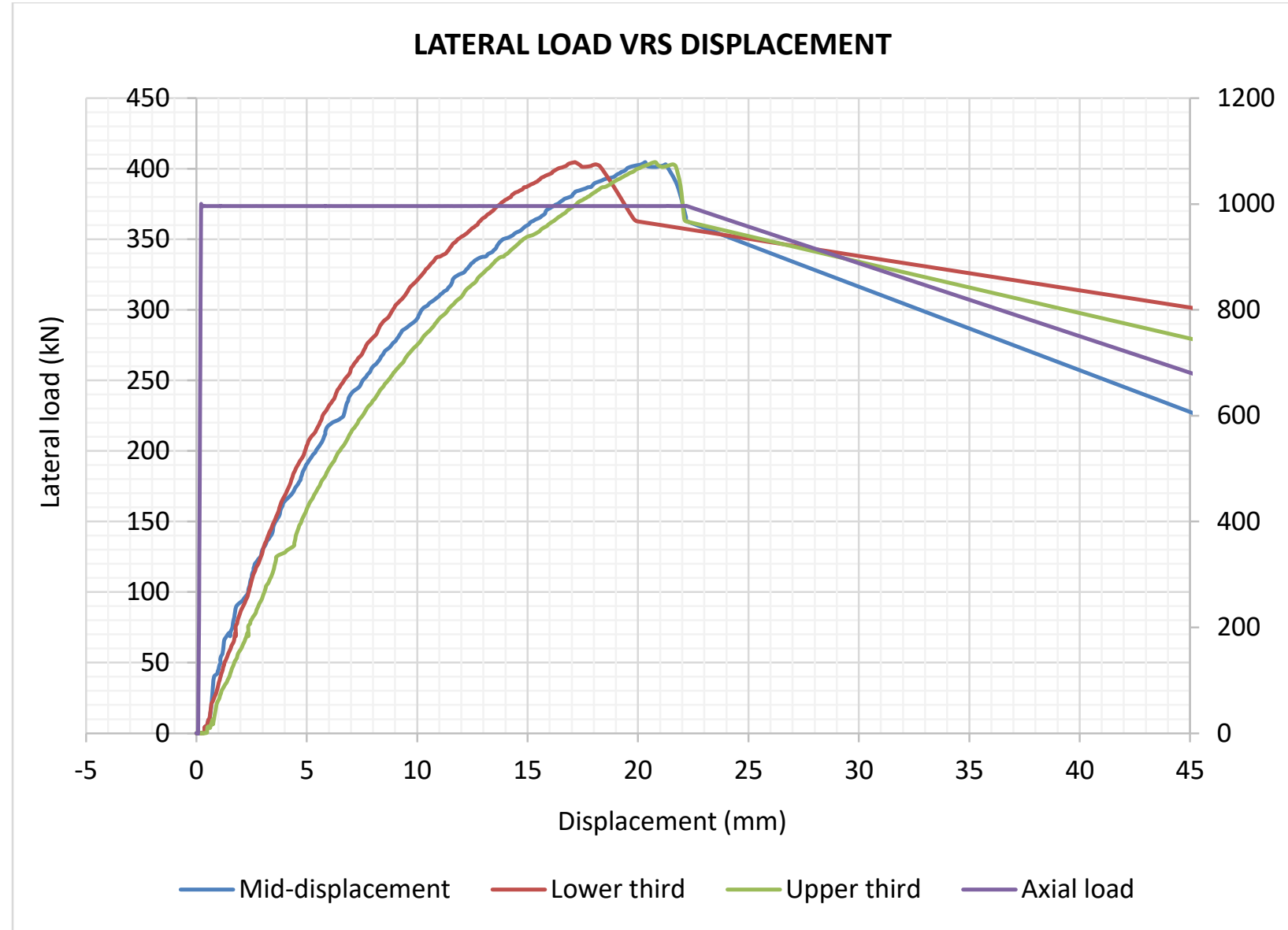

Figure 4-41: Lateral load against displacements for CONV-16.

Figure 4-42 presents the lateral load versus longitudinal reinforcement strain. The maximum compressive strain recorded was about $1150 \times 10^{-6} \mathrm{~mm} / \mathrm{mm}$ in the reinforcement close to the front face of the column at mid-height while the strains in the bottom front region were about $2700 \times 10^{-6} \mathrm{~mm} / \mathrm{mm}$; this is about the yield strain of the reinforcement. 


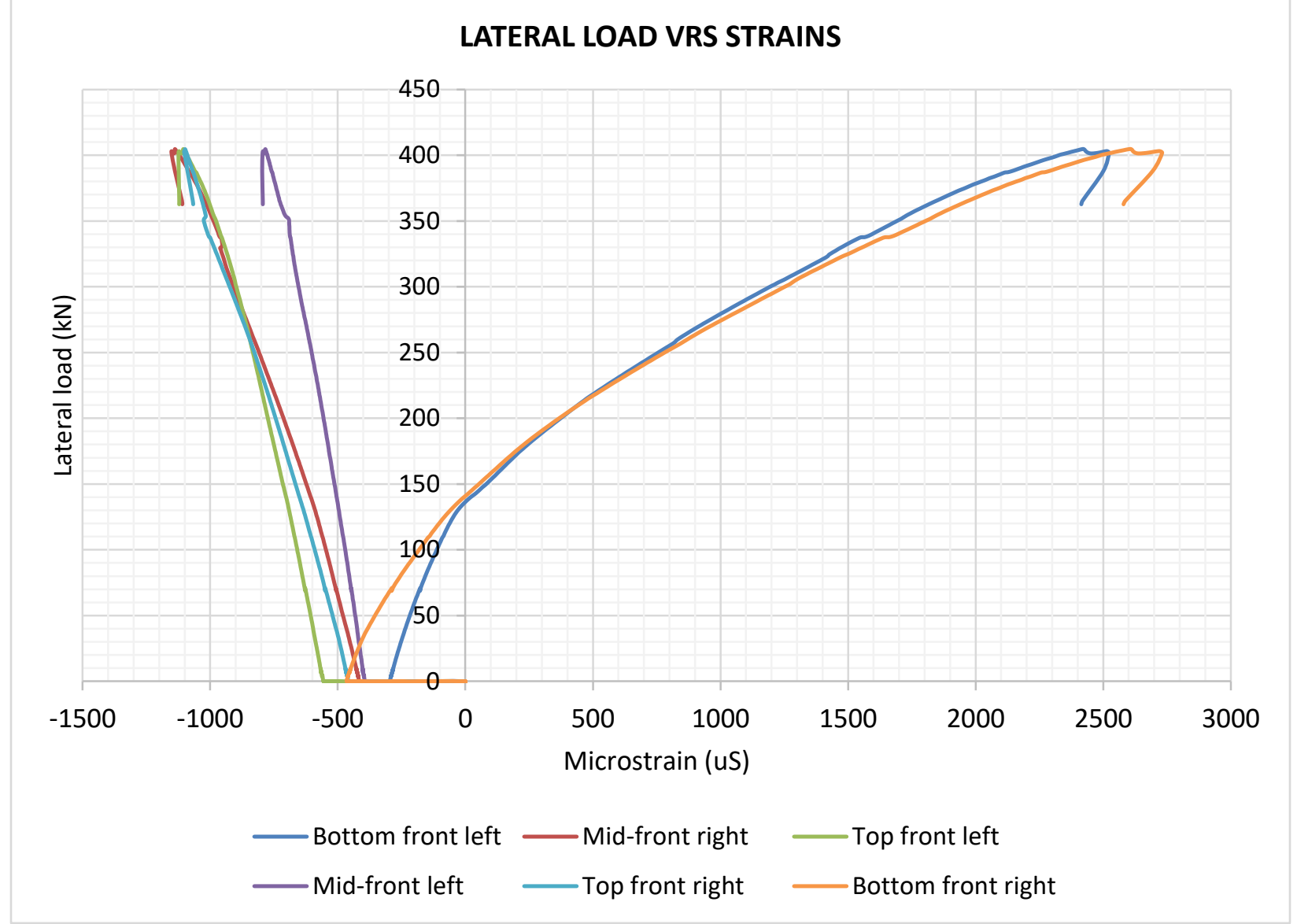

Figure 4-42: Strain at various locations on the longitudinal reinforcement (CONV-16).

CONV-16 failed in shear at the lower $350 \mathrm{~mm}$ length of the column. Honeycomb defects was visible in this region due to poor compaction and that might have affected the capacity of this column. In Figure 4-43, the longitudinal reinforcement exposed in the lap splice region was bent due to the actions of the both service and lateral loads. The high strains in the longitudinal reinforcement was due to both the effects of the axial load and flexural stress from bending. 


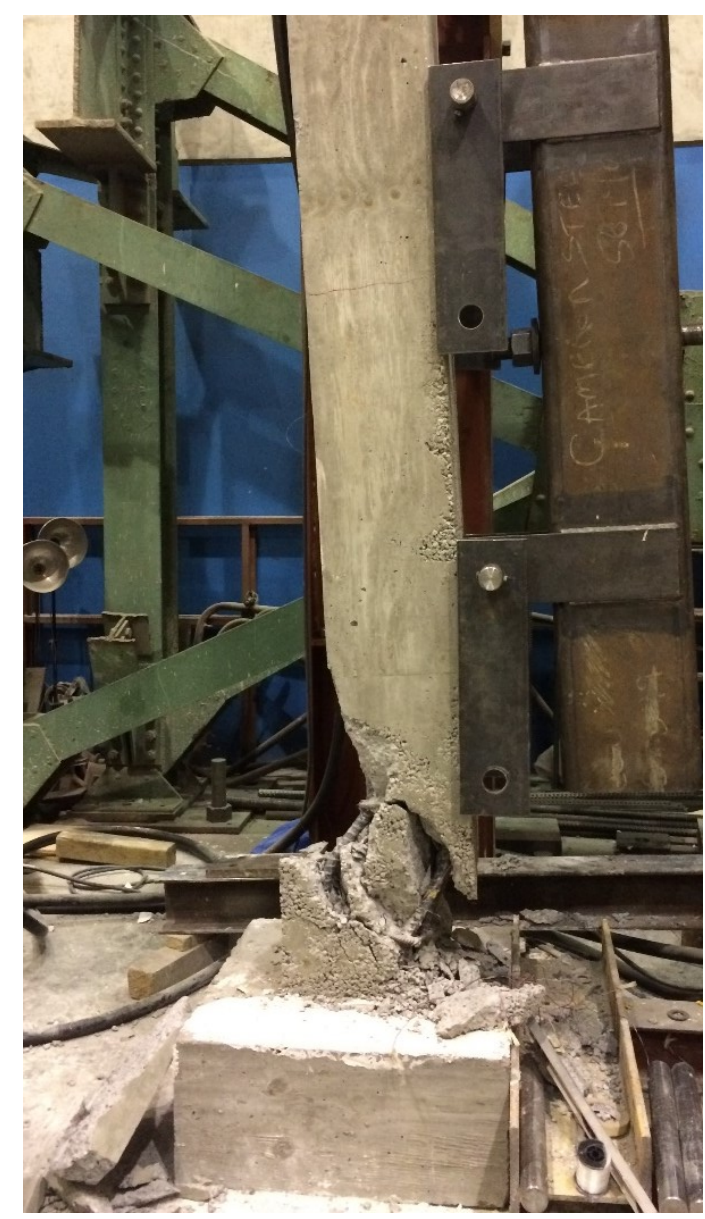

(a)

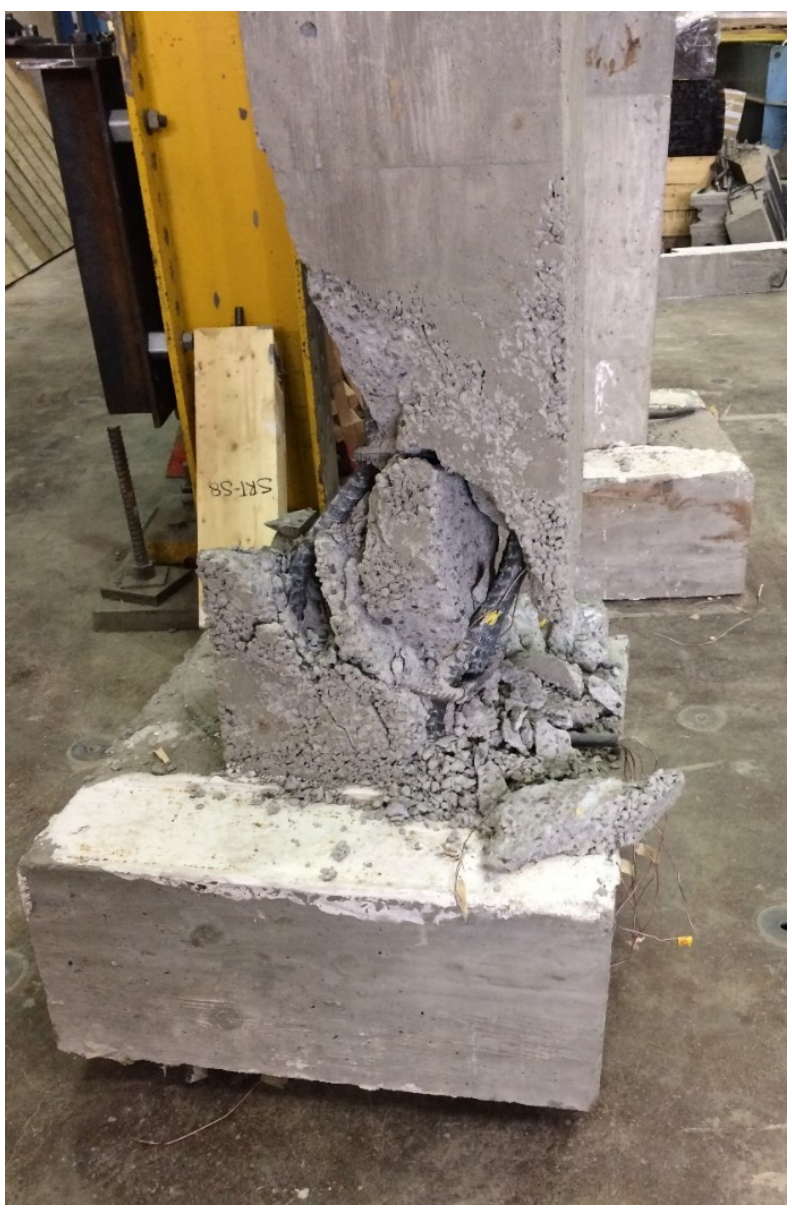

(b)

Figure 4-43: Severe shear failure with bent longitudinal reinforcement after the test (CONV-16).

\subsection{Column Test 11 (SEIS-18)}

SEIS-18 is a control column in this test program and was not subjected to loading from the nearfield explosion testing. The service load of $1000 \mathrm{kN}$ was resisted by the column without failure. Figure 4-44 presents the axial load versus longitudinal reinforcement strain and shows maximum strain of about $390 \times 10^{-6} \mathrm{~mm} / \mathrm{mm}$ in the top front region of the column. The other strain gauges at the mid-height and bottom recorded lower strains between $220 \times 10^{-6} \mathrm{~mm} / \mathrm{mm}$ and $260 \times 10^{-6}$ $\mathrm{mm} / \mathrm{mm}$ 


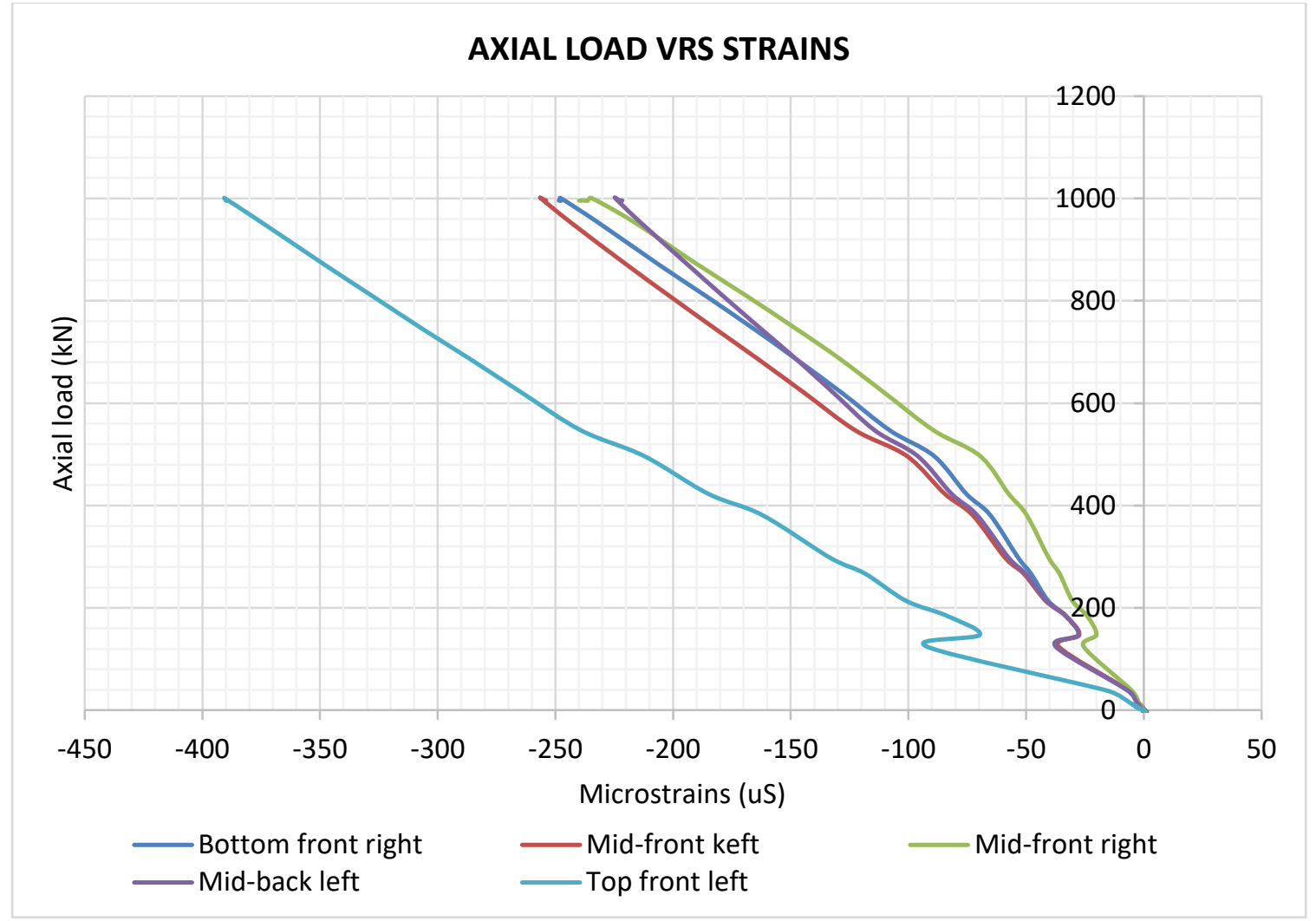

Figure 4-44: Strains in the axially loaded SEIS-18 column.

Figure 4-45 presents the lateral load versus displacement response of SEIS-18. The figure shows that, under the axial loading in the first load regime, the column experienced a mid-height displacement of about $1.05 \mathrm{~mm}$ towards the front face. This lateral displacement was recovered at a load of about $20 \mathrm{kN}$. SEIS-18 failed in a more ductile manner due to the closer tie spacing. A maximum lateral load of $483 \mathrm{kN}$ with a mid-displacement of $23.6 \mathrm{~mm}$. After the capacity was reached and the column could no longer take load, it was unloaded at the same rate. A permanent displacement of $14 \mathrm{~mm}$ was on the column when the load was fully removed. 


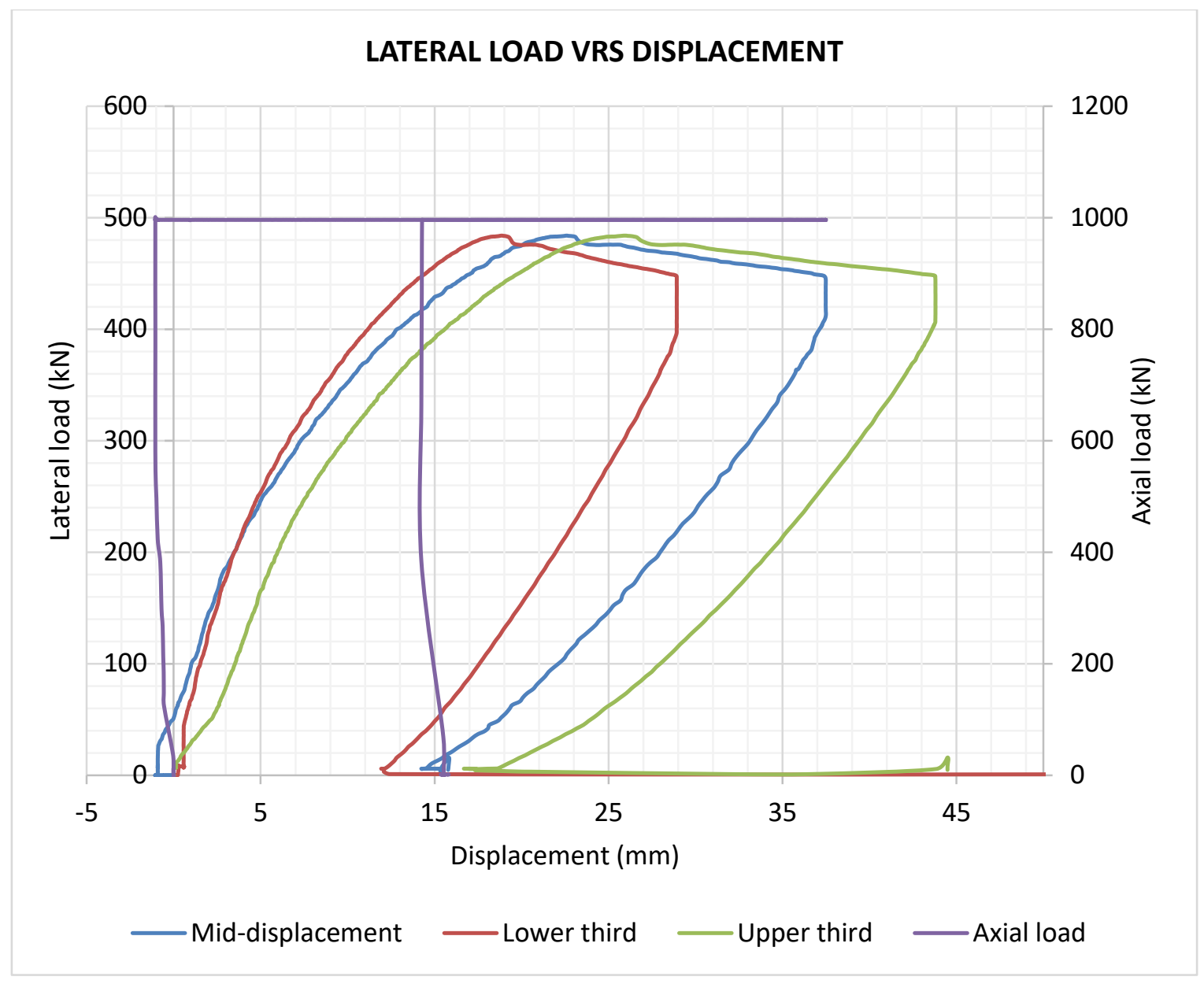

Figure 4-45: Load-displacement curves for column SEIS-18.

Figure 4-46 presents the lateral load versus longitudinal reinforcement strain response. Maximum compressive strain was recorded in the top and mid front regions $\left(1200 \times 10^{-6}\right.$ $\mathrm{mm} / \mathrm{mm}$ ). Strain in the mid-back region was about $1425 \times 10^{-6} \mathrm{~mm} / \mathrm{mm}$. This indicates that the reinforcement had not yielded at the time of failure. 


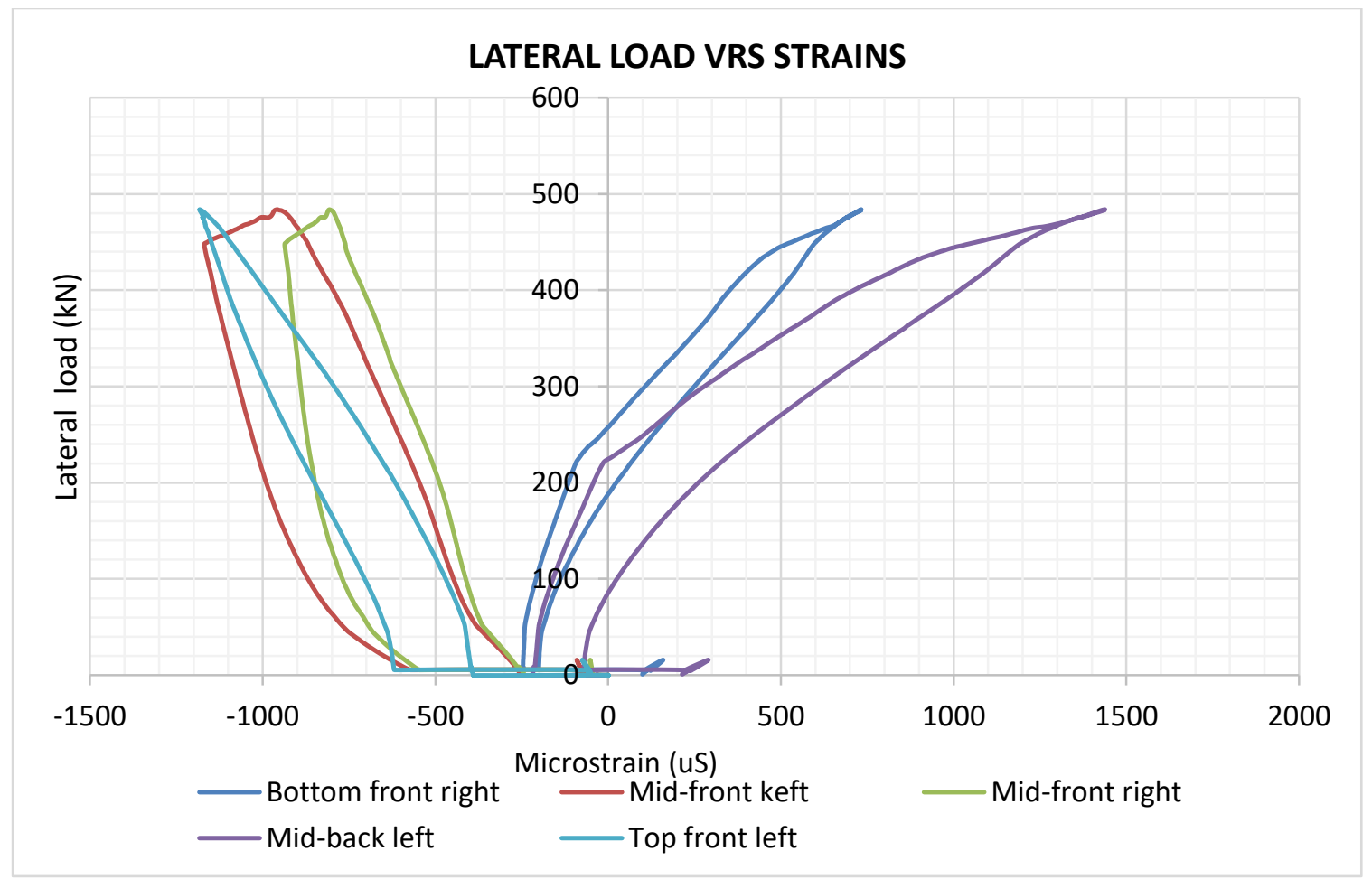

Figure 4-46: Longitudinal reinforcement strains during lateral loading of SEIS-18.

Flexural cracks developed just above the upper load contact point and propagated on the sides towards the front face. Concrete spalling occurred around the same location on the compression side (front face). The combination of tensile and compressive stresses caused failure in the column. The effectiveness of the transverse reinforcement spacing was evident in the mode of failure. Figure 4-47 shows a post-test photograph of SEIS-18. 


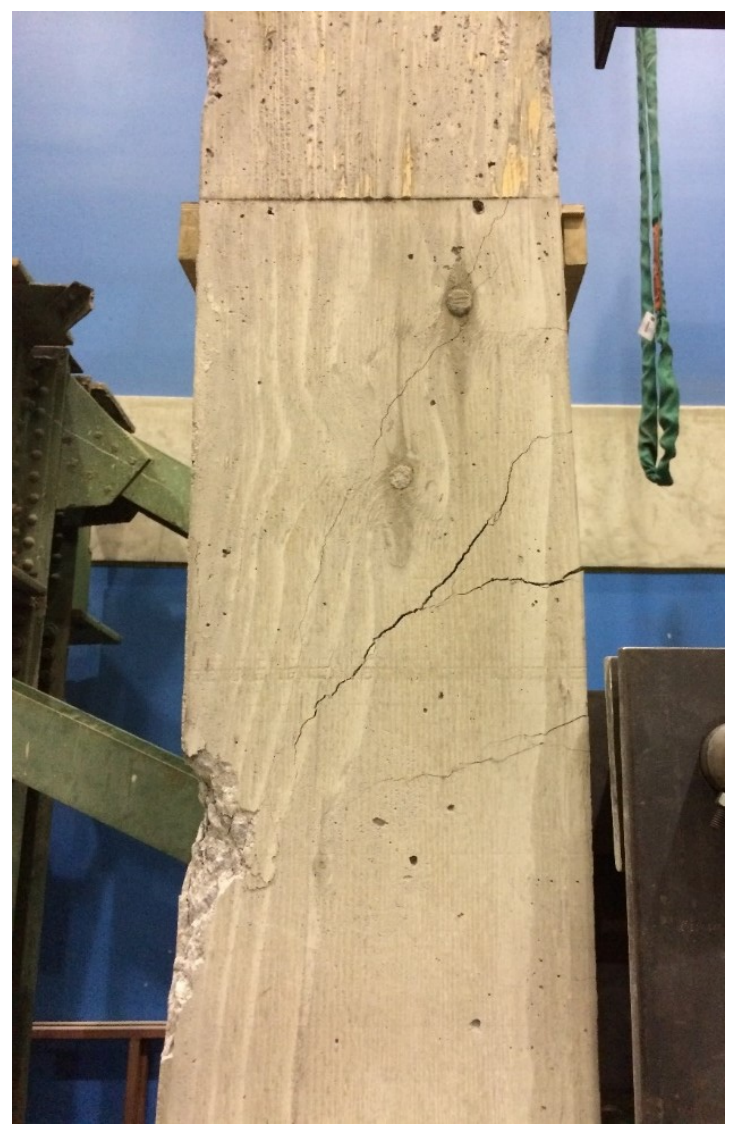

(a)
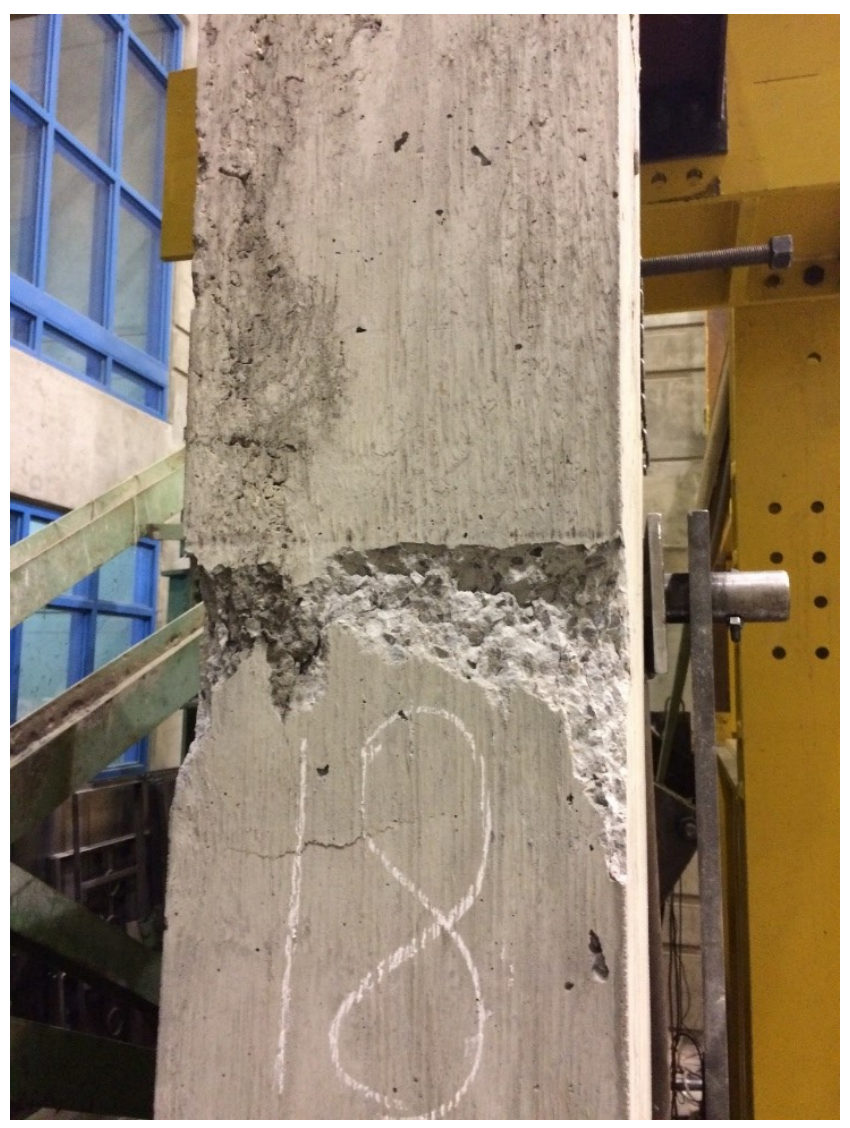

(b)

Figure 4-47: (a) Flexural cracks propagating from tension face onto sides along with shear cracks (b) Flexural cracks propagating from tension face onto sides along with shear cracks.

\subsection{Column Test 12 (SEIS-19)}

SEIS-19 was the last control column to be tested. The service load was resisted by thee column without failure or distress. Figure 4-48 presents the axial load versus longitudinal reinforcement strains during the axial loading regime. Only two strain gauges were functional in SEIS-19; strain in the top front was greater than in the middle region because it was closer to the point of axial load application. From the calculated axial shortening, the strain calculated from Equation 
4-1 $\left(380 \times 10^{-6} \mathrm{~mm} / \mathrm{mm}\right)$ compares well with the measured strain in the mid-region $\left(420 \times 10^{-6}\right.$ $\mathrm{mm} / \mathrm{mm})$.

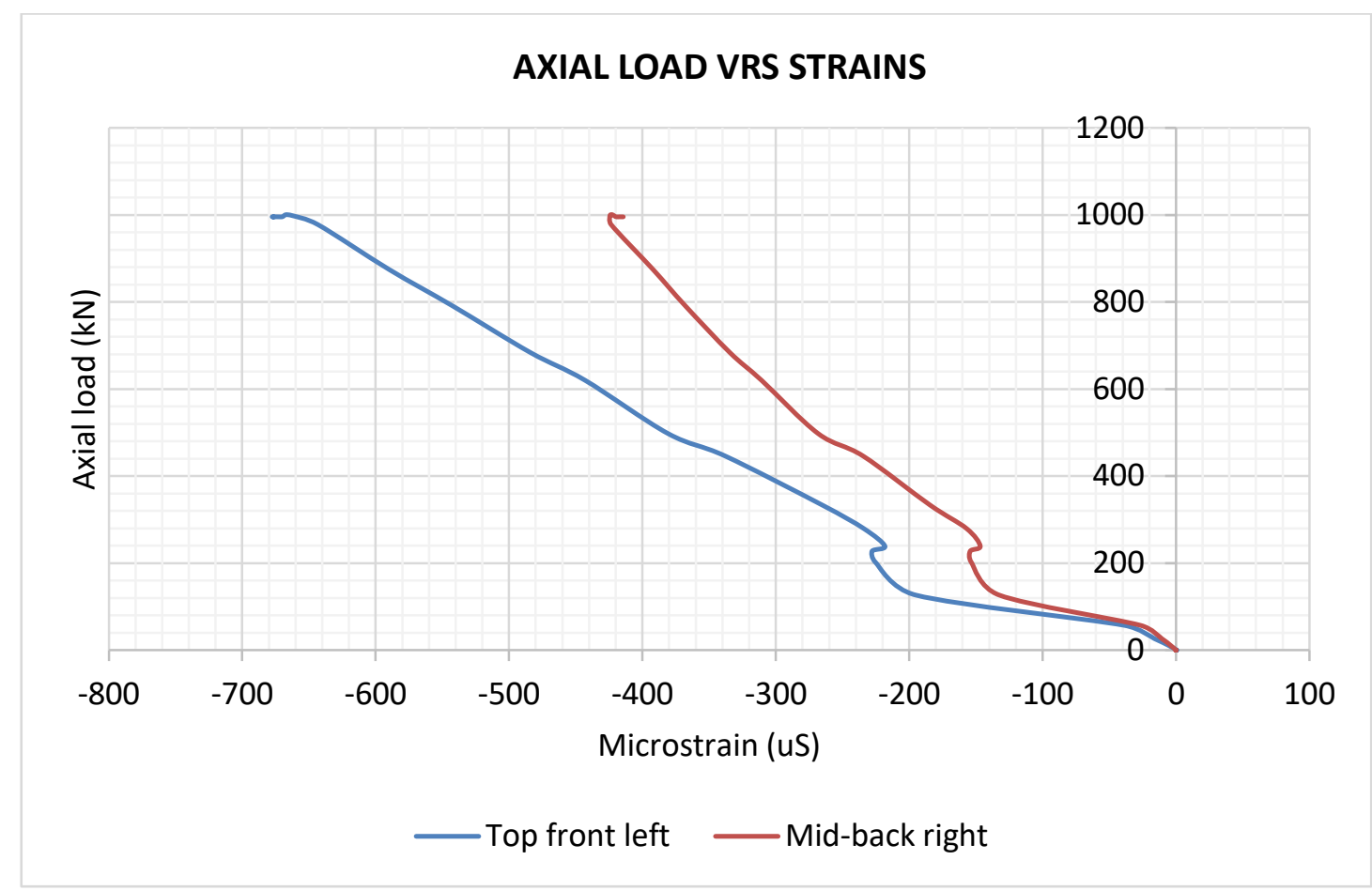

Figure 4-48: Strain reading with increasing axial load during the first stage of the test (SEIS-19).

After the full service load was applied, lateral loading was applied at the same rate of 1.5 $\mathrm{mm} /$ minute. Figure 4-49 presents the lateral load versus displacement response of SEIS-19. The first tension cracks were observed when the lateral load was about $330 \mathrm{kN}$. These cracks widened and propagated to the sides of the column at $415 \mathrm{kN}$. The maximum load for SEIS-19 was $462.3 \mathrm{kN}$ with a corresponding mid-height displacement of $24.2 \mathrm{~mm}$ (Figure 4-49). After the peak lateral load, the column was unloaded. The unloading slope was linear unlike the loading curve, which changed throughout loading phase. The axial load was maintained throughout the second stage of the test. 


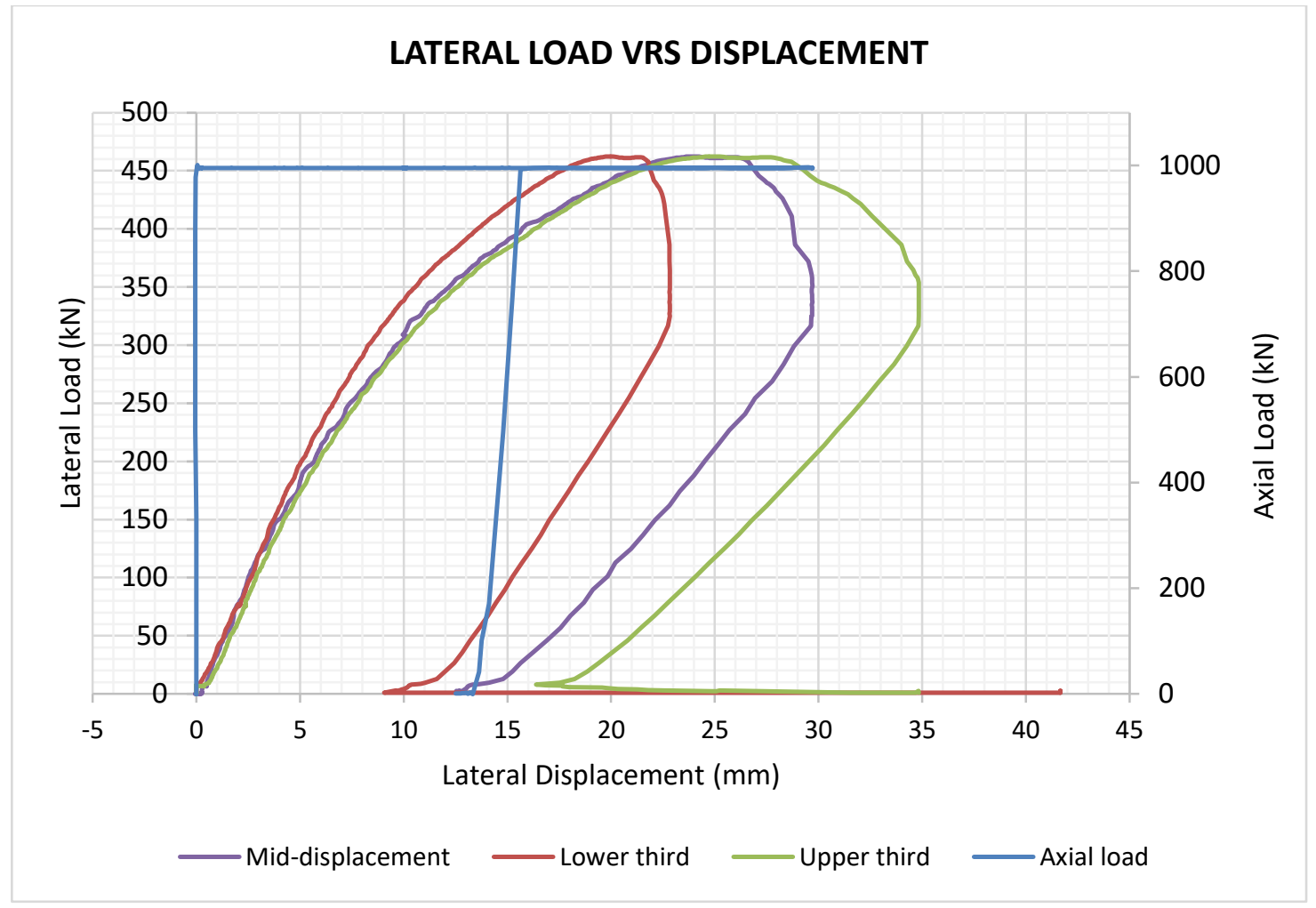

Figure 4-49: Load-displacement curve for column SEIS-19.

Figure 4-50 presents the strains during the second stage of loading. Strains in the top front location reached a maximum of $1800 \times 10^{-6} \mathrm{~mm} / \mathrm{mm}$ (located $2350 \mathrm{~mm}$ above top of footing). The strain gauge in the mid-back region recorded a value of about $1400 \times 10^{-6} \mathrm{~mm} / \mathrm{mm}$; this was less than the yield strain. The strains readings also show the unloading process with the curves following back along the loading curve. 


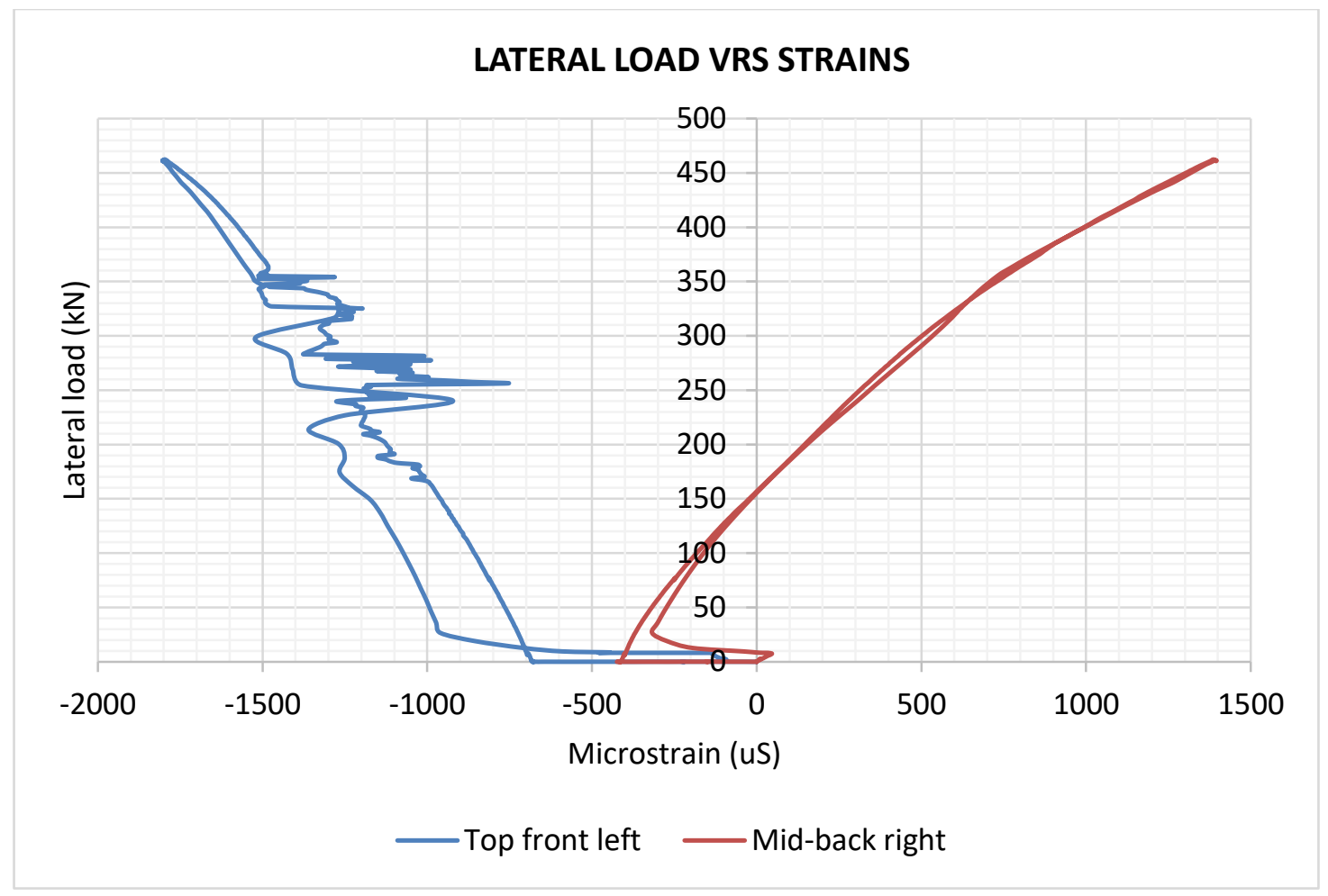

Figure 4-50: Strains in the top and middle locations on SEIS-19 during lateral load application.

Concrete of size $400 \times 300 \times 30 \mathrm{~mm}$ in the zone of high compression stress spalled off towards the end of the test (Figure 4-51a). Flexural cracks were visible on the back face around the upper load contact point. The cracks got wider as the maximum lateral load was reached and the width of the cracks reduced when the column was unloaded. 


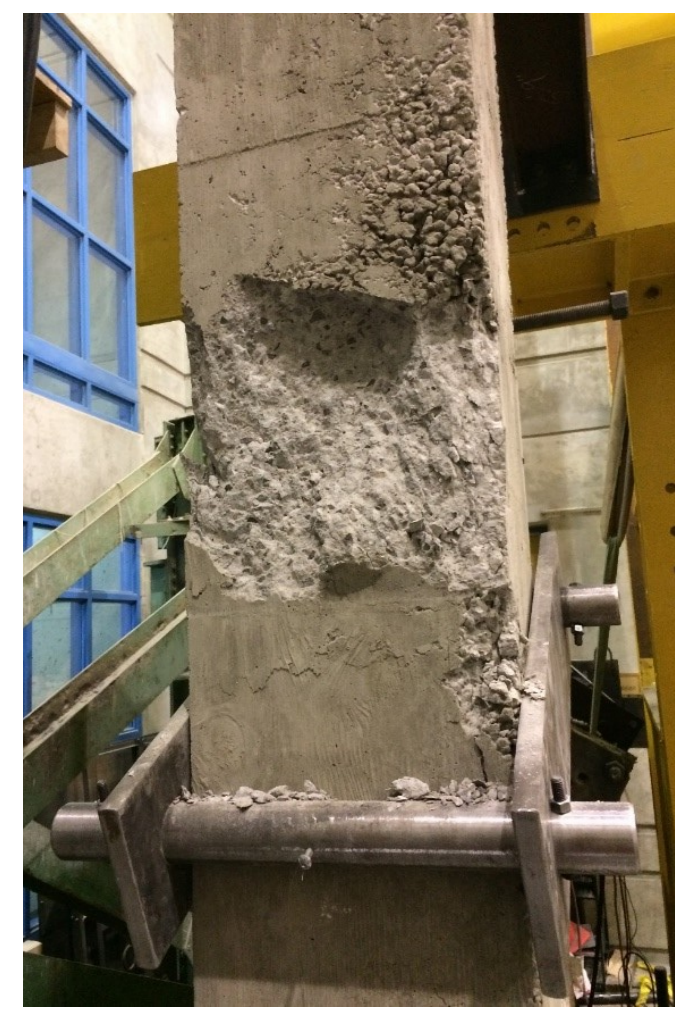

(a)

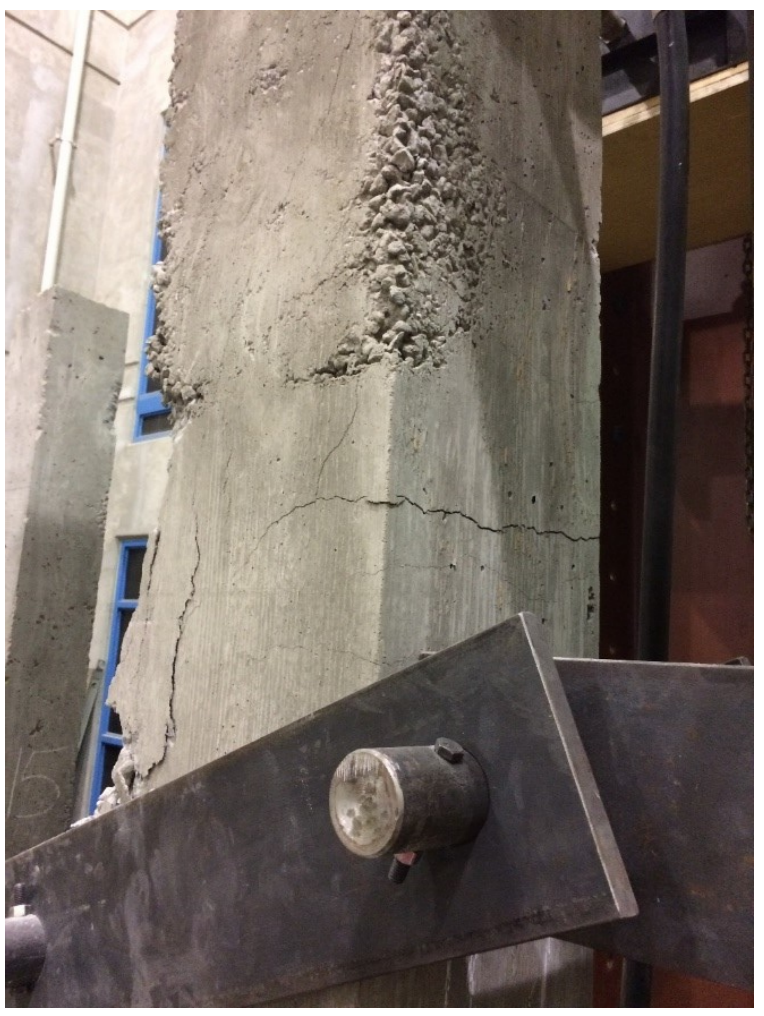

(b)

Figure 4-51: (a) Concrete spalled off on the compression side (front) at the upper load contact point (b) Tension cracks due to flexure in SEIS-19.

\subsection{Column Test 13 (CONV-15; Pre-stressed)}

CONV-15 was the only post-tensioned column that survived the explosion field-testing $(\mathrm{z}=0.86$ $\mathrm{m} / \mathrm{kg}^{1 / 3}$ ). In this program, no service load was applied on CONV-15. The amount of pre-stress on the column was difficult to determine. The post-tensioning strands and cap stuck out about 50 $\mathrm{mm}$. An assembly of steel plates was used to raise the footing off the floor of the structure' laboratory; leaving a void in the middle for the cap to fit in unobstructed (Figure 4-52). 


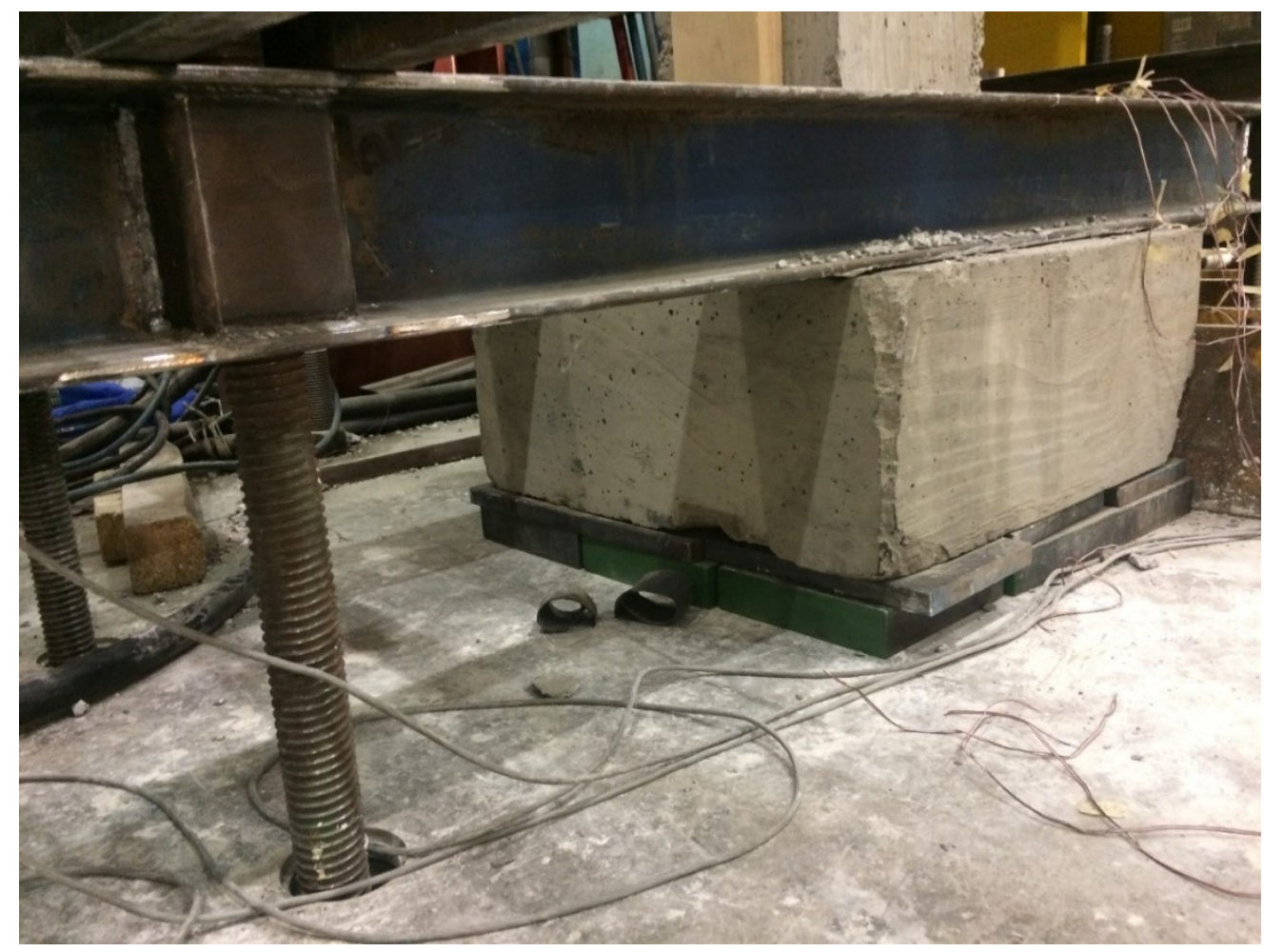

Figure 4-52: CONV-15 put on an assembly of steel washers to accommodate the post-tensioning cap.

The same rate of lateral loading was used in testing CONV-15. From the load-displacement curve in Figure 4-53, the loading portion had a constant slope. This reduced near the peak load of $274.6 \mathrm{kN}$ and a corresponding mid-height displacement of $21.4 \mathrm{~mm}$. The lateral load dropped gently to about $125 \mathrm{kN}$, then the column was unloaded at the same rate. Overall, the column had an average lateral stiffness of about $13.75 \mathrm{kN} / \mathrm{mm}$. 


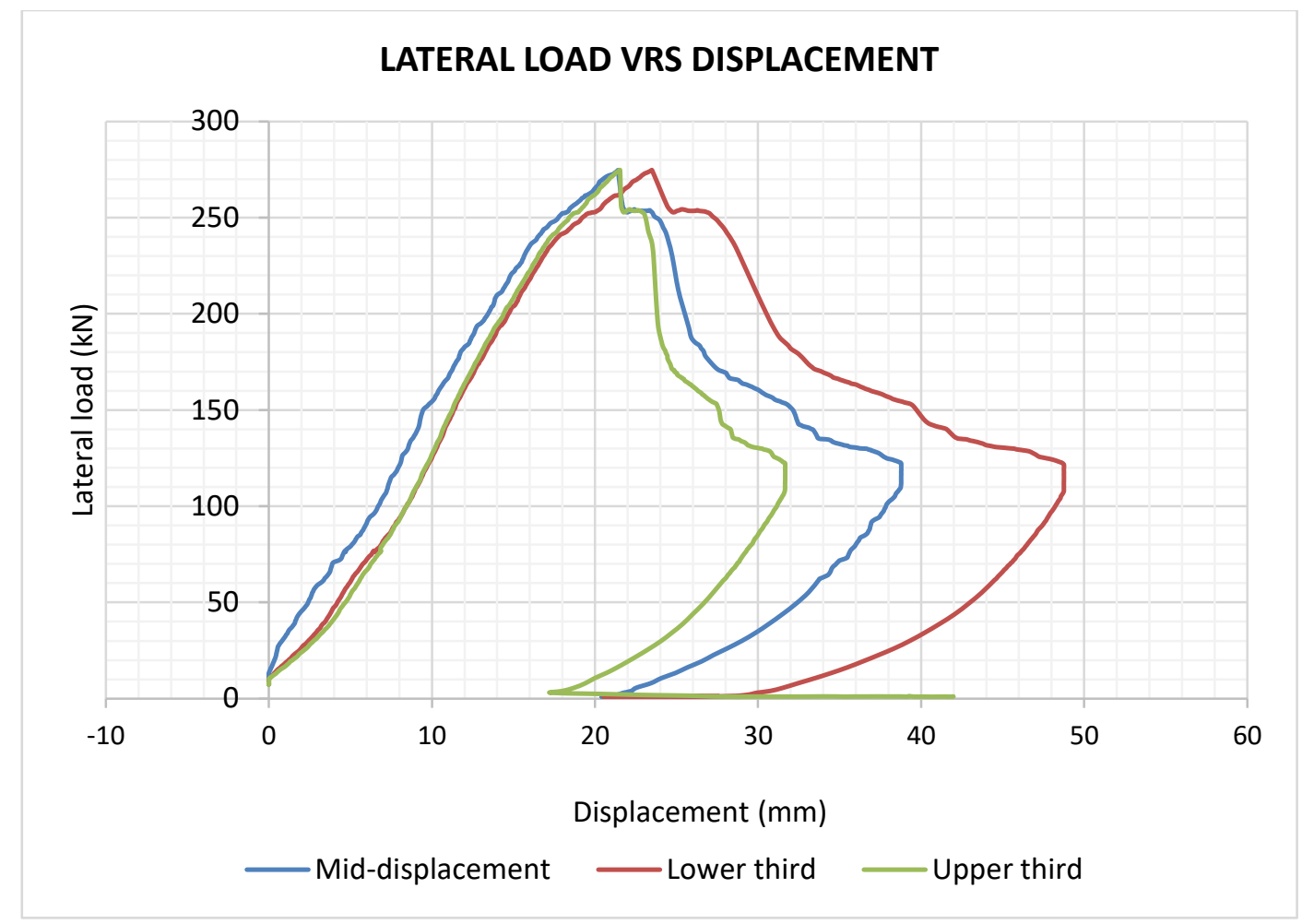

Figure 4-53: Lateral load versus displacement for CONV-15 (post-tensioned).

Figure 4-54 presents the strains in the longitudinal reinforcement as the lateral load was applied. Strains in the mid-back region were about $2500 \times 10^{-6} \mathrm{~mm} / \mathrm{mm}$, which was equivalent to the yield strain of the reinforcement. The maximum compressive strain was recorded in the mid-front gauge $\left(1000 \times 10^{-6} \mathrm{~mm} / \mathrm{mm}\right)$. 


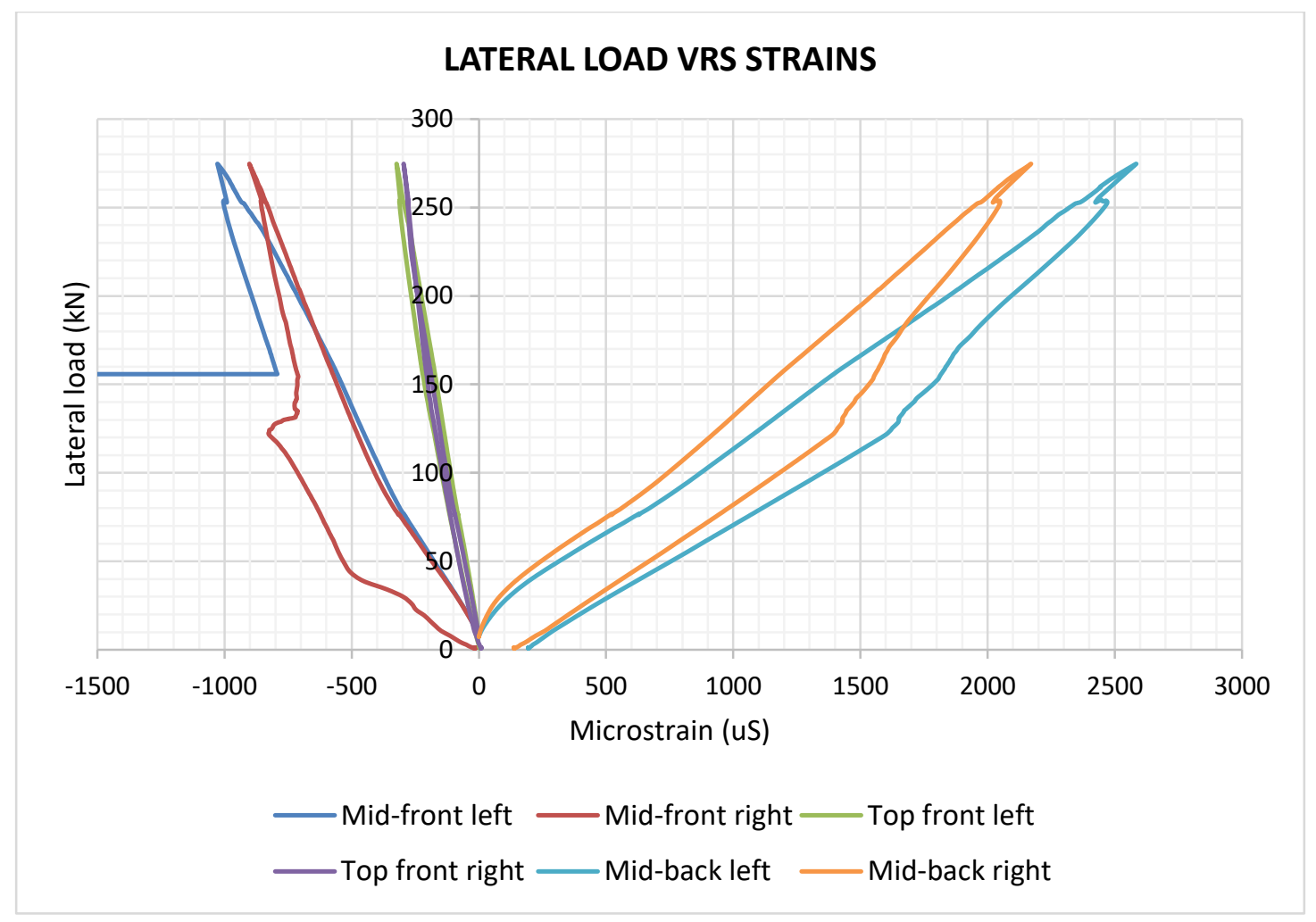

Figure 4-54: Strain recording in CONV-15 during the application of the lateral load.

Shear cracks formed during the test and widened with subsidiary ones forming closely together. These cracks developed at roughly $30^{\circ}$ to the vertical. Figure $4-55$ shows the formation and development of shear failure in the column. A major crack was observed in the shear span and led to failure of CONV-15. 

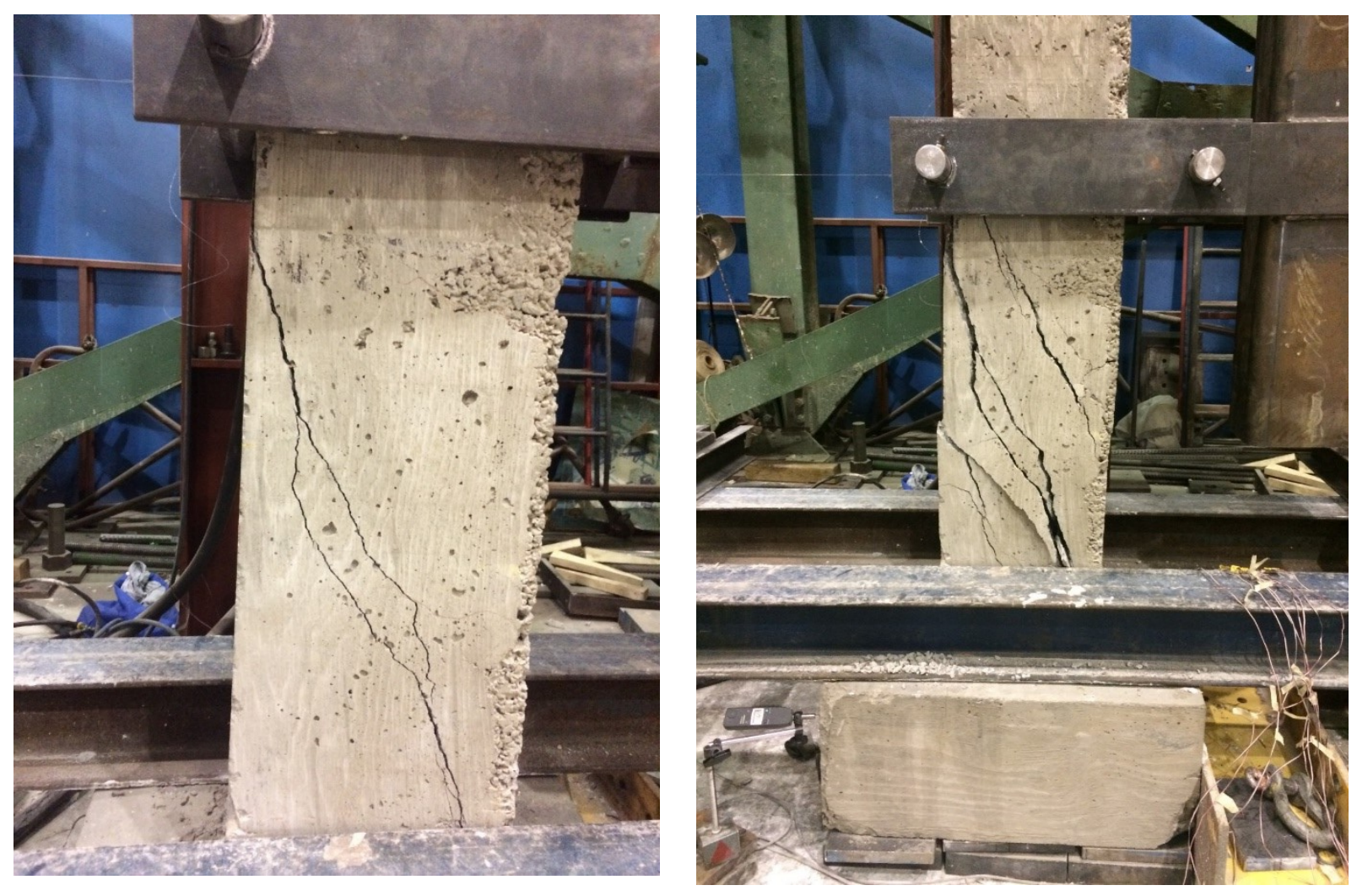

Figure 4-55: (a) Shear cracks beginning to develop. (b) Fully formed shear failure in CONV-15. 


\subsection{Discussion of Results}

To a high degree, this experimental program was successful; instrumentation worked well and the data collected was reasonable. In the first test, cracks developed in the footing indicating some degree of support rotation. This was corrected by torqueing the nuts that were part of the hold-down arrangement. In subsequent tests, a digital gauge was used to monitor rotation of the hold-down system. Little to no rotation occurred with the digital gauges recording less than 0.9 $\mathrm{mm}$ displacement of the hold-down beams. Some strain gauges failed during the blast fieldtesting and hence did not record any data in this residual capacity test program. The effects of scaled distance and transverse reinforcement detailing on the response of the reinforced concrete columns are discussed in this section.

\subsubsection{Conventional columns}

Seven (7) conventionally designed columns were tested in this residual capacity program. Of these, five (5) were blast-damaged with one (1) having been post-tensioned previously to investigate the effect of axial load on column behaviour under blast loading. The other two (2) were control columns (CONV-16 and CONV-17), tested for comparison with the blast-damaged columns. All conventionally designed columns resisted the full service load of $1000 \mathrm{kN}$; about $32 \%$ of the axial load capacity of the columns. The residual capacities of the blast-damaged column under lateral loading are compared to the average of the capacities of the control columns. 


\subsubsection{Effect of scaled distance}

The two conventionally designed reinforced concrete columns; CONV-16 and CONV-17 tested with a service load of $1000 \mathrm{kN}$, had lateral capacity of $404.6 \mathrm{kN}$ and $420.5 \mathrm{kN}$, respectively. The average lateral capacity of these columns $(412.55 \mathrm{kN})$ will be used as the reference for comparing to the blast-damaged columns. The effect of scaled distance on the residual capacity of the conventional columns is discussed in this section. CONV-07, which was blast-damaged at a scaled distance of $0.58 \mathrm{~m} / \mathrm{kg}^{1 / 3}$, exhibited the highest capacity under lateral loading of $445 \mathrm{kN}$. CONV-06 with similar characteristics failed at a load of $154.2 \mathrm{kN}$. The capacity of CONV-06 was $37.4 \%$ while CONV-07 was $108 \%$.

Of the three columns, previously tested at a scaled distance range of $0.82-0.88 \mathrm{~m} / \mathrm{kg}^{1 / 3}(\mathrm{CONV}$ 11, CONV-12 and CONV-15). CONV-11 reached a maximum lateral load of $365 \mathrm{kN}$ which corresponds to a residual capacity of $88.6 \%$. CONV-12 reached a maximum lateral load of 299 $\mathrm{kN}$ (residual capacity of $75.2 \%$ ) while the post-tensioned CONV-15 had a residual capacity of $275 \mathrm{kN}(66.6 \%)$ compared to the average of the control columns.

Figure 4-56 compares the lateral load versus displacement response of the conventional columns. From the figure, the stiffness of CONV-15 is lowest compared with all the other conventional columns. This is due to the absence of the service load. It also is an indication of significant loss in prestressing force in the post-tensioned column in the blast event. It is uncertain how much of the effective post-tension stress remained on the column after blast damage. It is however likely, from the stiffness of the column, that the stress on the column was less than ALR of 0.32 . The stiffness of the other columns were similar. 
Table 4-1 summarizes the test results of the conventionally designed columns. In general, the larger the scaled distance the higher the residual capacity in comparison with the control columns.

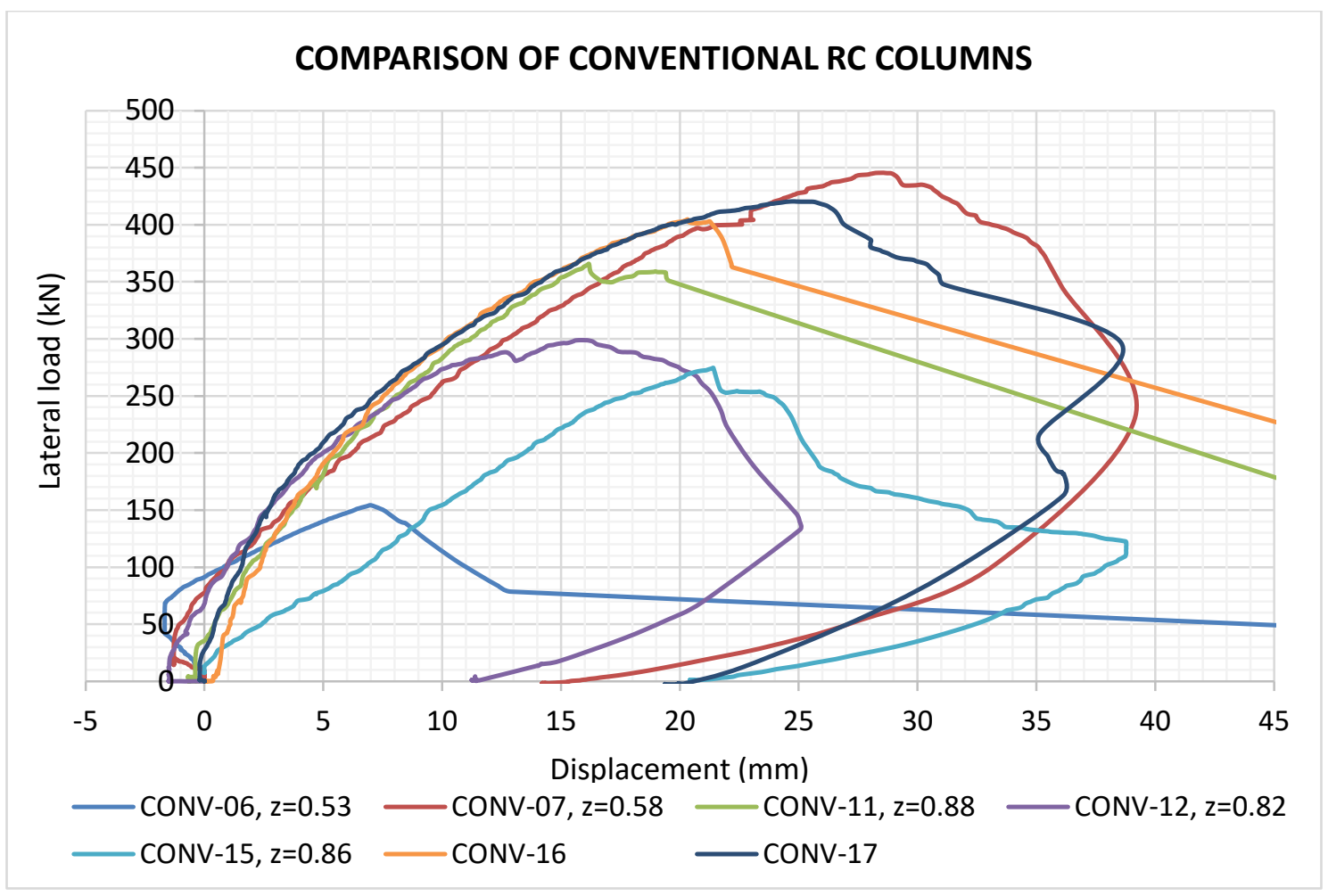

Figure 4-56: Comparison of capacity of conventionally designed RC columns. 
Table 4-1: Summary of test results for conventional columns (loads and displacements).

\begin{tabular}{|c|c|c|c|c|c|c|c|c|c|c|c|c|}
\hline \multirow{3}{*}{ Column } & \multirow{3}{*}{$\begin{array}{l}\mathbf{A L} \\
\mathbf{R}\end{array}$} & \multirow{3}{*}{$\begin{array}{l}\text { Standoff } \\
\text { distance } \\
\text { (m) }\end{array}$} & \multirow{3}{*}{$\begin{array}{c}\text { Scaled } \\
\text { distance, } \\
z \\
\left(\mathbf{m} / \mathbf{k g}^{1 / 3}\right)\end{array}$} & \multirow{3}{*}{$\begin{array}{l}\text { Permanent } \\
\text { mid-height } \\
\text { displacement } \\
(\mathrm{mm})\end{array}$} & \multicolumn{2}{|c|}{ AXIAL LOAD } & \multicolumn{4}{|c|}{ LATERAL LOAD } & \multirow{3}{*}{$\begin{array}{c}\text { Average } \\
\text { stiffness } \\
(\mathrm{kN} / \mathbf{m m})\end{array}$} & \multirow{3}{*}{$\begin{array}{c}\text { Residual } \\
\text { capacity } \\
(\%)\end{array}$} \\
\hline & & & & & \multirow{2}{*}{$\begin{array}{l}\text { Axial } \\
\text { load } \\
(\mathrm{kN})\end{array}$} & \multirow{2}{*}{$\begin{array}{c}\text { Mid- } \\
\text { displacement } \\
(\mathrm{mm})\end{array}$} & \multirow{2}{*}{$\begin{array}{c}\text { Lateral } \\
\text { load } \\
(\mathbf{k N})\end{array}$} & \multicolumn{3}{|c|}{$\begin{array}{l}\text { Lateral deflection } \\
\qquad(\mathrm{mm})\end{array}$} & & \\
\hline & & & & & & & & Lower & Mid & Upper & & \\
\hline CONV-06 & 0 & 2.66 & 0.53 & 16 & 1000 & -3.2 & 154.2 & 10.1 & 9.4 & 9.5 & 16.4 & 37.4 \\
\hline CONV-07* & 0 & 2.5 & 0.58 & -30 & 1000 & -1.28 & 445.5 & 23.4 & 29.78 & 29.02 & 14.95 & 108.0 \\
\hline CONV-11 & 0 & 4.4 & 0.88 & -10 & 1000 & -0.68 & 365.6 & 17.2 & 16.9 & 22.7 & 21.6 & 88.6 \\
\hline CONV-12 & 0 & 4.1 & 0.82 & -11 & 1000 & -1.5 & 298.9 & 17.5 & 17.4 & 19.8 & 13.16 & 72.5 \\
\hline CONV-15 & 0.32 & 4.26 & 0.86 & -5 & 0 & - & 274.6 & 23.5 & 21.4 & 21.5 & 12.8 & 66.6 \\
\hline CONV-16 & 0 & - & - & - & 1000 & 0.05 & 404.6 & 17.2 & 20.33 & 20.8 & 19.9 & $\mathrm{~N} / \mathrm{A}$ \\
\hline CONV-17 & 0 & - & - & - & 1000 & -0.2 & 420.5 & 21.7 & 25.0 & 23.9 & 16.82 & $\mathrm{~N} / \mathrm{A}$ \\
\hline
\end{tabular}

*- column subjected to 100-kg ANFO explosion, all others subjected to 150-kg ANFO explosion 


\subsubsection{Seismic columns}

Six (6) columns were detailed according to requirements in CSA A23.3-04 to resist primarily gravity loading but to have enough ductility to sustain the lateral displacement of the seismic force resisting system of the building. In general, the SEIS- columns were more ductile during the testing. All the columns resisted the service load level ALR of 0.32 without failure. The results obtained are discussed here.

\subsubsection{Effect of scaled distance}

SEIS-18 and SEIS-19, which were the control columns, carried lateral loads of $483.9 \mathrm{kN}$ and $462.3 \mathrm{kN}$ respectively. The average of the two $(473.1 \mathrm{kN})$, is used as the reference value for the blast-damaged columns comparison. Figure 4-57 presents a lateral load versus displacement behaviour of the seismic column. At scaled distances of $0.52 \mathrm{~m} / \mathrm{kg}^{1 / 3}$ for SEIS-09 and 0.58 $\mathrm{m} / \mathrm{kg}^{1 / 3}$ for SEIS-08, the columns sustained lateral loads of $292.9 \mathrm{kN}$ and $318.5 \mathrm{kN}$ respectively. The percentage residual lateral load capacity were $67.3 \%$ and $61.9 \%$ for SEIS-08 and SEIS-09 respectively, in comparison with the average control column lateral load capacity. SEIS-09 had a lower stiffness due to the damage sustained in the blast testing (concrete spall on the mid-back region exposing the reinforcement shown in Figure 4-15). The stiffness is generally the same for all the seismically detailed columns $(18-20.5 \mathrm{kN} / \mathrm{mm})$. At scaled distances of $0.82 \mathrm{~m} / \mathrm{kg}^{1 / 3}$ for SEIS-13 and $0.86 \mathrm{~m} / \mathrm{kg}^{1 / 3}$ for SEIS-14, the columns sustained maximum lateral loads of 461.2 $\mathrm{kN}$ and $416.4 \mathrm{kN}$ respectively. The corresponding percentage residual lateral load capacity of SEIS-13 and SEIS-14 were $97.5 \%$ and $88.0 \%$ respectively. In general, the larger the scaled distance the higher the residual capacity of the columns. Figure 4-57 shows a graphical comparison of all the columns designated as SEIS-\#. Table 4-2 is a summary of the test results of the seismically detailed columns. 


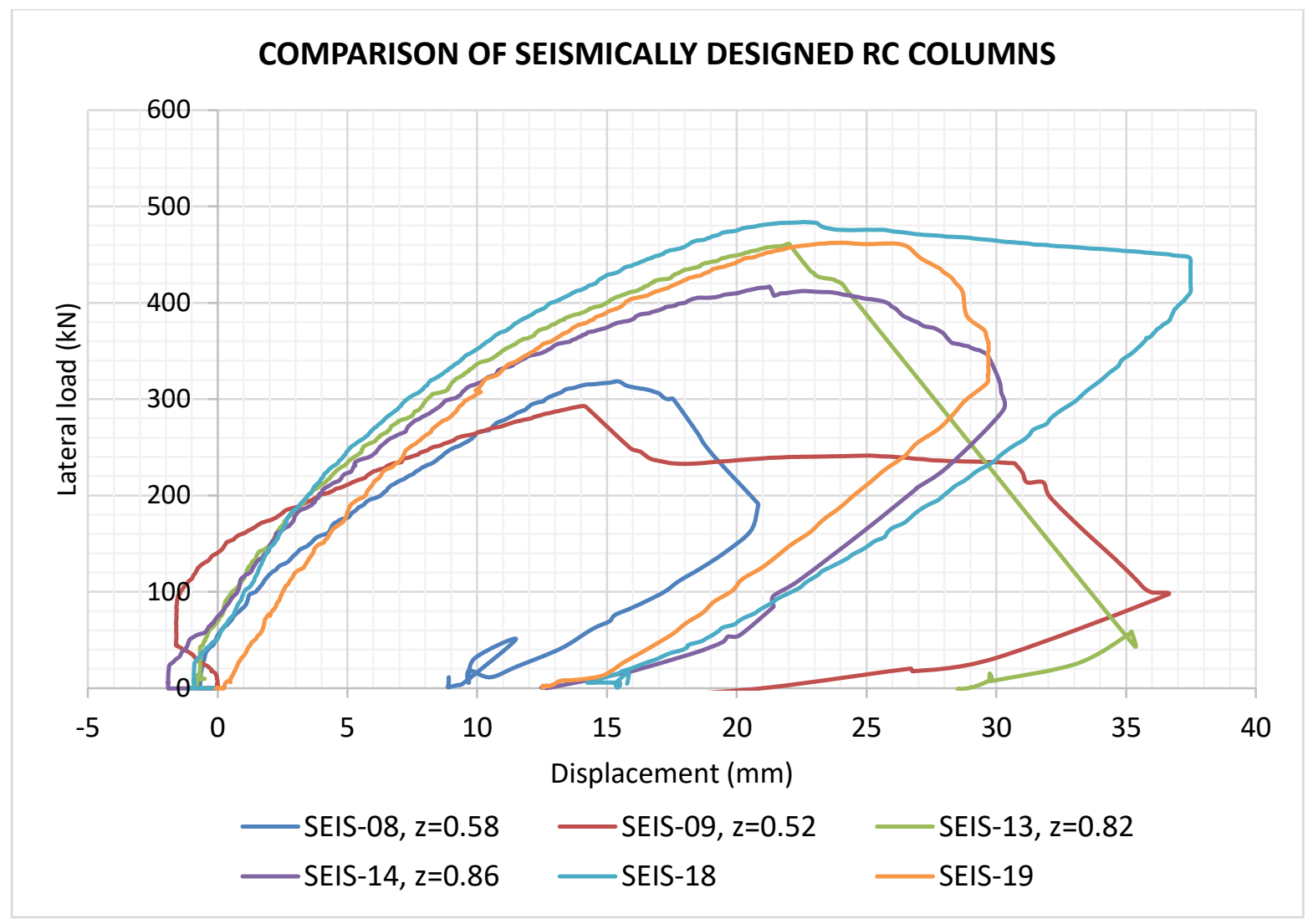

Figure 4-57: Comparison of seismically detailed columns. 
Table 4-2: Summary of test results for seismic columns (loads and displacements).

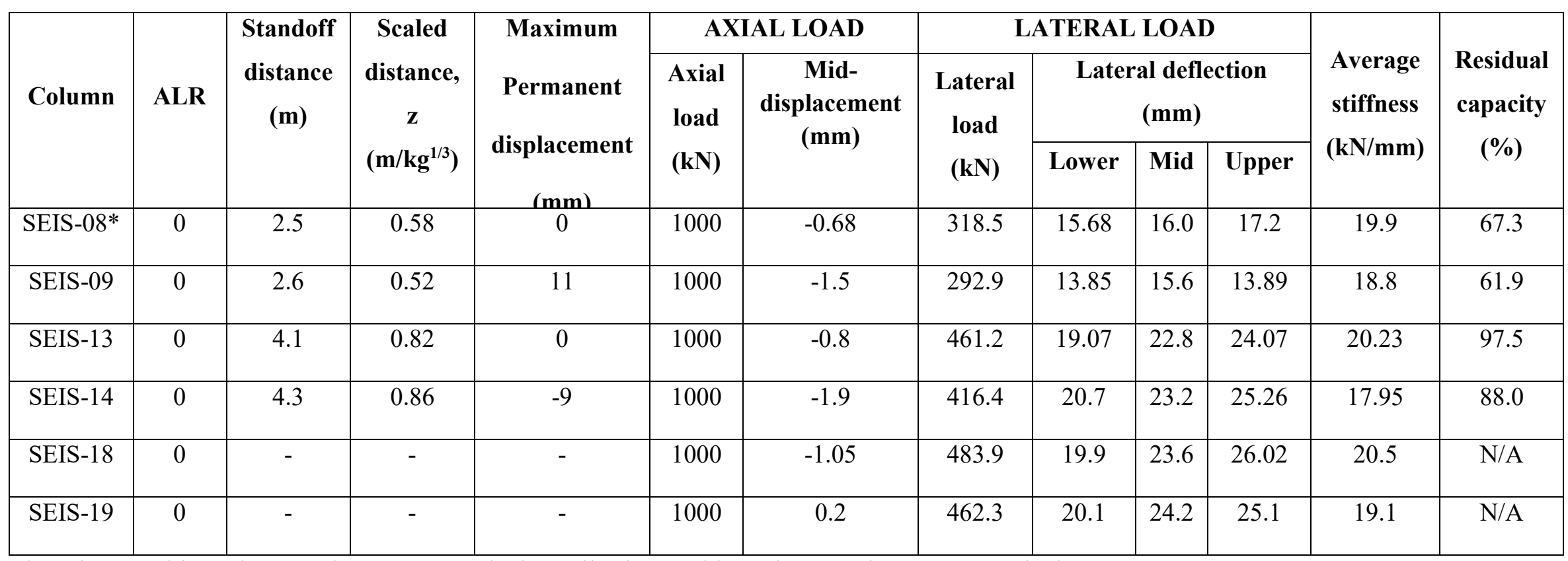

*- column subjected to 100-kg ANFO explosion, all others subjected to 150-kg ANFO explosion 


\subsubsection{Effect of transverse reinforcement detailing}

The effect of transverse reinforcement is discussed from the test results. All conventional columns had transverse reinforcement (10M) spaced at 300-mm on centres. The seismic columns on the other hand were detailed with $10 \mathrm{M}$ bars spaced at $75 \mathrm{~mm}$ in the upper and lower plastic hinge zones of $450 \mathrm{~mm}$ (Figure 3-1).

\subsubsection{1 $\mathrm{Z}=0.55 \mathrm{~m} / \mathrm{kg}^{1 / 3}$}

Four columns were previously tested at a scaled distances ranging from $0.52 \mathrm{~m} / \mathrm{kg}^{1 / 3}$ to 0.58 $\mathrm{m} / \mathrm{kg}^{1 / 3}$. As mentioned in an earlier section, CONV-07 had an abnormally higher capacity. In general, the seismically detailed columns had a higher residual capacity. As shown in Figure 458, SEIS-08 and SEIS-09 had higher residual lateral capacities compared CONV-06. CONV-07 however had the greatest capacity. This may be attributed to the increased lateral load capacity because of the higher post-blast permanent displacement. 


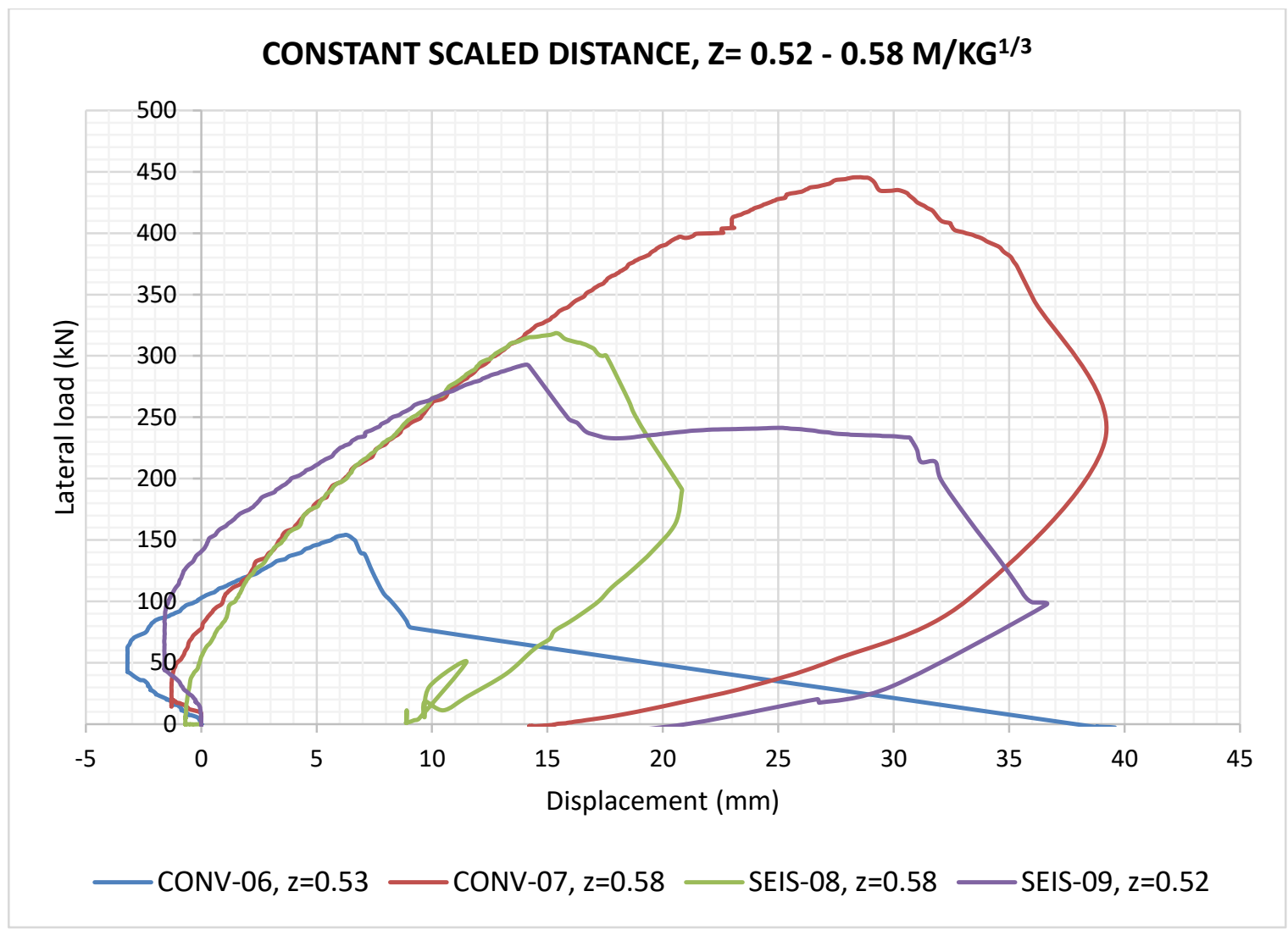

Figure 4-58: Comparison of column tested at a scaled distance of about $0.55 \mathrm{~m} / \mathrm{kg} 1 / 3$.

\subsubsection{2 $\mathrm{Z}=0.86 \mathrm{~m} / \mathrm{kg}^{1 / 3}$}

Five of the test columns had been previously tested at a scaled distance of $0.86 \mathrm{~m} / \mathrm{kg}^{1 / 3}$. SEIS-13 and SEIS-14 exhibited higher lateral load capacity than the conventional columns (CONV-11, CONV-12, and CONV-15. Although the seismically detailed columns were not designed for blast, they have an inherent capability for better performance when exposed to blast loading as compared to the conventional columns. Figure 4-59 shows the comparison of columns tested at a scaled distance of about $0.86 \mathrm{~m} / \mathrm{kg}^{1 / 3}$. 


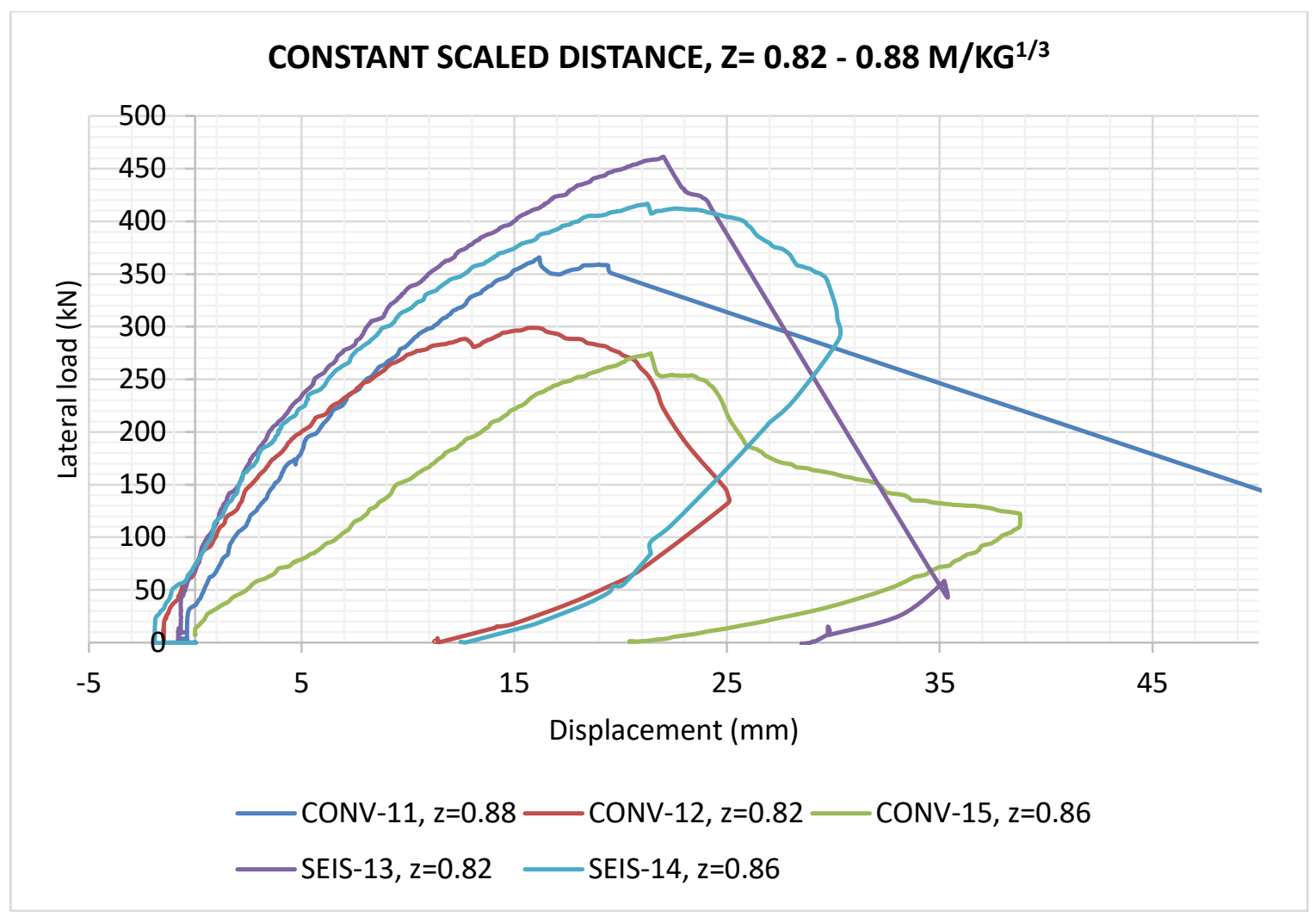

Figure 4-59: Constant scaled distance $(z=0.86 \mathrm{~m} / \mathrm{kg1} / 3)$.

\subsubsection{Undamaged columns $(z=$ infinity $)$}

SEIS- 18 and SEIS-19 showed slightly higher lateral resistance compared to CONV-16 and CONV-17 (Figure 4-60). They also were slightly more ductile. Both seismically detailed columns failed in flexure while CONV-16 failed in shear. CONV-17 failed in flexure due to an increased bending moment. This resulted due to the inadequate rigid support. Another observation was that both seismic columns did not fail abruptly; rather after attaining maximum lateral loads, they were unloaded until all of their lateral loads were taken off. Smaller cracks that had developed between the load points during the lateral load application stage closed up when the columns were unloaded. A maximum lateral displacement of about $38 \mathrm{~mm}$ was reached by 
SEIS-18 while CONV-16 which failed in shear, attained a maximum lateral displacement of 22 $\mathrm{mm}$ before failing abruptly in shear.

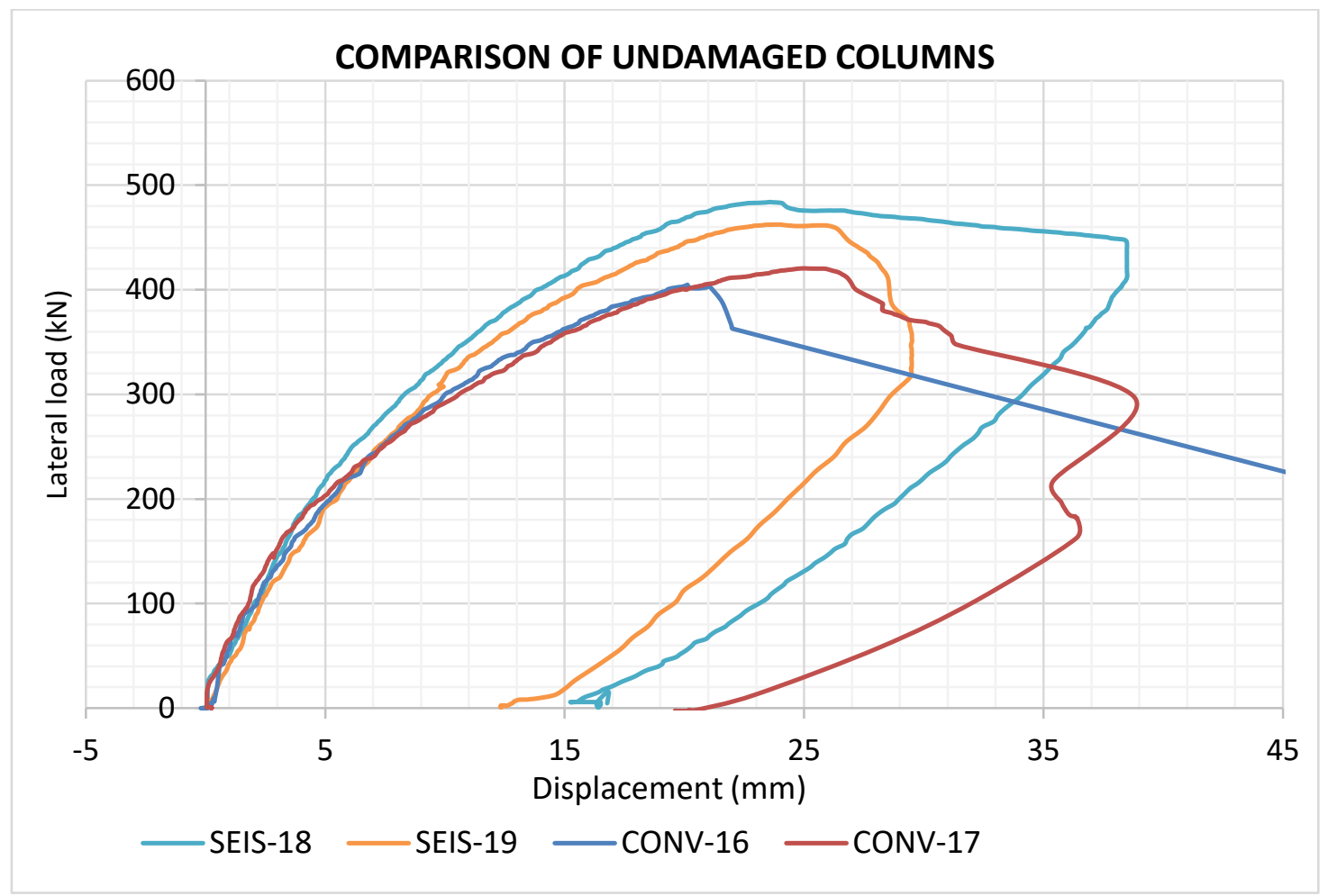

Figure 4-60: Comparison of the performance of undamaged control columns.

\subsubsection{Numerical Model}

A numerical model was created in OpeenSees to investigate behaviour of the reinforced concrete columns under lateral loading while sustaining the service axial load level and to compare with the experimental results of the virgin columns. For modeling unconfined concrete in the cover of the members, Hognestad's model (Hognestad, 1951) was used. The tensile strength for the concrete cover was ignored in this material model.

$f_{c}^{\prime}=41.3 \mathrm{MPa} \quad E_{c}=4500 \sqrt{f_{c}^{\prime}}=28920 \mathrm{MPa} \quad \varepsilon_{o}=2 f_{c}^{\prime} / E_{c}=0.00286$ 
The parameters defined above are based on the definitions of the Hognestad's model shown in Figure 4-61. Concrete01 model was used in the OpenSees code to define the concrete cover (unconfined concrete). In order to reflect the crushing of the concrete cover in the members, the ultimate crushing stress of the concrete was selected as $85 \%$ of the maximum strength. The command line for using this material model in OpenSees is as follows:

$$
\text { uniaxialMaterial Concrete01 \$matTag \$fpc \$epsc0 \$fpcu \$epsU }
$$

Where \$matTag is the material tag for the concrete cover;

\$fpc: compressive strength of concrete at 28 days;

\$epsc0: concrete strain at maximum strength;

\$fpcu: concrete crushing strength and

\$epsU: concrete strain at crushing strength.

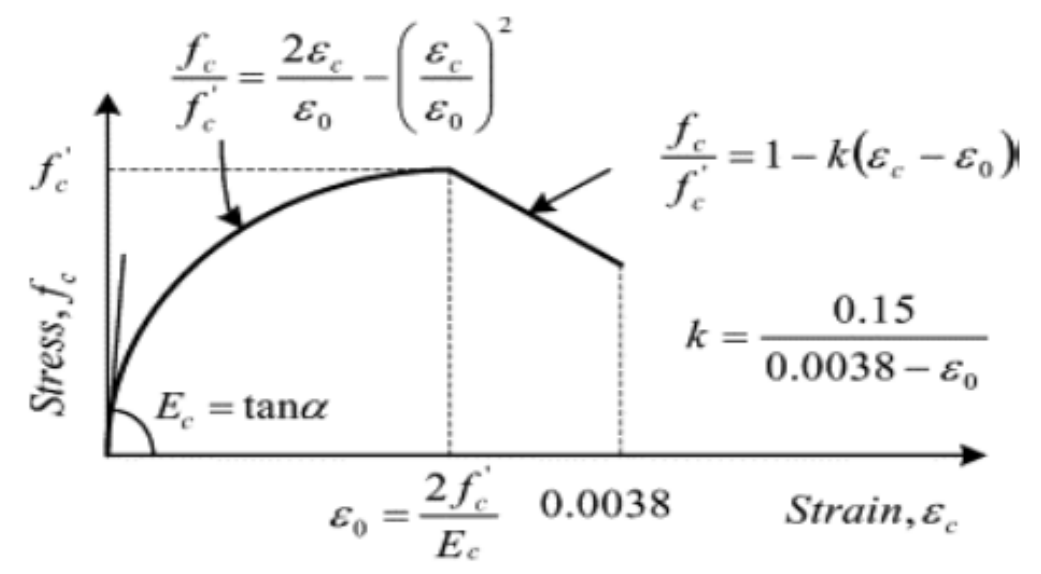

Figure 4-61: Unconfined concrete model by Hognestad (Wu et al 2006)

Concrete model concrete 07 in OpenSees was used for simulating the confined concrete material. This model is based on derivations by Chang and Mander (1994) and is shown in Figure 4-62. The longitudinal and transverse detailing of the columns were used to determine the properties of 
the confined core. The calculations of the properties of the confined concrete in the core of the columns are presented in the following:

$$
\begin{aligned}
& \text { Effective confined area, } A_{e}=\left(b_{c} d_{c}-\sum \frac{\left(w_{i}^{\prime}\right)^{2}}{6}\right)\left(1-0.5 \frac{s}{b_{c}}\right)\left(1-0.5 \frac{s}{d_{c}}\right) \\
& =\left(195 \times 195-4 \frac{(195)^{2}}{6}\right)\left(1-0.5 \frac{75}{195}\right)\left(1-0.5 \frac{75}{195}\right)=8268.75 \mathrm{~mm}^{2}
\end{aligned}
$$

Concrete core area, $A_{c}=b_{c} d_{c}-A_{s}=195 \times 195-4 \times 500=36025 \mathrm{~mm}^{2}$

$k_{e}=A_{e} / A_{c}=0.2295$

$\rho_{x}=\rho_{y}=\frac{A_{s}}{s \times d_{c}}=\frac{2 \times 100}{75 \times 195}=0.0136$

confinement stress, $f_{x}=f_{y}=k_{e} \rho_{x} f_{y h}=1.4513 \mathrm{MPa}$

$q=f_{x} / f_{y}=1.0 \quad x^{\prime}=\frac{f_{x}+f_{y}}{2 f_{c}}=0.035$

$A=\left(6.8886-(0.6096+17.275 q) e^{-4.989 q}=6.767\right.$

$B=\frac{4.5}{\frac{5}{A}\left(0.9849-0.6303 e^{-3.9839 q}\right)-0.1}=7.28$

$k_{1}=A\left(0.1+\frac{0.9}{1+B x^{\prime}}\right)=5.53 \quad \rightarrow \quad f_{c c}^{\prime}=f_{c}^{\prime}\left(1+k_{1} x^{\prime}\right)=49.29 \mathrm{MPa}$

$k_{1}=5 k_{1}=27.65 \rightarrow \varepsilon_{c c}=\varepsilon_{o}\left(1+k_{2} x^{\prime}\right)=0.00563$

$X_{n}=30 \quad \& \quad X_{p}=2 \quad n=\frac{E_{c} \varepsilon_{c c}}{f_{c c}^{\prime}}=\frac{28920 \times 0.0084}{57.34}=3.3 \quad r=n /(n-1)=1.435$ 


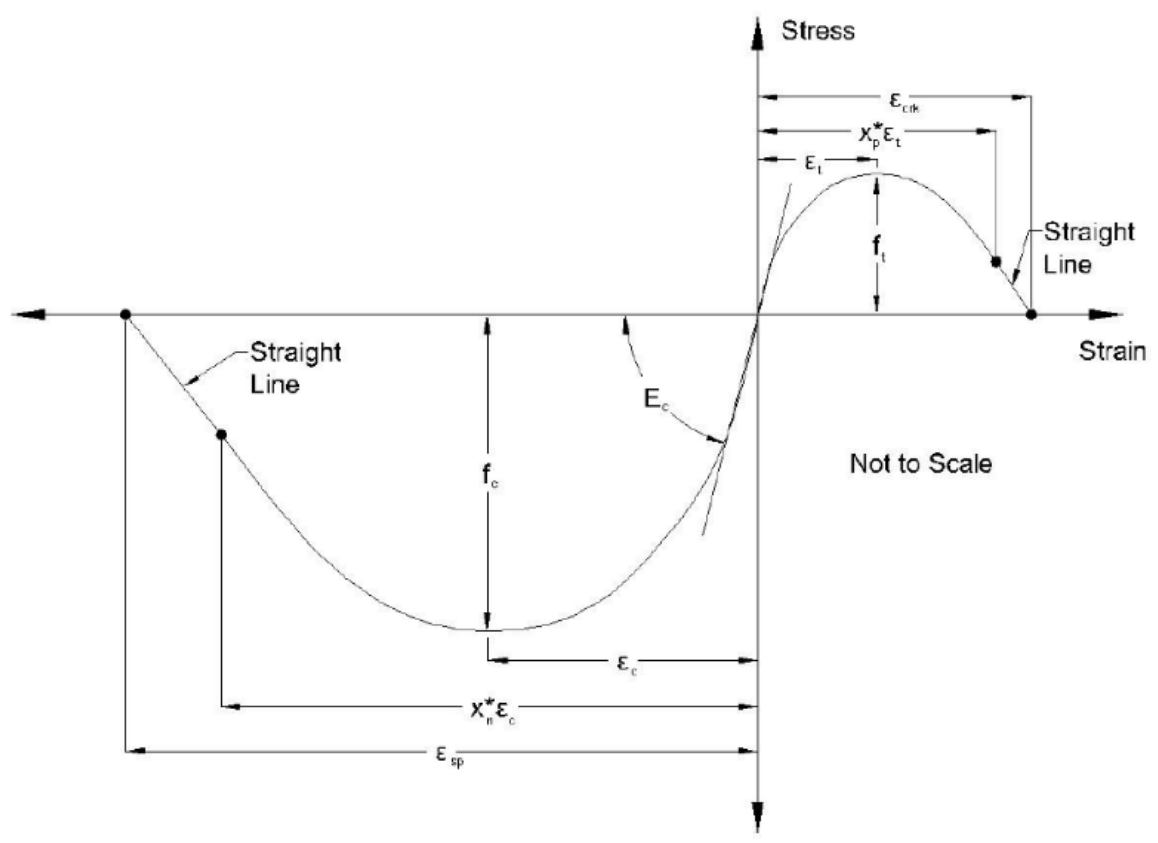

Figure 4-62: Concrete model developed by Chang and Mandar 1994.

The corresponding command line for defining concrete07 material in OpenSEES is: uniaxialMaterial Concrete07 \$matTag \$fc \$ec \$Ec \$ft \$et \$xp \$xn \$r

The above calculations are based on the transverse reinforcement spacing of $75 \mathrm{~mm}$ to model the seismic columns. The same calculation was done to obtain the compressive strength and strain at maximum strength in the conventional column. The transverse spacing was set to $300 \mathrm{~mm}$. The confinement effects are not so significant in the conventional columns with relatively wider spacing of the transverse reinforcement. The confinement effects are however included in the modelling of the core material of the conventional column.

Material steel02 was used to model the longitudinal reinforcement in the columns. The main parameters required are the yield strength and modulus of elasticity. For other parameters in the model, the values as recommended in the manual of the software were used. The command line for using this type of material model in OpenSees is shown as follows: 


\section{uniaxialMaterial Steel02 \$matTag \$Fy \$E \$b \$R0 \$cR1 \$cR2}

From Figure 4-63, when the column is modelled with a fixed base, the peak load is about $550 \mathrm{kN}$ compared to an average of $445 \mathrm{kN}$ of the experimental results. Likewise, the stiffness is higher in the OpenSees model with fixed supports. OpenSees models with pinned supports reached a peak load of about $380 \mathrm{kN}$. There could be a myriad of reasons for this observation. First, the concrete columns tested showed honeycomb defects as well as other minor variations in dimension. The concrete pour sequence introduced a construction joint between column and footing. In addition, fixed support conditions are difficult to attain experimentally in reinforced concrete. A certain percentage of fixity will be achieved but never full fixity. Thus, the observation that the experimental curves fall in-between the fixed and pinned base models in OpeenSees. However, the experimental response of the columns was better modelled with the pin-supported numerical OpenSees model. 


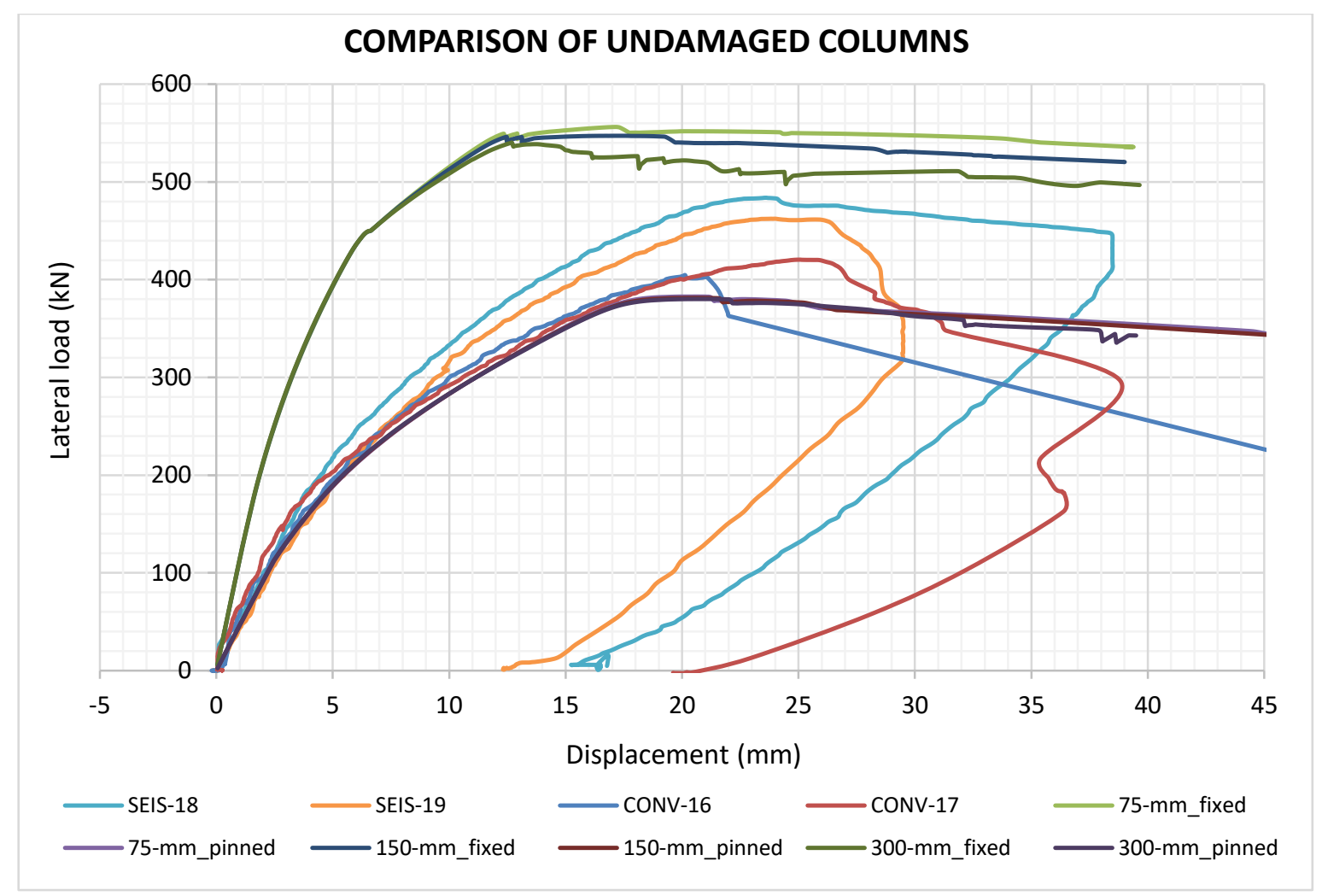

Figure 4-63: OpeenSees model compared to experimental results. 


\section{Chapter: Conclusion}

\subsection{Summary}

In the present study, residual capacity of blast damaged conventional and seismic columns was evaluated. All thirteen (13) reinforced concrete columns were able to carry the design service load after to blast loading from explosion in the close-in range $\left(\mathrm{z}<1.0 \mathrm{~m} / \mathrm{kg}^{1 / 3}\right)$. In this testing program, the working strain gauges, and string potentiometers were connected for relevant data to be recorded. Like most experimental work, some changes were made after the first test. One important modification was to torque the threaded rods to the laboratory strong floor to ensuring that the fixity at the base was adequate. Another problem that was identified during the testing was the fact that the lateral actuator restrained the free movement of the test columns during the axial loading stage.

These issues notwithstanding, the tests showed the effects of lateral reinforcement detailing on the behaviour of blast-damaged reinforced concrete columns. This section presents the conclusions and recommendation from the residual capacity testing of blast-damaged reinforced concrete columns.

\subsection{Conclusions}

The following conclusions can be made from the results of the residual capacity program presented in this report.

- Blast-damaged reinforced concrete columns were capable of resisting service level axial loading after blast damage at scaled distances ranging from $0.52 \mathrm{~m} / \mathrm{kg}^{1 / 3}$ to $0.88 \mathrm{~m} / \mathrm{kg}^{1 / 3}$. 
- Columns exposed to blast loading from higher scaled distances will exhibit higher residual capacity, post-blast in comparison to column exposed to blast loading at lower scaled distances.

- The residual capacity of columns with a damage from explosions at scaled distance of 0.86 $\mathrm{m} / \mathrm{kg}^{1 / 3}$ is not significantly reduced.

- Closer spacing of transverse reinforcement (seismic of transverse reinforcement) provides an inherently higher resistance to blast and post-blast residual capacity.

\subsection{Limitations}

From the process of testing and the results of this investigation, the following limitations were encountered:

- No rigidity was provided for the top support. This is not exactly the case in rigid cast-inplace concrete structures.

- Load cells could be used to track the lateral load distribution to the two contact points to ensure an equal distribution of load.

- One shortcoming in the work was that the columns under the blast load did not have an axial service load on it. This is a common difficulty in field-testing. Although the field work is outside this thesis report, it might have had an effect on the columns' residual capacity.

- A few strain gauges were damaged from the blast loading as hence were not useful in this work. 


\section{References}

Astarlioglu, S., Krauthammer, T., Morency, D., and Tran, T. P. (2013). "Behavior of reinforced concrete columns under combined effects of axial and blast-induced transverse loads." Engineering Structures, Elsevier Ltd, 55, 26-34.

Bao, X., and Li, B. (2010). "Residual strength of blast damaged reinforced concrete columns." International Journal of Impact Engineering, 37(3), 295-308.

Baylot, J. T., and Bevins, T. L. (2007). "Effect of responding and failing structural components on the airblast pressures and loads on and inside of the structure." Computational Structures, 85(11), 891-910.

Braimah, A. (2012). "Blast Load on Structures". CIVE 5707/IPIS 5507 Blast Load Effects on Structures Lecture Notes, Carleton University, Ottawa, ON,".

CSA (2004). Design of concrete structures, CSA Standard A23.3-04. Canadian Standards Association, Mississauga, Ontario.

Elsanadedy, H. M., Almusallam, T. H., Abbas, H., Al-Salloum, Y. A., and Alsayed, S. H. (2011). "Effect of blast loading on CFRP-Retrofitted RC columns - a numerical study." Latin American Journal of Solids and Structures, 8(1), 55-81. 
Echevarria, A., Zaghi, A., Christenson, R. and Plank, R. "Residual Axial Capacity Comparison of CFFT and RC Bridge Columns after Fire". Polymers 7.5 (2015): 876-895.

Echevarria, A., Zaghi, A. E., Chiarito, V., Christenson, R. and Woodson, S. "Experimental Comparison of the Performance and Residual Capacity of CFFT and RC Bridge Columns Subjected To Blasts". Journal of Bridge Engineering. (2015): 04015026.

Fujikake, K., and Peerasak Aemlaor. 'Damage of Reinforced Concrete Columns under Demolition Blasting'. Engineering Structures 55 (2013): 116-125.

Giakoumelis, G., \& Lam, D. (2004). 'Axial capacity of circular concrete-filled tube columns'. Journal of Constructional Steel Research, 60(7), 1049-1068.

Janke, L., Czaderski, C., Ruth, J. and Motavalli, M. "Experiments on the Residual Load-Bearing Capacity of Prestressed Confined Concrete Columns". Engineering Structures 31.10 (2009): 2247-2256.

Khandelwal, K. and El-Tawil. S. "Assessment of Progressive Collapse Residual Capacity using Pushdown Analysis", ASCE Journal of Structural Engineering, (2008).

Li B., Nair A. and Kai Q. "Residual Axial Capacity of Reinforced Concrete Columns with Simulated Blast Damage". Journal of Performance of Constructed Facilities, Vol. 26, No. 3, June 1, 2012. 
Luccioni, B., Ambrosini, R., and Danesi, R. (2004). "Analysis of building collapse under blast loads." Engineering Structures, 26(1), 63-71.

Morrill, K., and Malvar, L. (2004). "Blast resistant design and retrofit of reinforced concrete columns and walls." Proc of structures ..., (818), 1-8.

Jayasooriya, R., Thambiratnam, D. P., Perera, N. J. and Kosse, V. 'Blast and Residual Capacity Analysis of Reinforced Concrete Framed Buildings'. Engineering Structures 33.12 (2011): 34833495 .

Roller, C., Mayrhofer, C., Riedel, W., and Thoma, K. (2013). "Residual load capacity of exposed and hardened concrete columns under explosion loads." Engineering Structures, Elsevier Ltd, $55,66-72$.

Sezen, H., and Moehle, J. (2004). "Strength and deformation capacity of reinforced concrete columns with limited ductility." Proceedings of the 13th World Conference on Earthquake Engineering.

Sheikh, Shamim A., and Ching-Chung Yeh. "Tied concrete columns under axial load and flexure." Journal of Structural Engineering 116.10 (1990): 2780-2800.

Siba, F. (2014). "Experimental program conducted to test near-field blast loading on reinforced concrete columns." Master's Thesis, Civil Engineering Department, Carleton University, Ottawa. 
Wei, Hua et al. "Experimental Study on Partially Deteriorated Strength Concrete Columns Confined With CFRP”. Engineering Structures 31.10 (2009): 2495-2505.

Williamson E.B, Bayrak O., Davis C. and Williams G.D. "Performance of Bridge Columns Subjected to Blast Loads. I: Experimental Program”. Journal of Bridge Engineering, Vol. 16, No. 6, November 1, 2011. CASCE, ISSN 1084-0702/2011/6-693-702/\$25.00.

Williamson E.B, Bayrak O., Davis C. and Williams G.D. "Performance of Bridge Columns Subjected to Blast Loads. II: Results and Recommendation”. Journal of Bridge Engineering, Vol. 16, No. 6, November 1, 2011. CASCE, ISSN 1084-0702/2011/6-693-702/\$25.00.

Wu, Ke-Chiang, Bing Li, and Keh-Chyuan Tsai. "The Effects Of Explosive Mass Ratio On Residual Compressive Capacity of Contact Blast Damaged Composite Columns". Journal of Constructional Steel Research 67.4 (2011): 602-612.

Wu, Ke-Chiang, Bing Li, and Keh-Chyuan Tsai. "Residual Axial Compression Capacity of Localized Blast-Damaged RC Column". International Journal of Impact Engineering 38.1 (2011): 29-40.

Yandzio E, Gough M. Protection of buildings against explosions. SCI Publication; 1999.

Zhao, B. "Facts and lessons related to the explosion accident in Tianjin Port, China". Natural Hazards (2016) Volume 84, pp. 707- 713. 


\section{Appendix: Summary of Results}

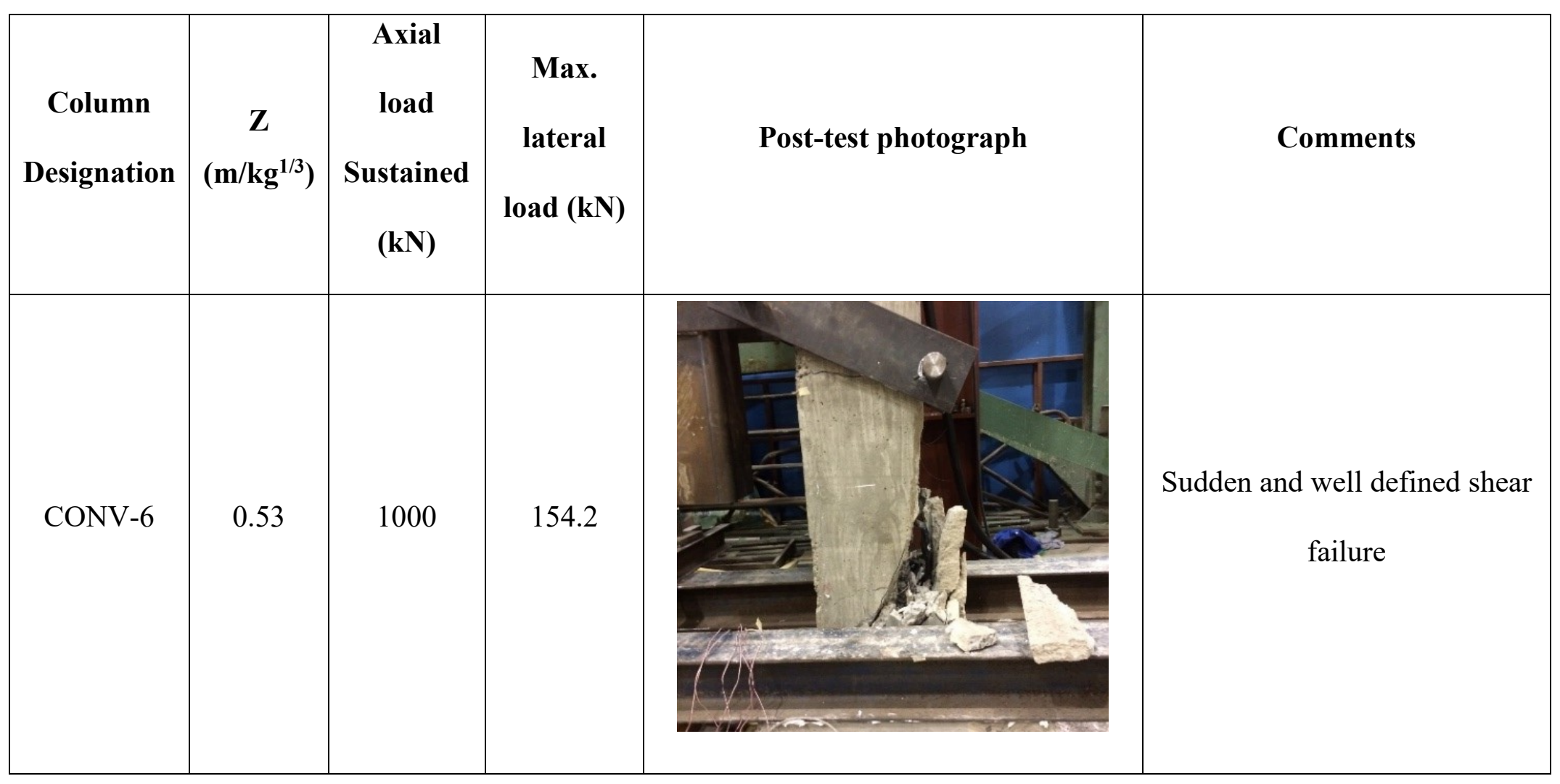




\begin{tabular}{|l|l|l|l|l|l|}
\hline CONV-7 & 0.58 & 1000 & 445.5 & & Shear failure \\
\hline CONV-11 & 0.88 & & & &
\end{tabular}




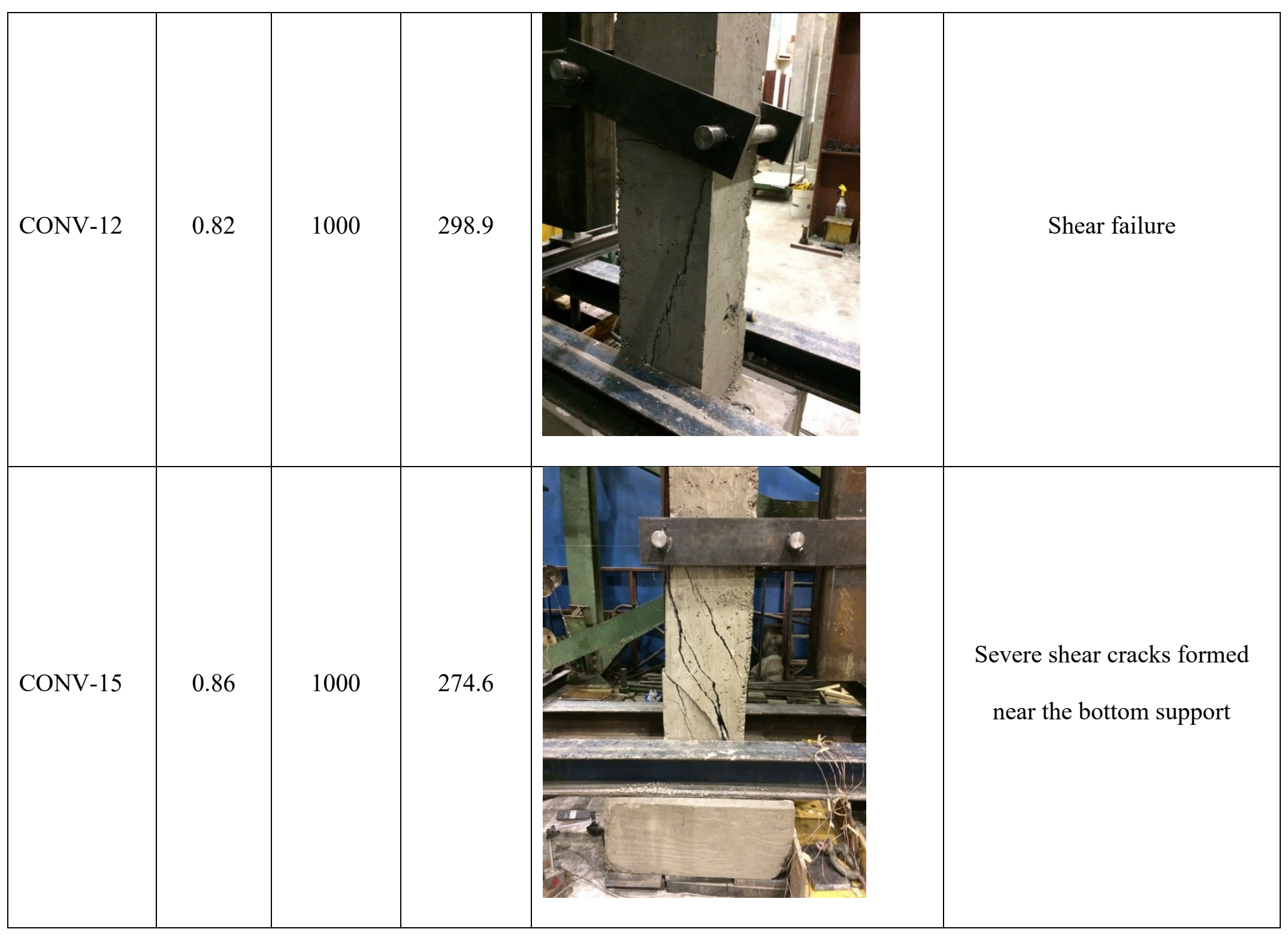




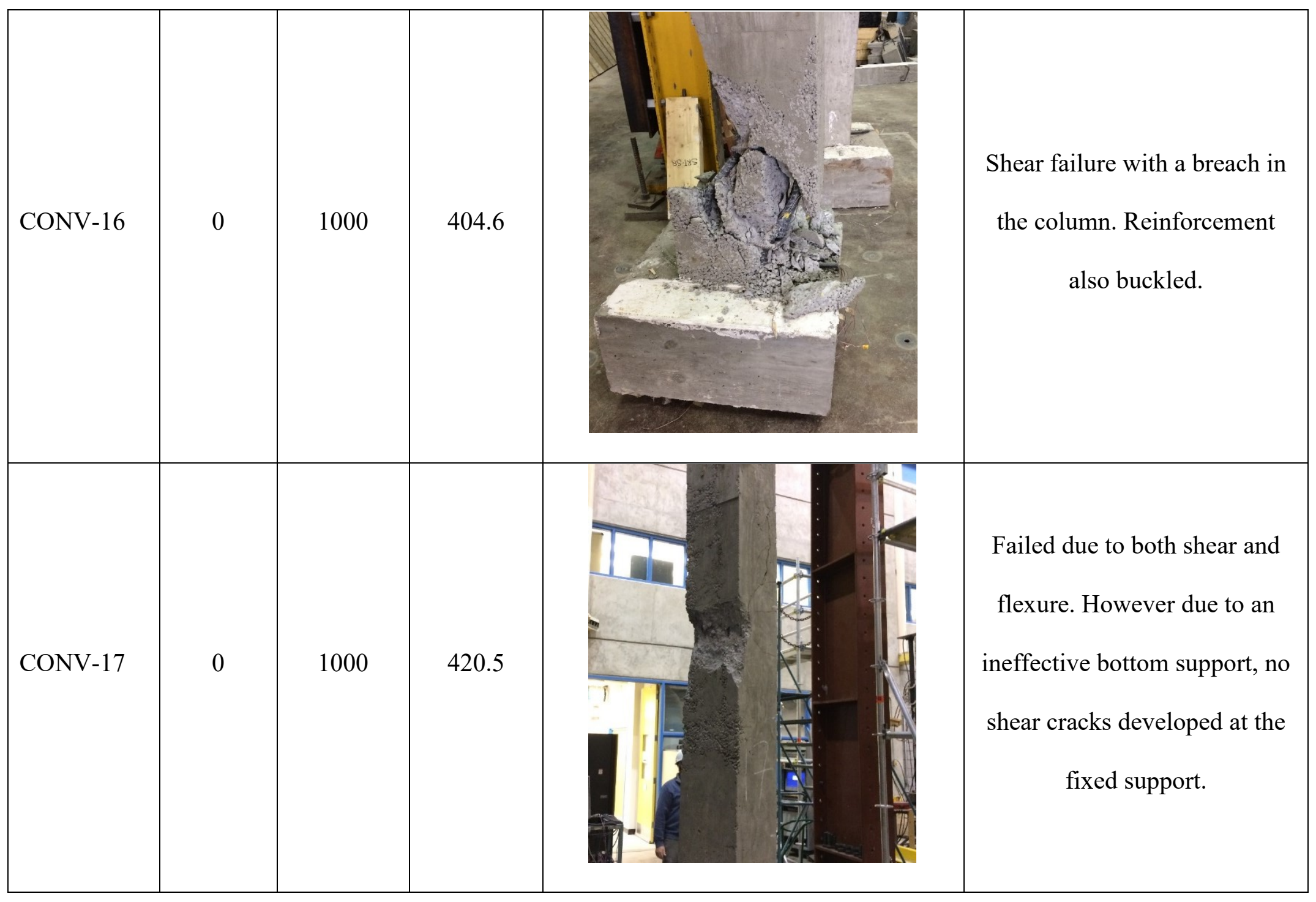




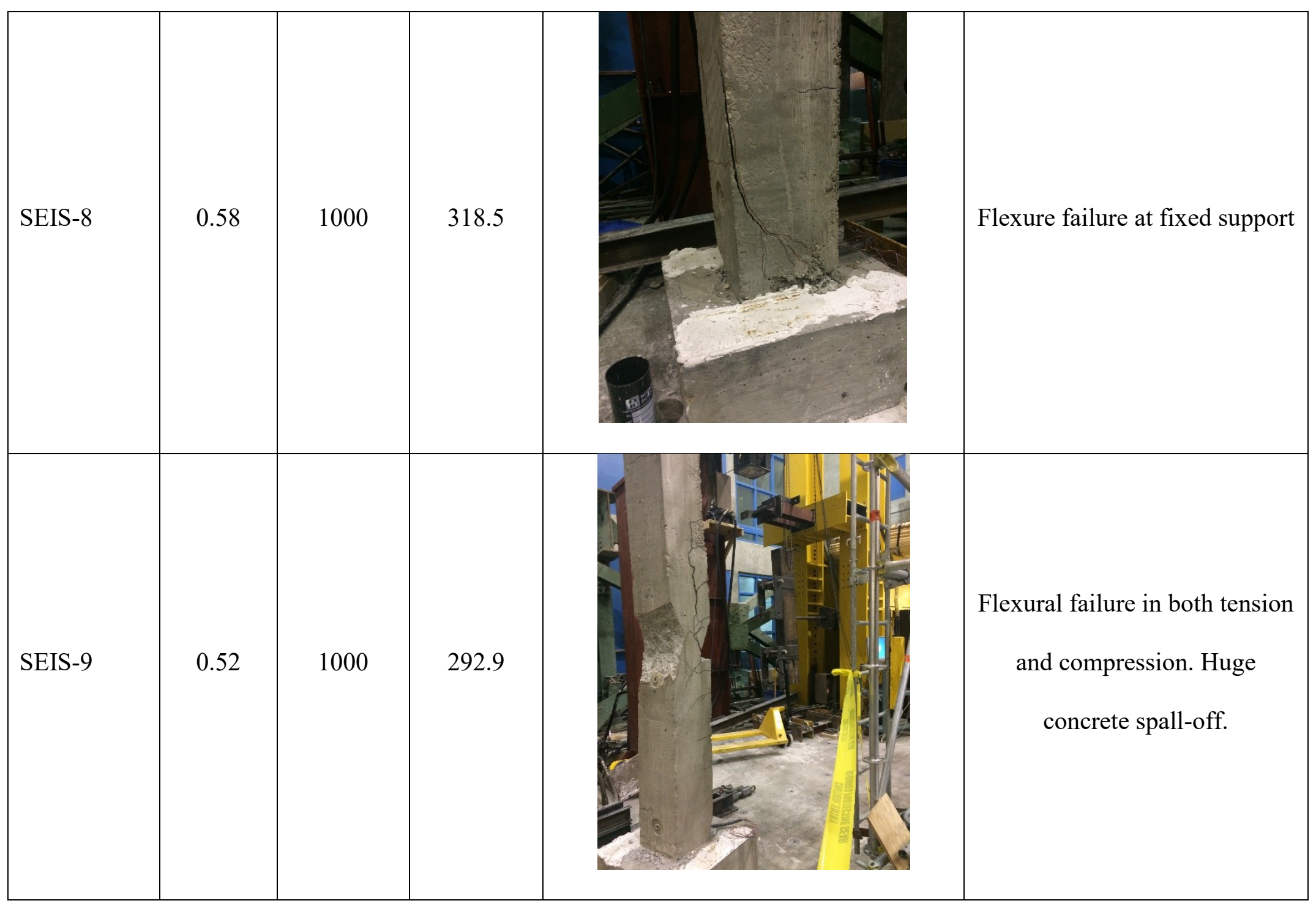




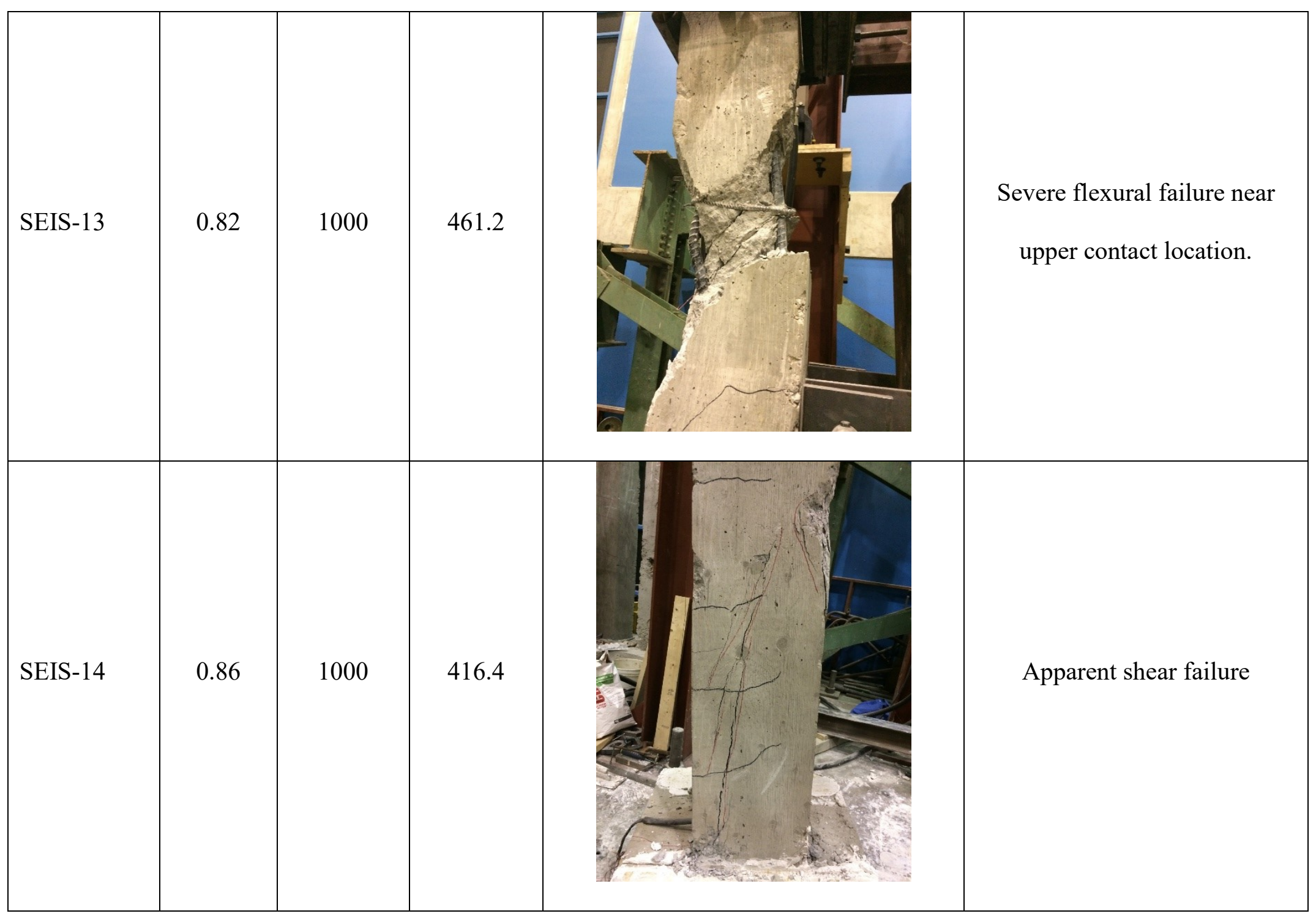




\begin{tabular}{|l|l|l|l|l|l|}
\hline SEIS-18 & 0 & 1000 & 483.9 & Softening due to flexural \\
tension failure
\end{tabular}


Table 5-1: Summary of column strains under axial load only.

\begin{tabular}{|c|c|c|c|c|c|c|c|c|c|c|c|}
\hline \multirow{3}{*}{$\begin{array}{c}\text { Column } \\
\text { Designation }\end{array}$} & \multirow{3}{*}{ ALR } & \multirow{3}{*}{$\begin{array}{c}\text { Scaled } \\
\text { distance, } z \\
\left(\mathrm{~m} / \mathrm{kg}^{1 / 3}\right)\end{array}$} & \multicolumn{9}{|c|}{ AXIAL LOAD } \\
\hline & & & \multirow{2}{*}{$\begin{array}{l}\text { Axial } \\
\text { load } \\
(\mathbf{k N})\end{array}$} & \multicolumn{8}{|c|}{ Microstrains (uS) } \\
\hline & & & & BFL & BFR & MFL & MFR & TFL & TFR & MBL & MBR \\
\hline CONV-6 & 0 & 0.53 & 1000 & - & - & -4060 & - & -960 & - & -2200 & - \\
\hline CONV-7 & 0 & 0.58 & 1000 & & & & & & & & \\
\hline CONV-11 & 0 & 0.88 & 1000 & - & - & -870 & - & -843 & -788 & -670 & -744 \\
\hline CONV-12 & 0 & 0.82 & 1000 & & & -962 & -820 & -750 & -670 & -745 & -12 \\
\hline CONV-15 & 0.32 & 0.86 & 0 & - & - & - & - & - & - & - & - \\
\hline CONV-16 & 0 & 0 & 1000 & - & - & -554 & -417 & -392 & -458 & -295 & -464 \\
\hline CONV-17 & 0 & 0 & 1000 & -380 & - & - & -468 & +1386 & - & -332 & -495 \\
\hline SEIS-8 & 0 & 0.58 & 1000 & - & - & -724 & -522 & -331 & -357 & - & -140 \\
\hline SEIS-9 & 0 & 0.52 & 1000 & - & - & -1481 & -892 & -733 & -804 & -785 & - \\
\hline SEIS-13 & 0 & 0.82 & 1000 & - & - & - & -217 & -689 & - & - & - \\
\hline SEIS-14 & 0 & 0.86 & 1000 & - & -1433 & - & -811 & - & -577 & - & - \\
\hline SEIS-18 & 0 & 0 & 1000 & - & -248 & -254 & -243 & -391 & - & -219 & - \\
\hline SEIS-19 & 0 & 0 & 1000 & - & - & - & - & -660 & - & - & -420 \\
\hline
\end{tabular}


Table 5-2: Summary of strains under lateral load.

\begin{tabular}{|c|c|c|c|c|c|c|c|c|c|c|c|}
\hline \multirow{3}{*}{$\begin{array}{c}\text { Column } \\
\text { Designation }\end{array}$} & \multirow{3}{*}{ ALR } & \multirow{3}{*}{$\begin{array}{c}\text { Scaled } \\
\text { distance, } z \\
\left(\mathrm{~m} / \mathrm{kg}^{1 / 3}\right)\end{array}$} & \multicolumn{9}{|c|}{ LATERAL LOAD } \\
\hline & & & \multirow{2}{*}{$\begin{array}{c}\text { Lateral } \\
\text { load } \\
(\mathbf{k N})\end{array}$} & \multicolumn{8}{|c|}{ Micro strains (uS) } \\
\hline & & & & BFL & BFR & MFL & MFR & TFL & TFR & MBL & MBR \\
\hline CONV-6 & 0 & 0.53 & 154.2 & - & - & $\mathrm{N} / \mathrm{A}$ & - & $\mathrm{N} / \mathrm{A}$ & - & $\mathrm{N} / \mathrm{A}$ & - \\
\hline CONV-7 & 0 & 0.58 & 445.5 & & & & & & & & \\
\hline CONV-11 & 0 & 0.88 & 365.6 & - & - & -1671 & - & -1402 & -1447 & +1254 & +1256 \\
\hline CONV-12 & 0 & 0.82 & 298.9 & - & - & -1812 & -1770 & -1417 & -1118 & $\mathrm{~N} / \mathrm{A}$ & $\mathrm{N} / \mathrm{A}$ \\
\hline CONV-15 & 0.32 & 0.86 & 274.6 & - & - & -1028 & -902 & -323 & -295 & +2584 & +2171 \\
\hline CONV-16 & 0 & 0 & 404.6 & - & - & -1106 & -1138 & -784 & -1098 & +2424 & +2609 \\
\hline CONV-17 & 0 & 0 & 420.5 & -960 & - & - & -1964 & +1627 & - & +3196 & +2508 \\
\hline SEIS-8 & 0 & 0.58 & 318.5 & - & - & -1182 & - & -331 & -311 & - & +94 \\
\hline SEIS-9 & 0 & 0.52 & 292.9 & - & - & -2135 & -1461 & -950 & -1077 & +128 & - \\
\hline SEIS-13 & 0 & 0.82 & 461.2 & - & - & - & +340 & -1472 & - & - & - \\
\hline SEIS-14 & 0 & 0.86 & 416.4 & - & -3.7 & - & -1515 & - & -1001 & - & - \\
\hline SEIS-18 & 0 & 0 & 483.9 & & +732 & -957 & -806 & -1182 & & +1438 & \\
\hline SEIS-19 & 0 & 0 & 462.3 & - & - & - & - & -1800 & - & - & +1400 \\
\hline
\end{tabular}

